Published in final edited form as:

Rev Mineral Geochem. 2016 ; 81(1): 161-238. doi:10.2138/rmg.2016.81.04.

\title{
Highly Siderophile Elements in Earth, Mars, the Moon, and Asteroids
}

\author{
James M.D. Day, \\ Geosciences Research Division, Scripps Institution of Oceanography, La Jolla, CA 92093-0244, \\ USA
}

\author{
Alan D. Brandon, and \\ Department of Earth and Atmospheric Sciences, University of Houston, Houston, TX \\ 77204-5007, USA
}

Richard J. Walker

Department of Geology, University of Maryland, College Park, MD 20742, USA

\section{INTRODUCTION}

The highly siderophile elements (HSE: Os, Ir, Ru, Rh, Pt, Pd, Re, Au) are key tracers of planetary accretion and differentiation processes due to their affinity for metal relative to silicate. Under low-pressure conditions the HSE are defined by having metal-silicate partition coefficients in excess of $10^{4}$ (e.g., Kimura et al. 1974; Jones and Drake 1986; O'Neill et al. 1995; Borisov and Palme 1997; Mann et al. 2012). The HSE are geochemically distinct in that, with the exception of $\mathrm{Au}$, they have elevated melting points relative to iron $(1665 \mathrm{~K})$, low vapour pressures, and are resistant to corrosion or oxidation. Under solar nebular conditions, $\mathrm{Re}, \mathrm{Os}, \mathrm{Ir}, \mathrm{Ru}, \mathrm{Rh}$, and $\mathrm{Pt}$, along with the moderately siderophile elements (MSE) Mo and W, condense as refractory-metal alloys. Palladium and $\mathrm{Au}$ are not as refractory and condense in solid solution with FeNi metal (Palme 2008). Assuming abundances of the HSE in materials that made up the bulk Earth were broadly similar to modern chondrite meteorites, mass balance calculations suggest that $>98 \%$ of these elements reside in the metallic core (O'Neill and Palme 1998). In practical terms, the resultant low HSE abundance inventories in differentiated silicate crusts and mantles enables the use of these elements in order to effectively track metallic core formation and the subsequent additions of HSE-rich impactors to planets and asteroids (Fig. 1). In detail, the absolute and relative abundances of the HSE in planetary materials are also affected by mantle and crustal processes including melting, metasomatism, fractional crystallization, and crust-mantle remixing, as well as later impact processing, volatility of Re under oxidizing conditions, and low-temperature secondary alteration (cf., Day 2013; Gannoun et al. 2016, this volume). In the absence of metal, the HSE are chalcophile, so these elements are also affected by processes involving growth and breakdown of sulfides.

Work over the last several decades has led to a large available database for understanding processes affecting the HSE for planetary bodies. This chapter summarises this progress for rocky Solar System bodies, including the Earth, Moon, Mars and some asteroids, and examines the conceptual framework for interpreting these data. The first section outlines the 
motivation for measuring the HSE in planetary materials. The second section briefly considers methods for measuring and interpreting HSE abundance and Os isotopic data. The third section provides an outline of natural HSE abundance variations and Os isotope compositions in planetary materials. The fourth section outlines current interpretations of the available data and outstanding issues. The final sections offer some comparative planetology, implications for terrestrial planet formation, synthesis and future directions. This chapter does not consider nucleosynthetic variations, as these are the subject of a review by Yokoyama and Walker (2016, this volume), and does not provide a detailed consideration of experimental work, which is the subject of Brenan et al. (2016, this volume). While comparisons are made with terrestrial HSE compositions, these data are considered in detail elsewhere in this volume, or in Walker et al. (1997), Shirey and Walker (1998), Carlson (2005), Walker (2009), and Day (2013).

\section{MOTIVATION FOR STUDY AND BEHAVIOR OF THE HSE IN PLANETARY MATERIALS}

The HSE have a strong affinity for Fe-metal (or in the absence of metal, sulfide), rather than co-existing silicates or oxides, at low pressures. Experimental studies at relatively low pressures $\left(10^{5}\right.$ Pascals), to pressures as high as $18 \mathrm{GPa}$, consistently show liquid metal/liquid silicate concentration ratios ( $D$ values) varying from $10^{3}$ to $10^{6}$ (e.g., Kimura et al. 1974; Jones and Drake 1986; Borisov et al. 1994; O'Neill et al. 1995; Holzheid et al. 2000; Ertel et al. 2001; Fortenfant et al. 2003; Yokoyama et al. 2009; Mann et al. 2012). The variations in $D$ values partly reflect experimental charge issues (e.g., Brenan et al. 2016, this volume), but recent combined HSE experiments indicate significant interelement fractionation at a range of temperatures and pressures during metal-silicate equilibration (Mann et al. 2012). Consequently, the relative and absolute HSE abundances in planetary cores, mantles, and crusts might be expected to dominantly reflect metal-silicate equilibration at the conditions (e.g., pressure, temperature, oxygen fugacity, composition) relevant to the planetary body.

Despite the fundamental control of core formation on HSE fractionation during planetary differentiation, terrestrial mantle peridotites and estimates of lunar and martian mantle compositions do not appear to solely record the effects of this process, and instead define mantles with broadly chondritic-relative abundances of the HSE (Fig. 1) (See section below, 'What does chondritic or nearly/ broadly chondritic actually mean?). Chondritic-relative HSE abundances in terrestrial, martian and lunar mantles are supported by long-term Re/Os and Pt/Os for the terrestrial mantle within $\sim \pm 5 \%$ and $\sim \pm 10 \%$ of chondrites, respectively (e.g., Brandon et al. 2006; Walker 2009), and Re/Os within $\sim \pm 10 \%$ for at least some portions of the martian and lunar mantles (Brandon et al. 2012; Day and Walker 2015). Furthermore, there is compelling evidence for similar crust-mantle partitioning behavior for Earth and the Moon (Day et al. 2010). These observations indicate that a process other than metal-silicate equilibration during core formation was involved in setting initial HSE abundances in planetary mantles, with the most likely candidate being late accretion of chondritic impactors after the major phases of core formation (Turekian and Clark 1969; Kimura et al. 1974; Chou 1978; Wanke 1981), although other classes of model, including incomplete core separation (Jones and Drake 1986), lowered metal-silicate $D$ values 
(Ringwood 1977; Brett 1984; Murthy 1991), and variants of these models (e.g., Kramers 1998) have also been proposed. Combined with precise chronometry, it is possible to examine the timing of key planetary growth episodes and post-core formation (late) accretion addition using the HSE (Fig. 2; Day et al. 2012a). These initial parameters for establishing core-mantle-crust HSE abundances in planetary bodies are a key motivation for measuring the HSE in planetary materials, as they reveal the fundamentals of planetary accretion and differentiation.

Within differentiated planetary mantles, the HSE exhibit contrasting behaviors during melting. The HSE comprise Re and Au, along with the platinum group elements (PGE), defined as Os, Ir, Ru, Rh (the so-called Ir-group PGE, or IPGE; Barnes et al. 1985) and Pt and Pd (the Pt-group PGE, or PPGE). The PPGE (melting temperature $<2000{ }^{\circ} \mathrm{C}$ ), Re and $\mathrm{Au}$ are typically more incompatible during melting and crystallization relative to the IPGE (melting temperature $>2000{ }^{\circ} \mathrm{C}$; Barnes et al. 1985). For this reason, studies of the cosmochemical behavior of the HSE will typically list the HSE in order of melting temperature of the pure metal, or $50 \%$ condensation temperatures at pressures appropriate for the nebula (e.g., Fig. 1), whereas studies using the HSE to investigate mantle melting processes on Earth will typically order the HSE according to relative incompatibility during melting, which is generally considered to be: $\mathrm{Re} \leq \mathrm{Au}<\mathrm{Pd}<\mathrm{Pt} \leq \mathrm{Rh}<\mathrm{Ru} \leq \mathrm{Ir} \leq \mathrm{Os}$ (Pearson et al. 2004; Becker et al. 2006; Fischer-Gödde et al. 2011). While most other planetary bodies appear to show similar relative incompatibilities, the oxidation state of their mantle plays a major control on melting behavior (Birck and Allègre 1994; Day and Walker 2015). The main controls on HSE fractionation behavior during partial melting of the mantle are sulfide phases, platinum-group element minerals (PGM) (e.g., Jagoutz et al. 1979; Lorand et al. 2013; O'Driscoll and Gonzalez-Jimenez, 2016, this volume), and the presence or absence of residual metal. Experimental determination of sulfide-silicate partitioning of the HSE (with the exception of Re) are generally $>10^{4}$ (e.g., Peach et al. 1990, 1994) and the presence or absence of sulfide in the system plays a major role in HSE fractionation (e.g., Rehkämper et al. 1999). The HSE can also be used to track later differentiation and melting events in planetary bodies, after the major phases of core formation and accretion. Combined with two long-lived radiogenic decay schemes embedded within the HSE, the ${ }^{187} \mathrm{Re}-{ }^{187} \mathrm{Os}$ and ${ }^{190} \mathrm{Pt}-{ }^{186} \mathrm{Os}$ systems, as well as the short-lived ${ }^{107} \mathrm{Pd}-{ }^{107} \mathrm{Ag}$ system, these elements offer powerful geochemical tools for interrogating planetary formation, accretion and differentiation processes.

\section{METHODS APPLIED TO INVESTIGATING SIDEROPHILE ELEMENTS IN PLANETARY MATERIALS}

While not exhaustive, this section provides an overview of analytical techniques for the HSE, as well as modeling methods aimed at understanding fundamental processes, including melting processes in the presence of metallic liquids (core-formation processes), silicate partial-melting and estimation of planetary mantle HSE abundances. Some other 'tools' for examining planetary materials are given in later sections (e.g., estimating compositions of impactors from lunar impact melt breccia compositions). Analytical methods are also discussed in Meisel and Horan (2016, this volume). 


\section{HSE ABUNDANCES}

Despite important data on $\mathrm{Au}$ and/or Rh abundances obtained by standard addition (e.g., Walker et al. 2008; Fischer-Gödde et al. 2010, 2011), or neutron activation analyses (e.g., Wolf et al. 1979), these elements are mono-isotopic and are not reported in most studies that measure HSE abundances using isotope-dilution methodologies. This review primarily focuses on the coupled information derived from HSE abundances and Os isotopes, with an emphasis on Os, Ir, Ru, Pt, Pd, and Re abundances. Therefore, the focus is on preparation and analysis methods utilizing isotope dilution. Where available, $\mathrm{Rh}$ and Au data are discussed, but the reader should note that the analysis of these elements, along with the chalcogens (S, Te, Se; see Harvey and Day 2016, this volume) are currently rarely determined in tandem with Os isotopes, especially in low abundance planetary materials. This is due to the need for generally high abundances of $\mathrm{Rh}$ and Au for reliable and accurate internal-external standardization (comparison with the ${ }^{193}$ Ir of the sample and external standard solutions; Meisel et al. 2003; Fischer-Gödde et al. 2010), or for low analytical blank work required for S, Te, and Se.

A technique that allows for the combined determination of all HSE abundances, as well as other highly siderophile and chalcophile elements (e.g., Ni, Co, W, Mo), is laser-ablation inductively coupled plasma mass spectrometry (LA-ICP-MS). LA-ICP-MS is a particularly useful technique for in situ analysis of individual sulfide and metal phases that have significant concentrations (> $\mu g . g^{-1}$ level) of the HSE (e.g., Campbell and Humayun 1999), and this method of analysis has been extensively applied to the study of iron meteorites (e.g., Petaev and Jacobsen 2004; Walker et al. 2008), chondrites (e.g., Campbell et al. 2002; Humayun 2012), as well as some achondrite meteorite groups (e.g., van Acken et al. 2012; Day et al. 2012b; Yang et al. 2015). Because of the high affinity of the HSE in metal, LAICP-MS also allows for the in situ analysis of HSE abundances in metal or sulfide grains, even in rocks with relatively low bulk HSE abundances (cf., Alard et al. 2005). For example, Day et al. (2012a) used LA-ICP-MS analysis of metal grains in diogenite meteorites to show that the HSE were almost exclusively hosted in metal within brecciated clasts, with only $\sim 0.001-0.01$ mass \% metal required to explain whole-rock HSE abundances (Fig. 3). Combined with detailed petrography and petrology showing that the metal grains were situated within crystalline portions of the diogenite meteorites, this study was able to establish early addition (within 2-3 Ma of Solar System formation) of the HSE to the diogenite parent body. LA-ICP-MS is therefore a powerful technique for understanding planetary HSE inventories, especially when used in combination with detailed petrographic, mineral chemistry and whole-rock studies.

Methods for the preparation of whole rocks, mineral phases and other components (e.g., glasses, clasts) of planetary samples for HSE analysis include irradiation for neutron activation analysis and spectroscopic techniques (e.g., Goldberg et al. 1952; Lovering et al. 1957; Wasson 1967), nickel-sulfide fire assay (e.g., Ravizza and Pyle 1997), alkali fusion (Morgan and Walker 1989), selective leaching techniques (e.g., Walker et al. 2004) and dissolution in reducing media (e.g., HF-HBr; Birck et al. 1997). Neutron activation analysis is a particularly effective method for analyzing $\mathrm{Ir}$ and $\mathrm{Au}$, which can be measured without dissolving the sample, or applying radiochemical separation procedures. Other HSE are less- 
effectively measured by this method, and the preferential analysis of Ir is partly responsible for the misconception of 'Ir anomalies' defining the Cretaceous-Palaeogene boundary (e.g., Alvarez et al. 1980), when, in fact, all the HSE are enriched in these layers (Goderis et al. 2013). The most popular current method of analysis is through digestion in concentrated $\mathrm{HCl}-\mathrm{HNO}_{3}$ mixtures in Carius tubes at temperatures $\leq 270{ }^{\circ} \mathrm{C}$, or using quartz vessels that are sealed and heated in a High-Pressure Asher (HPA) device at temperatures $\leq 320^{\circ} \mathrm{C}$ and pressures $\leq 15 \mathrm{MPa}$ (Shirey and Walker 1995; Meisel et al. 2003). The Carius tube and HPA digestion methods allow for the most complete digestion in combination with the lowest total analytical blanks (e.g., Reisberg and Meisel 2002) and allow equilibration of spikesample mixtures while completely retaining volatile $\mathrm{OsO}_{4}$ species during oxidation of the sample. For example, analysis of extremely low abundances of the HSE in whole-rock lunar materials has been made possible through low total analytical blank HPA analysis and through the thorough pre-cleaning of Carius tubes (Day and Walker 2015a).

Procedures for the chemical purification and analysis of the HSE are varied, but the most typical modern technique after Carius tube/HPA digestion is a solvent extraction (Cohen and Waters 1996) followed by a micro-distillation procedure (Birck et al. 1997) to separate and purify Os, and by an anion exchange column chemistry procedure to provide pure $\mathrm{Ir}, \mathrm{Ru}, \mathrm{Pt}$, Pd, Re ( \pm Rh, \pm Au) separations (e.g., Rehkämper and Halliday 1997; Pearson and Woodland 2000; Reisberg and Meisel 2002; Fischer-Gödde et al. 2010). Concentrations of $\mathrm{Ir}, \mathrm{Ru}, \mathrm{Pt}, \mathrm{Pd}, \mathrm{Re}, \mathrm{Rh}$, and $\mathrm{Au}$ are then typically measured using inductively coupled plasma mass spectrometry techniques that allow the precise analysis of isotopic ratios of spikesample mixtures (see also Meisel and Horan 2016, this volume). Studies have shown that an additional HF-digestion step is sometimes necessary to extract all the Re in some silicate rocks, as the Carius tube/HPA $\mathrm{HCl}-\mathrm{HNO}_{3}$ acid mixture is ineffective at breaking down silica-bonds (Ishikawa et al. 2014). This method typically has to be applied after Os extraction due to the danger of residual fluorides attacking the sides of the Pyrex or quartz Carius tube or HPA vessel walls, or from the early loss of Os, as $\mathrm{OsO}_{4}$. An HF digestionstep has been reported to access up to 9-15\% more Re from within silicate phases, compared with Carius tube/HPA digestion ( $\mathrm{Li}$ et al. 2014), at least for some basaltic rocks. There is, however, a particular disadvantage to this method for ancient samples (i.e., most planetary materials), as measured Re/Os or Pt/Os obtained by HF silicate digestion after Os extraction will not reflect those in equilibrium with measured ${ }^{187} \mathrm{Os} /{ }^{188} \mathrm{Os}$ or ${ }^{186} \mathrm{Os} /{ }^{188} \mathrm{Os}$, leading to the potential for young apparent ages and the loss of meaningful Re-Os or Pt-Os isotope chronology (Day et al. 2015).

\section{The rhenium-osmium, platinum-osmium and palladium-silver isotope systems}

The ability of relative and absolute HSE abundances to record processes acting on rock materials are complemented by the existence of the long-lived ${ }^{190} \mathrm{Pt}-{ }^{186} \mathrm{Os}\left({ }^{190} \mathrm{Pt} \rightarrow{ }^{186} \mathrm{Os}\right.$ $+a+Q ; \lambda=1.48 \times 10^{-12} \mathrm{a}^{-1}$; Walker et al. 1997) and ${ }^{187} \mathrm{Re}-{ }^{187} \mathrm{Os}\left({ }^{187} \mathrm{Re}-{ }^{187} \mathrm{Os}+\beta-+\right.$ $\bar{v} ; \lambda=1.6668 \times 10^{-11} \mathrm{a}^{-1}$; Selby et al. 2007) chronometers. Both long-lived radiogenically produced isotopes of Os are minor constituents of rocks with broadly chondritic Re/Os and $\mathrm{Pt} / \mathrm{Os}\left({ }^{186} \mathrm{Os}=1.6 \% ;{ }^{187} \mathrm{Os}=1.5 \%\right.$; Shirey and Walker 1998). In the case of the ${ }^{187} \mathrm{Re}-$ ${ }^{187} \mathrm{Os}$ system, where ${ }^{187} \mathrm{Re}$ is a major isotope $(62.6 \%)$ of $\mathrm{Re}$, and has a half-life of $\sim 42 \mathrm{Ga}$, the range of natural materials spans several orders of magnitude and ${ }^{187} \mathrm{Os} /{ }^{188} \mathrm{Os}$ can 
reasonably range from a Solar System initial ratio of $0.0952 \pm 0.0002$ to nearly pure ${ }^{187} \mathrm{Os}$, derived from samples essentially devoid of non-radiogenic Os and with high concentrations of Re (e.g., molybdenite; Luck and Allègre 1982). This characteristic means that the difference of ${ }^{187} \mathrm{Os} /{ }^{188} \mathrm{Os}$ between natural samples allows routine analysis of low Os abundance samples to percent precision or better, with the most widely used method of analysis being negative thermal ionisation mass spectrometry (N-TIMS; Völkening et al. 1991; Creaser et al. 1991) either by peak-jumping of small signals $\left(\sim 3 \mathrm{mV}^{192} \mathrm{OsO}_{3}{ }^{-}\right.$or less) using a secondary electron multiplier, or by static or dynamic measurements of larger signals (typically $>0.5 \mathrm{~V}^{192} \mathrm{OsO}_{3}{ }^{-}$) using Faraday collectors (see Shirey and Walker 1998; Reisberg and Meisel 2002; Carlson 2005). Publications pre-dating the exploitation of ${ }^{186} \mathrm{Os} /$ ${ }^{188} \mathrm{Os}$ variations often reported ${ }^{187} \mathrm{Os} /{ }^{186} \mathrm{Os}$ variations, assuming ${ }^{186} \mathrm{Os}$ to be a stable isotope. Although radiogenic ingrowth corrections on ${ }^{186}$ Os are generally trivial, all studies now report ${ }^{187} \mathrm{Os} /{ }^{188} \mathrm{Os}$. A correction factor of 0.12035 is commonly applied to convert ${ }^{187} \mathrm{Os} /{ }^{186} \mathrm{Os}$ to ${ }^{187} \mathrm{Os} /{ }^{188} \mathrm{Os}$ (e.g., $1.0553\left({ }^{187} \mathrm{Os} /{ }^{186} \mathrm{Os}\right) \times 0.12035=0.1270\left({ }^{187} \mathrm{Os} /{ }^{188} \mathrm{Os}\right)$ ).

By contrast with the ${ }^{187} \mathrm{Re}-{ }^{187} \mathrm{Os}$ decay system, ${ }^{190} \mathrm{Pt}$ is a minor isotope of $\mathrm{Pt}(0.0129 \%)$ and has a much longer half-life $(\sim 40 \mathrm{Ga})$, so ${ }^{186} \mathrm{Os} /{ }^{188} \mathrm{Os}$ variations in nature are generally small. For example, in the terrestrial mantle variations are of the order of $\sim 0.00015 \%$, with an 'average' mantle value of $0.119837 \pm 5(2 \sigma)$ (Brandon et al. 2006). The typically minor variations of ${ }^{186} \mathrm{Os} /{ }^{188} \mathrm{Os}$ in planetary materials require external analytical precision of better than $30 \mathrm{ppm}$. To obtain sufficient analytical precision, comparatively large quantities of Os are needed (typically 50-75 ng of Os) to generate sufficient signals on ${ }^{186}$ Os given the typical ionisation efficiency of Os by N-TIMS ( 2-6\%; Creaser et al. 1991). For example, to generate a stable $100 \mathrm{mV}$ signal on ${ }^{186} \mathrm{Os}$ ( $1.6 \%$ of chondritic Os), a $\sim 2.6 \mathrm{~V}$ signal on ${ }^{192} \mathrm{Os}$ (the most abundant natural isotope of Os at $40.98 \%$ ) is required. For this reason, and due to the precious nature of planetary materials, most studies utilizing high-precision measurement of Os have focused on meteorites characterized by high concentrations, such as iron meteorites (e.g., Cook et al. 2004) or chondrites (e.g., Brandon et al. 2005a). In addition to sample issues, some studies have argued for polyatomic interferences, leading to complications with high-precision ${ }^{186} \mathrm{Os} /{ }^{188} \mathrm{Os}$ measurements (e.g., Luguet et al., 2008). Inevitably, these forms of analytical challenge mean that there are far fewer high-precision ${ }^{186} \mathrm{Os} /{ }^{188} \mathrm{Os}$ data currently available than there are for ${ }^{187} \mathrm{Os} /{ }^{188} \mathrm{Os}$. Nonetheless, ${ }^{186} \mathrm{Os} /$ ${ }^{188} \mathrm{Os}$, in conjunction with ${ }^{187} \mathrm{Os} /{ }^{188} \mathrm{Os}$ and HSE abundances have the potential to provide robust constraints on planetary mantle differentiation processes.

In addition to the Re-Os and Pt-Os isotope systems, the now-extinct isotope ${ }^{107} \mathrm{Pd}$ decays to ${ }^{107} \mathrm{Ag}$ with a half-life of $6.5 \mathrm{Ma}$. The Pd-Ag isotope system can be used to define the chronology of iron meteorite formation and the timing and mechanisms of early volatile depletion, since $\mathrm{Ag}$ is a moderately volatile siderophile element (50\% condensation temperature $=996 \mathrm{~K})$. As a result, some volatile-depleted iron meteorites have $\mathrm{Pd} / \mathrm{Ag}>10^{5}$, compared with a solar $\mathrm{Pd} / \mathrm{Ag} \sim 3$, leading to very high ${ }^{107} \mathrm{Ag} /{ }^{109} \mathrm{Ag}$ in some irons (Chen and Wasserburg 1996), and measureable differences in carbonaceous chondrites (Schönbachler et al. 2008). The resulting ages of iron meteorites defined by Pd-Ag chronology are 9-20 $\mathrm{Ma}$ after Solar System formation and are longer than Hf-W isotope chronology ( 1-3 Ma) (e.g., Kruijer et al. 2014). The varying ages are interpreted to reflect the chronology of different events: metal-silicate differentiation in the case of $\mathrm{Hf}-\mathrm{W}$, and the timing of volatile 
depletion in the case of $\mathrm{Pd}-\mathrm{Ag}$ (Horan et al. 2012). It should be noted, however, that large uncertainties may exist due to neutron capture reactions on $\mathrm{Ag}$ in meteorites (Leya and Masarik 2013).

\section{Standardization in planetary studies}

In general, well-calibrated isotope dilution methodologies and efficient digestion and spikesample equilibration procedures will lead to the determination of reliable HSE concentrations in most materials. Nonetheless, standard reference materials run at regular intervals within geochemical studies offer useful indicators of the efficiency and reliability of digestion procedures, chemistry and analytical methods. There are three issues that make the selection of standard materials challenging for planetary materials. First, the large range in HSE concentrations of planetary materials, from approximately $\mu \mathrm{g} . \mathrm{g}^{-1}$ levels in chondrites and iron meteorites, to $\mathrm{pg} \cdot \mathrm{g}^{-1}$ levels in some lunar rocks, means that no single standard will be appropriate for regular analysis with this diversity of material types. Second, clear differences in bulk composition relative to terrestrial materials make matrixmatching difficult. For example, matrices (iron metal, carbonaceous chondrite, lunar anorthosite), or oxidation state (cf., terrestrial basalts are approximately at the quartzmagnetite-fayalite (QFM) buffer, versus iron-wüstite (IW) minus six to eight for enstatite achondrites) all pose challenges to selection of an appropriate reference standard. Third, fundamental differences in partitioning behavior result in terrestrial basalts having higher $\mathrm{Re} / \mathrm{Os}$ than most planetary basalts, making their use as standards improper.

The available masses of some chondrites and iron meteorites make them ideal reference materials for comparison with other iron meteorites, chondrites, or primitive achondrites. The Allende CV3 chondrite meteorite has been measured in numerous studies as a reference material for comparison with chondrites and primitive achondrite meteorites (Table 1). Iron meteorites such as Filomena, Coahuila and Hoba are also regularly used as natural standards for LA-ICP-MS analysis. Some studies of differentiated achondrites and Apollo samples have utilized terrestrial peridotites (e.g., GP13, UB-N, HARZ-01) or basalt (TDB-1). However, the higher Pt, Pd, and Re concentrations of most terrestrial basaltic standards (e.g., Meisel and Moser 2004a,b) make their use non-ideal in the study of 'basaltic' achondrites (e.g., lunar crust or mare basalt, angrites, eucrites, shergottite-nakhla-chassignite [SNC] meteorites), and TDB-1, in particular, is a very heterogeneous diabase sample (Ishikawa et al. 2014). To circumvent this issue, recent studies (Day et al. 2010; Riches et al. 2012; Day and Walker 2015) have analyzed samples in duplicate or triplicate, demonstrating reproducibility of analysis for these planetary materials, as well as enabling optimal spiking of samples.

\section{Metal-sulfide-silicate modeling in chondritic systems}

The HSE are both strongly siderophile and chalcophile, and are sensitive tracers of the earliest stages of chondritic melting, when the first melts to be generated are $\mathrm{Fe}-\mathrm{Ni}-\mathrm{S}$-rich (e.g., Mittlefehldt et al. 1996). Therefore, understanding the effects of metallic composition on partitioning behavior is important for any processes involving metallic liquid separation. Examples of such processes include asteroidal core formation (e.g., Jones and Drake 1982; Wasson 1999), or the separation of metallic core from silicate mantle during core formation 
(e.g., Righter and Drake 1997; Li and Agee 1996). Distributions of the HSE between a liquid metal phase and solid metal restite during partial melting in the $\mathrm{Fe}-\mathrm{Ni}-\mathrm{S}$ system are strongly dependent on the S-content of extracted melts, and on $\mathrm{C}$ and $\mathrm{P}$ that enter the metallic phase (e.g., Chabot and Jones 2003; Chabot et al. 2014). Parameterization of solidmetal-liquid-metal $D$-values has been established by several authors as a function of the metallic liquid composition, with the most commonly used iteration derived from Chabot and Jones (2003). Studies utilizing this parameterization have shown that these forms of models can be generally applied to studies of chondritic components (Horan et al. 2009), iron meteorites (Walker et al. $2008 \mathrm{McCoy}$ et al. 2011), and some primitive achondrite groups (Rankenburg et al. 2008; Day et al. 2012b).

An example of the method is shown in Figure 4, where a CI-chondrite (Orgueil) starting composition is used with $\mathrm{Pd} / \mathrm{Os} \sim 1.6$, and where it is assumed that all HSE were initially sited in metal. These types of model typically assume HSE partitioning only between solid metal and liquid metal, consistent with high $D$-values for the HSE $\left(>10^{4}\right)$ for metal-silicate at the low pressures of asteroidal interiors (e.g., Righter 2003). It should be noted that the choice of starting composition is important, because the range of initial interelement fractionation observed in chondrites is quite significant $(\mathrm{Pd} / \mathrm{Os}=0.88-1.69$; see below). Since HSE preferentially partition into metal, the HSE concentration present in the metal will depend on the percentage of metal in the parent body, which is also a reflection of its oxidation state. To estimate initial metal abundance in primitive achondrites, Rankenburg et al. (2008) compared total $\mathrm{Fe}$ and olivine composition in ureilites with the total $\mathrm{Fe}$ content of carbonaceous chondrites (e.g., Orgueil), which have relatively constant total Fe of $\sim 24.5$ \pm 1.5 wt.\% (Jarosewich 1990). As described in Walker et al. (2008) there is a hybrid method to that of the parameterization method of Chabot and Jones (2003) for estimating changing $D$ values for the HSE, which involves observation of linear trends on logarithmic plots of the HSE (e.g., Cook et al. 2004). This technique is only really applicable to iron meteorites, as the initial $D_{(\text {Irr }}$ is normally chosen as an 'anchor' because its solid metal-liquid metal partitioning is the best experimentally constrained of the HSE and as primitive achondrite and 'anatectic' chondrite datasets are often not as well defined as linear HSE trends for iron meteorites.

\section{Partial melt modeling of planetary mantles}

Partial melting generally promotes HSE fractionation (Barnes et al. 1985; Rehkämper et al. 1999), as shown by the differences in relative and absolute HSE abundances for terrestrial high-degree partial melts (e.g., komatiites) versus lower-degree equivalents (e.g., alkali basalts; Day 2013). The HSE are strongly controlled by sulfide and HSE-rich alloys (formed by incongruent melting of sulfide) during partial melting of the terrestrial mantle (Barnes et al. 1985; Ballhaus et al. 2006). Numerous studies have modeled HSE behavior during terrestrial mantle melting (e.g., Fryer and Greenough 1992; Rehkämper et al. 1999; Bézos et al. 2005), showing that a range of physical and chemical factors control resultant HSE abundances in primary melts. In addition to the composition of the mantle source, and the strong control of sulfide during melting, the 'shape' and dynamic processes acting on the melting regime are important (e.g., O’Hara 1985). 
These observations have led to the concept of two different shaped primary melt regimes. One is batch-melting of a columnar (cylindrical) melting regime, assuming uniform melting of a mantle source and extraction of all the S-hosted HSE by magmas once sulfide is completely exhausted (20-25\% partial melting in the terrestrial mantle, for example). This form of model reproduces the compositions of both terrestrial low-degree alkali basalts and high-degree partial melts, such as komatiites, reasonably well (Rehkämper et al. 1999), and is most consistent with an upwelling 'mantle plume-like' melting regime on Earth, or for most forms of basaltic melting on planetary bodies (Fig. 5). An alternative shaped melting regime that is applicable to adiabatic decompression melting is the triangular or corner-flow melting regime. This model assumes initial melting commences when mantle material crosses the solidus and where partial melting increases with vertical displacement, and assumes near-fractional melting, typically in 1\% increments (Rehkämper et al. 1999). In this melting regime, mixing between deeper, S-saturated low-degree partial melts with low HSEconcentrations, and shallower, higher-degree partial melt with potentially S-undersaturated and HSE-rich compositions can occur. The triangular melting regime generates different outcomes for calculated HSE abundances for samples relative to the columnar melting regime, because of the hybridisation of melts.

The HSE systematics are critically dependent on the presence or elimination of sulfides in the residue, so blended melts in a triangular melt regime will lead to more elevated HSE abundances at lower degrees of partial melting (10-20\%) that better conform to the melting characteristics of some terrestrial tholeiitic lavas. In a mantle with $250 \mu \mathrm{g} . \mathrm{g}^{-1} \mathrm{~S}$ and $4.4 \mathrm{ng} . \mathrm{g}$ ${ }^{-1} \mathrm{Pd}$, this translates to generation of melts with $1000 \mu \mathrm{g} . \mathrm{g}^{-1} \mathrm{~S}$ in a triangular melting regime that form by $13 \%$ partial melting and contain $2 \mathrm{ng} \cdot \mathrm{g}^{-1} \mathrm{Pd}$, versus $>20 \%$ partial melting required in a columnar melting regime to obtain similar Pd enrichments in the resultant magma. In these melting models, the key factor is whether partial melting was significant enough to exhaust residual sulfides in any part of the melting regime (Rehkämper et al. 1999; Mavrogenes and O'Neill 1999). Refined models developed for HSE abundances generated by partial melting to produce MORB (Bézos et al. 2005) and hotspot volcanics (Rehkämper et al. 1999) have allowed elucidation of distinct melt regimes.

For most planetary examples, melting regimes are likely to conform to a columnar melting condition due to the absence of obvious plate-tectonic processes on Solar System bodies, other than Earth. Estimating the degree of partial melting for many asteroidal parent bodies is challenging because of uncertainties regarding source composition and $\mathrm{S}$ content in their sources. Estimates of the degree of partial melting and $\mathrm{S}$ content have been produced for lunar and martian melt sources, with martian melts having similar estimated degrees of partial melting and $\mathrm{S}$ content to terrestrial basalts considered to derive from columnar melting regimes (Fig. 5). The HSE contents of martian melts indicate similar absolute abundances of these elements in their source, with sulfide-melt partitioning and degree of Sundersaturation during partial melting similar to terrestrial basalts. By contrast, the lower HSE contents of lunar basalts, and their lower estimated degrees of partial melting either require much higher sulfide-melt partitioning, or lower initial HSE and S abundances in the lunar mantle. As discussed below, detailed work indicates the latter scenario as the cause of differences in melting models for lunar, compared with terrestrial or martian basalts. 


\section{"Pristinity" of crustal and mantle samples}

Studies of lunar crustal samples have recognized the importance of identifying samples that experienced limited impactor contamination on the lunar surface. These studies have used Ir contents, petrography and other geochemical arguments to establish a 'pristinity' filter (e.g., Chao et al. 1976; Hertogen et al. 1977; Warren and Wasson 1977). The Ir abundance filter for 'pristinity' (<130 pg.g ${ }^{-1}$ Ir, Warren and Wasson 1977) was based on observations that most chondrites and iron meteorites have much higher HSE concentrations than lunar crustal rocks (typically $>10^{5}$ enrichment), so even limited $(<0.1 \%)$ meteoritic addition will dominate the HSE inventory of impact-contaminated rocks. The HSE in particular, are sensitive tracers of impactor contamination in rocks with initially low HSE abundances. Osmium isotopic composition is especially diagnostic of meteoritic contamination because the limited range in Re/Os among chondrites - and some iron meteorites-leads to a restricted, well-defined range in present-day ${ }^{187} \mathrm{Os} /{ }^{188} \mathrm{Os}$ (e.g., Fig. 6). Additionally, chondritic materials (as well as some irons) are characterised by limited variations in the absolute abundances of these elements ( $<40 \%$; Horan et al. 2003). The diagnostic capability of Os isotopes is based on the assumption that magmatic processes under most conditions should lead to formation of crustal rocks with non-chondritic relative HSE abundances and ratios, including Re/Os (e.g., Day et al. 2010). Thus, non-mare lunar samples with chondritic or near-chondritic ${ }^{187} \mathrm{Os} /{ }^{188} \mathrm{Os}$ and relative HSE abundances are presumed to have HSE dominated by one or more exogenous components, even if Ir abundances are sufficiently low to qualify as pristine using prior criteria (Warren and Wasson 1977). This pristinity filter can potentially be extended to other planetary materials. Distinguishing between endogenous (internal origin) and exogenous (external origin) components is important when considering basalts and other silicate materials with very low HSE abundances.

\section{Estimation of planetary mantle composition}

Few, if any bona fide mantle samples are currently available from planetary bodies other than Earth. On Earth, entrained mantle xenoliths, abyssal peridotites, peridotite massifs and ophiolites allow direct access to upper mantle materials. Some diogenite meteorites may represent mantle samples from the Howardite-Eucrite-Diogenite parent body, although they most probably represent samples of the lower crust. There is also the likelihood that ureilites and brachinites represent melt restites from their respective parent bodies.

Analysis of terrestrial mantle peridotites has shown that partial melting leads to fractionation of weakly to strongly incompatible Re, Pt, Pd and Au from the remaining HSE (Os, Ir, Ru, $\mathrm{Rh}$ ) such that crust-forming processes will affect relative and absolute mantle HSE abundances (e.g., Lorand et al. 1999; Schmidt et al. 2000; Pearson et al. 2004; FischerGödde et al. 2011). Since melting through adiabatic decompression is almost unavoidable in all upwelling terrestrial mantle materials, a hypothetical mantle composition that is supposedly unaffected by these processes, typically termed 'primitive mantle' (PM), has to be estimated. Methods to estimate PM composition generally project to fertile mantle compositions by plotting compatible Mg (e.g., Morgan 1986), or elements that are strongly controlled by melt depletion, such as Al (Reisberg and Lorand 1995; Meisel et al. 1996; Becker et al. 2006). These methods will be discussed later in the context of obtaining a terrestrial primitive upper mantle (PUM) composition. 
In contrast to Earth, for most highly differentiated planetary bodies, alternative methods are required to establish estimated mantle HSE abundances from derivative partial melts. There are currently two favored methods, both of which have their strengths and weaknesses. The first uses $\mathrm{HSE}-\mathrm{MgO}$ co-variations (e.g., Fig. 7a) and assumes that these compatible elements can be regressed to a mantle $\mathrm{MgO}$ composition (typically 35 wt. \% $\mathrm{MgO}$; Warren et al. 1999; Day et al. 2007). This method allows for easy recognition of materials that are not pristine and that contain excess impactor material, as these samples will plot at higher HSE abundances for a given $\mathrm{MgO}$ content than the main dataset from any given planetary body. The second method uses interelement HSE co-variation. The interelement HSE covariation method relies on comparison of concentrations of two HSE of differing compatibility and assumes that at low degrees of melting incompatible/compatible HSE ratios will be high, and as melting degree increases such ratios will decrease, until at high melting degrees the ratio will be approximately equal to the source (Fig. 7b). An advantage of this method is that the $\mathrm{MgO}$ content of the sample does not need to be known. However, the method — as with the HSE-MgO co-variation method—is not independent of partitioning behavior, mineral fractionation, or to $\mathrm{S}$ saturation and crustal contamination of mantlederived melts. It is imperative that samples that have experienced later impactor contamination (see Pristinity criterion, above) are identified and not used in either method.

While both the $\mathrm{MgO}$ and interelement HSE co-variation methods give results that are broadly similar (Fig. 8), the interelement co-variation method gives non-chondritic Re/Os and $\mathrm{Pd} / \mathrm{Os}$ for lunar and martian mantle estimates (Table 2), despite chondritic Re/Os in most samples, as defined by their present-day ${ }^{187} \mathrm{Os} /{ }^{188} \mathrm{Os}$ (Day et al. 2007; Brandon et al. 2012; Day and Walker 2015). The low Re/Os calculated by the interelement co-variation method would result in ${ }^{187} \mathrm{Os} /{ }^{188} \mathrm{Os}$ around 10 to $14 \%$ lower than measured in lunar or martian samples, assuming a starting composition with initial Solar System ${ }^{187} \mathrm{Os} /{ }^{188} \mathrm{Os}$ of 0.0952 (see section on 'Planetary Formation Processes'). Conversely, the MgO-HSE covariation method predicts broadly chondritic-relative abundances of the HSE in lunar mantle estimates and a 'blind-test' regression of terrestrial lavas (Day et al. 2007) closely matches the terrestrial PUM composition (Becker et al. 2006). The Re/Os from these calculations result in ${ }^{187} \mathrm{Os} /{ }^{188} \mathrm{Os}$ that is in much closer agreement with ${ }^{187} \mathrm{Os} /{ }^{188} \mathrm{Os}$ in lunar or martian samples, being within 5\%, 0-2.5\% and 3\% of the PUM estimate, for terrestrial, lunar and martian $\mathrm{MgO}-\mathrm{HSE}$ co-variation methods, respectively. Another disadvantage of the interelement HSE co-variation method appears to be in significant dispersion of characteristic ratios in terrestrial peridotites (e.g., Fig. 7b), implying that this method does not satisfactorily account for mantle heterogeneity, whereas the $\mathrm{MgO}$ regression method seems to account for this variability reasonably well.

Using a large dataset of HSE abundances in lunar mare basalts and martian shergottites, it is possible to estimate mantle $\mathrm{HSE}$ abundances using the MgO-regression method (Table 2). Relative to CI-chondrites, the Earth $(\sim 0.009 \pm 0.003)$ and Mars $(\sim 0.007 \pm 0.004)$ have similar HSE abundances, with the Moon being some 20-120 times more depleted in these elements $(\sim 0.00022 \pm 0.00006$; Fig. 8$)$. It is more challenging to provide similar estimates for other planetary bodies, given either limited available datasets, or evidence for heterogeneity. This is exemplified by HSE abundance and Os isotope datasets obtained for diogenites (Day et al. 2012a; Dale et al. 2012), aubrites (van Acken et al. 2012), and angrites 
(Riches et al. 2012), which show up to five orders of magnitude HSE abundance variation, but in broadly chondritic-relative proportions. For these reasons, we do not report estimated mantle or crustal compositions for asteroidal parent bodies due to the large uncertainties associated with making these calculations. It appears that HSE abundances in the mantles of fully differentiated asteroidal bodies can reasonably range from lunar mantle estimates, to values that exceed the terrestrial or martian mantle composition.

\section{What do chondritic or nearly/broadly chondritic actually mean?}

Previously, some authors have used the terms 'broadly chondritic', 'nearly chondritic', 'chondrite-relative', or similar phraseology, to describe the estimated compositions of planetary mantles. It has also been suggested that large variations cannot be clearly seen in logarithmic plots, such as Figure 8, arguing that the use of these diagrams does not provide compelling arguments for mantle compositions with chondritic abundances of the HSE (Righter et al. 2015). Major chondrite meteorite group (carbonaceous, ordinary, enstatite) HSE contents and measured ${ }^{187} \mathrm{Os} /{ }^{188} \mathrm{Os}$ are reported in Table 3. By definition, any sample with interelement ratios identical to chondrites would be termed as having relative abundances that are chondritic, even if absolute abundances of the HSE are significantly lower, or higher, than in chondrite meteorites. Data for chondrites are plotted in Figure 9a on a linear scale, relative to the mantle estimates for Earth (from Becker et al. 2006) and Mars (MgO-HSE regression method), multiplied by 150 and the Moon (from Day et al. 2007), multiplied by 6000 (the average levels of depletion of the HSE in the planetary mantles of these bodies, relative to chondrites), and in Figure $9 \mathrm{~b}$ on a logarithmic scale. These diagrams illustrate that nearly/broadly chondritic means that, in detail, not all interelement ratios are identical to chondrite meteorite groups, but that the majority of elements are in chondritic relative proportions. Most critically, Re/Os in the mantle estimates yield chondritic ${ }^{187} \mathrm{Os} /$ ${ }^{188} \mathrm{Os}$, consistent with ${ }^{187} \mathrm{Os} /{ }^{188} \mathrm{Os}$ measured in terrestrial peridotites (e.g., Becker et al. 2006), or from mantle-derivative melts from Mars or the Moon (Brandon et al. 2000, 2012; Day et al. 2007; Day and Walker 2015). This terminology is adopted for the rest of the manuscript; nearly/broadly chondritic abundances of the HSE are qualified by the requirement of chondritic Re/Os and the majority of the HSE being in chondritic-relative proportions; chondritic abundances means that all interelement ratios are in the same proportions as in chondrites.

\section{PLANETARY MATERIALS}

In this overview of HSE abundances and Os isotope systematics in planetary materials, three 'scientific liberties' are taken, for the sake of brevity. First, many of the meteorites discussed are not described in detail, although references are provided that include this information. Second, supporting petrology, geochemical or isotopic information is not discussed unless directly relevant, although the cited references offer this detail. Third, data references are dominated by the relatively recent literature. This is partly due to the increase in high-quality isotope dilution data available, and more comprehensive HSE coupled with Os isotope datasets. The available planetary materials include meteorites, as well as materials from the Moon that were collected robotically, or by humans, in the late 1960s to early 1970s (Table 4). Meteorites are typically found in cold or hot deserts and include falls and finds. Finds are 
those meteorites that were located, typically on stranding surfaces, after some period of terrestrial residence that can exceed thousands to tens of thousands of years. Falls are those meteorites observed to pass through the Earth's atmosphere and that are almost immediately collected. Meteorite falls and the Apollo and Luna lunar collections are those materials presumed to be least affected by modification on the Earth's surface.

\section{Early Solar System materials}

During the earliest stages of Solar System formation, elements are considered to have condensed, according to their condensation temperatures, leading to inevitable chemical fractionation. Six of the HSE (Re, Os, Ir, Pt, Rh, Ru), as well as W, Mo, Zr, and Hf, are considered ultra-refractory trace elements with low vapour pressures, and $50 \%$ condensation temperatures $>1400 \mathrm{~K}$ (Table 3 ; the $50 \%$ condensation temperature $\left(50 \% \mathrm{~T}_{\mathrm{c}}\right.$ ) is a term used to describe the extent of condensation or volatility of minor and trace elements and can also be computed for major elements. At this temperature, half of an element is in the gas phase and the other half is sequestered into condensates (Lodders 2003)). Because of their low initial abundances, these elements are considered to have condensed within refractory metal alloys in a predictable fashion (Palme and Wlotzka 1976; Fegley and Palme 1985; Campbell et al. 2001). By contrast, two of the HSE (Pd, $\mathrm{Au}$ ), as well as numerous moderately and slightly siderophile elements (Ag, As, $\mathrm{Bi}, \mathrm{Co}, \mathrm{Cr}, \mathrm{Cu}, \mathrm{Ge}, \mathrm{Ni}, \mathrm{P}, \mathrm{Pb}, \mathrm{Sb}, \mathrm{Sn}, \mathrm{Te}$ ) have lower $50 \% T_{\mathrm{c}}$ and are considered to have become sequestered in $\mathrm{Fe}-\mathrm{Ni}$ alloy phases (pure $\mathrm{Fe}$ $50 \% T_{\mathrm{c}}=1357 \mathrm{~K}$; Lodders 2003 ). Combined with the moderately volatile nature of Au at nebular conditions, these factors can lead to a fundamental difference in behavior between $\mathrm{Au}$ and Pd, and the rest of the HSE. Analysis of nano-meter sized metal alloys in spinel grains from Allende have HSE, W and Mo concentrations that are in excellent agreement with calculated concentrations from condensation in a cooling gas of solar composition, supporting the theoretical calculations (Eisenhour and Buseck 1992). Subsequently, exsolution, oxidation and sulfurisation led to the formation of complex assemblages in some early formed chondritic materials (Bischoff and Palme 1987).

The most primitive and least modified accessible materials from the Solar System are represented by chondrite meteorites. Chondrites can be divided on the basis of their bulk chemistry, isotopic compositions, oxidation states and proportions of components (chondrule, refractory inclusion, metal or matrix abundance) into three main classes: carbonaceous, ordinary and enstatite chondrites. A number of sub-divisions are provided within each chondrite class based on bulk composition and oxygen-isotopic composition (e.g., carbonaceous chondrites $=\mathrm{CI}, \mathrm{CM}, \mathrm{CR}, \mathrm{CV}, \mathrm{CO}, \mathrm{CK}$ ) and iron contents (e.g., ordinary chondrites $=$ high $[\mathrm{H}]$, low $[\mathrm{L}]$, low metallic Fe and low Fe contents [LL]; enstatite chondrites $=$ high $[\mathrm{EH}]$ and low $[\mathrm{EL}]$ iron), as well as petrological grades from secondary alteration (see Brearley and Jones 1998 for an in-depth review). Of these meteorites, the CIchondrites are considered to be most representative of the bulk Solar System composition, having abundances of nearly all elements that approximate the solar photosphere composition (e.g., Anders and Grevesse 1989). On most plots of HSE abundances presented relative to chondritic values, it is the CI-chondrite value, as represented by the Orgueil meteorite fall that is most commonly used for normalisation (Table 3). 
Abundances of the HSE have been determined from all three major chondrite classes, as well as for the Rumuruti class of chondrites (Fig. 10). The patterns defined by the majority of chondrite meteorites show limited, yet significant, interelement variation. By contrast, absolute abundance variations of bulk samples are considerably greater within groups and between groups: carbonaceous chondrites ( 0.8-1.9 $\times$ CI-chondrite), ordinary chondrites ( 0.6-2.4 $\times$ CI-chondrite) and enstatite chondrites $(\sim 0.2-2 \times$ CI-chondrite). The generally higher HSE concentrations measured in most chondrite classes, relative to Orgueil is considered to reflect dilution by the presence of increased volatile components in CIchondrites. In addition, variations in concentration have also been interpreted to reflect heterogeneities in aliquots of meteorite samples, resulting from the presence of variable proportions of metal or HSE-rich refractory inclusions, or HSE-poor sulfides (e.g, Palme et al. 1994; Horan et al. 2009). For example, one carbonaceous chondrite, Lancé (CO3) is omitted from Figure 10 due to its very high measured abundance of Re, Os, Ir, Ru, and Pt (5-19 $\times$ CI-chondrite; Horan et al. 2003) that is considered to reflect an unusual concentration of metal-rich 'fremdlinge' that are found within refractory inclusions (e.g., Fegley and Palme 1985). Other processes that can significantly alter the primary distributions of the siderophile elements include later impact processes (Norman and Mittlefehldt 2002). Impact-affected chondrites are generally easily avoided in chondrite comparisons due to textural and disturbed chemical differences imparted by collisional processes.

Separated magnetic and nonmagnetic components from the ordinary chondrites Dhajala (H3.8) and Ochansk (H4) show that metal from both meteorites contains $~ 90 \%$ of the total HSE budget. The abundances of Re, Os, Ir, Ru, and Pt in the nonmagnetic fractions (14-120 ng. $\mathrm{g}^{-1}$ ) are much higher than would be expected if they had equilibrated with the metal phases, suggesting the presence of two HSE-bearing carrier phases that formed separately, and never subsequently equilibrated (Horan et al. 2009). Study of individual components within some chondrites, including calcium-aluminum-rich inclusions (CAIs), chondrules, and matrix (Archer et al. 2014) reveal that CAIs are characterized by significant depletions in Pd relative to the other HSE, while the other HSE are in generally bulk chondritic relative abundances. The depletions in Pd have been linked with initial formation of CAIs through condensation, or subsequent processing by evaporative processes. Chondrules generally have relative HSE patterns similar to CAIs, although they have lower absolute abundances (Archer et al. 2014). Matrix samples have nearly chondritic absolute abundances of all HSE measured.

The $187 \mathrm{Re}-{ }^{187}$ Os systematics of bulk chondrites fall around a precise Solar System isochron defined by IIIAB iron meteorites (Fig. 11), but do not themselves define isochronous relationships. As the majority of chondrites measured to date are falls, the dispersion is not interpreted to reflect terrestrial alteration. Instead, most of the deviations from the isochron are considered consistent with minor, relatively recent redistribution of Re and/or Os on a scale of millimeters to centimeters, with other disturbances as a result of aqueous alteration or shock events on chondrite parent bodies within the past $2 \mathrm{Ga}$ (Walker et al. 2002). In certain instances, analyses of bulk material and metal-rich separates of chondrites can yield isochronous information. For example, components of the ordinary (LL6) chondrite St. Severin were found to have a formation age of $4.68 \pm 0.15 \mathrm{Ga}$, with an 
initial ${ }^{187} \mathrm{Os} /{ }^{188} \mathrm{Os}$ of $0.0953 \pm 0.0013$ (Chen et al. 1998). Based on an expanded dataset of whole-rock chondrite compositions, the average ${ }^{187} \mathrm{Re} /{ }^{188} \mathrm{Os}$ for carbonaceous chondrites is $0.392 \pm 0.018$ (excluding the CK chondrite, Karoonda), compared with $0.424 \pm 0.029$ and $0.426 \pm 0.018$ for ordinary and enstatite chondrites, respectively ( $1 \sigma$ standard deviations). Measured ${ }^{187} \mathrm{Os} /{ }^{188} \mathrm{Os}$ for carbonaceous chondrites averages $0.1262 \pm 0.0005$ (again, excluding Karoonda), and ordinary and enstatite chondrites average $0.1284 \pm 0.0020$ and $0.1280 \pm 0.0008$, respectively ( $1 \sigma$ standard deviations). While the Re/Os ratios of chondrites within each group are, in general, quite uniform, an $\sim 8 \%$ difference in Re/Os and minimal overlap in ${ }^{187} \mathrm{Os} /{ }^{188} \mathrm{Os}$ of ordinary and enstatite chondrites, relative to carbonaceous chondrites, indicates long-term differences in Re/Os for these materials, most likely reflecting chemical fractionation early in Solar System history (Walker et al. 2002).

Rhenium-Os isotope studies of CAIs in carbonaceous chondrites have revealed that their ${ }^{187} \mathrm{Os} /{ }^{188} \mathrm{Os}$ are indistinguishable from CI chondrites with an average ${ }^{187} \mathrm{Os} /{ }^{188} \mathrm{Os}$ of 0.1265 and ${ }^{187} \mathrm{Re} /{ }^{188} \mathrm{Os}$ of 0.3964 (Becker et al. 2001). Studies of ${ }^{187} \mathrm{Re}-{ }^{187} \mathrm{Os}$ for chondritic components (i.e., CAIs, FeNi metal, chondrules, chondrule fragments, pre-solar/solar grains, organics) in the Allende meteorite (Archer et al. 2014), and in ordinary chondrites Dhajala and Ochansk (Horan et al. 2009) indicate open-system behavior in non-metal fractions, leading to deviations of as much as $40 \%$ from a $4.568 \mathrm{Ga}$ primordial isochron for components in Dhajala and Ochansk. Open-system behavior is considered to have occurred within the last 2 billion years, and, in some cases, could have resulted from terrestrial alteration, even in falls, with open-system behavior being most readily observed in small, mm-size sub-samples of Allende, consistent with Re and/or Os mobility on that scale (Chen et al. 1998; Archer et al. 2014).

Alteration processes on chondrite parent bodies have been important in homogenizing Os isotopes, as well as affecting the distribution of the HSE within chondrite classes. Presolar trace phases bearing Os isotopic anomalies have been shown to exist only in the most unequilibrated chondrites. This observation, coupled with Os isotopic heterogeneity among all materials known to represent bulk planetesimals indicates that an $s$-process carrier, possibly insoluble organic material (IOM), was incorporated in all primitive materials (Brandon et al. 2005a; Reisberg et al. 2009; Yokoyama et al. 2010). These studies have also demonstrated that the presolar materials bearing the Os isotopic anomalies are effectively destroyed by metamorphism, and possibly by parent-body processes (Yokoyama et al. 2011; Walker 2012; Yokoyama and Walker 2016, this volume). Parent body processes have also affected HSE distributions, with increasing HSE abundances in increasing petrological grades of carbonaceous chondrites (Fig. 12). These correlations are consistent with prior observations for aqueous alteration on chondrite parent bodies affecting HSE distributions (e.g., Brandon et al. 2005b), as well as the sequential loss of volatile compounds in carbonaceous chondrites, leading to concentration of the HSE in volatile poor samples (Horan et al. 2003). Similar trends are not as clear in ordinary or enstatite chondrites, but are evident when all chondrites are plotted as a function of petrological grade (Fig. 12d). 


\section{Fragments of planetary cores and/or metal-rich melt pools}

Iron Meteorites.-Metallic nickel iron constitutes the largest mass proportion of extraterrestrial material available for study, even though observed iron meteorite falls account for only 5\% of total falls (Mittlefehldt et al. 1998). The discrepancy exists due to the durability of iron meteorites during asteroidal disruption, fall as meteorites to Earth, and preservation and recognition on Earth. For a general overview of the metallography, mineralogy, and cooling rates of iron meteorites, please refer to Mittlefehldt et al. (1998) and Goldstein et al. (2009).

Iron meteorites typically consist of metallic iron with $\sim 5-20 \mathrm{wt}$. \% Ni. Initial studies used $\mathrm{Ga}$ and $\mathrm{Ge}$ abundances to classify iron meteorites into four groups (I-IV), in order of decreasing abundances (Goldberg et al. 1952; Lovering et al. 1957). Gallium and Ge vary between groups because they are the most volatile siderophile elements. Subsequent studies (Wasson 1967; Wasson et al. 1998) measured Ni, Ga, Ge, Ir, Cr, Co, Cu, As, Sb, W, Re, Pt, and $\mathrm{Au}$ abundances and subdivided the four $\mathrm{Ga}-\mathrm{Ge}$ groups into 14 separated clusters labelled A-G, and attached these sub-definitions to the Roman numerals (Fig. 13). Within the chemically classified iron meteorites, there are two classes. The first class are IIAB, IID, IIIAB, IVA, IVB (possibly IC, IIIF), which are generally free of silicates and have compositional trends that can be explained by solid metal-liquid metal fractionation during solidification of molten iron - these have been referred to as the 'magmatic irons' (Wasson 1985). The second class of iron meteorite includes IAB and IIE and has been referred to as 'non-magmatic'. These meteorites contain more abundant silicate material, with chemical trends that are commonly weaker than for 'magmatic irons' (Scott 1972), with trace-element distributions that cannot be modelled by fractional crystallization alone (Chabot and Jones 2003; Chabot and Haack 2006). The 'non-magmatic' irons are considered by some to derive from impact melting of planetesimals, with variation in HSE concentrations due to mixing of melts and solids (e.g., Choi et al. 1995; Wasson and Kallemeyn 2002).

For the magmatic irons, chemical trends are generally consistent with fractional crystallization from a single molten pool or core of metallic iron (e.g., Scott 1972; Scott and Wasson 1976; Goldstein et al. 2009). However, differences in S contents within the pools or cores led to changing partitioning behaviors during crystallization (e.g., Chabot and Jones 2003). In addition to extensive work performed to examine HSE behavior within iron meteorites using LA-ICP-MS techniques (e.g., Hirata and Nesbitt 1997; Campbell and Humayun 1999; Petaev and Jacobsen 2004), high quality HSE abundance and Re-Pt-Os isotope datasets are available for a number of iron meteorite groups. These studies have shown that the HSE within individual bulk samples are generally homogeneous at the $\pm 10 \%$ level and show highly correlated linear trends of the HSE on logarithmic plots (e.g., Morgan et al. 1992, 1995; Walker et al. 2008; McCoy et al. 2011). The linear trends are interpreted to reflect the coherent and predictable behavior of the HSE resulting from magmatic processes, confirming crystallization of each group from a single mass of iron as a function of $\mathrm{S}, \mathrm{P}$ and C content (Pernicka and Wasson 1987; Chabot and Jones 2003 Petaev and Jacobsen 2004; Walker et al. 2008). Examples of IVA and IVB iron meteorite HSE distributions are shown in Figure 14. The very different fractionation behaviors and absolute abundances of the HSE within IVA and IVB irons are interpreted to reflect generally chondritic proportions of these 
elements in the IVA parent body (McCoy et al. 2011), whereas IVB irons represent complex processing and equilibrium solids and solid-liquid mixtures within an oxidized body, with reduction in the abundances of redox-sensitive elements such as Re, Os, and Ir (Walker et al. 2008).

The earliest report of ages of iron meteorites came from the Re-Os isotope system, with Herr et al. (1961) determining an age for iron meteorites of $4.0 \pm 0.8 \mathrm{Ga}$. Analytical advances have led to progressively improved ${ }^{187} \mathrm{Re}-{ }^{187}$ Os age determinations of iron meteorites (Luck and Allègre 1983; Hirata and Masuda 1992; Shen et al. 1996; Smoliar et al. 1996; Horan et al. 1998; Chen et al. 2002; Cook et al. 2004; Walker et al. 2008; McCoy et al. 2011). The ages of iron meteorite suites, derived from ${ }^{187} \mathrm{Re}-{ }^{187}$ Os systematics, range from $4579 \pm 39 \mathrm{Ma}$ for IVB irons to $4517 \pm 32 \mathrm{Ma}$ for IIIAB iron meteorites, with corresponding initial ${ }^{187} \mathrm{Os} /{ }^{188} \mathrm{Os}$ from 0.0953 to 0.0958 (Fig. 15), close to the Solar System initial ${ }^{187} \mathrm{Os} /{ }^{188} \mathrm{Os}$ composition of $0.0952 \pm 0.0002$. In addition to ${ }^{187} \mathrm{Re}-{ }^{187} \mathrm{Os}$ chronology, some studies have generated ${ }^{190} \mathrm{Pt}-186$ Os data for iron meteorites (Fig. 15f), establishing relatively young ages of $4323 \pm 80 \mathrm{Ma}$ and $4325 \pm 26 \mathrm{Ma}$ for IIAB and IIIAB iron meteorites, respectively (Walker et al. 1997; Cook et al. 2004). The young Pt-Os isotope ages have been interpreted to reflect error in the ${ }^{190} \mathrm{Pt}$ decay constant, with an estimate from the IIIAB irons suggesting a revised $\lambda$ of $1.415 \times 10^{-12} \mathrm{a}^{-1}$ (Cook et al. 2004).

Some ${ }^{187} \mathrm{Re}-{ }^{187}$ Os ages are significantly younger than for metal-silicate segregation ages derived from the ${ }^{182} \mathrm{Hf}_{-}{ }^{182} \mathrm{~W}$ ( $<2$ Ma after Solar System formation; e.g., Kruijer et al. 2014) or ${ }^{107} \mathrm{Pd}-{ }^{107} \mathrm{Ag}$ systems ( $₫ 0 \mathrm{Ma}$ after Solar System formation (Chen et al. 2002), noting caveats of cosmic ray exposure (CRE) potentially leading to young apparent ages in the $\mathrm{Pd}-$ Ag isotope system (Leya and Masarik 2013)). The differences could reflect the variance in timing between core segregation and core crystallization. The ${ }^{187} \mathrm{Re}-{ }^{187}$ Os system records the time of fractionation of the two elements, resulting from fractional crystallization. In the case of $\mathrm{Hf}$ and $\mathrm{W}$, both are refractory and, thus, are expected to occur in chondritic relative proportions in bulk, undifferentiated planetary bodies. However, during metal segregation, the lithophile element $\mathrm{Hf}$ is retained in the mantle, while $\mathrm{W}$ preferentially partitions into the metal core. Consequently the abundance of ${ }^{182} \mathrm{~W}$ in the metal and silicate can be used to infer the time of metal-silicate fractionation. Thus, for iron meteorites, the determination of core formation ages using the ${ }^{182} \mathrm{Hf}-{ }^{182} \mathrm{~W}$ system is straightforward, because the $\mathrm{W}$ isotope composition of the irons remains unchanged subsequent to core formation, except for cosmic-ray-induced neutron-capture effects (e.g., Masarik 1997; Leya et al. 2003).

Stony-iron meteorites (pallasites and mesosiderites).-The classification between iron meteorites and stony iron meteorites can be somewhat hazy, given that some iron meteorites can contain silicates (e.g., silicate-bearing IAB and IIE irons), and that some primitive meteorites, termed winonaites, may be related to IAB irons (e.g., Kimura et al. 1992; Benedix et al. 1998). For the purpose of this review, stony-iron meteorites are restricted to meaning pallasites and mesosiderites. Pallasites are composed of roughly equal amounts of silicate (olivine, pyroxene) and metal \pm troilite. Within the pallasites, 'maingroup pallasite' is the term typically used to describe the main compositional cluster, whereas the term 'anomalous metal pallasite' is used to describe the Eagle Station pallasite group (Wasson and Choi 2003). Main group pallasites have similar $\Delta^{17} \mathrm{O}$ values $(\sim-0.2 \%$ ) 
to IIIAB irons, howardiite-eucrite-diogenites (HED) and mesosiderites, indicating possible links between these meteorite groups (Clayton and Mayeda 1996). Mesosiderites are composed of metal mixed with mostly basaltic, gabbroic or pyroxenitic lithologies with only minor olivine. Pallasites have classically been interpreted to represent core-mantle boundary mixtures from asteroids, whereas mesosiderites appear to represent impact-mixtures of metallic nickel-iron and lithologies similar to HED meteorites (Mittlefehldt et al. 1998).

Available HSE abundance data indicates that most main-group pallasites are depleted in Re, Os and Ir compared to CI-chondrites, but show remarkably limited variance in Pd and $\mathrm{Au}$, and if related by metallic liquid-crystal fractionation, must have evolved with a solid metalliquid metal $D$-value approaching one (Fig. 16). Eagle Station group pallasites can exhibit very high concentrations of the HSE, but otherwise show similar strong depletions in Re, Os and $\mathrm{Ir}$, relative to $\mathrm{Ru}, \mathrm{Pt}$ and $\mathrm{Pd}$, as compared to main group pallasites. Limited HSE abundance data are currently available for mesosiderites.

Rhenium-Os isotope systematics have been determined for nine pallasites (eight main group and Eagle Station; Fig. 16b) and for four mesosiderites (Shen et al. 1998; Chen et al. 2002). A combined analysis of the pallasite ${ }^{187} \mathrm{Re}-{ }^{187} \mathrm{Os}$ data defines an age of $4.50 \pm 0.04 \mathrm{Ga}$ and an initial ${ }^{187} \mathrm{Os} /{ }^{188} \mathrm{Os}$ of $0.0956 \pm 5$ (Chen et al. 2002). A pallasite isochron reported in an extended abstract by Lee et al. (2006) for 12 main group pallasites yielded a ${ }^{187} \mathrm{Re}-{ }^{187} \mathrm{Os}$ age of $4.548 \pm 0.087 \mathrm{Ga}$ and an initial of $0.0952 \pm 9$. These ages and initials are generally in agreement with the IIIAB iron ${ }^{187} \mathrm{Re}-{ }^{187} \mathrm{Os}$ age $\left(4517 \pm 32 \mathrm{Ma} ;{ }^{187} \mathrm{Os} /{ }^{188} \mathrm{Os}_{\mathrm{i}}=0.0958 \pm 3\right)$, although the uncertainties are large, indicating a greater degree of open-system behavior in pallasites compared with iron meteorites. Mesosiderite metal lies along the IIIAB isochron, consistent with early derivation of these materials and consistent with the short crystallization time-intervals inferred from short-lived chronometers.

\section{Primitive achondrite meteorites}

Primitive achondrite meteorites are considered to include materials that experienced a greater degree of metamorphism or melting than chondrites, but that did not fully differentiate. By definition, these meteorites likely reflect the earliest stages of planetary melting and metal-silicate segregation processes, so are of great interest when exploring the behavior of HSE resulting from differentiation in planetary bodies.

Winonaites.-Winonaites have reduced mineral compositions and mineralogy, and O isotopic compositions distinct from primitive achondrite groups, other than silicate inclusions in IAB irons (Benedix et al. 1998). However, unlike IAB irons, winonaites lack metallic matrices and consist mostly of silicates. Winonaites are likely to have formed from a chondritic precursor material unlike that of known chondrites, where extensive heating caused metamorphism and partial melting of both FeNi-FeS and silicate material (Fig. 17). Impact brecciation during cooling is likely to have mixed lithologies with different thermal histories, and subsequent metamorphism produced recrystallization, grain growth, and reduction of mafic silicates (Benedix et al. 1998). Winonaites are interpreted to have crystallized very early, with ${ }^{182} \mathrm{Hf}-182 \mathrm{~W}$ ages $\sim 5 \mathrm{Ma}$ after CAI formation (Schulz et al. 2010). However, a larger thermal event at $\sim 15 \mathrm{Ma}$ after CAI formation is also recognized in 
these meteorites (Schulz et al. 2010). Limited work has been done to characterize HSE abundances and no Os isotope chronology has yet been reported for these meteorites.

Acapulcoite-Lodranites.-Acapulcoite and lodranite meteorites offer some of the most important insights into the very earliest stages of partial melting and melt migration. These meteorites have essentially identical O-isotope compositions (e.g., Clayton and Mayeda 1996, 1999) and similar mineralogy, mineral compositions, thermal histories and exposure ages, indicating their genesis on the same parent body (e.g., McCoy et al. 1996, 1997a,b; Mittlefehldt et al. 1996; Weigel et al. 1999), which some authors consider was composed of CR-like carbonaceous chondrite precursor material (e.g., Rubin 2007). Acapulcoites and lodranites also crystallized early, with ${ }^{182} \mathrm{Hf}-{ }^{182} \mathrm{~W}$ ages $\sim 4 \mathrm{Ma}$ after CAI formation (Schulz et al. 2010).

Acapulcoites have been suggested to represent high-grade metamorphic rocks in which partial melting in the Fe-Ni-S system occurred (Palme et al. 1981; Mittlefehldt et al. 1996), whereas lodranites are considered residues after partial melting, and removal of $\mathrm{Fe}, \mathrm{Ni}-\mathrm{FeS}$ and basaltic partial melts (Bild and Wasson 1976; McCoy et al. 1997a). These modes-oforigin, combined with the mineralogy of acapulcoites and lodranites, which allows estimation of the modal abundances of metal and sulfide phases (Mittlefehldt et al. 1996; Rubin 2007) make acapulcoites and lodranites potential 'natural experiments' of HSE fractionation during the initial phases of planetary differentiation (Fig. 17). Measurements of Ir abundances (7-5200 ng.g ${ }^{-1}$; Palme et al. 1981; Mittlefehldt et al. 1996; Weigel et al. 1999) are highly variable in acapulcoites and lodranites, with lodranites having generally lower HSE abundances to acapulcoites. Recent work has shown that acapulcoites and lodranites have very similar relative and absolute HSE abundances to brachinite-like achondrites (Dhaliwal et al. 2015) and confirm the broadly chondritic measured ${ }^{187} \mathrm{Os} /{ }^{188} \mathrm{Os}$ in these meteorites (GRA 95209 $=0.1279$; Walker et al. 2002).

Ureilites.-Ureilites are one of the most abundant meteorite-types and are essentially extremely depleted peridotites, composed of $>60 \%$ olivine, $30 \%$ pyroxene and variable carbon-content (Mittlefehldt et al. 1998). These rocks are widely considered to represent asteroidal mantle restites (e.g., Warren and Kallemeyn 1992; Scott et al. 1993; Walker and Grove 1993; Goodrich et al. 2004; Warren et al. 2006). Numerous HSE abundance studies have been performed on ureilites, with a compilation of instrumental neutron activation analysis data presented in Warren et al. (2006), and with HSE abundances measured by isotope dilution methodologies presented in Rankenburg et al. (2008) (Fig. 18). These studies have shown that ureilite siderophile element fractionations are consistent with removal of a S-rich metallic melt and preferential loss of $\mathrm{Pd}$, and do not require special conditions, such as smelting or removal of C-rich melts, to explain HSE fractionations.

Rhenium-Os isotope systematics have been determined for $>20$ ureilites (Fig. 19), but the data do not define isochrons. Instead the data indicate likely Re mobility during weathering, as most studied ureilites are meteorite finds (Rankenburg et al. 2007). Ureilite ${ }^{187} \mathrm{Os} /{ }^{188} \mathrm{Os}$ spans a broad range from 0.1174 to 0.1302 , with an average of $0.1258 \pm 23(1 \sigma)$, which is similar to carbonaceous chondrites $(0.1262 \pm 5)$, and quite distinct from enstatite or ordinary chondrites. Rankenburg et al. (2007) interpreted the similarity in ${ }^{187} \mathrm{Os} /{ }^{188} \mathrm{Os}$ between 
ureilites and carbonaceous chondrites to reflect formation within the same region of the solar nebula and for limited Re/Os fractionation due to the stability of a metallic phase during the interval of magmatic processing in the ureilite parent body.

Brachinites, Brachinite-like achondrites and GRA 06128/9.-Discovery of the Graves Nunataks 06128 and 06129 (hereafter GRA 06128/9) meteorites in Antarctica has led to a major improvement of understanding of brachinite meteorites. GRA 06128/9 are felsic meteorites composed of $>75$ modal $\%$ sodium-rich plagioclase and have andesite to trachy-andesite compositions (Day et al. 2009). Brachinites, on the other hand, are olivinedominated achondrites (> 80 modal \%), containing Ca-rich pyroxene (Mittlefehldt et al. 1998; Day et al. 2012a; Keil 2014). Despite their contrasting mineralogies, these meteorite types have been linked, with brachinites representing partial melt residues and the GRA 06128/9 meteorites equating to high Fe/Mg, silica-saturated melts, after 13-30\% partial melting (Fig. 17; Day et al. 2012a). Brachinite-like achondrites include meteorites such as Northwest Africa (NWA) 5400 and NWA 6077 and are interpreted to have formed from single-stage S-rich metal segregation, in a similar manner to ureilites, whereas brachinites and GRA 06128/9 have characteristic depletions in Ir, Pt and Pd, relative to Re and Os (Fig. 18).

GRA $06128 / 9$ have ${ }^{187} \mathrm{Os} /{ }^{188} \mathrm{Os}$ between 0.1261 and 0.1312 , with five of seven separate measurements lying close to a 4.568 Ga IIIAB iron meteorite reference isochron (Fig. 19). The two samples that lie furthest from the reference isochron have higher measured $\mathrm{Re}$ concentrations than calculated, suggesting recent open-system behavior of $\mathrm{Re}$ (gain) or Os (loss). Brachinites have measured ${ }^{187} \mathrm{Os} /{ }^{188}$ Os of between 0.1204 and 0.1301 . Only splits from NWA 1500, NWA 4872, NWA 4882, and Brachina plot close to the reference isochron, with all other samples having measured Re that is either higher or lower than calculated Re* (concentration of Re calculated assuming chondritic ${ }^{187} \mathrm{Os} /{ }^{188} \mathrm{Os}$ at the estimated time of sample crystallization, using the measured Os concentration and calculated Re/Os). None of the brachinite-like achondrites have Re-Os isotope systematics that lie on the reference isochron and have measured ${ }^{187} \mathrm{Os} /{ }^{188} \mathrm{Os}$ of between 0.1255 and 0.1282 . Disturbance of the $\mathrm{Re}-\mathrm{Os}$ isotope system has been studied in detail in some brachinites, with LA-ICP-MS analyses of sulfide and alteration products demonstrating the mobility of Re and/or Os (Day et al. 2012a; Hyde et al. 2014). These studies have also shown that HSE abundance patterns remain faithful recorders of processes acting on the brachinite parent body(ies).

Primitive meteorites from oxidized parent bodies.-An increasing number of meteorites with $\mathrm{FeO}$-rich compositions are being recognized, suggestive of evolution from more oxidized chondritic sources (Day and Warren 2015). These FeO-rich meteorite types include the brachinites, brachinite-like achondrites and GRA 06128/9 meteorites (above), the achondrite Lewis Cliff (LEW) 88763 (Swindle et al. 1998; Day et al. 2015), the recrystallized primitive achondrite Tafassasset (Gardner-Vandy et al. 2012) and the poikilitic cumulate Northwest Africa (NWA) 6693 (Warren et al. 2013). High-FeO partially-melted achondrite meteorites are important materials for understanding inherent variation in oxygen fugacity and volatile abundances in the early Solar System, as well as for examining the nature of precursor 'chondritic' parental materials forming planets and planetesimals. 
HSE abundances have been determined for LEW 88763 and are within the range of bulk chondrites and within approximately a factor of two of the abundances measured in the CIchondrite Orgueil (Fig. 18). LEW 88763 has been interpreted as a metamorphosed chondritic composition, indicating limited partial melting of a FeO-rich parent body (Swindle et al. 1998; Day et al. 2015b). Available Os, Ir and Ru abundances for NWA 6693 (Warren et al. 2013), which is interpreted as a poikilitic cumulate, are similar to the abundances measured in LEW 88763 . These values are very similar to some brachinite-like achondrites and suggest relatively limited melting of chondritic precursor materials. Isotope dilution HSE abundances of NWA 6693, as well as for Miller Range (MIL) 090206 and MIL 090405 have recently been reported, indicating that NWA 6693 has lower absolute abundances of the HSE than LEW 88763, while the Miller Range samples have similar HSE contents to Brachinite-like achondrites (Day and Warren 2015).

The measured ${ }^{187} \mathrm{Os} /{ }^{188} \mathrm{Os}$ of 0.1262 for LEW 88763 is similar to the ratios reported for carbonaceous chondrites, including Allende (Fig. 19). The chondritic Os coupled with the low measured ${ }^{187} \mathrm{Re} /{ }^{188} \mathrm{Os}(0.26)$ for this meteorite is consistent with recent Re-loss, assuming an ancient crystallization age $>4.5 \mathrm{Ga}$ (e.g., Swindle et al. 1998). The recent study by Day and Warren (2015) showed that NWA 6693 has supra-chondritic ${ }^{187} \mathrm{Os} /{ }^{188} \mathrm{Os}$ (0.1339) while other high-FeO primitive achondrites measured so far have Os isotopic compositions within the range of chondrite meteorites.

\section{Meteorites from differentiated asteroids}

Meteorites from differentiated asteroids include the strongly-reduced aubrite achondrites, angrites, and the HED suite of meteorites. Existing data for all of these meteorite groups suggest similar heritages of core formation and HSE-depletion of silicate mantles, late accretion of chondritic material and/or core material, and potential break-up and reassembly, in some instances.

Aubrites.-Aubrites, or enstatite achondrites, are generally brecciated pyroxenites that consist primarily of $\mathrm{FeO}$-free enstatite and formed under highly reducing conditions (IW-6 to IW-8; Mittlefehldt et al. 1998). Aubrites are interpreted to have formed on one or more parent body(ies) after core formation (Casanova et al. 1993), as the low HSE concentrations (Wolf et al. 1983; van Acken et al. 2012) are consistent with removal of metal to form a core (Righter 2003). Aubrites span a wide range in HSE concentrations, from one to three orders of magnitude lower than in chondrites, with the exception of the Shallowater and Mt. Egerton meteorites (Fig. 20). While Os/Ir, Ru/Ir and Pt/Ir are generally chondritic in aubrites, a number of aubrites show significant enrichments in Re and Pd, suggesting extensive magmatic and impact histories (van Acken et al. 2012). Osmium isotopic compositions in aubrites range from 0.1174 to 0.130 ; as enstatite chondrites to lower than known carbonaceous chondrites. However, ${ }^{187} \mathrm{Re}-{ }^{187}$ Os systematics of aubrites tend to be strongly disturbed, indicating relatively recent open-system behavior, and broadly indicating the addition of Re (Fig. 20b). The majority of studied aubrite meteorites are finds, so terrestrial modification of the Re-Os isotope system is likely in some instances. 
Angrites.-Angrites are broadly basaltic achondrite meteorites that crystallized from asteroidal magmas generated within one or more early formed differentiated planetary bodies within $\sim 2-10$ Ma of Solar System formation (e.g., Kleine et al. 2012). Recent studies have shown that the HSE occur in broadly chondritic absolute and relative abundances in some angrite magma source regions (Riches et al. 2012; Dale et al. 2012), and some authors have argued that the angrite parent body (APB) mantle contains HSE abundances broadly similar to those of the terrestrial mantle (Dale et al. 2012). This interpretation is improbable, as angrite meteorites span a wide range of HSE-abundances, from $<0.005 \mathrm{ng} . \mathrm{g}^{-1} \mathrm{Os}$ $(\sim 0.00002 \times$ CI chondrite; e.g., NWA 1296; Angra dos Reis), to $\sim 0.3$ to $0.5 \times$ carbonaceous chondrite abundances (e.g., 97.2-206 ng.g ${ }^{-1}$ Os; NWA 2999 and NWA 4931) (Fig. 21a). As with the currently available suite of aubrites (above) and eucrites and diogenites (below), this makes estimation of mantle composition for their respective parent bodies extremely challenging without integrated petrological information.

Measured ${ }^{187} \mathrm{Os} /{ }^{188} \mathrm{Os}$ of studied angrites ranges from 0.1056 to 0.213 , with measured ${ }^{187} \mathrm{Re} /{ }^{188} \mathrm{Os}$ in angrites (excluding the aliquant of Sahara 99555 measured by Dale et al. 2012) ranging from 0.128 to 1.49. Coarse-grained, slowly-cooled-angrites (NWA 4590; NWA 4801) generally have more reproducible HSE-abundances and ${ }^{187} \mathrm{Os} /{ }^{188} \mathrm{Os}$ than quenched angrites $( \pm 12-55 \%$ and $\pm 13-139 \%$ and $\pm 0.4-0.9 \%$ to $\pm 13-34 \%$ for HSE abundances and Os-isotopes, respectively; Riches et al. 2012). The Re-Os isotope compositions of a number of angrite meteorites are coincident with, or fall close to, a 4.568 Ga isochron in Figure 21b. Combined, the HSE-abundance and ${ }^{187} \mathrm{Os} /{ }^{188} \mathrm{Os}$ compositions of angrites indicate that the silicate mantle of the APB had HSE-abundances in chondritic relative proportions, but at variable abundances at the time of angrite crystallization, rather than having 'mantle' abundances of the HSE broadly similar to the terrestrial mantle (Dale et al. 2012). Thus, as with aubrites and diogenites (see below), HSE-systematics of angrites are seemingly consistent with protracted post-core formation accretion of materials with chondritic-relative abundances of the HSE to their parent body, and these accreted materials were rapidly, yet inefficiently, mixed into angrite magma source regions early in Solar System history.

Howardite-Eucrite-Diogenites (HED).-HED meteorites comprise the largest suite of crustal and possibly mantle igneous rocks available from any Solar System body, other than Earth and the Moon. With a few exceptions (e.g., Scott et al. 2009), the HED meteorites have O-isotopic compositions similar to IIIAB irons, main-group pallasites and mesosiderites (e.g., Mittlefehldt et al. 1998). The HED meteorites, based on spectroscopic data, may originate from the $\sim 530 \mathrm{~km}$ diameter differentiated asteroid 4 Vesta, or related objects (McCord et al. 1970). Regardless of parent body origin, HED meteorites represent some of the earliest examples of partial melting and igneous processes on Solar System bodies of sufficient size to undergo internal differentiation, with crystallisation ages 2-3 Ma after current estimates for the Solar System formation age at 4568.3 $\pm 0.7 \mathrm{Ma}$ (Nyquist et al. 2009). Diogenites range from orthopyroxenites to harzburgites to dunites (e.g., Mittlefehldt et al. 1998; Day et al. 2012b), whereas eucrites are basaltic, containing low-Ca pyroxene and calcic plagioclase, and include coarse-grained dolerite samples, termed cumulate eucrites, and basaltic eucrites that are generally unbrecciated and of one lithology (monomict). 
Howardites are polymict breccias (e.g., Wahl 1952) and, along with polymict brecciated eucrites and diogenites, suggest that impact-induced mixing occurred on the exterior of their parent body(ies) (Mittlefehldt et al. 1998).

Siderophile elements in HED meteorites are generally higher in polymict breccias than in monomict breccias and unbrecciated samples. Warren et al. (2009) provided a recent update of general HED meteorite groupings and demonstrated that howardites are generally better described as fragmental impact breccias, rather than regolith, from the HED parent body(ies). Study of eucrites and some diogenite HSE abundances has been undertaken by Dale et al. (2012), with more detailed studies of diogenites by Day et al. (2012b). The HSE abundance data for diogenites span nearly five orders of magnitude variation, with the majority of eucrites clustering at the lower end of HSE abundances for the diogenites (Fig.

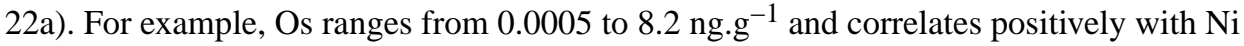
abundances (Fig. 3). HSE abundances are in generally chondritic-relative proportions and the highest abundances of these elements in a eucrite are measured in Dhofar 007, an anomalous eucrite that has witnessed chondritic impactor addition (Dale et al. 2012; e.g., Fig. 6). In situ LA-ICP-MS HSE abundance analysis of metal and sulfide grains in MIL 07001, the sample with the highest whole-rock HSE abundances, indicate that the HSE are almost exclusively hosted in metal included within silicate mineral grains and clasts indicating that the HSE in diogenites are not present in the brecciated matrices, but in the unbrecciated igneous clasts measured in those samples (Day et al. 2012b).

Measured ${ }^{187} \mathrm{Os} /{ }^{188}$ Os for most diogenite meteorites are within the range of chondritic meteorites (Fig. 22b). Although the majority of the diogenites have Re-Os isotope systematics broadly consistent with ancient ( $>4.5 \mathrm{Ga}$ ) crystallisation ages, many of the samples show isotopic evidence for minor, late-stage, open-system behavior from terrestrial weathering (Day et al. 2012b). Eucrites and anomalous eucrites do not define isochronous relations and instead show apparent addition of Re in some eucrite samples (Dale et al. 2012).

\section{Mars}

A large suite of meteorites, showing substantial lithological variation, are available from Mars. As well as broadly basaltic meteorites, collectively termed shergottites, clinopyroxene-rich cumulate rocks, termed nakhlites, and dunite cumulates that are probably associated with the nakhlites, termed chassignites, an ancient orthopyroxenite (ALHA 84001), and a broadly basaltic breccia (NWA 7034/7533/7475) have been described in the literature. Given the diversity of martian meteorite samples, the synonymous association of the Shergotty-Nakhla-Chassigny (SNC) group with Mars is now somewhat defunct. Within the shergottite suite, the samples span a remarkable range in $\mathrm{Sr}-\mathrm{Nd}$ isotopic compositions that cluster with light rare earth element depletion and enrichment, and range in age from $\sim 156$ to $\sim 586 \mathrm{Ma}$ (references in Brandon et al. 2012). Nakhlites and chassignites appear to come from a single or associated set of lava flows on Mars and have ages of 1300 Ma, and the basaltic breccia Northwest Africa (NWA) 7034 has components dated as old at $4400 \mathrm{Ma}$ (Humayun et al. 2013). Collectively, martian meteorites provide evidence for a strongly differentiated martian mantle, as well as evidence for interaction between mantle-derived 
melts and martian crust (e.g., Blichert-Toft et al. 1999; Borg et al. 2002; Basu Sarbadhikari et al. 2009; Brandon et al. 2012).

Numerous studies have examined HSE abundances in martian meteorites. Treiman et al. (1987) attempted some of the first estimates of HSE abundances in the 'shergottite parent body' although these constraints were about a factor of three lower than later estimates (Warren et al. 1999; Jones et al. 2003). Examination of the Re-Os isotope system and measurement of HSE abundances by isotope dilution methodologies of martian meteorites has led to an expansion of the available information of HSE abundances in Mars (Brandon et al. 2000, 2012; Riches et al. 2011; Dale et al. 2012; Filiberto et al. 2012; Tait et al. 2015). By far the most comprehensive Re-Os isotope and HSE abundance study of martian meteorites to date was performed on shergottite meteorites by Brandon et al. (2012), and data from this study along with more limited data from Riches et al. (2011), Dale et al. (2012) and Filiberto et al. (2012) are shown in Figure 23. Notable features of the dataset include elevated Re abundances, similar to those observed in terrestrial basalts, and chondrite-normalized HSE patterns that range from comparatively flat to increasingly fractionated as HSE abundance totals decrease by approximately three orders of magnitude.

The database for the HSE abundances in shergottites suggests that their martian mantle sources have HSE abundances that are similar to their abundances in the terrestrial mantle (Brandon et al. 2000, 2012; Dale et al. 2012; Day 2013). Quantification of martian mantle source composition was provided on a limited dataset by Dale et al. (2012), and has been estimated more recently on a larger dataset by Day (2013) (Fig. 8 and Table 2). The estimate from Dale et al. (2012) was based on the interelement co-variation method. This estimate is systematically lower for Re, Os, Ir, and Ru compared with MgO-regression methods, and yields non-chondritic Re/Os. The $\mathrm{MgO}$ regression method yields nearly identical Re, Os, Ir, and $\mathrm{Ru}$ abundances of the terrestrial and martian mantles, although estimated $\mathrm{Pt}$ and $\mathrm{Pd}$ concentrations are notably depleted in the martian mantle, according to these calculations.

Rhenium-Os isotopic systematics of martian meteorites are plotted in Figure 23b. Some samples with sufficiently suprachondritic Re/Os, which might be expected to give Os model ages roughly consistent with ages determined by other radiogenic systems, don't. This can be accounted for by Re and/or Os open-system behavior during sample residence at or near the martian and/or terrestrial surfaces (Brandon et al. 2000, 2012). In some meteorites, the alteration effects can be circumvented by analysis of leached residues, which have been treated with mild to strong reagents (e.g., ultra-pure $\mathrm{H}_{2} \mathrm{O}$, dilute $\mathrm{C}_{2} \mathrm{H}_{4} \mathrm{O}_{2}, \mathrm{HCl}, \mathrm{HNO}_{3}$ or HF). For those shergottites believed to record robust Re-Os isotopic systematics, calculated initial ${ }^{187} \mathrm{Os} /{ }^{188} \mathrm{Os}$ for their respective crystallization ages are well-correlated with the initial ${ }^{143} \mathrm{Nd} /{ }^{144} \mathrm{Nd}$ (Fig. 24). Shergottites from mantle sources with long-term melt-depleted characteristics (initial $\varepsilon N d$ of +36 to +40 ) have chondritic initial $\gamma \mathrm{Os}$ ranging from -0.5 to +2.5 . Shergottites with intermediate initial $\varepsilon N d$ of +8 to +17 have a range in initial $\gamma O s$ of -0.6 to +2.3 , which overlaps the range for depleted shergottites. Shergottites from long-term enriched sources, with initial $\varepsilon \mathrm{Nd}$ of $\sim-7$, are characterized by suprachondritic $\gamma$ Os values of +5 to +15 . Brandon et al. (2012) showed that these relationships likely relate to contributions from depleted and enriched reservoirs formed in a martian magma ocean at $c a$. 4.5 Ga. These models indicate that the shergottite end-member sources were generated by 
mixing between residual melts and cumulates that formed at variable stages during solidification of a magma ocean.

Highly siderophile element abundance and Os isotope data have also been reported for the basaltic breccia meteorite NWA 7034/7533. Siderophile element abundances occur in approximately chondritic ratios and reach levels equivalent to $~ 5 \% \mathrm{CI}$ chondrite (Humayun et al. 2013). This is comparable to the highest levels found in lunar impact melt breccias. The relatively high HSE abundances of NWA 7034/7533, combined with ${ }^{187} \mathrm{Os} /{ }^{188} \mathrm{Os}$ that cluster around $\sim 0.125-0.126$ indicates that impactor contributions to NWA 7034 had largely carbonaceous chondrite, rather than ordinary chondrite, or enstatite chondrite compositions (Goderis et al. 2014).

\section{The Moon}

The Moon is the only body in our Solar System, other than Earth, where humans have explored and collected samples. The Apollo 11, 12, 14, 15, 16 and 17 missions resulted in the collection of $\sim 382 \mathrm{~kg}$ of material, including rocks interpreted to come from the early lunar crust, impact melt breccias, regolith and igneous volcanic rocks. The Apollo sample collection is augmented by the three robotic return missions, Luna 16, 20 and 24, that returned $\sim 0.32 \mathrm{~kg}$ of core tube, in addition to an expanding collection of lunar meteorites comprised dominantly of feldspathic breccias, basaltic breccias, Th-rich moderately mafic breccias and $\sim 10$ unbrecciated mare basalts.

Mare basalts.-Mare basalts represent variably fractionated partial melts of lunar interior mantle sources. The available collection spans a range of ages from 3-3.8 Ga and includes both low- ( $<4 \mathrm{wt} . \%)$ and high-Ti variants ( $>10 \mathrm{wt} . \%)$. The high-Ti mare basalts from the Apollo 11 and 17 sites are unique, as no other Solar System basaltic rocks are known to have such high Ti contents. Before the turn of the $21^{\text {st }}$ century, reliable abundances of Ir, Au, \pm Re, \pm Pd, \pm Os were available for about 40 mare basalts (e.g., Wolf et al. 1979) and Os abundances and ${ }^{187} \mathrm{Os} /{ }^{188} \mathrm{Os}$ data were generated for basalts 15555 and 70017 by Birck and Allègre (1994). Since that time a low blank, isotope dilution dataset for HSE abundances and Os isotopes has been generated for Apollo 12, 15, 17 mare basalts, and the mare basalt meteorites (Day et al. 2007; Day and Walker 2015).

Mare basalt HSE abundances obtained by isotope dilution methods, along with Re-Os isotope data and comparative plots of $\mathrm{MgO}$ versus Os isotopes are presented in Figures 2527. Striking features of the combined HSE dataset for mare basalts are: (1) the very low abundances of the HSE ( $<0.0001 \times$ CI-chondrites); (2) relatively flat, chondritic-relative patterns in high- $\mathrm{MgO}$ mare basalts; (3) strongly fractionated HSE patterns in low-MgO mare basalts, and (4) chondritic measured ${ }^{187} \mathrm{Os} /{ }^{188} \mathrm{Os}$ in mare basalts with high $\mathrm{MgO}$ contents. On Earth, strongly fractionated HSE patterns are typically associated with the effects of crystal-liquid fractionation and/or partial melting processes (e.g., Day 2013), and this is how the variations in mare basalt HSE abundances have been interpreted and modeled (Day and Walker 2015). Data currently available for HSE abundances of Apollo 11 basalts are restricted to Ir and Au in a few samples (Ganapathy et al. 1970; Anders et al. 1971), with 
only modest differences between A-(Average $\left.=21 \mathrm{pg} . \mathrm{g}^{-1} \mathrm{Ir}, 72 \mathrm{pg} \cdot \mathrm{g}^{-1} \mathrm{Au}\right)$ and B-type (Average $=6 \mathrm{pg} . \mathrm{g}^{-1} \mathrm{Os}, 30 \mathrm{pg} \cdot \mathrm{g}^{-1} \mathrm{Au}$ ) basalts.

Controversy exists over whether Apollo 14 basalts such as 14053, 14072, 14076, 14078 and 14276 are mantle-derived volcanic products, or recrystallized impact-melt rocks, with elevated HSE abundances measured for some samples ( $\mathrm{Ir}=\sim 10 \mathrm{pg} . \mathrm{g}^{-1}$ to $\sim 10,000 \mathrm{pg} . \mathrm{g}^{-1}$; Rose et al. 1972; Brunfelt et al. 1973; Hughes et al. 1973; Ebihara et al. 1992). Since HSE abundances are sensitive indicators of impactor additions, Warren et al. (1997) assessed whether Apollo 14 high-Al mare basalts were impact-melt products, establishing low HSE abundances in most samples, and 14053 in particular. Conversely, while HSE abundances for 14053 and 14072 are broadly consistent with Apollo 12, 15 and 17 mare basalts, 14276 and 14310 likely contain significant meteoritic components (Fig. 28), with Fischer-Gödde and Becker (2012) finding high HSE abundances in 14310; some of these 'basalts' may in fact be recrystallized impact melt rocks.

There is a relationship of increasing dispersion of measured ${ }^{187} \mathrm{Os} /{ }^{188} \mathrm{Os}$ with decreasing $\mathrm{MgO}$ in mare basalts (Fig. 27). Apollo 12 mare basalts span a range in ${ }^{187} \mathrm{Os} /{ }^{188} \mathrm{Os}$ from 0.1268 to 0.2080 . This range is similar to ${ }^{187} \mathrm{Os} /{ }^{188} \mathrm{Os}$ for Apollo $15(0.122-0.160)$ and Apollo 17 (0.1255-0.173) mare basalts, but does not extend to the high ${ }^{187} \mathrm{Os} /{ }^{188} \mathrm{Os}$ from some Antarctic La Paz mare basalts (0.1362-0.463). MIL 05035 has the lowest measured ${ }^{187} \mathrm{Os} /{ }^{188} \mathrm{Os}$ of any mare basalt meteorite measured to date $(0.1244)$. Ratios of ${ }^{187} \mathrm{Re} /{ }^{188} \mathrm{Os}$ for Apollo 12 mare basalts vary from 0.38 to 1.88 and this range of values is more restricted than for Apollo 15 (0.15-6.7), Apollo 17 (0.4-7.9) or mare basalt meteorites ( $\mathrm{La} \mathrm{Paz}=2.5$ to 656 ; MIL $05035=25.2$ ). None of the mare basalt suites define isochronous relationships, although a number of aliquots of Apollo 12 mare basalts lie at or on a $3.2 \mathrm{Ga}$ reference isochron. A large number of mare basalt samples lie to the right of the $3.2 \mathrm{Ga}$ isochron, corresponding to young apparent ages. Apollo 12 olivine-, pigeonite- and ilmenite normative mare basalts provide an imprecise ${ }^{187} \mathrm{Re}-{ }^{187} \mathrm{Os}$ age of $3.0 \pm 0.9 \mathrm{Ga}$. This age is within uncertainty of ${ }^{147} \mathrm{Sm}-{ }^{143} \mathrm{Nd}$ ages for the same samples and the relationship yields an initial ${ }^{187} \mathrm{Os} /{ }^{188} \mathrm{Os}$ of $0.107 \pm 0.010$ (Day and Walker 2015).

Lunar pyroclastic glasses.-In terrestrial systems, high-MgO melts, such as picritic or komatiitic lavas provide the best estimates of abundances of the HSE in their mantle sources, because they are the result of high degrees of partial melting and all sulfide in the parent mantle has been interpreted to be incorporated into the melt (e.g., Rehkämper et al. 1999; Walker 2009; Day 2013). By extension, and despite some controversy as to their origin (e.g., Heiken et al. 1974), lunar picritic glass beads (13-20 wt. \% MgO) have been suggested to provide the best estimate of the lunar mantle composition because they are thought to have formed as deep (> $400 \mathrm{~km}$ ) high-degree partial melts of the lunar interior, with little apparent fractionation (e.g., Shearer and Papike 1993). Early studies concluded that the Ir contents of picritic high-Ti orange and low-Ti green glasses were only offset from the terrestrial array by a factor of 2 to 4 (Ganapathy et al. 1973; Morgan and Wandless 1979; Righter et al. 2000), leading some authors to conclude that the abundances of HSE in the lunar mantle sampled by the picritic glasses are similar to those in the terrestrial mantle (Ringwood 1992). If true, these glasses would provide an entirely different view of lunar mantle differentiation and HSE inventories than indicated by mare basalts. Pristine pyroclastic 
picritic glasses (see Delano 1986, for criteria identifying such glasses) have been found to have elevated volatile and siderophile abundances that correlate to the surfaces of the beads (e.g., Chou et al. 1974, 1975; Meyer et al. 1975; Cirlin and Housley 1979; Krähenbühl 1980; Delano and McGuire 1992; Delano et al. 1994). Models to explain the elevated abundances of volatiles on the surface of the picritic glass beads suggest vapor deposition as a consequence of graphite $\rightarrow$ CO breakdown (Sato 1979; Fogel and Rutherford 1995) at $\sim 40$ $\mathrm{MPa}(\sim 8.5 \mathrm{~km}$ from the lunar surface) resulting in $60-90 \%$ gas bubbles separated by thin walls of melt and ductile fragmentation to generate the glass beads (typically $<0.5 \mathrm{~mm}$ diameter) at the vent (Rutherford and Papale 2009; Nicholis and Rutherford 2009).

While the model of fire-fountaining through $\mathrm{CO}$ generation from graphite can explain many of the features of the picritic glass beads, some authors have presented data that are not consistent with the inventory of volatile or siderophile elements solely originating from fire fountaining, or a purely mantle-derived origin for the elemental inventory of the picritic glass beads. Cirlin and Housley (1979) found that some of the Apollo 17 picritic beads had vapor deposits on fracture surfaces, which they attributed to addition of volatiles significantly after formation of the picritic beads, during formation of the small crater near which they were found. The two most significant deposits of sampled picritic glass were found in the lunar soil at the rims of two small impact craters at the Apollo 15 and 17 sites (Spur and Shorty craters, respectively). Other authors have argued that even minor contamination from HSE-enriched impactors could strongly bias analyses of these glasses (Morgan and Wandless 1979; Walker et al. 2004).

Chou et al. (1975), Wasson et al. (1976), Reed et al. (1977), Krähenbühl (1980), Morgan and Wandless (1984) and Walker et al. (2004) have all performed size-fraction and/or etching experiments to show that HSE abundances do show surface correlation. In the most recent experiments, Walker et al. (2004) showed that the etchates, which are derived from the outer surfaces of the beads and represent 5-30\% of the volume of the beads, have chondritic relative abundances of the HSE and near-chondritic ${ }^{187} \mathrm{Os} /{ }^{188} \mathrm{Os}$, whereas the residues, which represent the interior of the beads, have distinctly lower, and non-chondritic relative HSE abundances and ${ }^{187} \mathrm{Os} /{ }^{188}$ Os (Figs. 29-30). Walker et al. (2004) ascribed this difference to meteoritic contamination on the outer surfaces of the glass beads after their formation and emplacement. A limitation of the Walker et al. (2004) study is that the strong etching experiments could not precisely pinpoint the location of HSE enrichment relative to the bead surfaces, and whether they correlate with surface volatile enrichments in the first 200-500 $\AA$ of the bead surfaces (e.g., Meyer et al. 1975). Furthermore, Pb isotopic studies of the glass beads imply different surface correlated $\mathrm{Pb}$ components in Apollo 15 and 17 beads, with Apollo 15 glasses showing a strong surface correlated common $\mathrm{Pb}$ component and lower ${ }^{238} \mathrm{U} /{ }^{204} \mathrm{~Pb}$ than Apollo 17 glasses (Tatsumoto et al. 1987); these results suggest different eruption and post-emplacement histories for the pyroclastic glass bead deposits.

Lunar crustal rocks. - Lunar crustal rocks are typically defined as early-formed anorthosites, troctolites, norites, dunites and other materials, with the lunar anorthositic crust considered to have been formed by large-scale differentiation of a partially to totally molten silicate Moon, with Mg-suite crustal rocks forming later as partial melts of the lunar interior (e.g., Warren and Taylor 2014). As discussed previously, crustal samples that formed by 
endogenous igneous processes unrelated to those that produced the later mare basalts, and that remained subsequently uncontaminated by post-crystallization impacts, have been termed "pristine" rocks. Criteria used to assess pristinity include: 1) low whole-rock siderophile element abundances ( $3 \times 10^{-4} \times$ CI chondrites; <130 pg.g ${ }^{-1}$ Ir); 2) low incompatible element concentrations (i.e., K, REE, P-poor); 3) coarse granularity; 4) phase homogeneity; 5) coarse exsolution lamellae; 6) preservation of cumulate textures; 7) radiometric ages $\geq 4.2 \mathrm{Ga}$, and 8 ) unradiogenic ${ }^{87} \mathrm{Sr} /{ }^{86} \mathrm{Sr}$ compositions (Warren and Wasson 1977).

Early studies reported low abundances $\left(<10 \mathrm{pg} . \mathrm{g}^{-1}\right)$ of some HSE for pristine rocks (Krähenbühl et al. 1973; Ganapathy et al. 1973; Morgan et al. 1974, 1975; Higuchi and Morgan 1975; Gros et al. 1976; Hertogen et al. 1977; Janssens et al. 1978; Warren and Wasson 1977, 1978, 1980; Anders 1979; Wolf et al. 1979; Warren et al. 1991; Ebihara et al. 1992). A coupled ${ }^{187} \mathrm{Os} /{ }^{188} \mathrm{Os}$ and highly siderophile element (HSE: Os, Ir, Ru, Pt, Pd, Re) abundance data for lunar crustal rocks 60025, 62255, 65315 (ferroan anorthosites, FAN), $76535,15455,77215$, and 78235 (magnesian-suite rocks, MGS) were reported by Day et al. (2010). These authors showed that Os isotopes permit more refined discrimination than previously possible of samples that have been contaminated by meteoritic additions. HSE abundance and Os isotope data for lunar crustal rocks are shown in Figure 31. Ferroan anorthosite samples 60025, 62255, and 65315 have absolute HSE abundances approximately four to six orders of magnitude lower than in CI chondrites, generally show relative enrichments of Re and can have suprachondritic ratios of PPGE (Pt-group PGE: Pt, Pd) to IPGE (Ir-group PGE: Os, Ir, Ru). MGS rocks, including troctolite 76535, norites 15455 , 77215 , and 78235 and dunite 72415 have absolute HSE abundances that are three to five orders of magnitude lower than in CI chondrites.

Ferroan anorthosites (FAN) and magnesian suite (MGS) samples have relatively restricted ranges in ${ }^{187} \mathrm{Re} /{ }^{188} \mathrm{Os}$, with FAN having supra-chondritic measured ${ }^{187} \mathrm{Os} /{ }^{188} \mathrm{Os}(0.145-$ $0.225)$ and MGS having sub- to supra-chondritic Os isotope compositions (0.116-0.158). Lunar crustal samples do not define an isochronous relationship using measured ${ }^{187} \mathrm{Re} /{ }^{188} \mathrm{Os}$ values (Fig. 31b), and strongly negative calculated initial $\gamma_{\mathrm{Os}}$ values are too low to be possible, assuming a $4.46 \mathrm{Ga}$ age for FAN (Norman et al. 2003). These calculations are not strongly age dependent, so such low values require some level of relatively recent opensystem behavior of Re (addition) and/or Os (loss) in lunar crustal rocks (Day et al. 2010).

Lunar impact melt breccias.-Lunar crustal samples collected during the Apollo program and as lunar meteorites contain both ample physical and geochemical evidence for impactor materials with generally chondritic and, in some cases, iron meteorite-like characteristics (e.g., Higuchi and Morgan 1975; Hertogen et al. 1977; Warren et al. 1989; Korotev 1994; Norman et al. 2002; Day et al. 2006; Puchtel et al. 2008; Fischer-Gödde and Becker 2012; Sharp et al. 2014; Liu et al. 2015). Lunar impact melt rocks are typically characterized through the relative and absolute abundances of the HSE, because of the high concentrations of these elements within potential impactors. Two approaches have been used to characterize impact melt rocks, using either homogenized sample powders (Norman et al. 2002), or taking sub-fragments of impactor materials and analyzing them separately to linear regressions which may then be used to potentially obtain the ratios of HSE in impactors 
(e.g., McDonald et al. 2001; Puchtel et al. 2008). An example of the second form of approach is shown in Figure 32. This approach works because of inherent heterogeneity of the HSE within the breccia, due to inefficient mixing of materials during impact. In the example, individual fragments of 67935 have been measured and have different Ir concentrations (Fig. 32a), illustrated as different absolute-and in one case relativeabundances of the HSE (Fig. 32b). Numerous lunar impact melt breccias subjected to this form of treatment yield highly correlated HSE versus Ir; however, in the case of 67935 it appears that one of the measured fragments had a close-to-chondritic composition, likely due to accumulative fractionation effects. This lunar impact melt breccia sample is also exceptional as it is the only lunar impact melt breccia to date that has yielded an isochron, equating to an age of $4.21 \pm 0.13 \mathrm{Ga}$ (Fischer-Gödde and Becker 2012) (Fig. 32c).

An important overall observation from isotope dilution Re-Os isotope and HSE abundance studies of lunar impact melt breccias is that many of the samples have nonchondritic relative HSE abundances (Fig. 33). Breccias from the Apollo 16 site bracket the extremes in absolute concentrations, with up to 5-10\% relative impactor additions. Many of the Apollo 14, 16 and 17 breccias have elevated $\mathrm{Ru} / \mathrm{Ir}$ and $\mathrm{Pd} / \mathrm{Ir}$, and this feature has been widely interpreted to reflect either different, 'broadly chondritic' impactor populations (Norman et al. 2002; Puchtel et al. 2008; Sharp et al. 2014), or the contribution from an evolved iron meteorite impactor (Fischer-Gödde and Becker 2012). On the other hand, brecciated meteorites are characterized by more chondritic relative abundances of the HSE. Average ${ }^{187} \mathrm{Re} /{ }^{188} \mathrm{Os}-$ ${ }^{187} \mathrm{Os} /{ }^{188} \mathrm{Os}$ systematics of Apollo breccias are plotted in Figure 33b. Most of these averages lie close to the $4.568 \mathrm{Ga}$ IIIAB iron isochron, with Apollo 17 impact melt breccias having an average ${ }^{187} \mathrm{Os} /{ }^{188} \mathrm{Os}$ composition of $\sim 0.131$.

\section{Terrestrial mantle composition}

Extensive research has been done on understanding terrestrial mantle and crustal composition, and the reader is referred to alternative chapters in this book for mantle composition (Aulbach et al. 2016; Becker and Dale 2016; Harvey et al. 2016; Luguet and Reisberg 2016, all in this volume), as well as to Peucker-Ehrenbrink and Jahn (2001) and Peucker-Ehrenbrink et al. (2012) for reviews of terrestrial crustal composition estimates. The basic method of obtaining mantle abundance is through projection of HSE data to a hypothetically undepleted mantle composition, typically termed as primitive mantle (PM) or primitive upper mantle (PUM). In this review, we refer to the composition as PM, since it is difficult to ascertain what fraction of Earth's mantle the estimate actually represents. How a composition estimate is achieved is demonstrated in Figure 34. Comparison of the HSE content to an indicator of melt depletion is plotted and data are then regressed to a primitive mantle composition of the melt depletion indicator (in the case of Fig. 34, $\mathrm{Al}_{2} \mathrm{O}_{3}$ ). For the most compatible elements, there is essentially no correlation, with the intersection of the data giving an Ir concentration of PM equal to $3.5 \pm 0.4$ ng.g ${ }^{-1}$ (Becker et al. 2006). For more incompatible HSE, linear correlations of the element over Ir (e.g, Fig. 34b) provide estimated abundances for these elements. Using these estimates, the overall evidence from peridotites suites is that the Earth's mantle has a generally uniform distribution of the HSE elements, albeit with some interelement ratios (e.g., Ru/Ir, Pd/Ir) that may be supra- 
chondritic (Fig. 35). By contrast, long-term Re/Os and Pt/Os ratios are within $\sim \pm 5 \%$ and $~$ $\pm 10 \%$, respectively (e.g., Meisel et al. 2001; Walker et al. 2005; Brandon et al. 2006).

\section{Secondary alteration effects}

While secondary alteration is generally not the focus of questions being addressed using the HSE, these effects can be significant in meteorites and planetary samples. Secondary alteration effects can be broken into three major categories; (1) sub-solidus alteration effects on parent bodies; (2) curational contamination, and (3) terrestrial weathering of meteorite finds, and some falls. Examples of sub-solidus alteration processes range from aqueous alteration on chondrite parent bodies (cf., Brearley and Jones 1998; Walker et al. 2002; Brandon et al. 2005b), possible neutron capture effects on Re (e.g., Herr et al. 1971; Michel et al. 1972; Day et al. 2010; Day and Walker 2015), to active weathering processes on the surface of a moderately large planet, such as Mars (Brandon et al. 2012). These types of studies have emphasized that aqueous alteration and thermal metamorphism can impact distributions of the HSE, and disturbance of primary magmatic signatures, most especially for the Re-Os isotope system. Contamination from handling and preparation of samples using metal tools (e.g., inevitable exposure to metal saw blades and other implements) on Earth has been suggested for some Apollo samples (Day et al. 2010). By far the most problematic secondary alteration process for meteorites occurs from terrestrial weathering, and is largely restricted to meteorite finds, although some falls also show disturbances (e.g., Walker et al. 2002). Disturbance of the Re-Os isotope system from terrestrial weathering processes has been documented in chondrites, ureilites, brachinites, brachinite-like achondrites, aubrites, angrites, diogenites, eucrites, martian and lunar meteorites (Horan et al. 2003; Rankenburg et al. 2007; Day et al. 2007, 2012a,b; Fischer-Gödde et al. 2010; Brandon et al. 2012; Dale et al. 2012; Riches et al. 2012; van Acken et al. 2012; Hyde et al. 2014). In the case of primitive achondrites, such as ureilites and brachinites, the effects of weathering are to force samples left or right of the $4.568 \mathrm{Ga}$ isochron in response to recent fractionation of Re from Os (e.g., Fig. 19).

In the majority of cases of disturbance of the Re-Os isotope system in meteorites, it has been suggested that late-stage open-system behavior of Re, rather than Os, is the culprit for disturbance, because of limited ranges in Ir/Os, yet large ranges in Re/Os. Variability in Re/Os among different splits of the same meteorites is most consistent with localized mobilization (cm- to mm-scale), rather than loss or gain of Re from the bulk meteorites (Day et al. 2012b). Similar variability has been seen in ureilites (Rankenburg et al. 2007) and in chondrites Kainsaz (CO3) and Elephant Morraine (EET) 96026 (R3) (Fischer-Gödde et al. 2010). It is also probable that fall through Earth's atmosphere and fusion-melting on the exterior of meteorites causes mobilization of the HSE (see below). Thus, it is not necessarily an exogenous source of terrestrial Re that causes disturbance, but the break-down and redistribution of phases containing Re, and possibly other HSE, such as sulfides and metals. Mobilization of the HSE in response to sulfide/metal break-down in the meteorites is supported by observations of Fe-S-rich veins cross-cutting fusion crust in GRA 06128 (Shearer et al. 2010) and the differences in composition between fresh and altered sulfide in some brachinites and brachinite-like achondrites (Day et al. 2012b; Hyde et al. 2014). Although some of the isotopic deviations are large for isochron applications and preclude 
use of the Re-Os isotope system for a precise age determination of some meteorites, the degree of open-system behavior appears to be minor to negligible for the other HSE (Os, Ir, $\mathrm{Ru}, \mathrm{Pt}, \mathrm{Pd}$ ). This is indicated by the large variations in Re/Os measured for different splits of meteorites, accompanied by limited variations in ${ }^{187} \mathrm{Os} /{ }^{188} \mathrm{Os}$, and limited variations in the interelement ratios of the other HSE (e.g., [Ir, Pt, Pd, Ru/Os]) (Hyde et al. 2014).

An extreme example of secondary alteration effects can be illustrated using low HSE abundance lunar meteorites. The center and fusion crust portions of LaPaz mare basalt, LAP 02224 were measured for Re-Os isotope composition (Day et al. 2007). These authors found that the outer fusion crust portion exhibits higher Re and lower Os concentrations, and one of the most radiogenic ${ }^{187} \mathrm{Os} /{ }^{188} \mathrm{Os}$ values of all the $\mathrm{LaPaz}$ meteorite samples measured (Fig. 36). The initial composition derived from the regression of the two points is consistent with the lowest pre-terrestrial isotopic composition of the LaPaz basalts. The "age" derived from the regression is likely to represent a mixture of the age of the fusion event as well as the 'age' of the meteorite, as total separation of fusion crust from unfused sample was not possible. Similar issues of fusion-related mobilization of Re have also been seen suggested for the low-mass ( $4.1 \mathrm{~g})$ achondrite LEW 88763, where analysis of sample portions exposed to friction induced heating were unavoidable (Day et al. 2015b).

\section{PLANETARY FORMATION PROCESSES}

The broad survey of planetary materials illustrates the significant variability in HSE abundances and Os isotope compositions from rocky planetesimals and planets. The utility of these data for understanding planetary formation processes has been emphasized by numerous studies and has spanned issues ranging from sources of materials to the early Solar System, planetary accretion and differentiation, post-core formation accretion, and the impactor populations in the Solar System. Below, these issues are briefly discussed in turn, followed by the implications for planetary formation processes.

\section{Initial conditions and homogeneity of starting materials}

It has been demonstrated that, while separate $s^{-}, r^{-}$, and possibly $p$-process enriched and depleted Os components occur in low metamorphic grade chondrites, measureable nucleosynthetic Os isotopic anomalies have not been shown to occur in bulk chondrites, some achondrites, or in iron meteorites (Brandon et al. 2005a; Reisberg et al. 2009; Yokoyama et al. 2010, 2011; van Acken et al. 2011; Walker 2012). The homogeneity in Os contrasts with isotopic heterogeneity present for other refractory siderophile elements, such as Mo, Ru and W (cf, Chen et al. 2010; Yokoyama and Walker 2016, this volume). The 'normal' Os implies that this element was homogeneously distributed throughout the protosolar nebula at the scale of planetary bodies, within the current level of analytical resolution, and that isotopically 'anomalous' phases were relatively easily homogenized during parentbody metamorphism and alteration.

A broadening survey of chondrite HSE abundances and ${ }^{187} \mathrm{Os} /{ }^{188} \mathrm{Os}$, along with precise initial Os isotope compositions of iron meteorites, indicate relatively well-mixed HSE abundances in the solar nebula, and define an initial ${ }^{187} \mathrm{Os} /{ }^{188} \mathrm{Os}$ of $0.0952 \pm 0.0002$ (Fig. 37). The uncertainty on the initial is due to the range of long-term Re/Os variations in 
chondrite meteorites, in combination with the initial Os isotope compositions of iron meteorite groups obtained from isochron and errorchron initials. For example, if the initial compositions of main group pallasites, IIIAB, IA, IVA and IVB iron meteorites are regressed, they define a slightly higher ${ }^{187} \mathrm{Os} /{ }^{188} \mathrm{Os}_{\mathrm{i}}(0.0954)$ compared with the chondrite average, but with overlapping uncertainties. Furthermore, relative interelement fractionations are evident between the main chondrite groups, from lower long-term Re/Os between carbonaceous $\left({ }^{187} \mathrm{Os} /{ }^{188} \mathrm{Os}=0.1258 \pm 16\right)$ and ordinary and enstatite chondrite groups $\left({ }^{187} \mathrm{Os} /{ }^{188} \mathrm{Os}>0.1280\right)$. More generally, absolute HSE abundances in some chondrite classes vary, due in part to dilution effects of volatile-rich and volatile-poor components and because of the inhomogeneous distribution of HSE host phases. These differences are manifested in the range of absolute abundances of the HSE in carbonaceous (0.7-1.9 $\times$ Orgueil), enstatite (0.3-2 $\times$ Orgueil), and ordinary chondrites (0.6-2.3 $\times$ Orgueil; Fig. 10). Averages for ordinary and enstatite chondrite groups also show differences in relative abundances of the HSE, with ordinary chondrites having higher Re/Os, Pd/Ir or Au/Ir than carbonaceous chondrites (Fig. 35).

To at least a first approximation, the relatively consistent abundances of most HSE in chondrite groups are useful in the context of studying planetary processes, because chondritic impactors can be assumed to have relatively consistent absolute HSE abundances that are far higher than in differentiated crustal and mantle materials. On the other hand, relative consistency can also potentially hamper definitive identification of a particular chondrite class, or mixtures of classes, that can be assigned to have dominantly formed a planetary body. The more or less even HSE distribution in the chondrites appears to reflect the high condensation temperatures of most of these elements at nebula conditions (> 1400 $\mathrm{K})$, and their early incorporation into high-temperature metal alloy phases in the earliest stages of Solar System accretion. The relatively even distribution of the HSE also implies that these early-formed alloys and refractory phases were well-mixed during the main phases of accretion, as equally-to less-refractory lithophile elements were condensing. The lack of Os isotope anomalies in bulk chondrites, but presence of persistent Mo and $\mathrm{Ru}$ isotope anomalies means that this relationship cannot simply reflect the dominance of early-formed, well-mixed condensed alloy phases to explain these similarities. Instead, it is possible that later exsolution, oxidation, sulfurisation processes, which led to generation of secondary Mo-sulfides, W-Mo oxides, and Os and Ru alloys (Bischoff and Palme 1987), may have led to the homogenization of some nucleosynthetic anomalies relative to others.

In contrast to $\mathrm{Re}, \mathrm{Os}, \mathrm{Ir}, \mathrm{Ru}, \mathrm{Pt}$, and $\mathrm{Rh}$, both $\mathrm{Pd}$ and $\mathrm{Au}$ have lower condensation temperatures and appear to have been inhomogeneously distributed at the scale of planetary bodies surveyed to date. Parent body processes (e.g., Brandon et al. 2005b; Yokoyama et al. 2011), or initial nebula heterogeneity from incorporation of these elements into slightly lower-temperature condensation phases, relative to the rest of the HSE, could be responsible for these differences.

For the purposes of understanding post-accretion processes in planetary materials, it is possible to define initial HSE abundances using chondrites. In the past, most studies have elected to use the CI-chondrite, Orgueil, for the normalization of HSE abundance data and the logic for this choice is robust given the close approximation of CI-chondrite bulk 
composition to solar photosphere abundances (e.g., Anders and Grevesse 1989). A compilation of bulk meteorites, however, shows that the distribution of measured ${ }^{187} \mathrm{Os} /$ ${ }^{188}$ Os clusters around ordinary or enstatite chondrite composition (Fig. 38), with only a limited number of meteorite groups showing strong correspondence with carbonaceous chondrite compositions (e.g., ureilites). On the basis of these types of plots, it can be generally concluded that terrestrial bodies have evolved with Re/Os within the range of enstatite and ordinary chondrite composition in the inner Solar System. While work remains to be done to understand inherent HSE variability during nebular formation, at the scale of terrestrial planets it can also generally be assumed that these elements were reasonably homogeneous distributed and that a CI-chondrite composition, while somewhat diluted by excess volatile components, relative to ordinary or enstatite chondrites, remains robust when making comparisons of meteorites HSE abundances.

\section{Partial melting and partitioning of the HSE}

Early partial melting and anatexis of chondritic parent bodies would have led to initial phases of sulfide- and metal-rich melt separation from silicate materials. Experiments on chondrites indicate that progressive partial melting produces a continuum of melt products ranging from Fe-Ni-S melts at relatively low temperatures $\left(\sim 988^{\circ} \mathrm{C}\right)$, to basaltic melts at higher temperatures (> $1050^{\circ} \mathrm{C}$; e.g., Jurewicz et al. 1991, 1995; Feldstein et al. 2001). These melt products are in accordance with observations of the compositions of various types of primitive achondrite meteorites, including winonaites, acapulcoite-lodranites, ureilites, brachinites and associated meteorites (Mittlefehldt et al. 1996; McCoy et al. 1997a; Benedix et al. 1998; Warren et al. 2006; Day et al. 2012b, 2015; Wang et al. 2014).

With $>30 \%$ partial melting, extensive separation of metal ( \pm sulfide) from silicate was achieved in some terrestrial bodies, leading to the generation of metallic cores and differentiated silicate mantles and crusts. This fundamental process of metal-silicate differentiation has led to HSE abundances that span about seven to ten orders of magnitude variation in planetary materials (Fig. 39). Experimental studies suggest liquid metal/liquid silicate concentration ratios ( $D$ values) vary from $10^{3}$ to $10^{6}$ (e.g., Kimura et al. 1974; Jones and Drake 1986; Borisov et al. 1994; O’Neill et al. 1995; Holzheid et al. 2000; Ertel et al. 2001; Fortenfant et al. 2003; Yokoyama et al. 2009; Mann et al. 2012), broadly consistent with the natural observation of $10^{7}-10^{10}$ variation, if solid-liquid iron metal partitioning is taken into account (see below). The meteorite data also illustrate that significant fractionation of the HSE can occur during metal-silicate differentiation, as demonstrated by primitive achondrite meteorites, such as brachinites, but also as defined by experimental studies of combined HSE abundances (Mann et al. 2012). Thus, while the earliest stages of partial melting of chondritic pre-cursor compositions remain poorly constrained, a first-order prediction is for rapid HSE fractionation at the onset of metal differentiation, leading to extreme differences in the HSE abundances of planetary cores and silicate mantles and crusts. Based on these lines of evidence, planetary mantles and crusts should be stripped of the HSE. That many differentiated planetary mantles and crusts have higher-than-expected abundances of the HSE, relative to these theoretical conditions, requires alternative interpretations, as discussed below. 


\section{Core crystallization}

Magmatic iron meteorites are considered to come from at least 60 individual parent bodies that accreted early, perhaps before the parent bodies of some chondrites, with decay of ${ }^{26} \mathrm{Al}$ $\left(\mathrm{t}_{1 / 2}=0.7 \mathrm{Ma}\right)$ implicated as the major heat-source responsible for melting (Goldstein et al. 2009). The large number of parent bodies is not matched by the current asteroid population, leading to the proposal that iron meteorite parent bodies formed at 1-2 AU and, after fragmentation, portions were scattered into the asteroid belt by protoplanets (Bottke et al. 2006). Alternatively, scattering occurred through the 'grand tack' movement of the gas giants that has been hypothesized for early stages of Solar System evolution (Walsh et al. 2011). These hypotheses are consistent with the early formation ages and cooling rates of many iron meteorites (Horan et al. 1992; Smoliar et al. 1996; Kruijer et al. 2014), as well as evidence for variable volatile depletions of some siderophile elements (Goldstein et al. 2009). Depletions in redox sensitive siderophile elements (e.g., W, Mo) and high concentrations of Os, Ir, and Ru in some iron meteorite groups (e.g., IVB) are also considered to reflect the genesis of iron cores within oxidized parent bodies, with high $\mathrm{FeO}$ in the corresponding silicate shell (e.g., Walker et al. 2008).

Iron meteorites exhibit large variations in both the relative and absolute abundances of the HSE, as illustrated by IVA and IVB meteorites (e.g., Fig. 14). While some of this variation might come from differences in the bulk HSE composition of the precursor material to the iron meteorite parent body, or from impact-induced mixing processes (e.g., the 'nonmagmatic irons'; Wasson and Wang 1986; Choi et al. 1995), large ranges of variation exist within iron groups, reflecting the role of solid-liquid metal crystallization processes (e.g., Scott 1972; Scott and Wasson 1976; Goldstein et al. 2009). Variations in HSE abundances among the magmatic iron groups are consistent with crystal-liquid fractionation during solidification of the parent body core. Conceptually, this process leads to segregating metal concentrating more compatible $\mathrm{HSE}$, including $\mathrm{Os}$, $\mathrm{Ir}, \mathrm{Ru}, \mathrm{Rh}$, and $\mathrm{Re}$, from $\mathrm{Pt}, \mathrm{Pd}$, and $\mathrm{Au}$ (e.g., Scott 1972; Pernicka and Wasson 1987; Walker et al. 2008; Goldstein et al. 2009; McCoy et al. 2011). Studies of the magmatic iron groups have also emphasized the importance of non-metal components, including $\mathrm{S}, \mathrm{C}, \mathrm{Si}$, P, and $\mathrm{O}$ in affecting the solidmetal-liquid-metal partitioning (e.g., Chabot and Drake 1999; Chabot and Jones 2003; Chabot et al. 2014), consistent with the requirement of a light element component in terrestrial planetary cores to satisfy cosmochemical constraints (e.g., Dreibus and Wanke 1985; McSween 1994; McDonough 2003).

\section{'Late-accretion'}

The term late-accretion has often been used synonymously with the terms "late veneer" and "heterogeneous accretion". These latter terms typically refer to specific processes where primitive materials and/or oxidized (cf., carbonaceous chondrites) were added to the Earth following the major phases of core formation. A 'late veneer' also implies addition of materials to the Earth's surface, whereas late accretion may have been a much more catastrophic process, involving delivery of massive impactors (e.g., Bottke et al. 2010) and mixing of the HSE into extensive regions of the silicate portions of planets. In addition to HSE delivery, the late veneer hypothesis conceptually allows for the relatively passive delivery of volatile elements to Earth (e.g., Drake and Righter 2002), albeit the amounts of 
delivery of such material may not be sufficient to satisfy mass balance constraints for both volatile and siderophile elements (Day and Moynier 2014). The elevated and broadly chondritic-relative HSE abundances estimated for Earth's mantle $(\sim 0.01 \times$ CI-chondrite $)$ have been interpreted to reflect minor $(\sim 0.5 \%)$ continued accretion following the cessation of core segregation (e.g., Kimura et al. 1974; Chou 1978) and have been termed 'late accretion'. For the purposes of this review, late accretion refers to post-core formation additions to differentiated planetary bodies. Such a process has undeniably occurred, given the evidence for impacts on planetary bodies and the fall of meteorites today, which all fall under the definition, 'late accretion'. A key aspect of the late accretion hypothesis is that it predicts broadly chondritic-relative HSE abundances within planetary mantles. This prediction is consistent with the HSE in the mantles of Earth, Mars and the Moon, and with chondritic long-term Re/Os and Pt/Os (e.g., Fig. 9).

Relatively volatile-free ordinary and enstatite chondrites have average Os and Ir concentrations of 680 and $560 \mathrm{ng} \cdot \mathrm{g}^{-1}$, respectively, whereas estimates of terrestrial primitive mantle and martian mantle composition are approximately $3-4 \mathrm{ng} \cdot \mathrm{g}^{-1}$. Conservative mass balance, assuming core segregation resulted in $>99 \%$ of the HSE being stripped from the silicate portion of Earth, indicates that $\sim 0.5 \%$ of the silicate mass is enriched in the HSE by late accretion. There are uncertainties in the mass balance of late-accreted materials, given the range in absolute chondritic abundances and whether parent bodies were volatile depleted or enriched, whether impacts to parent bodies were erosional (i.e., exceeded parentbody escape velocities) or accretional, or if effects of fractionation and loss of the HSE into planetary cores might be expected during large-scale accretion events (e.g., O'Keefe and Arhens 1977; Albarede et al. 2013; Day and Moynier 2014).

Late accretion has also been invoked for Mars, from the analysis of martian shergottites (e.g., Jones et al. 2003; Brandon et al. 2012), indicating that their mantle sources have generally chondritic-relative HSE abundances $(\sim 0.007 \times$ CI-chondrite). Indeed, late accretion of variable proportions has been proposed for all asteroidal bodies parental to differentiated achondrites (Day et al. 2012a; Dale et al. 2012; Riches et al. 2012; van Acken et al. 2012). Without late accretion, variable pressure and temperature experiments predict low abundances and significant interelement fractionation of the HSE through metal-silicate equilibration in most bodies (e.g., Mann et al. 2012).

Indication of the nature of late accretion processes comes from studies of lunar materials and their comparison with terrestrial or martian samples. Assuming that late accretion occurred after formation of the Earth-Moon system, the silicate portion of the Moon should have HSE abundances similar to those of Earth's mantle, even when accounting for the effects of size, impactor retention and gravitational focusing (Morgan et al. 2001; Walker et al. 2004). The Moon's mantle, however, does not appear to have such high HSE abundances. Based on available data, the lunar mantle has a relatively homogeneous distribution of the HSE, in chondritic-relative proportions, but that are $\sim 0.0002 \times$ CI-chondrite (Day and Walker 2015). The 'missing HSE' cannot be reconciled by their sequestration into a small lunar core, which would act to fractionate interelement ratios at low lunar interior pressures $(<4 \mathrm{GPa})$. 
The constraints on lunar late accretion have led to a number of proposed dynamical models for the lower HSE abundances in the lunar mantle, relative to the terrestrial or martian mantles, including stochastic delivery of leftover planetesimal populations dominated by massive projectiles (Bottke et al. 2010), residual populations of small planetesimals (Schlichting et al. 2012), or erosional accretion kinetics (Raymond et al. 2013). Models have even been generated in an attempt to date the Earth-Moon forming event from the differences in HSE concentrations between these bodies (Jacobson et al. 2014), and to invoke the late accretion component from moon-forming impact ejecta. HSE abundances in planetary materials lend themselves well to placing constraints on dynamical models precisely because they enable quantification of accretion additions but, as noted below, a cautious petrological approach has to be taken in many instances. Furthermore, alternative explanations for elevated HSE abundances in planetary mantles have to be carefully considered before assigning strong dynamical assertions to the data.

Any model for late accretion has to explain the homogeneity of the HSE, in chondriticrelative proportions, estimated for lunar mare basalt sources, which indicate efficient mixing of the HSE into the lunar interior, and even distribution within low- and high-Ti mare basalt mantle sources, indicating $\sim 0.02 \mathrm{wt}$. \% late accretion addition (versus $\sim 0.3-0.8 \mathrm{wt} . \%$ for Earth, or $\sim 0.8 \%$ for Mars; Day and Walker 2015). The obvious time for addition of chondritic HSE to the lunar interior is during large-scale differentiation of the Moon, but prior to the formation of a thick lunar crust. Generation of a thick crust early in the history of the Moon that acted as a 'shield' to HSE-rich late accreted materials can potentially explain low HSE abundances in the lunar mantle. In such a scenario, the lunar crust would have, on

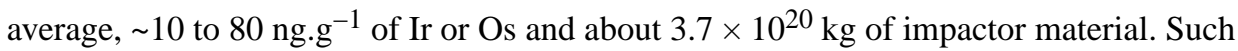
high HSE abundances, however, are rarely approached in lunar regolith or impact melt breccias and, instead, $\sim 1 \times 10^{19} \mathrm{~kg}$ of impactor material is thought to be present in the lunar crust (Day et al. 2010). Timing of late accretion additions to the Moon is poorly constrained but suggests addition prior to formation of the lunar crust at $\sim 4.3-4.4 \mathrm{Ga}$. Lunar late accretion estimates support the delivery of $\sim 1.47 \times 10^{19} \mathrm{~kg}$ undifferentiated 'chondritic' material to the Moon, relative to $2000-3000$ times more mass delivered to Earth ( 3 to $4.8 \times$ $10^{22} \mathrm{~kg}$ ) and proportional additions to Mars (4 to $5 \times 10^{21} \mathrm{~kg}$ ) (Day and Walker 2015).

While the timing of delivery of post-core formation materials to Earth, Mars, and the Moon remains weakly constrained, timing of delivery of late accreted materials to asteroids is becoming clearer. Day et al. (2012a) combined petrology and geochemistry to demonstrate that diogenite HSE abundances were established by metal-silicate equilibration, followed by minor, continued accretion, prior to complete solidification of their parent bodies. $\mathrm{Mn}-\mathrm{Cr}$ isotope chronology showed formation within 2-3 Ma of Solar System formation, while evidence for the HSE within unbrecciated portions indicates setting of HSE abundances prior to crystallization of diogenite meteorites. In turn, this requires that late accretion occurred earlier on differentiated asteroids than postulated for Earth, the Moon, and Mars. Similar late accretion additions have been observed for other differentiated asteroidal meteorites (Dale et al. 2012; Riches et al. 2012; van Acken et al. 2012), however, the timing of crystallization for these samples is weakly constrained. Late accretion was, therefore, a natural consequence of planetary accretion, with continued additions after the major phases of accretion, heating and differentiation. On smaller bodies, such as the parent bodies of 
diogenites, HSE variations may reflect regional rather than planet-wide effects, whereas for Earth, the Moon, and Mars, HSE abundances in materials derived from their mantles appear consistent with more homogeneous distribution through prolonged melting and/or solid-state convection.

\section{Alternative hypotheses for the abundances of the HSE in planetary mantles}

Two competing hypotheses to the late accretion hypothesis have been proposed to account for the more elevated HSE abundances than otherwise expected in planetary mantles. The inefficient core formation hypothesis posits that a portion of metal remains in the mantle during core formation (Arculus and Delano 1981; Jones and Drake 1982). By adjusting the proportion of metal in the silicate mantle it is possible to account for the HSE in the terrestrial mantle, but the variable partitioning of HSE between solid and liquid metal invariably leads to inescapable fractionation of the HSE (Jones and Drake 1986). The greatest issue with this hypothesis is that when the model proportions of different metal phases are optimized for one set of elements, other elements are predicted to be in greater or lesser concentrations in the mantle than permitted by a chondritic model for Earth.

The equilibrium hypothesis holds that HSE abundances in the terrestrial mantle reflect lowered partition coefficients either through changes in the composition of the system (e.g., Brett 1984), or high pressure-temperature partitioning (Ringwood 1977; Murthy 1991; Li and Agee 1996; Righter and Drake 1997). This model has also been extended to the martian mantle (Righter et al. 2015), where high inferred S content in the martian core may obviate modelling of an S-free system (Mann et al. 2012; Rai and Van Westrenen 2013). While experimental conditions now allow for the determination of metal-silicate partitioning at high pressures and temperatures, complications have led to difficulties in accurate determination of $D$ values (see Brenan et al. 2016, this volume). Although this hypothesis has merit (see summary in Walker 2009), and experimental data are available for pressures consistent with high-temperature and pressure conditions possibly pertinent to the terrestrial and martian mantles (e.g., Cottrell and Walker 2006; Righter et al. 2008; Wheeler et al. 2011), there are some challenges.

The most obvious challenge is that the partitioning characteristics of the HSE must be sufficiently similar at common pressures, temperatures and redox conditions to achieve nearly-chondritic abundances of the HSE and chondritic Re/Os, not just in Earth, but also for Mars. Osmium isotopes place stringent constraints on relative abundances of Re, Pt, and Os in planetary mantles and uniformity of $D$ values would have to be met to account for Re and Os within $\sim 5-10 \%$ and $\mathrm{Pt}$ and Os within $\sim 10 \%$. Recent work to constrain martian mantle HSE abundances used equilibration depths of $\sim 14 \mathrm{GPa}$ and temperatures of $\sim 2100{ }^{\circ} \mathrm{C}$ that are consistent with other martian siderophile element abundances ( $\mathrm{Fe}, \mathrm{Ni}, \mathrm{Co}, \mathrm{Mo}, \mathrm{W}, \mathrm{Mn}$, $\mathrm{V}, \mathrm{Cr}, \mathrm{P}, \mathrm{Ga}, \mathrm{Cu}, \mathrm{Sn}, \mathrm{Ge}, \mathrm{In}, \mathrm{Zn}, \mathrm{As}, \mathrm{Sb}$ ), and relevant parameterization, to obtain a martian mantle HSE abundance of $0.05 \mathrm{ng} . \mathrm{g}^{-1} \mathrm{Re}, 1.8 \mathrm{ng} . \mathrm{g}^{-1}$ Os, $2.2 \mathrm{ng} . \mathrm{g}^{-1} \mathrm{Ir}, 1.8 \mathrm{ng} . \mathrm{g}^{-1} \mathrm{Ru}, 4.98$ ng. $\mathrm{g}^{-1} \mathrm{Pt}$, and $4.22 \mathrm{ng} . \mathrm{g}^{-1} \mathrm{Pd}$ (Righter et al. 2015) (Table 3 and Fig. 40). While these values are consistent with the estimated HSE abundances in the mantle sources of shergottite meteorites, which isn't currently better constrained than $>50 \%$ (Table 2), the HSE pattern of the experimentally constrained high- $P$, high- $T$ equilibration composition for Mars is 
distinctly 'non-chondritic', with high Ir/Os, Ir/Ru and low Re/Os. Critically, even with potentially large associated uncertainties (not explicitly listed in Righter et al. 2015), the experimentally derived ${ }^{187} \mathrm{Re} /{ }^{188} \mathrm{Os}$ is $\sim 0.13$, equating to a modern-day ${ }^{187} \mathrm{Os} /{ }^{188} \mathrm{Os}$ evolution for Mars some $18 \%$ lower than the nearly chondritic ${ }^{187} \mathrm{Os} /{ }^{188} \mathrm{Os}$ measured in martian meteorites.

Perhaps the greatest single impediment to these hypotheses being applicable to all planetary bodies is that an increasing number of studies of bodies ranging in size from Earth to asteroids indicate broadly chondritic relative abundances of the HSE in their mantles. High pressure-temperature partitioning of the HSE to explain these abundances is impossible in bodies like the Moon (central pressure $=\sim 4 \mathrm{GPa}$ ), or smaller.

\section{Magmatic processes}

Partial melting promotes HSE fractionation (Barnes et al. 1985; Rehkämper et al. 1999), as demonstrated by differences in relative and absolute HSE abundances for high degree partial melts (e.g., most komatiites), versus lower degree equivalents (e.g., alkali basalts; see Day 2013, for a review). As explained above, the major controls on the HSE during mantle melting are the $\mathrm{S}$ content in the source(s) and the exhaustion of $\mathrm{S}$ during partial melting, potentially to form PGM and other refractory HSE-rich phases. For Earth and Mars, HSE partitioning appears to be similar during partial melting, with mantle melts being Sundersaturated and elevated incompatibility of Re due to relatively high $f_{\mathrm{O}_{2}}$. The compiled datasets of mantle-derived melts from planetary bodies reveals that fractional crystallization led to progressive fractionation of more compatible HSE from less compatible HSE in the order of $\mathrm{Ir} \geq \mathrm{Os}>\mathrm{Ru}>\mathrm{Pt}>\mathrm{Pd} \geq \mathrm{Re}$.

Unlike partitioning values for terrestrial (or martian) compositions, which suggest relative incompatibility of $\mathrm{Pt}, \mathrm{Pd}$ and Re in terrestrial mafic melts, similar partitioning behavior is inconsistent with observed HSE fractionations in lunar mare basalts. Day and Walker (2015) have shown that iterative calculations of partitioning of the HSE between olivine and melt indicate that $\mathrm{Os}, \mathrm{Ir}, \mathrm{Ru}, \mathrm{Pt}, \mathrm{Pd}$ and $\mathrm{Re}$ all behave compatibly in the relative order observed in fractionation trends for Apollo 12 mare basalts. Increased compatibility required to explain mare basalt HSE abundance systematics, relative to terrestrial values, indicates a fundamental difference in HSE behavior during fractional crystallization between Earth and the Moon. The most probable cause of these differences arises from the more reducing conditions of lunar compared with terrestrial melts, such that phases including FeNi metals occur. Birck and Allègre (1994) argued that Re is about three orders of magnitude more incompatible during terrestrial basalt petrogenesis as a function of oxygen fugacity inherited from the source regions of basalts. Results of modeling by Day and Walker (2015) support this conclusion, but also indicate that all of the HSE, with the possible exception of Pt, are more compatible during lunar and most differentiated asteroidal melting, compared with terrestrial petrogenesis.

The HSE abundances of the most MgO-rich mare basalts are consistent with their derivation from a lunar mantle with chondritic-relative proportions of the HSE. In terrestrial settings, partial melting promotes HSE fractionation, primarily because the HSE are strongly 
controlled by sulfide and HSE-rich alloys during partial melting of the mantle, allowing approximation of melting conditions from partial melting models (Barnes et al. 1985;

Rehkämper et al. 1999). For reduced bodies like the Moon, an additional complication is the potential effect of remnant metal in the source, due to low oxygen activity. The evidence for residual metal in the mantle source after partial melting is limited, however, with correlated $\mathrm{W} / \mathrm{Th}$ and $\mathrm{W} / \mathrm{U}$ in mare basalts that are indicative of a metal-free source, or complete exhaustion of metal during melting (Day and Walker 2015). Not least, the effect of metal in the source of mare basalts would be to strongly fractionate the HSE due to the variable but high metal-silicate partition coefficients (e.g., Mann et al. 2012), which is not observed in the mare basalt data. Indeed, the relatively unfractionated patterns of high $\mathrm{MgO}$ mare basalts indicate similar compatibility of the HSE during partial melting in the lunar mantle. Either metal did not exist in the source of mare basalts, or it was completely exhausted during mare basalt melt extraction.

\section{Later impacts into planetary crusts}

The HSE have been used extensively to study impactor compositions in terrestrial, as well as lunar impact melts. The low HSE in crustal or mantle materials from differentiated planets and planetesimals means that even small amounts of chondritic or iron impactor compositions can be detected using the HSE. Work on terrestrial impact craters has shown that while some impact melts contain high quantities of the HSE (e.g., Palme et al. 1978), a large number of terrestrial impact breccias and melts do not show HSE enrichments, suggesting projectiles either had low HSE contents or that the velocity of the impacting object was so high that it led to almost-complete vaporization, or produced a large amount of country rock melt, that concentrations of exogenous HSE were diluted by indigenous HSE (Koeberl 1998). The HSE have perhaps most famously been used to show a strong meteoritic signature in the Cretaceous-Palaeogene ('K/T') boundary layer (Orth et al. 1981; Goderis et al. 2013).

The 4.1-3.8 Ga ages of lunar impact basins suggest a phase of late bombardment in the inner Solar System, referred to as the late heavy bombardment (LHB) or lunar cataclysm (e.g., Tera and Wasserburg 1974). This period of late accretion cannot account for the overall late accretionary additions required to the Earth and Moon, accounting for less than $10 \%$ of current estimates (Morgan et al. 2001). As discussed previously, in order to derive the compositions of materials striking the Moon during the LHB, numerous studies have analyzed the compositions of lunar impact melt rocks. The assumption of these studies is that the HSE measured in the samples come from impactor materials incorporated into the samples. Plots of data from recent studies of lunar impact melt breccias show generally positive trends of ${ }^{187} \mathrm{Os} /{ }^{188} \mathrm{Os}$ versus Pt/Ir, Pd/Ir and Ru/Ir (Fig. 41). Fischer-Gödde and Becker (2012) found HSE ratios extending much higher than known chondrites in Apollo 16 impact melt rocks and noted the possible incorporation of two major HSE-rich materials; pre-existing, impact-contaminated granulites and a component resembling chemically evolved group IVA iron meteorites. Consequently, they proposed that both components became variably mixed during basin forming impacts, but were not substantially modified by HSE derived from the basin-forming impactors that created the rocks. 
Thus, the likely explanation for lunar impact melt breccia compositions is mixing between multiple, temporally distinct impactors striking the lunar crust. Possible explanations include mixing of chondritic and differentiated iron impactors (Fischer-Gödde and Becker 2012), or fractionation of the HSE in melt-sheets (e.g., Warren 2012). Shown in Figure 41 are mixing trends between lunar crustal compositions and a CI chondrite composition. The high ${ }^{187} \mathrm{Os} /$

${ }^{188} \mathrm{Os}$ and $\mathrm{Pt} / \mathrm{Ir}, \mathrm{Pd} / \mathrm{Ir}$ and $\mathrm{Ru} / \mathrm{Ir}$ of some lunar crustal samples make them good candidates for mixing to explain lunar impact melt breccia compositions. Given the percentage of impactor additions to lunar impact melt rocks estimated from the HSE $(<5 \%)$, and the very low HSE abundances of lunar crustal materials, it would require enrichment of the endogenous HSE in the lunar crust, possibly described by an R-factor style process (e.g., Campbell and Naldrett 1979), involving scavenging of the HSE in Fe-Ni metal and sulfides, to explain the relative mixing require for lunar impact melt rocks.

\section{COMPARATIVE PLANETOLOGY AND IMPLICATIONS FOR TERRESTRIAL FORMATION}

Studies of HSE abundances and Os isotopic compositions of planetary materials have fundamentally improved understanding of Solar System and planet formation processes. Chondritic meteorites inform on the source materials to, and initial bulk composition of, the Solar System, and processes acting on condensation and initial accretion in the solar nebula. Iron meteorites, stony-iron meteorites and primitive achondrites are the only available natural examples for observing the earliest stages of planetary melting and metal-silicate segregation and planetary partitioning into metallic cores, and silicate mantles and crusts. Meteorites from differentiated asteroids offer complementary evidence to the differentiation and evolution of the Earth. Martian samples provide evidence for the accretion and differentiation of a planet other than Earth, and samples from the Moon inform of the events occurring in the Earth-Moon system that have been erased or obscured by plate tectonics and weathering on Earth. In many ways, comparative planetology and the implications for Earth's formation is an inexhaustible subject. For this reason, the focus in this section is on the timing of processes and fundamental constraints that can be placed on the long-term evolution of terrestrial bodies.

The HSE exhibit interelement fractionation in some martian meteorites that are consistent with similar melting and fractional crystallisation processes acting on martian magmas compared with terrestrial hotspot volcanic rocks (e.g., Brandon et al. 2012; Tait et al. 2015). Martian shergottite meteorites therefore point to mantle sources with similar HSE contents to Earth's primitive mantle, and derivation of this signature in the martian mantle within the first 10-50 Ma of Solar System history (Brandon et al. 2012). The other planetary body for which there is an extensive suite of mantle-derived magmatic samples is the Moon. Lunar mare basalts have significantly lower HSE abundances to terrestrial and martian magmatic samples, and indicate derivation from a mantle source with broadly chondritic-relative abundances of the HSE that are depleted by 40 times relative to the terrestrial mantle. Examples are shown in Figure 42, where $\mathrm{MgO}$ and Os contents of terrestrial rocks and martian and lunar samples are plotted, showing similar depletion in Os with decreasing $\mathrm{MgO}$ 
content. While terrestrial and martian trends are similar, however, the trend for lunar mare basalts is systematically shifted to lower Os for a given $\mathrm{MgO}$ content.

Broad constraints on the chronology of Solar System materials are shown in Figure 43. The earliest formed objects in the Solar System are calcium, aluminium inclusions (CAIs) and chondrules, as well as some iron meteorites. The chronology suggests broadly synchronous accretion of chondritic parent bodies and full-differentiation of some planetary bodies within the first 2-3 Ma of Solar System formation. Evidence from diogenite meteorites indicates the cessation of major growth and onset of 'late accretion' within a similar time-scale. Thus, the evolution of the Solar System was probably not a simple age progression from dust to chondrules to chondrites to differentiated planets and planetesimals, but instead required closely associated planet formation processes in the earliest stages of the Solar System. That late accretion is simply a function of the accumulation of material into planetary mantles and crusts after the cessation of core growth offers important constraints on the evolution of individual planetary bodies. For example, $\mathrm{Hf}-\mathrm{W}$ isotope studies indicate formation of the martian core within 0-20 Ma of Solar System formation and more protracted growth for the Earth's core (Kleine et al. 2012). The more protracted growth of Earth's core may be a function of Earth-Moon system formation, indicating that both Earth and the Moon experienced late-accretion 10s of Ma after the beginning of late accretion in Mars. Thus, the similar HSE abundances estimated for the mantles of Earth and Mars may not have been delivered to these planets over the same time-scales.

The currently available data indicate that the lunar mantle is significantly depleted in the HSE relative to the terrestrial or martian mantles, but that the mantles of all of these bodies have followed a broadly chondritic long-term HSE evolution (Fig. 44). Combined with experimental metal-silicate partitioning data that indicate significant interelement fractionations of the HSE at low to moderately high pressures (e.g., Mann et al. 2012), the relative and absolute abundances of the HSE in the Earth, Moon, and Mars, therefore, point to mantles that witnessed variable additions of HSE from post-core formation accretion impactors, or late accretion (e.g., Kimura et al. 1974; Chou 1978; Becker et al. 2006; Day et al. 2007; Bottke et al. 2010; Brandon et al. 2012), although inefficient core formation, high$P$ partitioning of the HSE and other processes may also have played roles in the present-day distribution of the HSE in planetary mantles (e.g., Walker 2009).

Differences in the style of fractionation of the HSE in lunar mare basalts, relative to terrestrial basalts are consistent with the low oxygen activity of lunar melts and the increased compatibility of Re, Pt and Pd during fractional crystallization (Birck and Allègre 1994; Day and Walker 2015). Due to the generation of metal alloy phases at low $f_{\mathrm{O}_{2}}$, the HSE should be strongly affected by oxidation state, with some authors suggesting the presence of metal in some planetary mantles causing the HSE variations observed in some basaltic partial-melt products (e.g., Mavrogenes and O'Neill 1999; Dale et al. 2012). However, the redox states of planetary mantles do not appear to correlate particularly well with HSE contents (Fig. 45), and evidence from mare basalts is for the presence of metal within the samples, but not within their mantle sources. To a first order, these results suggest that, while important, redox conditions to do not correlate particularly well with planetary HSE abundances 
calculated from partial melt derivatives. Instead, HSE abundance and Os isotope studies of planetary volcanism provide evidence for both similar magmatic and planetary accretion processes acting on rocky bodies in the Solar System and for broadly chondritic HSE abundances within the mantles of these bodies.

\section{FUTURE DIRECTIONS}

Further detailed experimental and empirical determination of HSE partitioning behavior is required to resolve some of the problems associated with understanding planetary accretion and differentiation. Below we list some future directions of research that are likely to improve knowledge of these processes.

1. Further work is required on chondrite components (fremlindge, CAI's, chondrules, matrix materials) and on chondrite meteorite falls and finds. Examining chondrites and their components is likely to reveal the distribution of the HSE within early Solar System materials and will enable refined constraints on nucleosynthetic variations in siderophile elements, as well as refined determination of Re/Os and Pt/Os in the Solar System.

2. Examination of iron meteorites, and a search for their possible linkage with achondrites, is likely to be important. Unusual fractionations in some iron meteorite groups also need to be explained (e.g., McCoy et al. 2011).

3. The limited available Os isotope and isotope dilution HSE abundance data on pallasites and partially differentiated achondrites, such as winonaites or acapulcoitelodranites is remarkable, given their importance for understanding the earliest stages of core formation in asteroids. These meteorites may also reveal processes that act during metal-sulfide, as well as metal-silicate partitioning.

4. Additional elemental and isotopic data for martian and lunar samples will help define processes acting in establishing HSE abundances in the crusts and mantles of these bodies. Particular attention is required for examining potential crustal assimilation in martian meteorites, and potential regolith contamination processes in lunar suites and in asteroidal basalt suites.

5. Careful study of the petrology and geochemistry of achondrite meteorites is likely to reveal the contribution of late-accretion materials to parent bodies, as well as their indigenous HSE inventories. This form of 'pristinity index' is similar to that defined for lunar samples (e.g., Warren and Wasson 1978). Coupling this information with volatile and moderately-volatile elements is likely to be important for elucidating the amounts of late-accretion materials required to planetary bodies.

6. A major focus in future years is likely to be improvement and proliferation of the long-lived ${ }^{190} \mathrm{Pt}-{ }^{186} \mathrm{Os}$ system that will enable assessment of long-term Os-PtRe fractionation within and between large-scale planetary reservoirs. At least for the foreseeable future, the ability to precisely measure ${ }^{186} \mathrm{Os} /{ }^{188} \mathrm{Os}$ in planetary materials will continue to be restricted by the abundance of Os (typically > $30 \mathrm{ng}$ Os required for a high-precision Os isotope analysis), restricting this form of 
analysis to chondrites, iron meteorites and partially melted achondrites. Nonetheless, examination of the Pt-Os isotope system in these materials will be important for improving understanding of Pt/Os in Solar System materials.

7. Coupled chronometry-HSE studies are required to establish timing of lateaccretion to asteroids, Moon, Earth, and Mars. This form of study will ideally come hand-in-hand with combined petrographic examination, in order to elucidate the history of samples.

8. A fruitful area of future research will be the identification of impactor populations using nucleosynthetic variations in siderophile elements $(\mathrm{Mo}, \mathrm{Ru}$ etc.), in conjunction with the HSE.

9. Experiments are required to elucidate the behavior of the HSE at different, $f_{\mathrm{O}_{2}}$, $f_{\mathrm{S}_{2}}$, and volatile compositions during partial melting and crystal-liquid fractionation. Empirical evidence from lunar mare basalts suggests fundamentally different behaviors of the HSE at low $f_{\mathrm{O}_{2}}$ (Birck and Allegre 1994; Day and Walker 2015), with experiments so far conducted on Re (Mallman and O'Neill 2007).

10. The HSE place important constraints on the processes of accretion and differentiation and late accretion. A natural step, which is already being taken by some researchers, is to use the HSE as limitations on dynamical models to explain late accretion, planetesimal and asteroidal formation and Earth-Moon system formation.

\section{ACKNOWLEDGEMENTS}

Mario Fischer-Gödde, Jason Harvey and Kevin Righter are thanked for providing useful comments and suggestions that improved this review. Support from NASA for all three of our laboratories is gratefully acknowledged.

\section{REFERENCES}

Alard O, Luguet A, Pearson NJ, Griffin WL, Lorand J-P, Gannoun A, Burton KW, O'Reilly SY (2005) In situ Os isotopes in abyssal peridotites bridge the isotopic gap between MORBs and their source mantle. Nature 436:1005-1008 [PubMed: 16107845]

Albarède F, Ballhaus C, Blichert-Toft J, Lee C-T, Marty B, Moynier F, Yin Q-Z (2013) Asteroidal impacts and the origin of terrestrial and lunar volatiles. Icarus 222:44-52

Alvarez LW, Alvarez W, Asaro F, Michel HV (1980) Extraterrestrial cause for the Cretaceous-Tertiary mass extinction: Experimental results and theoretical interpretation. Science 208:1095-1108 [PubMed: 17783054]

Anders E (1979) Procrustean science: Indigenous siderophiles in the lunar highlands, according to Delano and Ringwood. The Moon and the Planets 20:219-239

Anders E, Grevesse N (1989) Abundances of the elements: meteoritic and solar. Geochim Cosmochim Acta 53:197-214

Anders E, Ganapathy R, Keays RR, Laul JC, Morgan JW (1971) Volatile and siderophile element in lunar rocks: comparison with terrestrial and meteoritic basalts. Proc Lunar Sci Conf 2nd:1021-1036

Archer GJ, Ash RD, Bullock ES, Walker RJ (2014) Highly siderophile elements and ${ }^{187}$ Re- ${ }^{187}$ Os isotopic systematics of the Allende meteorite: evidence for primary nebular processes and late-stage alteration. Geochim Cosmochim Acta 131:402-414 
Arculus RJ, Delano JW (1981) Siderophile element abundances in the upper mantle: evidence for a sulfide signature and equilibrium with the core. Geochim Cosmochim Acta 45:1331-1343

Aulbach S, Mungall JE, Pearson DG (2016) Distribution and processing of highly siderophile elements in cratonic mantle lithosphere. Rev Mineral Geochem 81:239-304

Ballhaus C, Bockrath C, Wohlgemuth-Ueberwasser C, Vera Laurenz V, Berndt J (2006) Fractionation of the noble metals by physical processes. Contrib Min Pet 152:667-684

Barnes S-J, Naldrett AJ, Gorton MP (1985) The origin of the fractionation of platinum-group elements in terrestrial magmas. Chem Geol 53:302-323

Basu Sarbadhikari A, Day JMD, Liu Y, Rumble D, Taylor LA (2009) Petrogenesis of olivine-phyric shergottite LAR 06319: Implications for enriched components in martian basalts. Geochim Cosmochim Acta 73:2190-2124

Becker H, Dale CW (2016) Re-Pt-Os isotopic and highly siderophile element behavior in oceanic and continental mantle tectonite. Rev Mineral Geochem 81:369-440

Becker H, Walker RJ, MacPherson GJ, Morgan JW, Grossman JN (2001) Rhenium-osmium systematics of calcium-aluminum-rich inclusions in carbonaceous chondrites. Geochim Cosmochim Acta 65:3379-3390

Becker H, Horan MF, Walker RJ, Gao S, Lorand J-P, Rudnick RL (2006) Highly siderophile element composition of the Earth's primitive upper mantle: Constraints from new data on peridotite massifs and xenoliths. Geochim Cosmochim Acta 70:4528-4550

Benedix GK, McCoy TJ, Keil K, Bogard DD, Garrison DH (1998) A petrologic and isotopic study of winonaites: evidence for early partial melting, brecciation, and metamorphism. Geochim Cosmochim Acta 62:2535-2553

Bézos A, Lorand J-P, Humler E, Gros M (2005) Platinum-group element systematics in mid-oceanic ridge basaltic glasses from the Pacific, Atlantic, and Indian Oceans. Geochim Cosmochim Acta 69:2613-2627

Bischoff A, Palme H (1987) Composition and mineralogy of refractory-metal-rich assemblages from a Ca,Al-rich inclusion in the Allende meteorite. Geochim Cosmochim Acta 51:2733-2749

Bild RW, Wasson JT (1976) The Lodran meteorite and its relationship to the ureilites. Mineral Mag 40:721-735

Birck J-L, Allègre CJ (1994) Contrasting Re/Os magmatic fractionation in planetary basalts. Earth Planet Sci Lett 124:363-379

Birck J-L, Roy-Barman M, Capmas F (1997) Re-Os isotopic measurements at the femtomole level in natural samples. Geostandards Newsletter 21:21-28

Blichert-Toft J, Gleason JD, Télouk P, Albarède F (1999) The Lu-Hf isotope geochemistry of shergottites and the evolution of the Martian mantle-crust system. Earth Planet Sci Lett 173:25-39

Borg LE, Nyquist LE, Wiesmann H, Reese Y (2002) Constraints on the petrogenesis of Martian meteorites from the $\mathrm{Rb}-\mathrm{Sr}$ and $\mathrm{Sm}-\mathrm{Nd}$ isotopic systematics of the lherzolitic shergottites ALH77005 and LEW88516. Geochim Cosmochim Acta 66:2037-2053

Borisov A, Palme H (1997) Experimental determination of the solubility of platinum in silicate melts. Geochim Cosmochim Acta 61:4349-4357

Borisov A, Palme H, Spettel B (1994) Solubility of palladium in silicate melts: implications for core formation in the Earth. Geochim Cosmochim Acta 58:705-716

Bottke WF, Nesvorny D, Grimm RE, Morbidelli A, O'Brien DP (2006) Iron meteorites as remnants of planetesimals formed in the terrestrial planet region. Nature 439:821-824 [PubMed: 16482151]

Bottke WF, Walker RJ, Day JMD, Nesvorny D, Elkins-Tanton L (2010) Stochastic late accretion to Earth, the Moon, and Mars. Science 330:1527-1530 [PubMed: 21148387]

Brandon AD, Walker RJ, Morgan JW, Goles GG (2000) Re-Os isotopic evidence for early differentiation of the Martian mantle. Geochim Cosmochim Acta 64:4083-4095

Brandon AD, Humayun M, Puchtel IS, Leya I, Zolensky M (2005a) Osmium isotope evidence for an sprocess carrier in primitive chondrites. Science 309:1233-1236 [PubMed: 16109878]

Brandon AD, Humayun M, Puchtel IS (2005b) Re-Os isotopic systematics and platinum group element concentration of the Tagish Lake carbonaceous chondrite. Geochim Cosmochim Acta 69:1619-1631 
Brandon AD, Walker RJ, Puchtel IS (2006) Platinum-osmium isotope evolution of the Earth's mantle: constraints from chondrites and Os-rich alloys. Geochim Cosmochim Acta 70:2093-2103

Brandon AD, Puchtel IS, Walker RJ, Day JMD, Irving AJ, Taylor LA (2012) Evolution of the martian mantle inferred from the ${ }^{187} \mathrm{Re}-{ }^{187}$ Os isotope and highly siderophile element abundance systematics of shergottite meteorites. Geochim Cosmochim Acta 76:206-235

Brearley AJ, Jones RJ (1998) Chondritic meteorites. Rev Mineral 36:3-001-3-398

Brenan JM, Bennett NR, Zajacz Z (2016) Experimental results on fractionation of the highly siderophile elements (HSE) at variable pressures and temperatures during planetary and magmatic differentiation. Rev Mineral Geochem 81:1-87

Brett R (1984) Chemical equilibration of the Earth's core and upper mantle. Geochim Cosmochim Acta 48:1183-1188

Brunfelt AO, Heier KS, Nilsson B, Sundvoll B, Steinnes E (1973) Geochemistry of Apollo 15 and 16 materials. Proc Lunar Sci Conf $4^{\text {th }}: 1209-1218$

Campbell IH, Naldrett AJ (1979) The influence of silicate:sulfide ratios on the geochemistry of magmatic sulfides. Econ Geol 74:1503-1505

Campbell AJ, Humayun M (1999) Trace element microanalysis in iron meteorites by laser ablation ICPMS. Anal Chem 71:939-946 [PubMed: 21662764]

Campbell AJ, Humayun M, Meibom A, Krot AN, Keil K (2001) Origin of zoned metal grains in the QUE 94411 chondrite. Geochim Cosmochim Acta 65:163-180

Campbell AJ, Humayun M, Weisberg MK (2002) Siderophile element constraints on the formation of metal in the metal-rich chondrites Bencubbin, Weatherford, and Gujba. Geochim Cosmochim Acta 66:647-660

Carlson RW (2005) Application of the Pt-Re-Os isotopic systems to mantle geochemistry and geochronology. Lithos 82:249-272

Casanova I, McCoy TJ, Keil K (1993) Metal-rich meteorites from the aubrite parent body. Lunar Planet Sci Conf 24:259-260 [Abs]

Chabot NL, Drake MJ (1999) Crystallization of magmatic iron meteorites: the role of mixing in the molten core. Meteor Planet Sci 34:235-246

Chabot NL, Jones JH (2003) The parameterization of solid metal-liquid metal partitioning of siderophile elements. Meteor Planet Sci 38:1425-1436

Chabot NL, Haack H (2006) Evolution of asteroidal cores In: Lauretta DS, McSween HY (eds) Meteorites and the early Solar System II, University of Arizona Press:pp 747-771

Chabot NL, Wollack EA, Humayun M, Shan EM (2014) The effect of oxygen as a light element in metallic liquids on partitioning behavior. Meteor Planet Sci, 50:530-546

Chen JH, Wasserburg GJ (1996) Extinct ${ }^{107} \mathrm{Pd}$ in the early solar system and implications for planetary evolution In Basu A, Hart SR (Eds) Earth Processes: Reading the Isotopic Code. Geophysical Monograph 95 AGU:1-20

Chen JH, Papanastassiou D, Wasserburg GJ (1998) Re-Os systematics in chondrites and the fractionation of the platinum group elements in the early solar system. Geochim Cosmochim Acta 62:3379-3392

Chen JH, Papanastassiou D, Wasserburg GJ (2002) Re-Os and Pd-Ag systematics in Group IIIAB irons and in pallasites. Geochim Cosmochim Acta 66:3793-3810

Chen JH, Papanastassiou D, Wasserburg GJ (2010) Ruthenium endemic isotope effects in chondrites and differentiated meteorites. Geochim Cosmochim Acta 74:3851-3862

Chao ECT, Minkin JA, Thompson CL (1976) The petrology of 77215, a noritic impact ejecta blanket. Proc Lunar Sci Conf 7th:2287-2308

Choi B-G, Ouyang X, Wasson JT (1995) Classification and origin of IAB and IIICD iron meteorites. Geochim Cosmochim Acta 59:593-612

Chou C-L (1978) Fractionation of siderophile elements in the Earth's upper mantle. Proc Lunar Planet Sci Conf 9th:219-230

Chou C-L, Baedecker PA, Bild RW, Wasson JT (1974) Volatile-element systematics and green glass in Apollo 15 lunar soils. Proc Lunar Sci Conf 5th:1645-1657 
Chou C-L, Boynton WV, Sundberg LL, Wasson JT (1975) Volatiles on the surface of Apollo 15 green glass and trace-element distributions among Apollo 15 soils. Proc Lunar Sci Conf 6th:1701-1727

Cirlin EH, Housley RM (1979) Scanning Auger microprobe and atomic absorption studies of lunar volcanic volatiles. Proc Lunar Planet Sci Conf 10th:341-354

Clayton RN, Mayeda TK (1996) Oxygen isotope studies of achondrites. Geochim Cosmochim Acta 60:1999-2017

Clayton RN, Mayeda TK (1999) Oxygen isotope studies of carbonaceous chondrites. Geochim Cosmochim Acta 63:2089-2104

Cohen AS, Waters FG (1996) Separation of osmium from geological materials by solvent extraction for analysis by thermal ionisation mass spectrometry. Anal Chim Acta 332:269-275

Cook DL, Walker RJ, Horan MF, Wasson JT, Morgan JW (2004) Pt-Re-Os systematics of group IIAB and IIIAB iron meteorites. Geochim Cosmochim Acta 68:1413-1431

Cottrell E, Walker D (2006) Constraints on core formation from Pt partitioning in mafic silicate liquids at hight temperatures. Geochim Cosmochim Acta 70:1565-1580

Creaser RA, Papanastassiou DA, Wasserburg GJ (1991) Negative thermal ion mass spectrometry of osmium, rhenium, and iridium. Geochim Cosmochim Acta 55:397-401

Dale CW, Burton KW, Greenwood RC, Gannoun A, Wade J, Wood B, Pearson DG (2012) Late accretion on the earliest planetesimals revealed by the highly siderophile elements. Science 336:72-75 [PubMed: 22491852]

Danielson LR, Sharp TG, Hervig RL (2005) Implications for core formation of the Earth from high pressure-temperature Au partitioning experiments. Lunar Planet Sci Conf 36:1955

Day JMD (2013) Hotspot volcanism and highly siderophile elements. Chem Geol 341:50-74

Day JMD (2015) Planet formation processes revealed by meteorites. Geol Today 31:14-22

Day JMD, Moynier F (2014) Evaporative fractionation of volatile stable isotopes and their bearing on the origin of the Moon. Philos Trans R Soc A 20130259 10.1098/rsta.2013.0259

Day JMD, Walker RJ (2015) Highly siderophile element depletion in the Moon. Earth Planet Sci Lett 423:114-124

Day JMD, Warren PH (2015) Highly Siderophile Element Abundance and Os Isotope Systematics of Partially Melted, FeO-Rich Achondrite Meteorites. Lunar Planet Sci Conf 45:1254

Day JMD, Pearson DG, Taylor LA (2007) Highly siderophile element constraints on accretion and differentiation of the Earth-Moon system. Science 315:217-219 [PubMed: 17218521]

Day JMD, Floss C, Taylor LA, Anand M, Patchen AD (2006) Evolved mare basalt magmatism, high $\mathrm{Mg} / \mathrm{Fe}$ feldspathic crust, chondritic impactors and the petrogenesis of Antarctic lunar meteorites Meteorite Hills 01210 and Pecora Escarpment 02007. Geochim Cosmochim Acta 70:5957-5989

Day JMD, Pearson DG, Hulbert LJ (2008) Rhenium-osmium isotope and platinum-group element constraints on the origin and evolution of the 1.27 Ga Muskox layered intrusion. J Petrol 49:12551295

Day JMD, Ash RD, Liu Y, Bellucci JJ, Rumble D, III, McDonough WF, Walker RJ, Taylor LA (2009) Early formation of evolved asteroidal crust. Nature 457:179-182 [PubMed: 19129845]

Day JMD, Walker RJ, James OB, Puchtel IS (2010) Osmium isotope and highly siderophile element systematics of the lunar crust. Earth Planet Sci Lett 289:595-605

Day JMD, Walker RJ, Qin L, Rumble D (2012a) Late accretion as a natural consequence of planetary growth. Nat Geosci 5:614-617

Day JMD, Walker RJ, Ash RD, Liu Y, Rumble D, Irving AJ, Goodrich CA, Tait K, McDonough WF, Taylor LA (2012b) Origin of felsic achondrites Graves Nunataks 06128 and 06129 and ultramafic brachinites and brachinite-like achondrites by partial melting of volatile-rich primitive parent bodies. Geochim Cosmochim Acta 81:94-128

Day JMD, Waters CL, Schaefer BF, Walker RJ, Turner S (2015a). Use of Hydrofluoric Acid Desilicification in the Determination of Highly Siderophile Element Abundances and Re-Pt-Os Isotope Systematics in Mafic-Ultramafic Rocks. Geostandards Geoanal Res. DOI: 10.1111/j. 1751-908X.2015.00367.x 
Day JMD, Corder CA, Rumble D, Assayag N, Cartigny P, Taylor LA (2015b) Common differentiation processes in oxidised and reduced asteroids revealed by the achondrite Lewis Cliff 88763 . Meteor Planet Sci:(in press)

Delano JW (1986) Pristine lunar glasses: criteria, data, and implications. J Geophys Res 91 (B4):D201-D21

Delano JW, McGuire J (1992) Abundances of sodium, sulfur, and potassium in lunar volcanic glasses. LPI Technical Report, 92-09 Part 1:pp.7-9

Delano JW, Hanson BZ, Watson EB (1994) Abundance and diffusivity of sulfur in lunar picritic magmas. Lunar Planet Sci Conf 25th:325-326 (LPI)

Dhaliwal JK, Day JMD, Corder CA, Tait KT, Marti K (2015) Highly siderophile element abundances and ${ }^{187} \mathrm{Re}-187$ Os systematics of Acapulcoite-Lodranite meteorites. Lunar Planet Sci Conf 45 th: 1595.

Drake M, Righter K (2002) Determining the composition of the Earth. Nature 416:39-44 [PubMed: 11882886]

Dreibus G, Wanke H (1985). Mars, a volatile-rich planet. Meteoritics 20:367-381

Ebihara M, Wolf R, Warren PH, Anders E (1992) Trace elements in 59 mostly highland moon rocks. Proc Lunar Planet Sci Conf 22nd:417-426

Eisenhour DD, Buseck PR (1992) Transmission electron microscopy of RMNs:Implications for singlephase condensation of the refractory siderophile elements. Meteoritics 27:217-218

Emsley J (1991) The elements. Clarendon Press, Oxford:251pp

Ertel W, O’Neill HStC, Sylvester PJ, Dingwell DB, Spettel B (2001) The solubility of rhenium in silicate melts: implications for the geochemical properties of rhenium at high temperatures. Geochim Cosmochim Acta 65:2161-2170

Fegley B, Palme H (1985) Evidence for oxidizing conditions in the solar nebula from Mo and W depletions in refractory inclusions in carbonaceous chondrites. Earth Planet Sci Lett 72:311-326

Feldstein SN, Jones RH, Papike JJ (2001) Disequilibrium partial melting experiments of the Leedey L6 chondrite: Textural controls on melting processes. Meteor Planet Sci 36:1421-1441

Fischer-Gödde M, Becker H (2012) Osmium isotope and highly siderophile element constraints on ages and nature of meteoritic components in ancient lunar impact rocks. Geochim Cosmochim Acta 77:135-156

Fischer-Gödde M, Becker H, Wombacher F (2010) Rhodium, gold and other highly siderophile element abundances in chondritic meteorites. Geochim Cosmochim Acta 74:356-379

Fischer-Gödde M, Becker H, Wombacher F (2011) Rhodium, gold and other highly siderophile elements in orogenic peridotites and peridotite xenoliths. Chem Geol 280:365-383

Filiberto J, Chin E, Day JMD, Franchi IA, Gross J, Greenwood RC, Penniston-Dorland S, Schwenzer S, Treiman A (2012) Geochemistry of intermediate olivine-phyric shergottite northwest Africa 6234, with similarities to basaltic shergottite northwest Africa 480 and olivine-phyric shergottite northwest Africa 2990. Meteor Planet Sci 47:1256-1273

Fogel RA, Rutherford MJ (1995) Magmatic volatiles in primitive lunar glasses: I. FTIR and EMPA analyses of Apollo 15 green and yellow glasses and revision of the volatile-assisted fire-fountain theory. Geochim Cosmochim Acta 59:201-215

Fortenfant SS, Guenther D, Dingwell DB, Rubie DC (2003) Temperature dependence of Pt and Rh solubilities in a haplobasaltic melt. Geochim Cosmochim Acta 67:123-131

Fryer BJ, Greenough JD (1992) Evidence for mantle heterogeneity from platinum-group-element abundances in Indian Ocean basalts. Can J Earth Sci 29:2329-2340

Gannoun A, Burton KW, Day JMD, Harvey J, Schiano P, Parkinson I (2016) Highly siderophile element and Os isotope systematics of volcanic rocks at divergent and convergent plate boundaries and in intraplate settings. Rev Mineral Geochem 81:651-724

Ganapathy R, Keays RR, Laul J, Anders E (1970). Trace elements in Apollo 11 lunar rocks: Implications for meteorite influx and origin of moon. Geochim Cosmochim Acta Suppl 1:1117

Ganapathy R, Morgan JW, Krahenbuhl U, Anders E (1973) Ancient meteoritic components in lunar highlands rocks: clues from trace elements in Apollo 15 and 16 samples. Proc Lunar Sci Conf 4th:1239-1261 
Gardner-Vandy KG, Lauretta DS, Greenwood RC, McCoy TJ, Killgore M, Franchi IA (2012) The Tafassasset primitive achondrite: Insights into initial stages of planetary differentiation. Geochim Cosmochim Acta 2012:142-159

Goderis S, Tagle R, Belza J, Smit J, Montanari A, Vanhaecke F, Claeys P (2013). Reevaluation of siderophile element abundances and ratios across the Cretaceous-Paleogene (K-Pg) boundary: Implications for the nature of the projectile. Geochim Cosmochim Acta 120:417-446

Goderis S, Brandon AD, Mayer B, Humayun M, Agee CB (2014) Tracing impactor signals prevalent in martian regolith breccia Northwest Africa 7034 with Os isotopes and platinum group elements. Lunar Planet Sci Conf 45th:2200 (Abs)

Goldberg E, Uchimaya A, Brown H (1952) The distribution of nickel, cobalt, gallium, palladium and gold in iron meteorites. Geochim Cosmochim Acta 2:1-25

Goldstein JI, Scott ERD, Chabot NL (2009) Iron meteorites: crystallization, thermal history, parent bodies, and origin. Chemie der Erde 69:293-325

Goodrich CA, Scott ERD, Fioretti AM (2004) Ureilitic breccias: clues to the petrologic structure and impact disruption of the ureilite parent asteroid. Chemie der Erde 64:283-327.

Goodrich CA, Kita NT, Spicuzza MJ, Valley JW, Zipfel J, Mikouchi T, Miyamoto M (2011) The Northwest Africa 1500 meteorite: Not a ureilite, maybe a brachinite. Meteor Planet Sci 45:19061928

Gros J, Takahashi H, Hertogen J, Morgan JW, Anders E (1976) Composition of the projectiles that bombarded the lunar highlands. Proc Lunar Sci Conf 7th:2403-2425

Harvey J, Day JMD (2016) Introduction to highly siderophile and strongly chalcophile elements in high temperature geochemistry and cosmochemistry. Rev Mineral Geochem 81:iii-Xv

Harvey J, Warren JM, Shirey SB (2016) Mantle sulfides and their role in Re-Os and Pb isotope geochronology. Rev Mineral Geochem 81:579-649

Heiken GH, McKay DS, Brown RW (1974) Lunar deposits of possible pyroclastic origin. Geochim Cosmochim Acta 38:1703-1718

Herr W, Hoffmeister W, Hirt B, Geiss J, Houtermans FG (1961) Versuch zur Datierung von Eisenmeteoriten nach der Rhenium-Osmium-Methode. Z Naturforsch 16a:1053-1058

Herr W, Herpers U, Michel R, Abdel Rassoul AA, Woelfle R (1971) Search for rhenium isotopic anomalies in lunar surface material by neutron bombardment. Proc Lunar Sci Conf 2nd:13371341

Hertogen J, Janssens M-J, Takahashi H, Palme H, Anders E (1977) Lunar basins and craters: Evidence for systematic compositional changes of bombarding population. Proc Lunar Sci Conf 8th:17-45

Higuchi H, Morgan JW (1975) Ancient meteoritic component in Apollo 17 boulders. Proc Lunar Sci Conf 6 th:1625-1651

Hirata T, Masuda A (1992) Rhenium and osmium systematics on iron and stony iron meteorites. Meteoritics 27:568-575

Hirata T, Nesbitt RW (1997) Distribution of platinum group elements and rhenium between metallic phases of iron meteorites. Earth Planet Sci Lett 147:11-24

Holzheid A, Sylvester P, O’Neill HStC, Rubie DC, Palme H (2000) Evidence for a late chondritic veneer in the Earth's mantle from high-pressure partitioning of palladium and platinum. Nature 406:396-399 [PubMed: 10935633]

Horan MF, Morgan JW, Walker RJ, Grossman JN (1992) Re-Os isotope constraints on the age of iron meteorites. Science 255:1118-1121 [PubMed: 17817787]

Horan MF, Smoliar M, Walker RJ (1998) ${ }^{182} \mathrm{~W}$ and ${ }^{187} \mathrm{Re}-{ }^{187}$ Os systematics of iron meteorites: chronology for melting, differentiation and crystallization of asteroids. Geochim Cosmochim Acta 62:545-554

Horan MF, Walker RJ, Morgan JW, Grossman JN, Rubin A (2003) Highly siderophile elements in chondrites. Chem Geol 196:5-20

Horan MF, Alexander CMO'D, Walker RJ (2009) Highly siderophile element evidence for early solar system processes in components from ordinary chondrites. Geochim Cosmochim Acta 73:69846997 
Horan MF, Carlson RW, Blichert-Toft J (2012) Pd-Ag chronology of volatile depletion, crystallization and shock in the Muonionalusta IVA iron meteorite and implications for its parent body. Earth Planet Sci Lett 351-352:215-222

Hughes TC, Keays RR, Lovering JF (1973) Siderophile and volatile trace elements in Apollo 14, 15 and 16 rocks and fines: evidence for extralunar component and Tl-, Au-, and Ag-enriched rocks in the ancient lunar crust. Proc Lunar Sci Conf Abs 4th:400-402

Humayun M (2012) Chondrule cooling rates inferred from diffusive profiles in metal lumps from the Acfer 097 CR2 chondrite. Meteoritics Planet Sci 47:1191-1208

Humayun M, Nemchin A, Zanda B, Hewins RH, Grange M, Kennedy A, Lorand J-P, Göpel C, Fieni C, Pont S, Deldicque D (2013) Origin and age of the earliest Martian crust from meteorite NWA 7533. Nature 503:513-516 [PubMed: 24256724]

Hyde BC, Day JMD, Tait KT, Ash RD, Holdsworth DW, Moser DE (2014) A study of weathering and heterogeneous mineral phase distribution in brachinite Northwest Africa 4872. Meteor Planet Sci 49:1141-1156

Ishikawa A, Senda R, Suzuki K, Dale CW, Meisel T (2014) Re-evaluating digestion methods for highly siderophile element and ${ }^{187}$ Os isotope analysis: Evidence from geological reference materials. Chem Geol 384:27-46

Jacobson SA, Morbidelli A, Raymond SN, O’Brien DP, Walsh KJ, Rubie DC (2014) Highly siderophile elements in Earth's mantle as clock for the Moon-forming impact. Nature 508:84-87 [PubMed: 24695310]

Jagoutz E, Palme H, Baddenhausen H, Blum K, Cendales M, Dreibus G, Spettel B, Lorenz V, Wanke $\mathrm{H}$ (1979) The abundance of major, minor and trace elements in the Earth's mantle derived from primitive ultramafic nodules. Proc Lunar Sci Conf 10th:2031-2050

Janssens M-J, Palme H, Hertogen J, Anderson AT, Anders E (1978) Meteoritic material in lunar highland samples from the Apollo 11 and 12 sites. Proc Lunar Planet Sci Conf 9th:1537-1550

Jarosewich E (1990) Chemical analyses of meteorites: A compilations of stony and iron meteorite analyses. Meteoritics 25:323-337

Jones JH, Drake MD (1982) An experimental geochemical approach to early planetary differentiation. Proc Lunar Planet Sci Conf 14:413-414

Jones JH, Drake MD (1986) Geochemical constraints on core formation in the Earth. Nature 322:221228

Jones JH, Neal CR, Ely JC (2003) Signatures of the highly siderophile elements in the SNC meteorites and Mars: a review and petrologic synthesis. Chem Geol 196:21-42

Jurewicz AJG, Mittlefehldt DW, Jones JH (1991) Partial melting of the Allende (CV) meteorite: implications for the origin of basaltic meteorites. Science 252:695-698 [PubMed: 17746669]

Jurewicz AJG, Mittlefehldt DW, Jones JH (1995) Experimental partial melting of the St. Severin (LL) and Lost City $(\mathrm{H})$ chondrites. Geochim Cosmochim Acta 59:391-408

Keil K (2014) Brachinite meteorites: Partial melt residues from an FeO-rich asteroid. Chemie der Erde 74:311-329

Kimura K, Lewis RS, Anders E (1974) Distribution of gold and rhenium between nickel-iron and silicate melts: implications for the abundance of siderophile elements on the Earth and Moon. Geochim Cosmochim Acta 38:683-701

Kimura M, Tsuchiyama A, Fukuoka T, Iimura Y (1992). Antarctic primitive achondrites Yamato-74025,-75300, and -75305: Their mineralogy, thermal history and the relevance to winonaite. Antarct Meteorite Res 5:165

Kleine T, Hans U, Irving A, Bourdon B (2012) Chronology of the angrite parent body and implications for core formation in protoplanets. Geochim Cosmochim Acta 84:186-20

Koeberl C (1998) Identification of meteoritical components in impactities In: Grady MM, Hutchison R, McCall GJH, Rothery DA (eds) Meteorites: flux with time and impact effects. Geol Soc London Spec Publ 140:133-152

Korotev RL (1994) Compositional variation in Apollo 16 impact-melt breccias and inferences for the geology and bombardment history of the Central Highlands of the Moon. Geochim Cosmochim Acta 58:3931-3969 
Krähenbühl U (1980) Distribution of volatile and non volatile elements in grain-size fractions of Apollo 17 drive tube 74001/2. Proc Lunar Planet Sci Conf 11th:1551-1564

Krähenbühl U, Morgan JW, Ganapathy R, Anders E (1973). Abundance of 17 trace elements in carbonaceous chondrites. Geochim Cosmochim Acta 37:1353-1370

Kramers JD (1998) Reconciling siderophile element data in the Earth and Moon, W isotopes and the upper lunar age limit in a simple model of homogeneous accretion. Chem Geol 145:461-478

Kruijer TS, Touboul M, Fischer-Godde M, Bermingham KR, Walker RJ, Kleine T (2014) Protracted core formation and rapid accretion of protoplanets. Science 344:1150-1154 [PubMed: 24904163]

Lee SR, Walker RJ, McCoy TJ, McDonough WF (2006) ${ }^{187} \mathrm{Re}-{ }^{187}$ Os isotopic and highly siderophile element systematics of pallasites. Lunar Planet Science XXXVII:1167 [Abs]

Leya I, Wieler R, Halliday AN (2003) The influence of cosmic-ray production on extinct nuclide systems. Geochim Cosmochim Acta 67:529-541

Leya I, Masarik J (2013) Thermal neutron capture effects in radioactive and stable nuclide systems. Meteor Planet Sci 46:665-685

Li J, Zhao PP, Liu J, Wang XC, Yang AY, Wang GQ, Xu JF (2014) Reassessment of Hydrofluoric acid desilicification in the Carius tube digestion technique for Re-Os isotopic determination in geological samples. Geostandards Geoanal Res 39:17-30

Li J, Agee CB (1996) Geochemistry of mantle-core differentiation at high pressure. Nature 381:686689

Liu C-Z, Snow JE, Brügmann G, Hellebrand E, Hofmann AW (2009) Non-chondritic HSE budget on Earth's upper mantle evidenced by abyssal peridotites from Gakkel ridge (Arctic Ocean). Earth Planet Sci Lett 283:122-132

Liu J, Sharp M, Ash RD, Kring DA, Walker RJ (2015). Diverse impactors in Apollo 15 and 16 impact melt rocks: evidence from osmium isotopes and highly siderophile elements. Geochim Cosmochim Acta 155:122-153

Lodders K (2003) Solar System abundances and condensation temperatures of the elements. Astrophys J 591:1220-1247

Lorand J-P, Pattou L, Gros M (1999) Fractionation of platinum-group elements and gold in the upper mantle: a detailed study in Pyrenean orogenic lherzolites. J Petrol 40:957-981

Lorand J-P, Luguet A, Alard O (2013) Platinum-group elements systematics and petrogenetic processing of the continental upper mantle: a review. Lithos 164-167:2-21

Lovering JF, Nichiporuk W, Chodos A, Brown H (1957) The distribution of gallium, germanium, cobalt, chromium and copper in iron and stony-iron meteorites in relation to nickel content and structure. Geochim Cosmochim Acta 11:263-278

Luck J-M, Allègre CJ (1982) The study of molybdenites through the ${ }^{187} \mathrm{Re}-{ }^{187}$ Os chronometer. Earth Planet Sci Lett 61:291-296

Luck J-M, Allègre CJ (1983) ${ }^{187}$ Re_- ${ }^{187}$ Os systematics in meteorites and cosmochemical consequences. Nature 302:130-132

Luguet A, Shirey SB, Lorand JP, Horan MF, Carlson RW (2007) Residual platinum-group minerals from highly depleted harzburgites of the Lherz massif (France) and their role in HSE fractionation of the mantle. Geochim Cosmochim Acta 71:3082-3097

Luguet A, Nowell GM, Pearson DG (2008) ${ }^{184} \mathrm{Os} /{ }^{188}$ Os and ${ }^{186} \mathrm{Os} /{ }^{188}$ Os measurements by Negative Thermal Ionisation Mass Spectrometry (N-TIMS): Effects of interfering element and mass fractionation corrections on data accuracy and precision. Chem Geol 248342-362

Luguet A, Reisberg L (2016) Highly siderophile element and ${ }^{187}$ Os signatures in non-cratonic basalthosted peridotite xenoliths: Unravelling the origin and evolution of the post-Archean lithospheric mantle. Rev Mineral Geochem 81:305-367

Mallmann G, O'Neill HStC (2007) The effect of oxygen fugacity on the partitioning of Re between crystals and silicate melt during mantle melting. Geochim Cosmochim Acta 71:2837-2857

Mann U, Frost DJ, Rubie DC, Becker H, Audétat A (2012) Partitioning of Ru, Rh, Pd, Re, Ir and Pt between liquid metal and silicate at high pressures and temperatures - Implications for the origin of highly siderophile element concentrations in the Earth's mantle. Geochim Cosmochim Acta 84:593-613 
Masarik J (1997) Contribution of neutron-capture reactions to observed tungsten isotopic ratios. Earth Planet Sci Lett 152:181-185

Mavrogenes JA, O'Neill HStC (1999) The relative effects of pressure, temperature and oxygen fugacity on the solubility of sulfide in mafic magmas. Geochim Cosmochim Acta 63:1173-1180

McCord TB, Adams JB, Johnson TV (1970) Asteroid Vesta: spectral reflectivity and compositional implications. Science 168:1445-1447 [PubMed: 17731590]

McCoy T, Keil K, Clayton RN, Mayeda TK, Bogard DD, Garrison DH, Huss GR, Hutcheon ID, Wieler R (1996) A petrologic, chemical and isotopic study of Monument Draw and comparison with other acapulcoites: evidence for formation by incipient partial melting. Geochim Cosmochim Acta 60:2681-2708

McCoy T, Keil K, Clayton RN, Mayeda TK, Bogard DD, Garrison DH, Wieler R (1997a) A petrologic and isotopic study of lodranites: evidence for early formation as partial melt residues from heterogeneous precursors. Geochim Cosmochim Acta 61:623-637

McCoy T, Keil K, Muenow DW, Wilson L (1997b) Partial melting and melt migration in the acapulcoite-lodranite parent body. Geochim Cosmochim Acta 61:639-650

McCoy TJ, Walker RJ, Goldstein JI, Yang J, McDonough WF, Rumble D, Chabot NL, Ash RD, Corrigan CM, Michael JR, Kotula PG (2011) Group IVA irons: new constraints on the crystallization and cooling history of an asteroidal core with a complex history. Geochim Cosmochim Acta 75:6821-6843

McDonald I, Andreoli MAG, Hart RJ, Tredoux M (2001) Platinum-group elements in the Morokweng impact structure, South Africa: Evidence for the impact of a large ordinary chondrite projectile at the Jurassic-Cretaceous boundary. Geochim Cosmochim Acta 65:299-309

McDonough WF (2003) Compositional model for the Earth's core. Treatise on Geochemistry, Volume 2, pp. 547-568

McSween HY (1994) What we have learned about Mars from SNC meteorites. Meteoritics 29:757779

Meisel T, Moser J (2004a) Reference materials for geochemical PGE analysis: new analytical data for $\mathrm{Ru}, \mathrm{Rh}, \mathrm{Pd}, \mathrm{Os}, \mathrm{Ir}, \mathrm{Pt}$ and Re by isotope dilution ICP-MS in 11 geological reference materials. Chem Geol 208:319-338

Meisel T, Moser J (2004b) Platinum-group element and rhenium concentrations in low abundance reference materials. Geostandards Geoanal Res 28:233-250

Meisel T, Horan MF (2016) Analytical methods for the highly siderophile elements. Rev Mineral Geochem 81:89-106

Meisel T, Walker RJ, Morgan JW (1996) The osmium isotopic composition of the Earth's primitive upper mantle. Nature 383:517-520

Meisel T, Walker RJ, Irving AJ, Lorand J-P (2001) Osmium isotopic compositions of mantle xenoliths: a global perspective. Geochim Cosmochim Acta 65:1311-1323

Meisel T, Reisberg L, Moser J, Carignan J, Melcher F, Brugmann G (2003) Re-Os systematics of UBN, a serpentinized peridotite reference material. Chem Geol 201:161-179

Meyer C, McKay DS, Anderson DH, Butler P (1975) The sources of subliminates on the Apollo 15 green and Apollo 17 orange glass samples. Proc Lunar Sci Conf 6th:1673-1699

Michel R, Herpers U, Kulus H, Herr W (1972) Isotopic anomalies in lunar rhenium. Proc Lunar Sci Conf 3rd:1917-1925

Mittlefehldt DW, Lindstrom MM, Bogard DD, Garrison DH, Field SW (1996) Acapulco- and Lodranlike achondrites: petrology, geochemistry, chronology, and origin. Geochim Cosmochim Acta 60:867-882

Mittlefehldt DW, McCoy TJ, Goodrich CA, Kracher A (1998) Non-chondritic meteorites from asteroidal bodies. Rev Mineral 36:4-001-4-196

Mittlefehldt DW, Bogard DD, Berkley JL, Garrison DH (2003) Brachinites: Igneous rocks from a differentiated asteroid. Meteor Planet Sci 38:1601-1625

Morgan JW (1986) Osmium isotope constraints on Earth's late accretionary history. Nature 317:703705 
Morgan JW, Lovering JF (1967) Rhenium and osmium abundances in some igneous and metamorphic rocks. Earth Planet Sci Lett 3:219-224

Morgan JW, Wandless GA (1979) 74001 drive tube: siderophile elements match IIB iron meteorite pattern. Proc Lunar Planet Sci Conf 10th:327-340

Morgan JW, Wandless GA (1984) Surface-correlated trace elements in 15426 lunar glasses (abs). Lunar Planet. Sci XV:562-563

Morgan JW, Walker RJ (1989) Isotopic determinations of rhenium and osmium in meteorites by using fusion, distillation, and ion-exchange separations. Anal Chim Acta 222:291-300

Morgan JW, Laul JC, Ganapathy R, Anders E (1971) Glazed lunar rocks: origin by impact. Science 172:556-558 [PubMed: 17802215]

Morgan JW, Laul JC, Krähenbühl U, Ganapathy R, Anders E (1972) Major impacts on the Moon: characterization from trace elements in Apollo 12 and 14 samples. Proc Lunar Sci Conf 3rd: $1377-1395$

Morgan JW, Higuchi H, Anders E (1975) Meteoritic material in a boulder from the Apollo 17 site: implications for its origin. The Moon 14:373-383

Morgan JW, Walker RJ, Grossman JN (1992) Rhenium-osmium isotope systematics in meteorites I: Magmatic iron meteorite groups IIAB and IIIAB. Earth Planet Sci Lett 108:191-202

Morgan JW, Horan MF, Walker RJ, Grossman JN (1995) Rhenium-osmium concentration and isotope systematics in group IIAB iron meteorites. Geochim Cosmochim Acta 59:2331-2344

Morgan JW, Walker RJ, Brandon AD, Horan MF (2001) Siderophile elements in Earth's upper mantle and lunar breccias: Data synthesis suggests manifestations of the same late influx. Meteor Planet Sci 36:1257-1275

Murthy V (1991) Early differentiation of the Earth and the problem of mantle siderophile elements: a new approach. Science 253:303-306 [PubMed: 17794697]

Nehru CE, Prinz M, Delaney JS, Dreibus G, Palme H, Spettel B, Wänke H (1983) Brachina: a new type of meteorite, not a chassignite. Proc Lunar Planet Sci Conf 10th:817-832

Nicholis MG, Rutherford MJ (2009) Graphite oxidation in the Apollo 17 orange glass magma: Implications for the generation of a lunar volcanic gas phase. Geochim Cosmochim Acta 73:5905-5917

Norman MD, Mittlefehldt DW (2002) Impact processing of chondritic planetesimals: siderophile and volatile element fractionation in the Chico L chondrite. Meteor Planet Sci 37:329-344

Norman MD, Bennett VC, Ryder G (2002) Targeting the impactors: siderophile element signatures of lunar impact melts from Serenatatis. Earth Planet Sci Lett 202:217-228

Norman MD, Borg LE, Nyquist LE, Bogard DD (2003) Chronology, geochemistry, and petrology of a ferroan noritic anorthosite clast from Descartes breccia 67215: clues to the age, origin, structure, and impact history of the lunar crust. Meteor Planet Sci 38:645-661

Nyquist LE, Kleine T, Shih C-Y, Reese YD (2009) The distribution of short-lived radioisotopes in the early solar system and the chronology of asteroid accretion, differentiation, and secondary mineralization. Geochim Cosmochim Acta 73:5115-5136

O’Driscoll B, González-Jiménez J (2016) Petrogenesis of the platinum-group minerals. Rev Mineral Geochem 81:489-578

O'Hara MJ (1985) Importance of the "shape" of the melting regime during partial melting of the mantle. Nature 314:58-62

O'Keefe JD, Ahrens TJ (1977) Impact-induced energy partitioning, melting, and vapourization on terrestrial planets. Proc Lunar Sci Conf 8:3357-3374

O'Neill HStC, Palme H (1998) Compositon of the silicate Earth: Implications for accretion and core formation In: Jackson I (ed) The Earth's mantle: structure, composition and evolution - the Ringwood volume. Cambridge University Press, pp. 3-126

O’Neill HStC, Dingwell DB, Borisov A, Spettel B, Palme H (1995) Experimental petrochemistry of some highly siderophile elements at high temperatures, and some implications for core formation and the mantle's early history. Chem Geol 120:255-273 
Orth CJ, Gilmore JS, Knight JD, Pillmore CL, Tschudy RH, Fassett JE (1981) An iridium abundance anomaly at the palynological Cretaceous-Tertiary boundary in northern New Mexico. Science 214:1341-1343 [PubMed: 17812258]

Palme H (2008) Platinum-group elements in cosmochemistry. Elements 4:233-238

Palme H, Wlotzka F (1976) A metal particle for a Ca,Al-rich inclusion from the meteorite Allende, and the condensation of refractory siderophile elements. Earth Planet Sci Lett 33:45-60

Palme H, Janssens M-J, Takahashi H, Anders E, Hertogen J (1978) Meteoritic material in five large impact craters. Geochim Cosmochim Acta 42:313-323

Palme H, Schultz L, Spettel B, Weber HW, Wanke H, Michel-Levy MC, Lorin JC (1981) The Acapulco meteorite: chemistry, mineralogy and irradiation effects. Geochim Cosmochim Acta 45:727-752

Palme H, Hutcheon ID, Spettel B (1994). Composition and origin of refractory-metal-rich assemblages in a Ca, Al-rich Allende inclusion. Geochim Cosmochim Acta 58:495-513

Papike JK, Spilde MN, Fowler GW, Layne GD, Shearer CK (1995) The Lodran primitive achondrite: petrogenetic insights from electron and ion microprobe analysis of olivine and orthopyroxene. Geochim Cosmochim Acta 59:3051-3070

Peach CL, Mathez EA, Keays RR (1990) Sulfide meltsilicate melt distribution coefficients for noble metals and other chalcophile elements as deduced from MORB: Implications for partial melting. Geochim Cosmochim Acta 54:3379-3389

Peach CL, Mathez EA, Keays RR, Reeves SJ (1994) Experimentally determined sulfide silicate-melt partition coefficients for iridium and palladium. Chem Geol 117:361-377

Pearson DG, Woodland SJ (2000) Solvent extraction/anion exchange separation and determination of PGEs (Os, Ir, Pt, Pd, Ru) and Re-Os isotopes in geological samples by isotope dilution ICP-MS. Chem Geol 165:87-107

Pearson DG, Irvine GJ, Ionov DA, Boyd FR, Dreibus GE (2004) Re-Os isotope systematics and platinum group element fractionation during mantle melt extraction: a study of massif and xenolith peridotite suites. Chem Geol 208:29-59

Pernicka E, Wasson JT (1987) Ru, Re, Os, Pt and Au in iron meteorites. Geochim Cosmochim Acta 51:1717-1726

Petaev MI, Jacobsen SB (2004) Differentiation of metal-rich meteoritic parent bodies: I. Measurements of PGEs, Re, Mo, W, and Au in meteoritic Fe-Ni metal. Meteor Planet Sci 39:1685-1697

Peucker-Ehrenbrink B, Jahn B-M (2001) Rhenium-osmium isotope systematics and platinum-group element concentrations: loess and the upper continental crust. Geochem Geophys Geosyst 2:

Peucker-Ehrenbrink B, Hanghoj K, Atwood T, Kelemen PB (2012) Rhenium-osmium isotope systematics and platinum group element concentrations in oceanic crust. Geol 40:199-202

Puchtel IS, Walker RJ, James OB, Kring DA (2008) Osmium isotope and highly siderophile element systematics of lunar impact melt rocks: Implications for the late accretion history of the Moon and Earth. Geochim Cosmochim Acta 72:3022-3042

Rai N, Van Westrenen W (2013) Core-mantle differentiation in Mars. J Geophys Res: Planets 118:1195-1203

Rankenburg K, Brandon AD, Humayun M (2007) Osmium isotope systematics of ureilites. Geochim Cosmochim Acta 71:2402-2413

Rankenburg K, Humayun M, Brandon AD, Herrin JS (2008) Highly siderophile elements in ureilites. Geochim Cosmochim Acta 72:4642-4659

Ravizza G, Pyle D (1997) PGE and Os isotopic analyses of single samples aliquots with NiS fire assay preconcentration. Chem Geol 141:251-268

Raymond SN, Schlichting HE, Hersant F, Selsis F (2013) Dynamical and collisional constraints on a stochastic late veneer on the terrestrial planets. Icarus 226:671-681

Reed GW, Allen RO, Jovanovic S (1977) Volatile metal deposits on lunar soils - relation to volcanism. Proc Lunar Sci Conf 8th:3917-3930

Rehkamper M, Halliday AN (1997) Development and application of new ion-exchange techniques for the separation of the platinum group and other siderophile element from geological samples. Talanta, 44:663-672 [PubMed: 18966788] 
Rehkämper M, Halliday AN, Fitton JG, Lee D-C, Wieneke M, Arndt NT (1999) Ir, Ru, Pt and Pd in basalts and komatiites: new constraints for the geochemical behavior of the platinum-group elements in the mantle. Geochim Cosmochim Acta 63:3915-393

Reisberg L, Lorand J-P (1995) Longevity of sub-continental mantle lithosphere from osmium isotope systematics in orogenic peridotite massifs. Nature 376:159-162

Reisberg L, Meisel T (2002) The Re-Os isotopic system: a review of the analytical techniques. Geostandards Newsletter 26:249-26

Reisberg L, Dauphas N, Luguet A, Pearson DG, Gallino R, Zimmermann C (2009) Nucleosynthetic osmium isotope anomalies in acid leachates of the Murchison meteorite. Earth Planet Sci Lett 277:334-344

Riches AJV, Liu Y, Day JMD, Puchtel IS, Rumble D, McSween HY, Walker RJ, Taylor LA (2011) Petrology and geochemistry of Yamato 984028: A cumulate lherzolitic shergottite with affinities to Y 000027, Y 000047, and Y 000097. Polar Sci 4:497-514

Riches AJV, Day JMD, Walker RJ, Simonetti A, Liu Y, Neal CR, Taylor LA (2012) Rhenium-osmium isotope and highly siderophile element abundance systematics of angrite meteorites. Earth Planet Sci Lett 353-354:208-21

Righter K (2003) Metal-silicate partitioning of siderophile elements and core formation in the early Earth. Ann Rev Earth Planet Sci 31:135-174

Righter K, Drake MJ (1997) Metal-silicate equilibrium in a homogeneous accreting Earth: new results for Re. Earth Planet Sci Lett 146:541-553

Righter K, Walker RJ, Warren PH (2000) Significance of highly siderophile elements and osmium isotopes in the lunar and terrestrial mantle In: Canup RM, Righter K (Eds.) Origin of the Earth and Moon. Univ. Arizona Press, Tuscon, pp. 291-322

Righter K, Humayun M, Danielson L (2008) Partitioning of palladium at high pressures and temperatures during core formation. Nature Geosci 1:321-323

Righter K, Danielson LR, Pando KM, Williams J, Humayun M, Hervig RL, Sharp TG (2015) Highly siderophile element (HSE) abundances in the mantle of Mars are due to core formation at high pressure and temperature. Meteor Planet Sci 50:1-28

Ringwood AE (1977) Composition of the core and implications for the origin of Earth. Geochem J 11:111-135

Ringwood AE (1992) Volatile and siderophile element geochemistry of the Moon: a reappraisal. Earth Planet Sci Lett 111:537-555

Rose HJ, Cuttitta F, Annell CS, Carron MK, Christian RP, Dwornik EJ, Greenland LP, Ligon DT (1972) Compositional data for twenty-one Fra Mauro lunar materials. Proc Lunar Sci Conf 3rd: $1215-1229$

Rubin AE (2007) Petrogenesis of acapulcoites and lodranites: a shock-melting model. Geochim Cosmochim Acta 71:2383-2401

Rutherford MJ, Papale P (2009) Origin of basalt fire-fountain eruptions on Earth versus the Moon. Geology 37:219-222

Sato M (1979) The driving mechanism of lunar pyroclastic eruptions inferred from oxygen fugacity behavior of Apollo 17 orange glass. Proc Lunar Planet Sci Conf 10th:311-325

Schlichting HE, Warren PH, Yin QZ (2012) The last stages of terrestrial planet formation: dynamical friction and the late veneer. Astrophys J 752:8

Schmidt G, Palme H, Kratz KL, Kurat G (2000) Are highly siderophile elements (PGE, Re and Au) fractionated in the upper mantle? New results on peridotites from Zabargad. Chem Geol 163:167-188

Schönbächler M, Carlson RW, Horan MF, Mock TD, Hauri EH (2008) Silver isotope variations in chondrites: Volatile depletion and the initial ${ }^{107} \mathrm{Pd}$ abundance of the solar system. Geochim Cosmochim Acta 72:5330-5341

Schulz T, Munker C, Mezger C, Palme H (2010) Hf-W chronometry of primitive achondrites. Geochim Cosmochim Acta 74:1706-1718

Scott ERD (1972) Chemical fractionation in iron meteorites and it interpretation. Geochim Cosmochim Acta 36:1205-1236 
Scott ERD, Wasson JT (1976) Chemical classification of iron meteorites - VIII. Groups IC, IIE, IIF and 97 other irons. Geochim Cosmochim Acta 40:103-115

Scott ERD, Taylor GJ, Keil K (1993) Origin of ureilite meteorites and implications for planetary accretion. Geophys Res Lett 20:415-418

Scott ERD, Greenwood RC, Franchi IA, Sanders IS (2009) Oxygen isotopic constraints on the origin and parent bodies of eucrites, diogenites, and howardites. Geochim Cosmochim Acta 73:58355853

Selby D, Creaser RA, Stein HJ, Markey RJ, Hannah JL (2007) Assessment of the ${ }^{187}$ Re decay constant by cross calibration of Re-Os molybdenite and $\mathrm{U}-\mathrm{Pb}$ zircon chronometers in magmatic ore systems. Geochim Cosmochim Acta 71:1999-2013

Sharp M, Gerasimenko I, Loudin L, Liu J, James OB, Puchtel IS, Walker RJ (2014) Characterization of the dominant impactor signature for Apollo 17 impact melt rocks. Geochim Cosmochim Acta 131:62-80

Shearer CK, Papike JJ (1993) Basaltic magmatism on the Moon: A perspective from volcanic picritic glass beads. Geochim Cosmochim Acta 57:4785-4812

Shearer CK, Burger PV, Neal C, Sharp Z, Spivak-Birndorf L, Borg L, Fernandes V, Papike JJ, Karner J, Wadhwa M, Gaffney AM, Shafer J, Geissman J, Atudorei N-V, Herd C, Weiss BP, King PL, Crowther SA, Gilmour JD (2010) Non-basaltic asteroidal magmatism during the earliest stages of Solar System evolution. A view from Antarctic achondrites Graves Nunataks 06128 and 06129. Geochim Cosmochim Acta 74:1172-1199

Shen JJ, Papanastassiou DA, Wasserburg GJ (1996) Precise Re-Os determinations and systematics of iron meteorites. Geochim Cosmochim Acta 60:2887-2900

Shen JJ, Papanastassiou DA, Wasserburg GJ (1998) Re-Os systematics in pallasites and mesosiderite metal. Geochim Cosmochim Acta 62:2715-2723

Shirey SB, Walker RJ (1995) Carius tube digestion for low-blank rhenium-osmium analysis. Anal Chem 67:2136-2141

Shirey SB, Walker RJ (1998) The Re-Os isotope system in cosmochemistry and high-temperature geochemistry. Ann Rev Earth Planet Sci 26:423-500

Smoliar MI, Walker RJ, Morgan JW (1996) Re-Os ages of group IIA, IIIA, IVA and IVB iron meteorites. Science 271:1099-1102

Swindle TD, Kring DA, Burkland MK, Hill DH, Boynton WV (1998) Noble gases, bulk chemistry, and petrography of olivine-rich achondrites Eagles Nest and Lewis Cliff 88763: Comparison to brachinites. Meteor Planet Sci 33:31-48

Tait K, Day JMD, Liu Y (2015) Update on highly-siderophile element abundances and Re-Os isotopic systematics of martian meteorites. Lunar Planet Sci Conf 46th:2138

Takeda H, Mori H, Hiroi T, Saito J (1994) Mineralogy of new Antarctic achondrites with affinity to Lodran and a model of their evolution in an asteroid. Meteorit 29:830-842

Tatsumoto M, Premo WR, Unruh DM (1987) Origin of lead from green glass of Apollo 15426: A search from primitive lunar lead. J Geophys Res 92 (B4):E361-E371

Tera F, Wasserburg GJ (1974) U-Th-Pb systematics on lunar rocks and inferences about lunar evolution and the age of the Moon. Proc Lunar Sci Conf 5th:1571-1599

Treiman AJ, Jones JH, Drake MJ (1987) Core formation in the shergottite parent body and comparison with the Earth. Proc Lunar Planet Sci Conf 17th:E627-E632

Turekian KK, Clark SP (1969) Inhomogeneous accumulation of the Earth from the primitive solar nebula. Earth Planet Sci Lett 6:346-348

van Acken D, Brandon AD, Humayun M (2011) High precision osmium isotopes in enstatite and Rumuruti chondrites. Geochim Cosmochim Acta 75:4020-4036

van Acken D, Brandon AD, Lapen TJ (2012) Highly siderophile element and osmium isotope evidence for postcore formation magmatic and impact processes on the aubrite parent body. Meteor Planet Sci 47:1606-1623

Völkening J, Walczyk T, Heumann KG (1991) Osmium isotope ratio determinations by negative thermal ionization mass spectrometry. Int J Mass Spectro Ion Proc 105:147-159 
Wahl W (1952) The brecciated stony meteorites and meteorites containing foreign fragments. Geochim Cosmochim Acta 2:91-117

Walker D, Grove T (1993) Ureilite smelting. Meteorit 28:629-636

Walker RJ (2009) Highly siderophile elements in the Earth, Moon and Mars: Update and implications for planetary accretion and differentiation. Chemie der Erde 69:101-125

Walker RJ (2012) Evidence for homogeneous distribution of osmium in the protosolar nebula. Earth Planet Sci Lett 351-352:36-44

Walker RJ, Morgan JW, Smoliar MI, Beary E, Czamanske GK, Horan MF (1997) Application of the ${ }^{190} \mathrm{Pt}-{ }^{186} \mathrm{Os}$ isotope system to geochemistry and cosmochemistry. Geochim Cosmochim Acta 61:4799-4807

Walker RJ, Horan MF, Morgan JW, Becker H, Grossman JN, Rubin A (2002) Comparative ${ }^{187}$ Re${ }^{187}$ Os systematics of chondrites: Implications regarding early solar system processes. Geochim Cosmochim Acta 66:4187-4201

Walker RJ, Horan MF, Shearer CK, Papike JJ (2004) Depletion of highly siderophile elements in the lunar mantle: evidence for prolonged late accretion. Earth Planet Sci Lett 224:399-413

Walker RJ, Brandon AD, Bird JM, Piccoli PM, McDonough WF, Ash RD (2005) ${ }^{186}$ Os- ${ }^{187}$ Os systematics of Os-Ir-Ru alloy grains, southwestern Oregon. Earth Planet Sci Lett 230:211-226

Walker RJ, McDonough WF, Honesto J, Chabot NL, McCoy TJ, Ash RD, Bellucci JJ (2008) Modeling fractional crystallization of group IVB iron meteorites. Geochim Cosmochim Acta 72:2198-2216

Walsh KJ, Morbedelli A, Raymond SN, O’Brien DP, Mandell AM (2011) A low mass for Mars from Jupiter's early gas-driven migration. Nature 475:206-209 [PubMed: 21642961]

Wang K, Day JMD, Korotev RL, Zeigler RA, Moynier F (2014) Iron isotope fractionation during sulfide-rich felsic partial melting in early planetesimals. Earth Planet Sci Lett 392:124-132

Wanke H (1981) Constitution of terrestrial planets. Philos Trans R Soc A 393:287-302

Warren PH (2012) Let's get real: not every lunar rock sample is big enough to be representative for every purpose. Second Conf Lunar Highlands Crust: 9034

Warren PH, Wasson JT (1977) Pristine nonmare rocks and the nature of the lunar crust. Proc Lunar Sci Conf 8th:2215-2235

Warren PH, Wasson JT (1978) Compositional-petrographic investigation of pristine nonmare rocks. Proc Lunar Planet Sci Conf 9th:185-217

Warren PH, Wasson JT (1980) Further foraging for pristine nonmare rocks: correlations between geochemistry and longitude. Proc Lunar Planet Sci Conf 11th:431-470

Warren PH, Kallemeyn GW (1989) Allan Hills 84025: The second brachinite, far more differentiated than Brachina, and an ultramafic achondrite clast from L chondrite Yamato 75097. Proc Lunar Planet Sci Conf 19th:475-486

Warren PH, Kallemeyn GW (1992) Explosive volcanism and the graphite-oxygen fugacity buffer on the parent asteroid(s) of the ureilite meteorites. Icarus 100:110-126

Warren PH, Taylor GJ (2014) The Moon In: Davis AM (Ed.) Treatise in Geochemistry, Vol. 1 Elsevier, Amsterdam, Edition 2:213-250

Warren PH, Jerde EA, Kallemeyn GW (1991) Prisitine Moon rocks: Apollo 17 anorthosites. Proc Lunar Planet Sci Conf 21:51-61

Warren PH, Jerde EA, Kallemeyn GW (1989) Lunar meteorites: siderophile element contents and implications for the composition and origin of the Moon. Earth Planet Sci Lett 91:245-260

Warren PH, Kallemeyn GW, Kyte FT (1997) Siderophile element evidence indicates that Apollo 14 high-Al mare basalts are not impact melts. Lunar and Planetary Science XXVIII:1501-1502.

Warren PH, Kallemeyn G, Kyte FT (1999) Origin of planetary cores: evidence from highly siderophile elements in martian meteorites. Geochim Cosmochim Acta 63:2105-2122

Warren PH, Ulff-Møller F, Huber H, Kallemeyn GW (2006) Siderophile geochemistry of ureilites: a record of early stages of planetesimal core formation. Geochim Cosmochim Acta 70:2104-2126

Warren PH, Kallemeyn G, Huber H, Ulff-Moller F, Choe W (2009) Siderophile and other geochemical constraints on mixing relationships between HED-meteoritic breccias. Geochim Cosmochim Acta 73:5918-5943 
Warren PH, Rubin AE, Isa J, Brittenham S, Ahn I, Choi B-G (2013) Northwest Africa 6693: A new type of FeO-rich, low-D ${ }^{17} \mathrm{O}$, poikilitic cumulate achondrite. Geochim Cosmochim Acta 107:135-154

Wasson JT (1967) The chemical classification of iron meteorites, I. A study of iron meteorites with low concentrations of gallium and germanium. Geochim Cosmochim Acta 31:161-180

Wasson JT (1985) Meteorite: their record of early Solar System history. WH Freeman, 267pp

Wasson JT (1999) Trapped melt in IIIAB irons: solid/liquid elemental partitioning during the fractionation of the IIIAB magma. Geochim Cosmochim Acta 63:2875-2889

Wasson JT, Wang J (1986) A nonmagmatic origin of group-IIE iron meteorites. Geochim Cosmochim Acta 50:725-732

Wasson JT, Kallemeyn GW (2002) The IAB iron-meteorite complex: A group, five subgroups, numerous grouplets, closely related, mainly formed by crystal segregation in rapidly cooling melts. Geochim Cosmochim Acta 66:2445-2473

Wasson JT, Choi B-G (2003) Main-group pallasites: chemical composition, relationship to III AB irons, and origin. Geochim Cosmochim Acta 67:3079-3096

Wasson JT, Boynton WV, Kallemeyn GW, Sundberg LL, Wai CM (1976) Volatile compounds released during lunar lava fountaining. Proc Lunar Sci Conf 7th:1583-1595

Wasson JT, Choi BG, Jerde EA, Ulff-Moller F (1998) Chemical classification of iron meteorites XII. New members of the magmatic groups. Geochim Cosmochim Acta 62:715-724

Weigel A, Eugster O, Koeberl C, Michel R, Krahenbuhl U, Neumann S (1999) Relationships among lodranites and acapulcoites: Noble gas isotopic abundances, chemical composition, cosmic-ray exposure ages, and solar cosmic ray effects. Geochim Cosmochim Acta 63:175-192

Wheeler KT, Walker D, McDonough WF (2011) Pd and Ag metal-silicate partitioning applied to Earth differentiation and core-mantle exchange. Meteor Planet Sci 46:199-217

Wolf R, Woodrow A, Anders E (1979) Lunar basalts and pristine highland rocks: comparison of siderophile and volatile elements. Proc Lunar Planet Sci Conf 10th:2107-2130

Wolf R, Ebihara M, Richter GR, Anders E (1983). Aubrites and diogenites: Trace element clues to their origin. Geochim Cosmochim Acta 47:2257-2270

Yang S, Humayun M, Righter Kev, Jefferson G, Fields D, Irving AJ (2015) Siderophile and chalcophile element abundances in shergottites: implications for martian core formation. Meteor Planet Sci 50:691-714

Yokoyama T, Walker RJ (2016) Nucleosynthetic isotope variations of siderophile and chalcophile elements in the Solar System. Rev Mineral Geochem 81:107-160 [PubMed: 30774562]

Yokoyama T, Walker D, Walker RJ (2009) Low osmium solubility in silicate at high pressures and temperatures. Earth Planet Sci Lett 279:165-173

Yokoyama T, Alexander CMO'D, Walker RJ (2010) Osmium isotope anomalies in chondrites: results for acid residues and related leachates. Earth Planet Sci Lett 291:48-59

Yokoyama T, Alexander CMO'D, Walker RJ (2011) Assessment of nebular versus parent body processes on presolar components present in chondrites: evidence from osmium isotopes. Earth Planet Sci Lett 305:115-123 

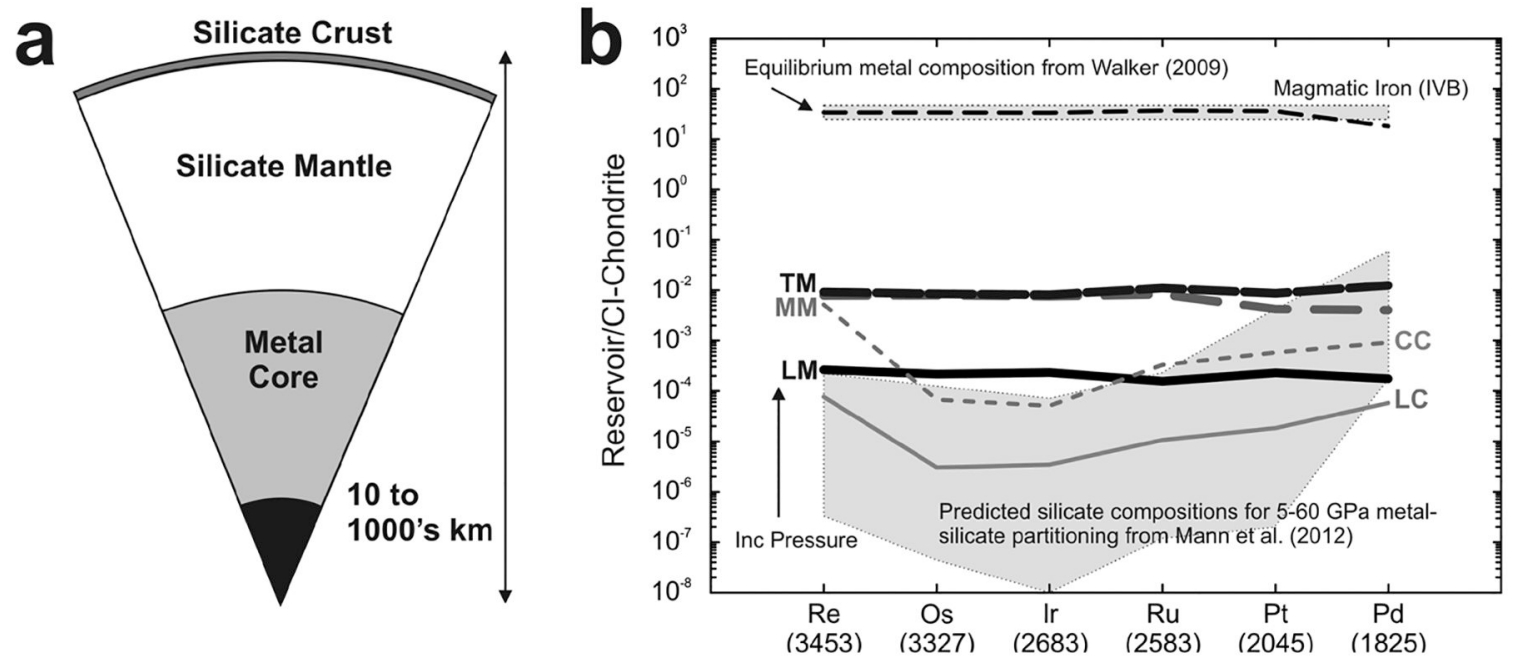

Figure 1.

(a) Schematic of a hypothetical differentiated rocky planetary body, broken into a metal core (solid inner = black; liquid outer $=$ gray) and silicate mantle and crust. (b) Baseline distributions of highly siderophile elements (not including monoisotopic $\mathrm{Rh}$ and $\mathrm{Au}$ ) in different core, mantle and crust reservoirs of Earth, the Moon and Mars (adapted from Day 2013). The mantles of Earth (terrestrial mantle [TM] = black stippled line), the Moon (lunar mantle $[\mathrm{LM}]=$ black line), and Mars (martian mantle $[\mathrm{MM}]=$ gray dashed line) have broadly chondritic relative abundances of the HSE, with the martian and terrestrial mantles having similar absolute abundances ( 0.007-0.008 $\times$ CI Chondrite), and the Moon's mantle being $>40$ times more depleted in the HSE $(\sim 0.0002 \times$ CI Chondrite). These patterns do not match predicted silicate compositions after core formation (Mann et al. 2012), suggesting that late-accretion addition of HSE-rich impactors may ultimately have been required to obtain chondritic relative HSE abundances in planetary mantles. Terrestrial continental crust ( $\mathrm{CC}=$ thin gray dashed line) shows similar crust-mantle partitioning characteristics to the lunar crust ( $\mathrm{LC}=$ thin gray line), indicating strong HSE fractionation during crustal growth. Data for equilibrium metal matches the least evolved magmatic iron meteorite HSE abundances (e.g., IVB iron meteorite Warburton Range; Walker et al. 2008). Reservoir data given in the tables and numbers beneath the elements are melting temperatures of pure elemental metals in Kelvin (Emsley 1991). 

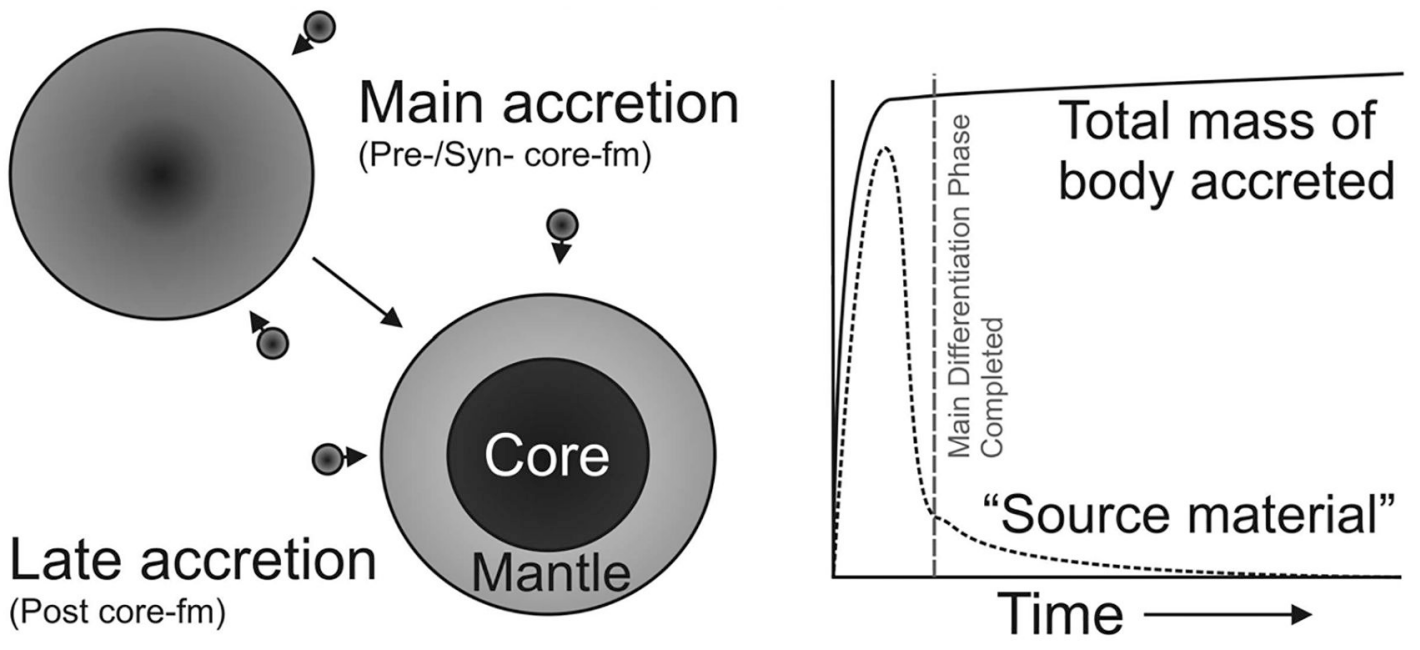

Figure 2.

Schematic diagram illustrating the distinction between core-formation accretion and postcore formation accretion, also known as late accretion (or, in some cases, a 'late veneer' for Earth). During the main phase of accretion, in the first 1-2 Ma of Solar System history, as the total mass of the body is predicted to increase rapidly, metal-silicate equilibration is expected to draw-down the HSE into a metallic core. After the main differentiation phase has completed and core formation ceases, late accretion commences, with a proportionally smaller predicted fraction of 'source material' being contributed into the silicate crust and mantles of planetary bodies. In the most general sense, the amount of late accretion added to a differentiated planet will be a function of cessation of metal-silicate equilibration (the main differentiation phase). 

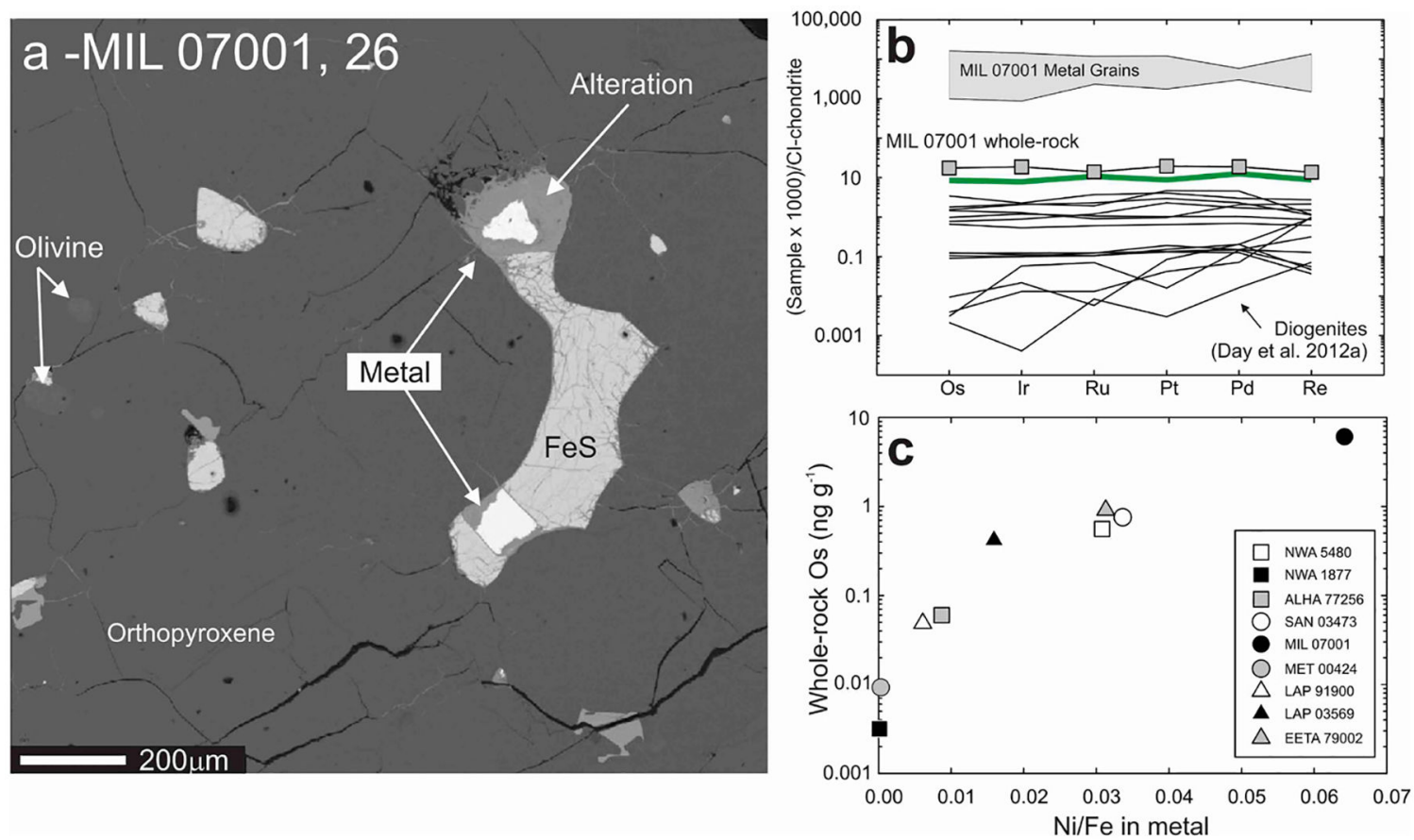

Figure 3.

Example of the use of combined petrology and LA-ICP-MS analyses to investigate the location of the HSE within rock samples. The left panel (a) shows a back-scatter electron image of a portion of olivine diogenite MIL 07001, 26, showing the textural relationship of metal and sulfide in the sample. Top right panel (b) shows the field of metal grain HSE abundances measured for MIL 07001 versus whole-rock measurements of MIL 07001 and other diogenites (shown as lines), illustrating the strong control metal grains have on the whole-rock composition of diogenites. Thick solid line in (b) is the terrestrial primitive mantle composition (Becker et al. 2006). The siting of the metal and sulfide grains in brecciated diogenites is not in the breccia matrix, indicating setting of the HSE prior to crystallisation of the diogenites. (c) Relationship between $\mathrm{Ni} / \mathrm{Fe}$ in metal grains from diogenite meteorites and their whole-rock HSE abundances (shown here in terms of Os concentration), emphasizing the siting of the HSE within metals in these particular meteorites. Figure adapted from Day et al. (2012a). 

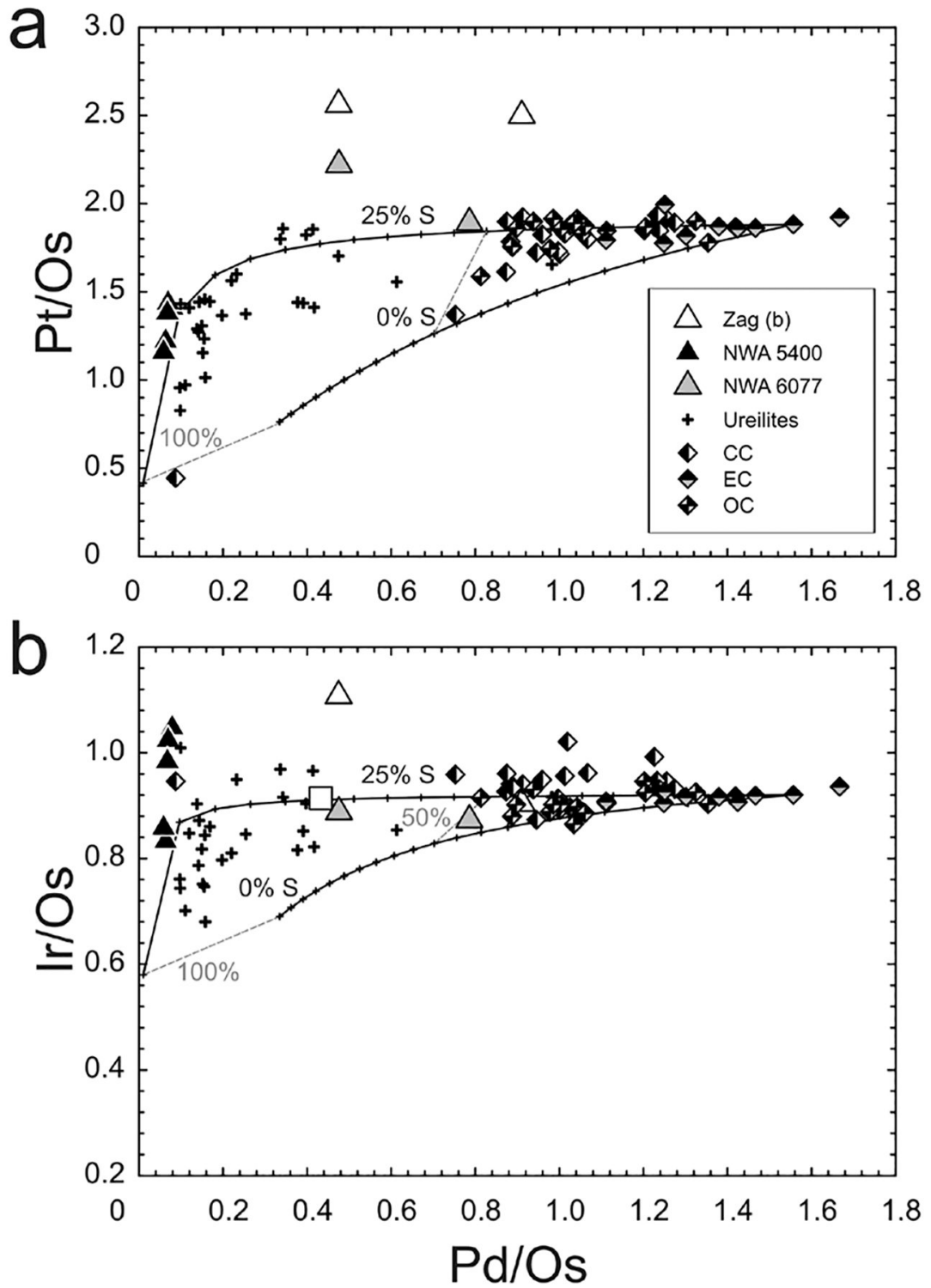

Figure 4.

Plots of $\mathrm{Pd} / \mathrm{Os}$ versus (a) $\mathrm{Pt} / \mathrm{Os}$ and (b) Ir/Os for primitive achondrites and chondrites, with calculated compositions of metal residues. Shown are chondrite (Horan et al. 2003; FischerGödde et al. 2010) ureilite (Rankenburg et al. 2008) and brachinite-like achondrite compositions (Day et al. 2012b). The melt calculations model the composition of residues that result from single episodes of batch melting. The starting HSE composition is the bulk composition of Orgueil with concentrations adjusted assuming that all of the HSE were originally in metal and that metal comprises $5 \%$ of the bulk. Curves show compositions of residues resulting from no sulfur, and $25 \%$ sulfur. Fractions of residue are labelled and are in increments of 5\%. Solid-metal-liquid-metal $D$ values were calculated using the parameterization of Chabot and Jones (2003). Carbonaceous chondrite [CC]; enstatite chondrite [EC]; ordinary chondrite [OC]. 


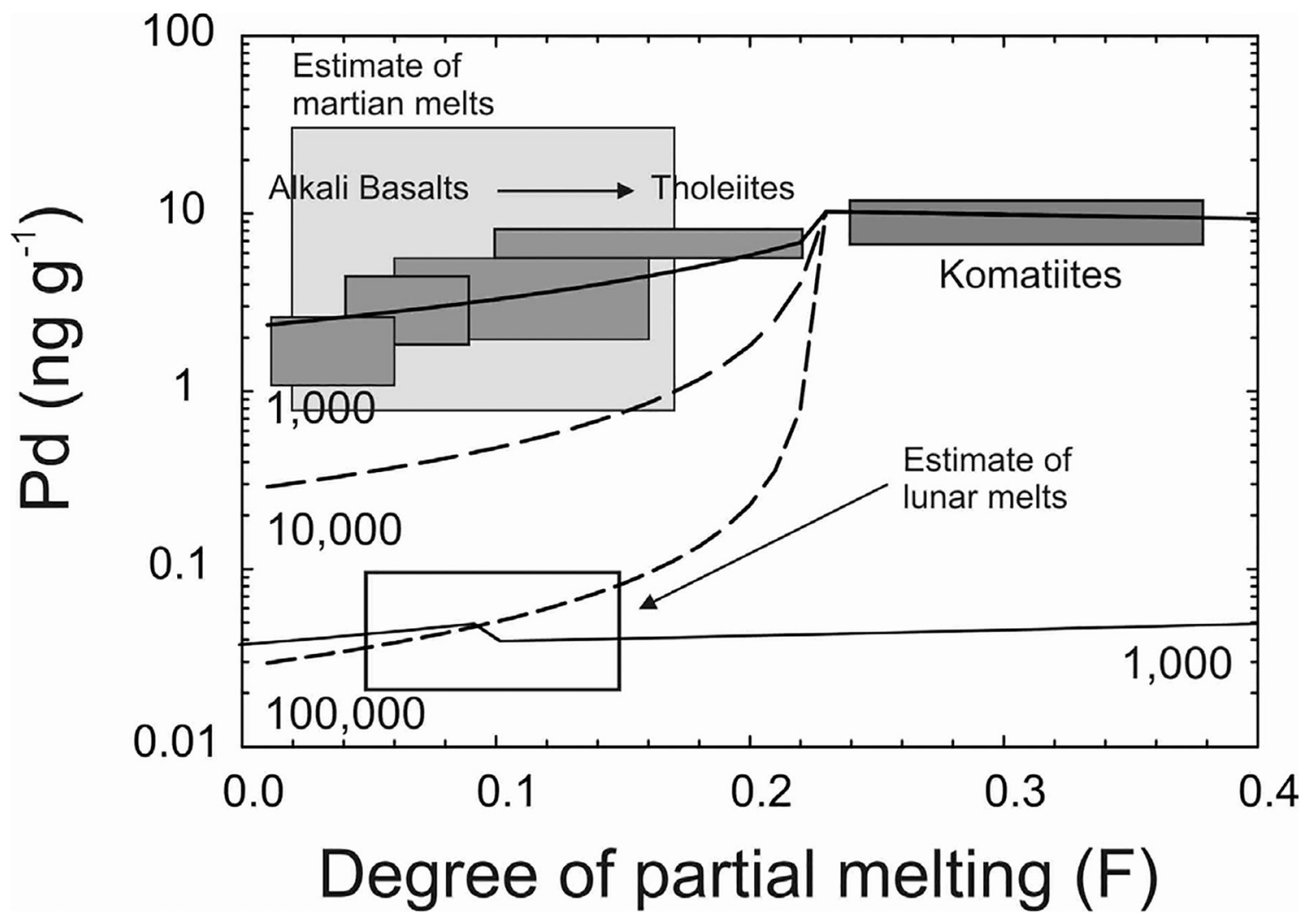

Figure 5.

Melting models for terrestrial Pd concentrations as a function of partial melting $(F)$ for different sulfide-melt partitioning $(1000,10,000,100,000)$ in a columnar melting regime. Terrestrial volcanic rocks ranging from komatiites to tholeiites and alkali basalts are shown as dark gray boxes (from Day 2013). The field of estimated partial melting and Pd concentrations of martian shergottites and lunar mare basalts are from Brandon et al. (2012) and Day and Walker (2015), respectively, with melt contents estimated from shergottites and lunar mare basalts with a range of $\mathrm{MgO}$ contents $(<10$ to $>19 \mathrm{wt}$. \% MgO). The lower solid line is sulfide-melt partitioning assuming a lower $\mathrm{S}$ concentration in the lu nar mantle $(\sim 75$ $\left.\mu \mathrm{g} . \mathrm{g}^{-1}\right)$ relative to the terrestrial or martian mantles $\left(>200 \mu \mathrm{g} . \mathrm{g}^{-1}\right)$ and lower initial mantle source composition (Day and Walker 2015). Palladium is assumed to be perfectly incompatible in silicates and the terrestrial model assumes a primitive mantle Pd composition. 


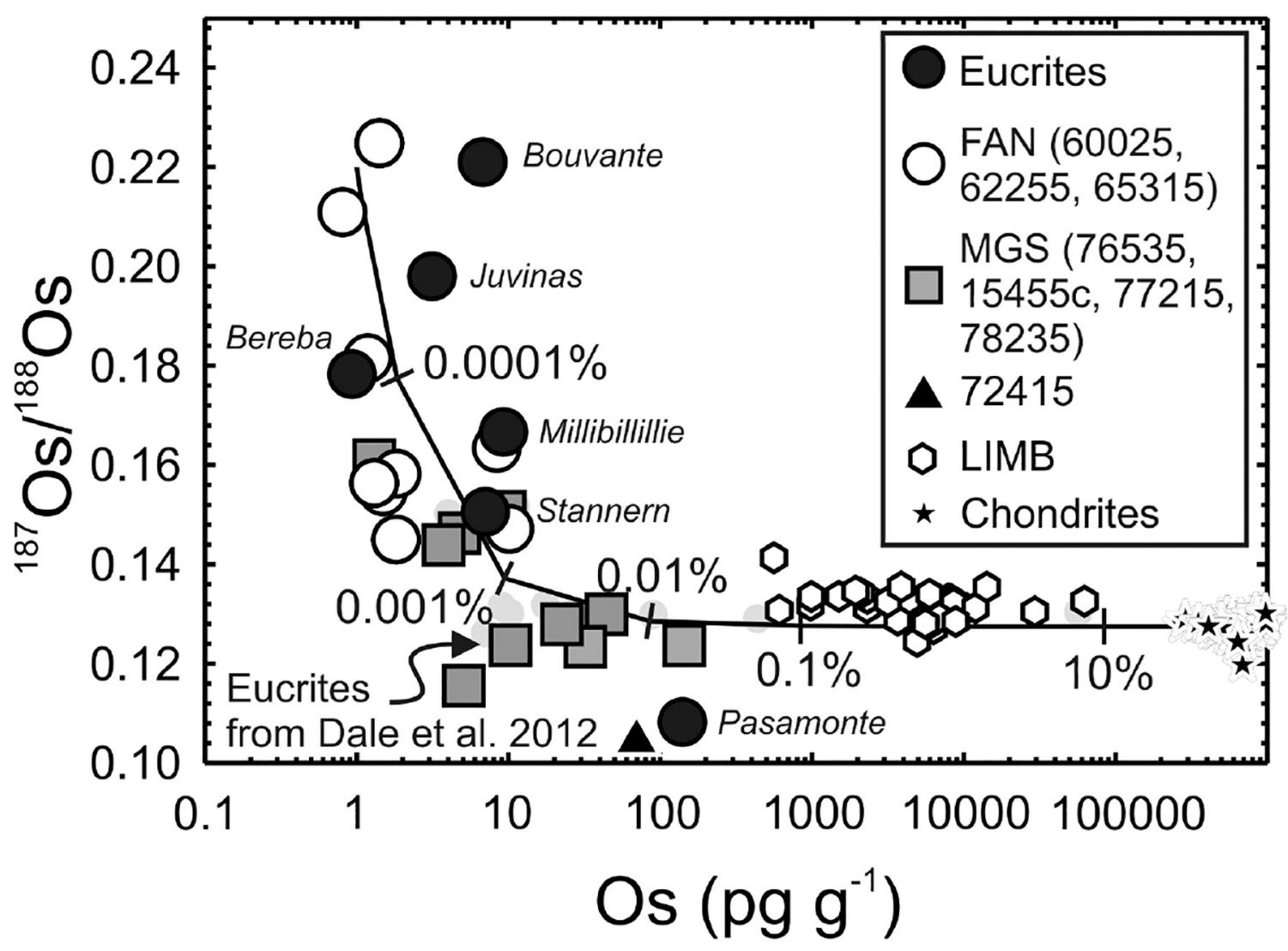

Figure 6.

Os concentration (pg.g ${ }^{-1}$ ) versus ${ }^{187} \mathrm{Os} /{ }^{188}$ Os for lunar pristine crustal rocks, lunar impactmelt breccias (LIMB; Puchtel et al. 2008) and chondrites (Horan et al. 2003) versus data for six eucrite falls (unpublished data of first author) and eucrites from Dale et al. (2012). Curve shows mixing between a hypothetical pristine ferroan anorthosite [FAN] lunar crust composition (represented by large aliquants of Apollo FAN 60025: ${ }^{187} \mathrm{Os} /{ }^{188} \mathrm{Os}=\sim 0.22$; Os $\left.=1 \mathrm{pg} . \mathrm{g}^{-1}\right)$ and average chondrite composition $\left({ }^{187} \mathrm{Os} /{ }^{188} \mathrm{Os}=0.1275 ; \mathrm{Os}=840,000 \mathrm{pg} . \mathrm{g}\right.$

${ }^{-1}$ ). Percentages (by mass) of the chondritic component are labeled. Note that the Os concentration data are logarithmic. Elevated HSE abundances and near-chondritic ${ }^{187} \mathrm{Os} /$ ${ }^{188}$ Os of some magnesian suite [MGS] samples (e.g., 77215, 78235) and Pasamonte, most likely indicate traces of meteoritic contamination. 

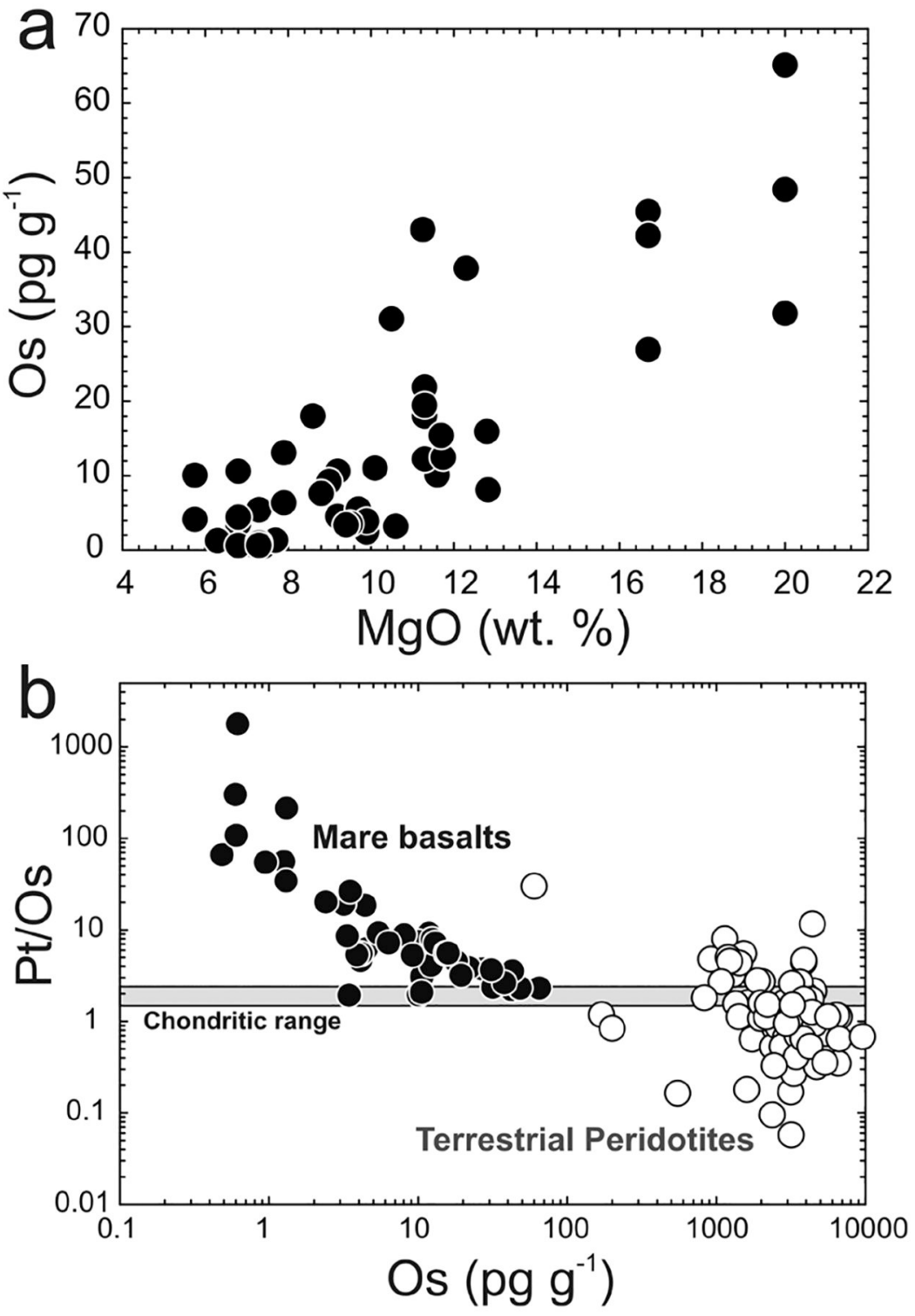

Figure 7.

$\mathrm{MgO}$ regression (a) versus interelement co-variation method (b) for estimating planetary mantle HSE abundances using lunar mare basalts. For $\mathrm{MgO}$ regression, a mantle $\mathrm{MgO}$ value is assumed and correlations of compatible $\mathrm{HSE}$ with $\mathrm{MgO}$ are used to regress to a mantle HSE content. In the interelement co-variation method, ratios of the HSE are plotted versus elemental concentration. Where the regression intercepts the chondritic range it is considered to represent the mantle HSE content. Note the large range in Os concentrations and Pt/Os in terrestrial peridotites (data from Becker et al. 2006; Liu et al. 2009 and references therein). 


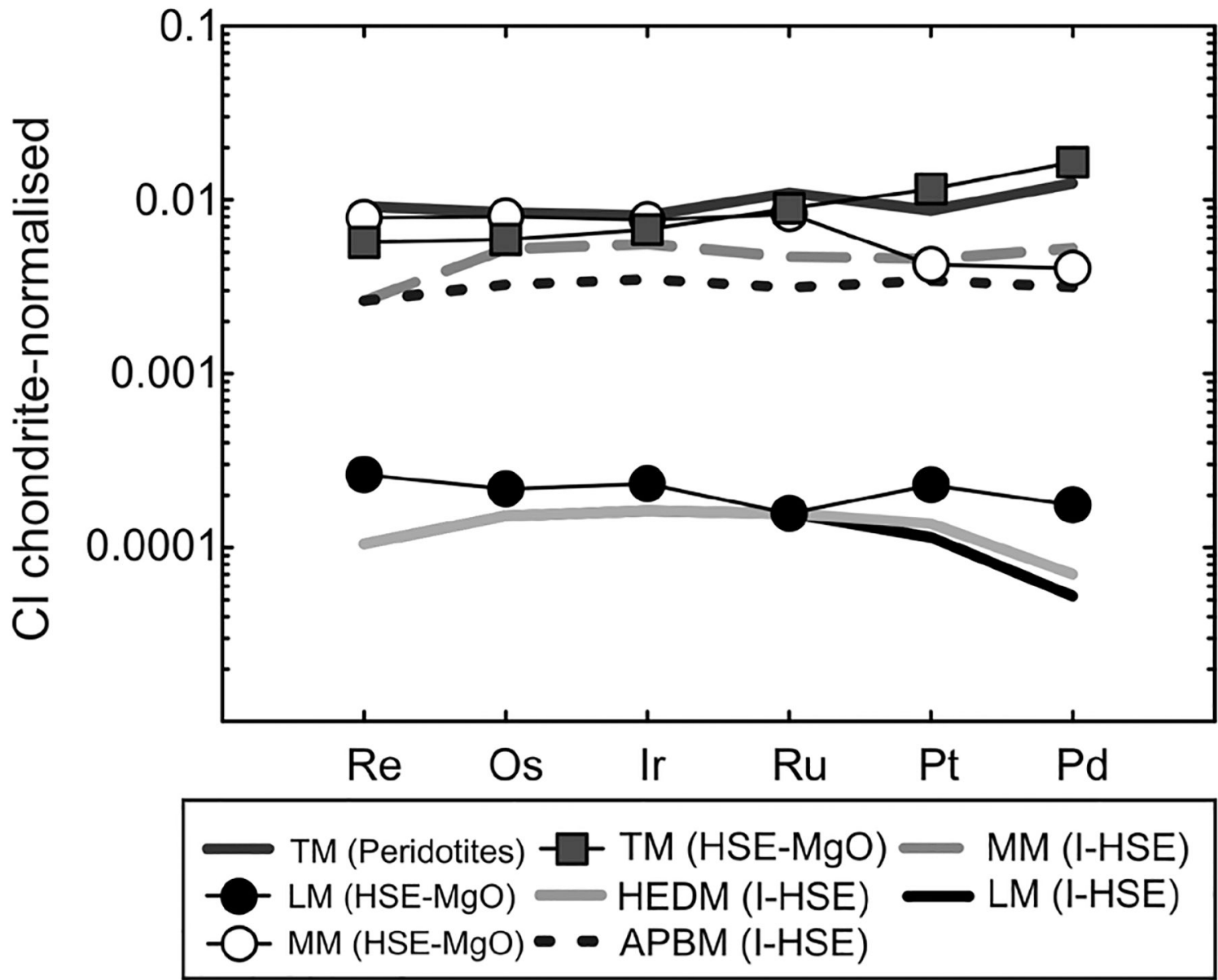

Figure 8.

Comparison of terrestrial mantle (TM) composition established from peridotites versus terrestrial, lunar (LM), martian (MM; I-HSE = dashed gray line), howardite-eucritediogenite (HEDM) and angrite parent body (APBM) mantle estimates based on HSE-MgO or interelement-HSE (I-HSE) covariation from volcanic products. Values are presented in Table 2 or for I-HSE in HEDM and APBM in Dale et al. (2012). HSE-MgO regression data for the APBM or HEDM are not presented due to the wide range in HSE contents for the meteorite suites, which indicate that further information is required prior to interpreting possible mantle HSE abundances for these bodies. 

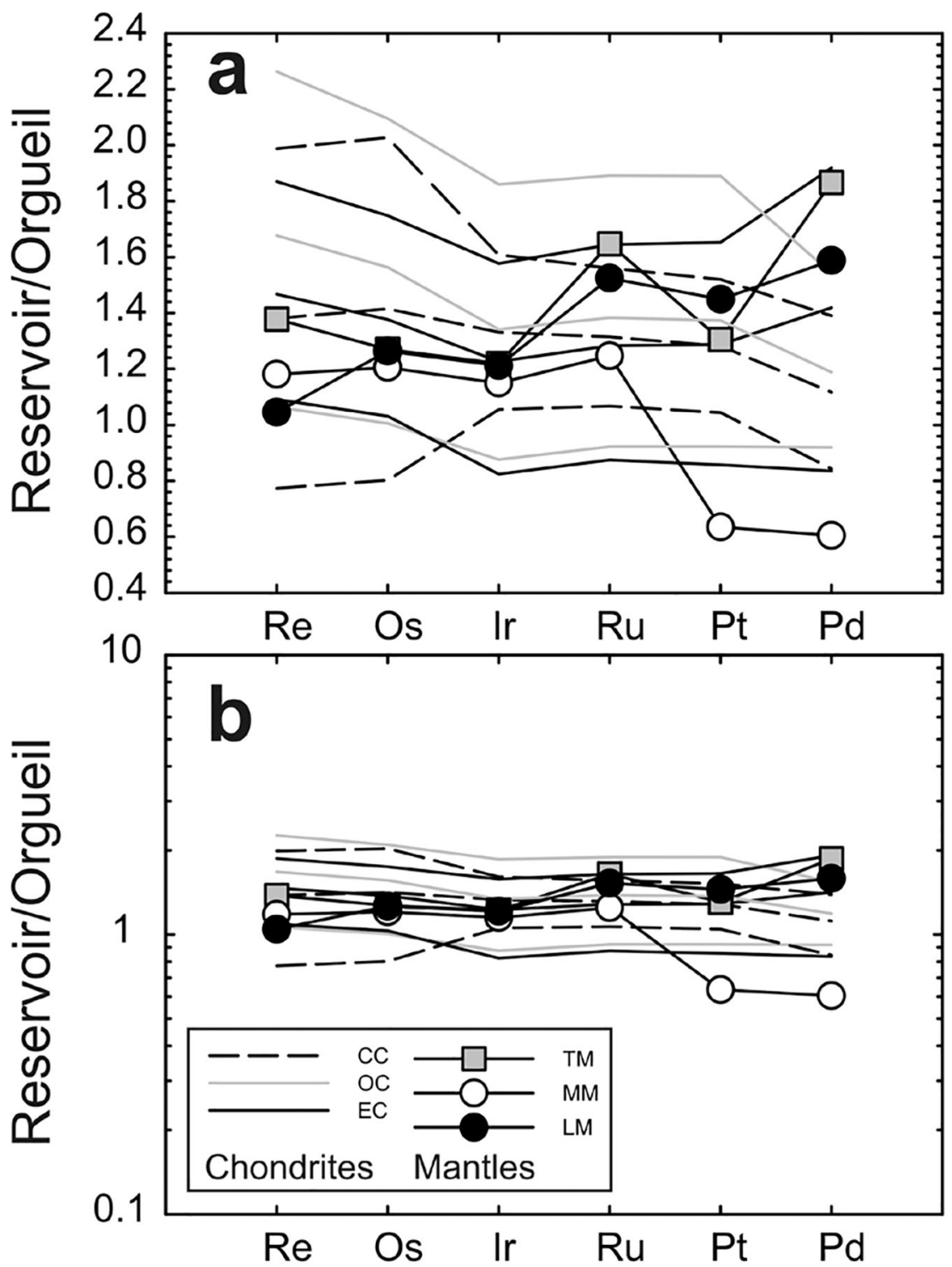

Figure 9.

Plots of average, minimum (lower lines) and maximum (upper lines) HSE abundances for carbonaceous (CC), ordinary (OC) and enstatite (EC) chondrites versus mantle estimates for Earth $(\times 150 ;$ TM), Mars $(\times 150 ;$ MM) and the Moon $(\times 6000 ; \mathrm{LM})$. Data are plotted with a linear $Y$-axis in (a) and a logarithmic $Y$-axis in (b). The mantles of Earth, Mars and the Moon have broadly or nearly chondritic relative abundances of the HSE. Chondrite compilation is given in Table 3 and Earth, Mars and Moon mantle HSE abundances are from Becker et al. (2006), Day (2013) and Day et al. (2007) and are provided in Table 2. Orgueil values (CI-chondrite composition) from Horan et al. (2003). 

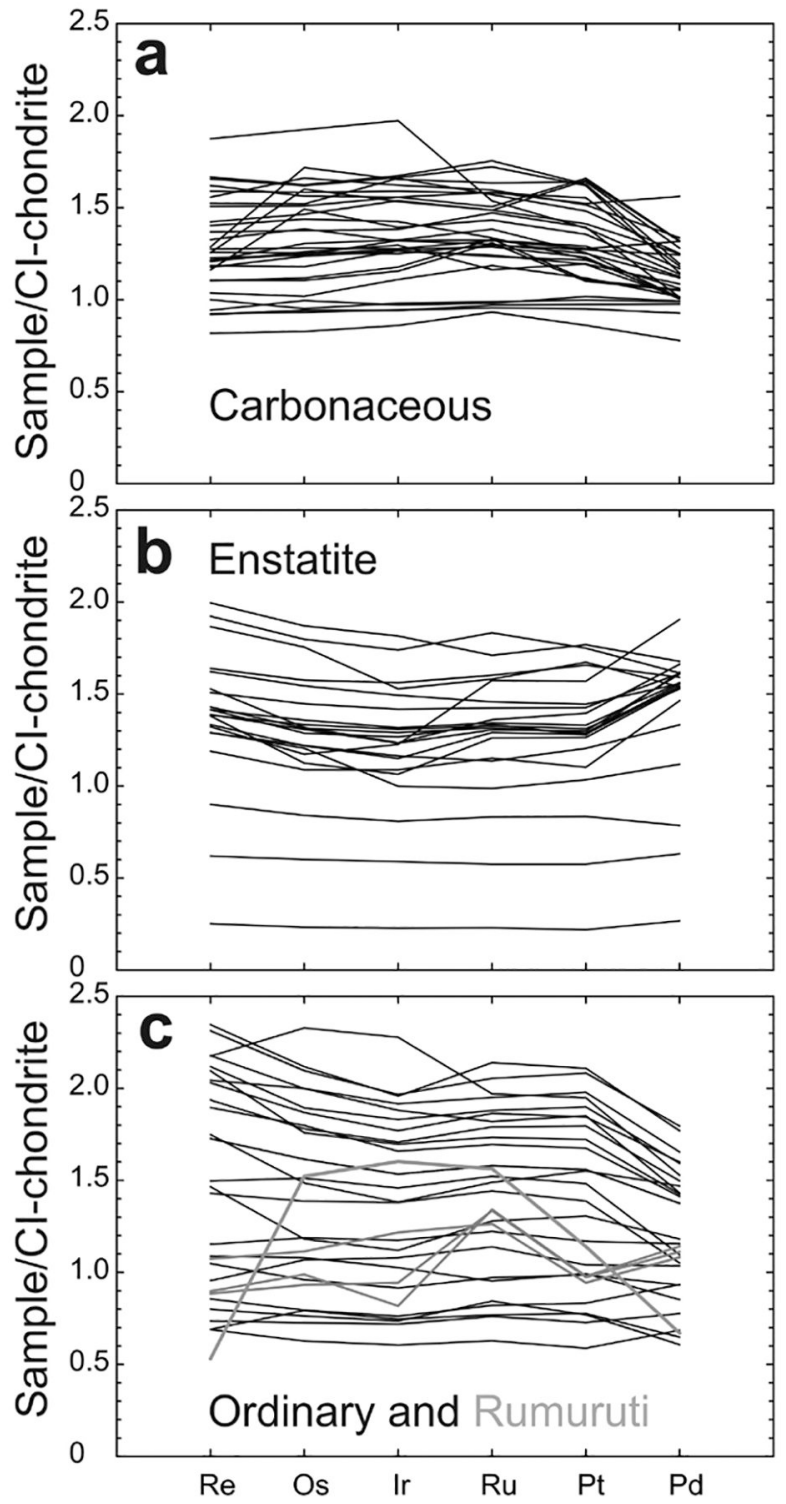

Figure 10.

CI-chondrite normalized plots of (a) Carbonaceous, (b) Enstatite and (c) Ordinary and Rumuruti chondrites. Rumuruti chondrites are sufficiently different from all other classes of chondrite, that they have been suggested to represent a new class (e.g., Brearley and Jones 1998). Data from Horan et al. (2003), Brandon et al. (2005a), Fischer-Gödde et al. (2010) and van Acken et al. (2011) and CI-chondrite normalization to Orgueil is provided in Table 3. 

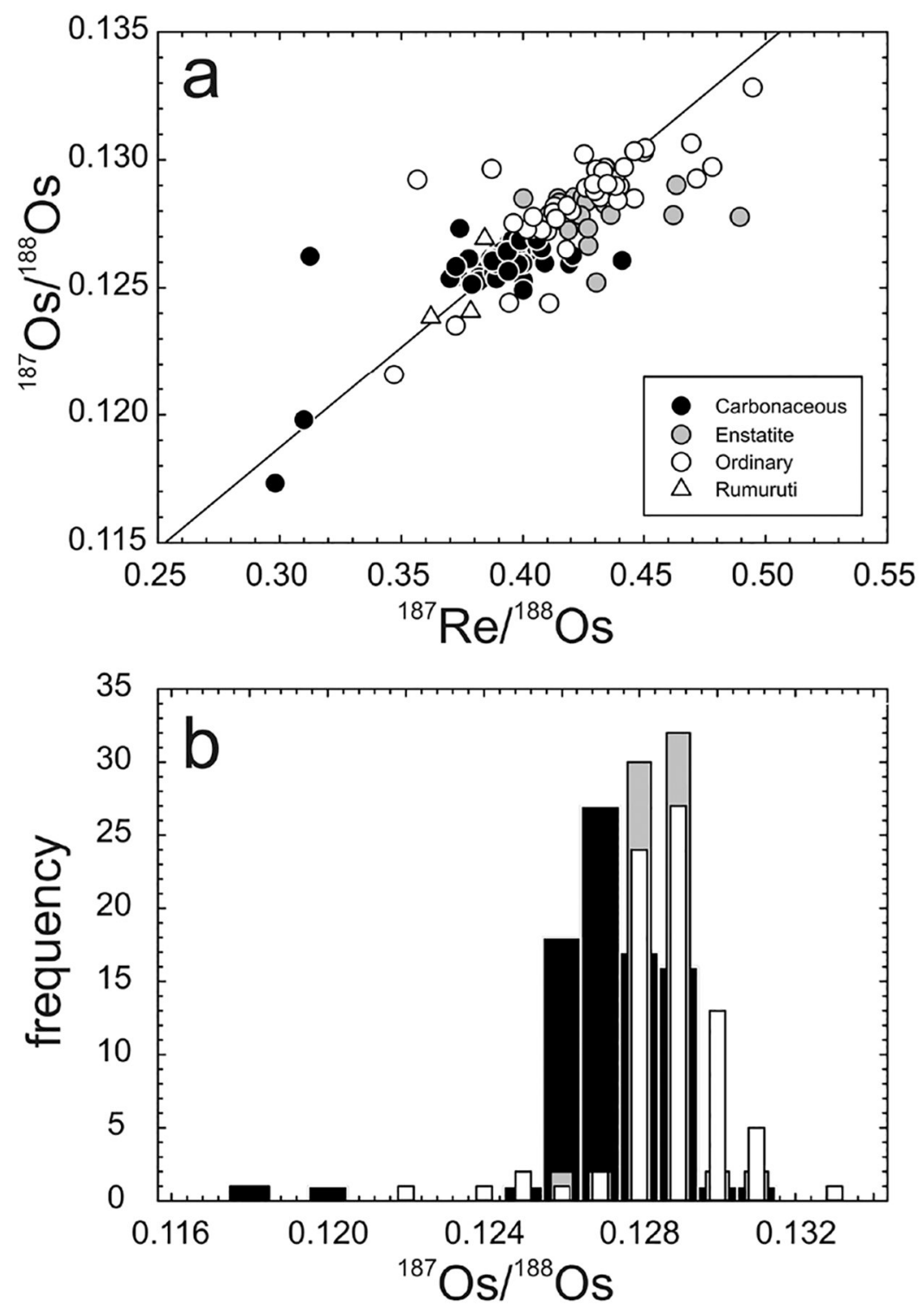

Figure 11.

Plots of (a) ${ }^{187} \mathrm{Re} /{ }^{188}$ Os versus ${ }^{187} \mathrm{Os} /{ }^{188}$ Os and (b) ${ }^{187} \mathrm{Os} /{ }^{188}$ Os versus frequency for carbonaceous, enstatite, ordinary and rumuruti chondrites. Shown in (a) is a $4568 \mathrm{Ma}$ primordial isochron using IIIAB iron meteorite data from Smoliar et al. (1996). Bar colors in (b) correspond to symbol colors in (a). Measured ${ }^{187} \mathrm{Os} /{ }^{188}$ Os for carbonaceous chondrites averages $0.1262 \pm 0.0005$ (excluding Karoonda), and ordinary and enstatite chondrites average $0.1284 \pm 0.0020$ and $0.1280 \pm 0.0008$, respectively ( $1 \sigma$ standard deviations $)$. Data are from Walker et al. (2002), Fischer-Gödde et al. (2010) and Brandon et al. (2005a). 


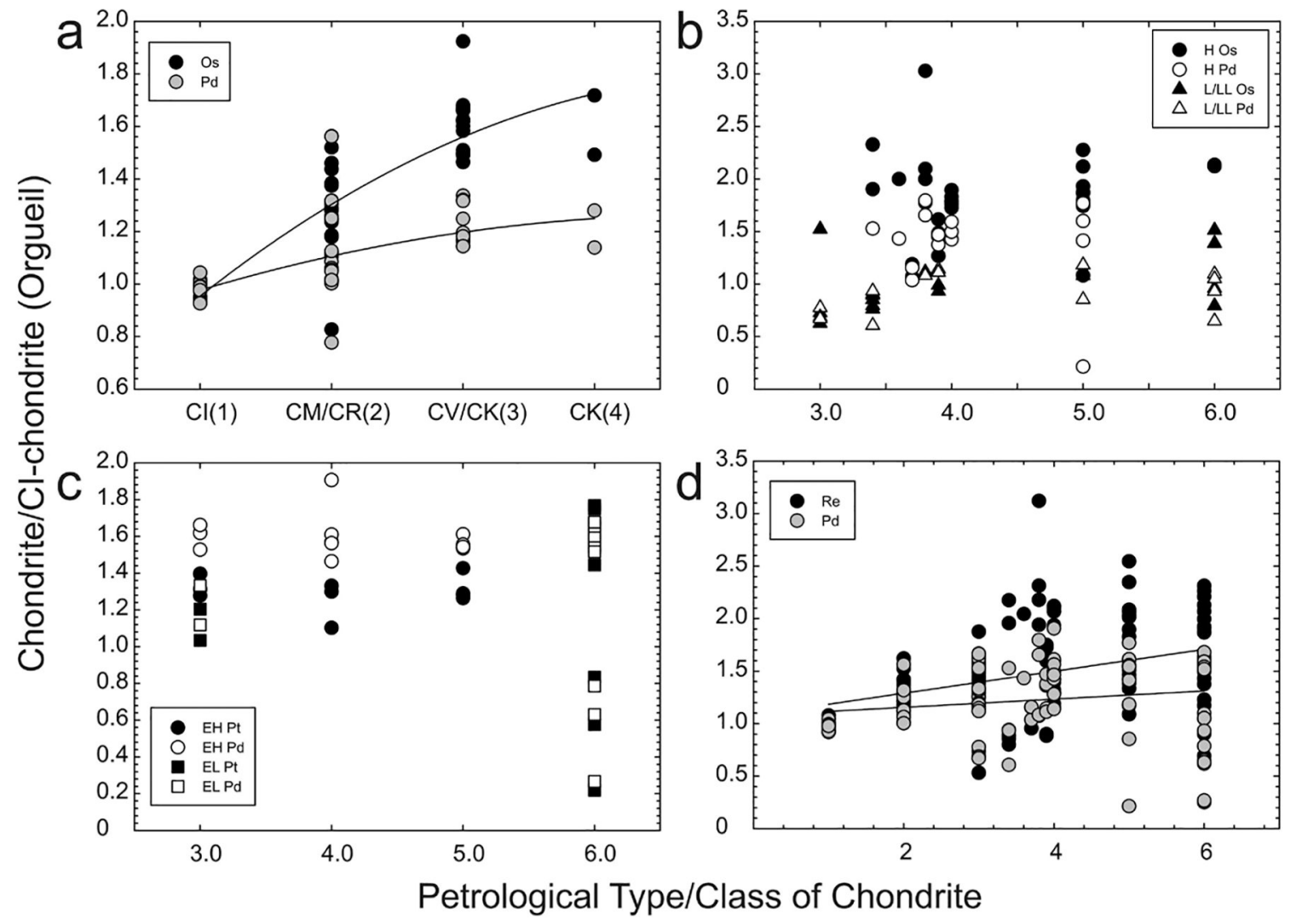

Figure 12.

Plots of normalized HSE abundances versus petrological type in each class of chondrite (a), (b), and (c) and for all chondrites solely as a function of petrological type (d). Lines in (a) and (d) are linear regressions of the HSE data plotted. Data are from Horan et al. (2003), Brandon et al. (2005a), and Fischer-Gödde et al. (2010). Petrological type/grade defined in Table 4. 

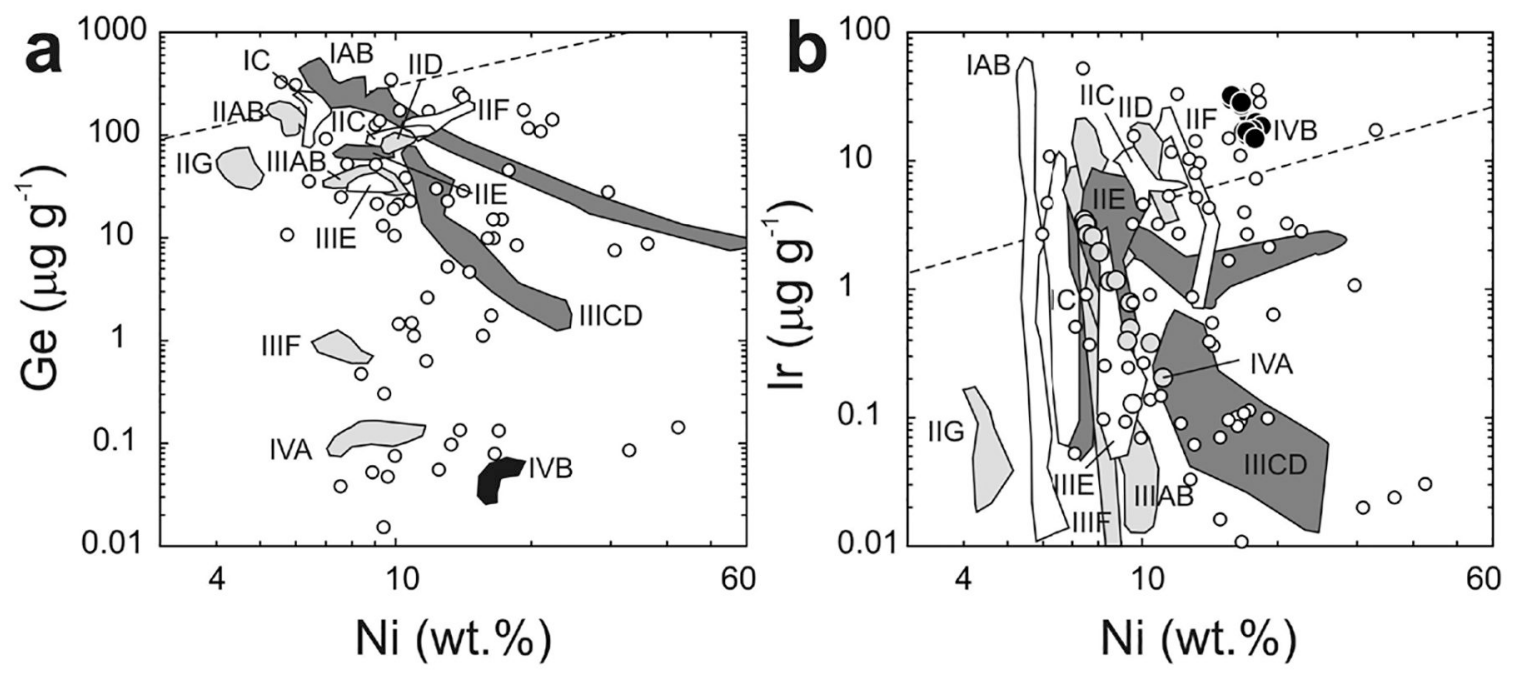

Figure 13.

Logarithmic plots of (a) germanium and (b) iridium versus nickel content for bulk compositions of all iron meteorites. The 'non-magmatic' iron groups (IAB, IIICD and IIE) are shown in dark gray. IVB irons are shown as black circles or a black shaded region and IVA irons are shown as a gray shaded region or gray circles in the plots and these samples are plotted in Figure 13. Other shading is used to distinguish iron meteorite groups and unfilled circles are ungrouped iron meteorites. Dashed lines denote the CI-chondrite ratios. Data are reported in Walker et al. (2008), Goldstein et al. (2009), McCoy et al. (2011) and references therein. 

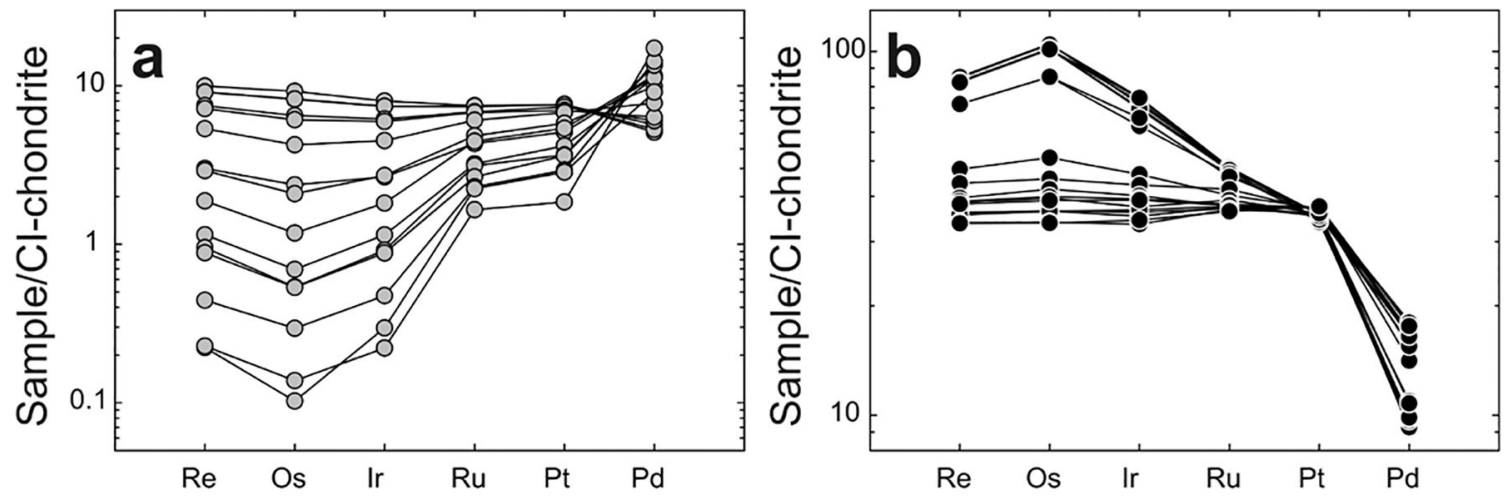

Figure 14.

CI-chondrite normalized abundances of the HSE for (a) IVA and (b) IVB iron meteorites. For both IVA and IVB irons, Ni contents generally increase with decreasing Re, Os, Ir, and Ru. Note differences in scale. Data from Walker et al. (2008) and McCoy et al. (2011). 

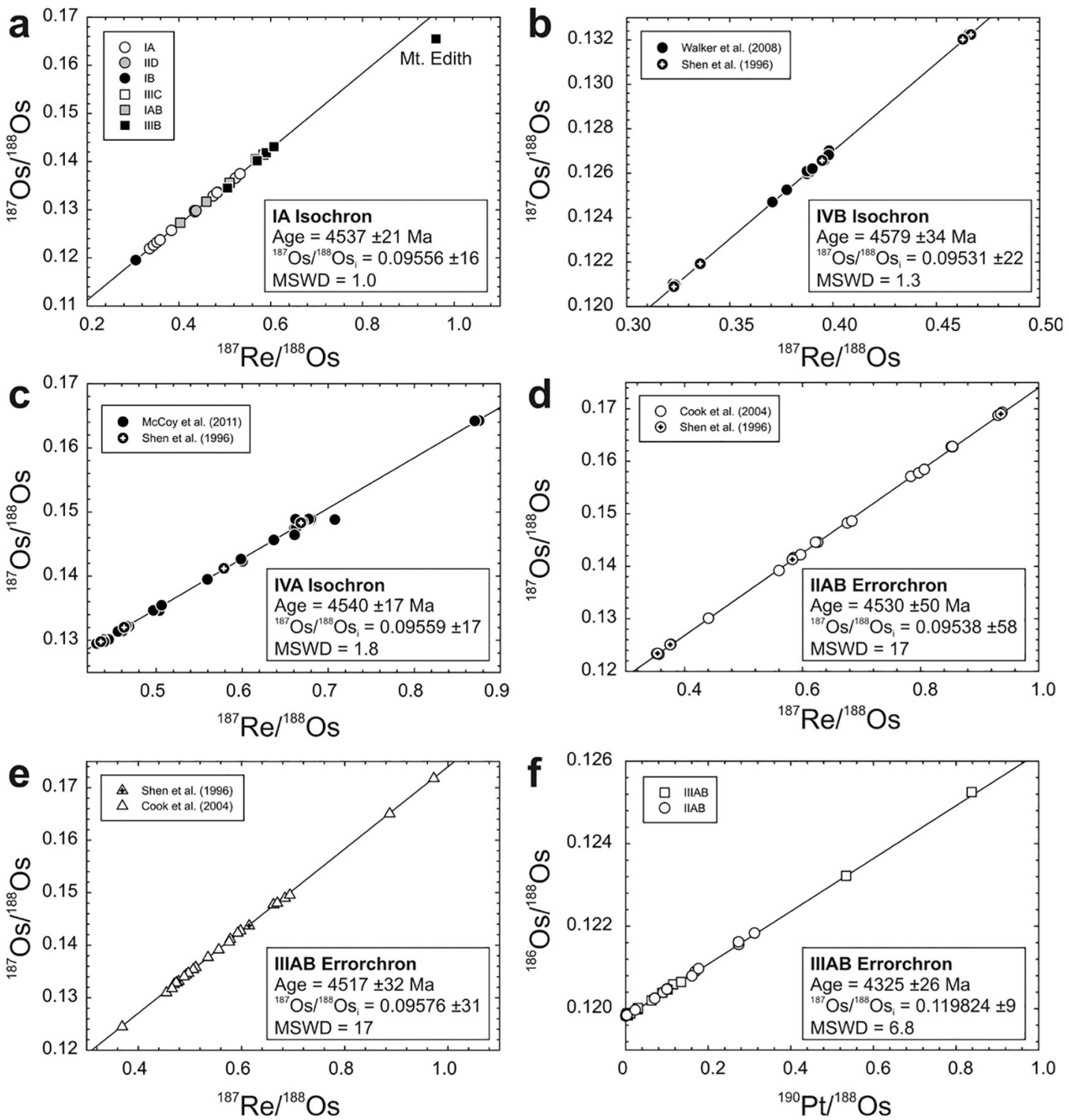

Figure 15.

${ }^{187} \mathrm{Re} /{ }^{188}$ Os versus ${ }^{187} \mathrm{Os} /{ }^{188}$ Os diagrams for (a) IA, IID, IB, IIIC, IAB, IIIAB, (b) IVB, (c) IVA, (d) IIAB and (e) IIIAB iron meteorites and ${ }^{190} \mathrm{Pt} /{ }^{188}$ Os versus ${ }^{186} \mathrm{Os} /{ }^{188} \mathrm{Os}$ diagram for (f) IIAB and IIIAB iron meteorites. Data and iso-/error-chrons are from Shen et al. (1996), Horan et al. (1998), Chen et al. (2002), Cook et al. (2004), Walker et al. (2008) and McCoy et al. (2011). 

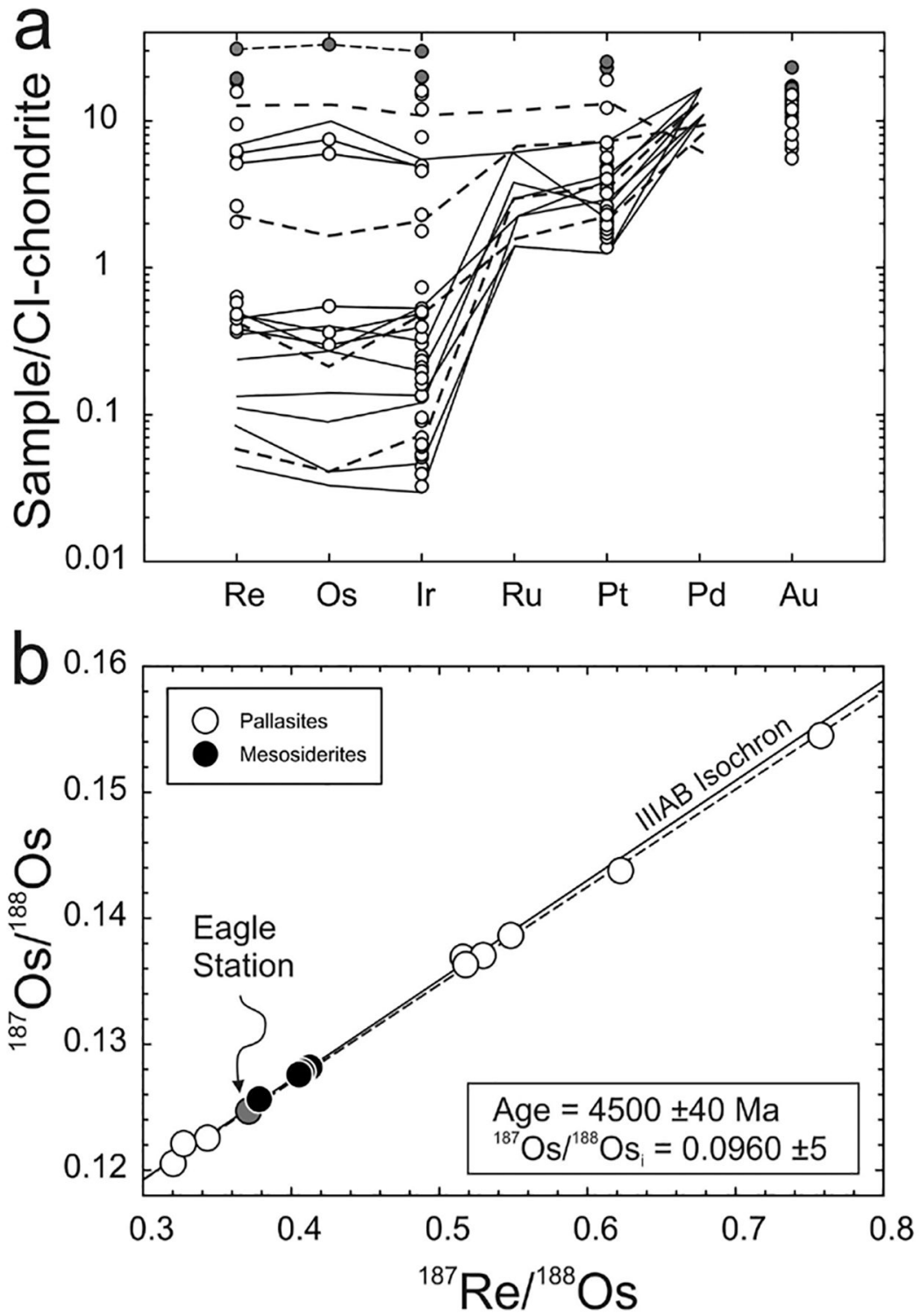

Figure 16.

The stony-iron meteorites. (a) CI-chondrite normalized HSE abundances for pallasites from Wasson and Choi (2003; unfilled circles) and Lee et al. (2006; lines) and (b) ${ }^{187} \mathrm{Re}^{188} \mathrm{Os}$ versus ${ }^{187} \mathrm{Os} /{ }^{188} \mathrm{Os}$ for pallasites and mesosiderites from Shen et al. (1998) and Chen et al. (2002). Shown in (b) is the IIIAB isochron (solid line, from Smoliar et al. 1996) and the best-fit slope for pallasites (dashed line) from Chen et al. (2002), along with calculated age and initial Os isotope composition. Dashed lines and gray symbols in (a) denote EagleStation, or anomalous metal pallasites (please refer to text). 

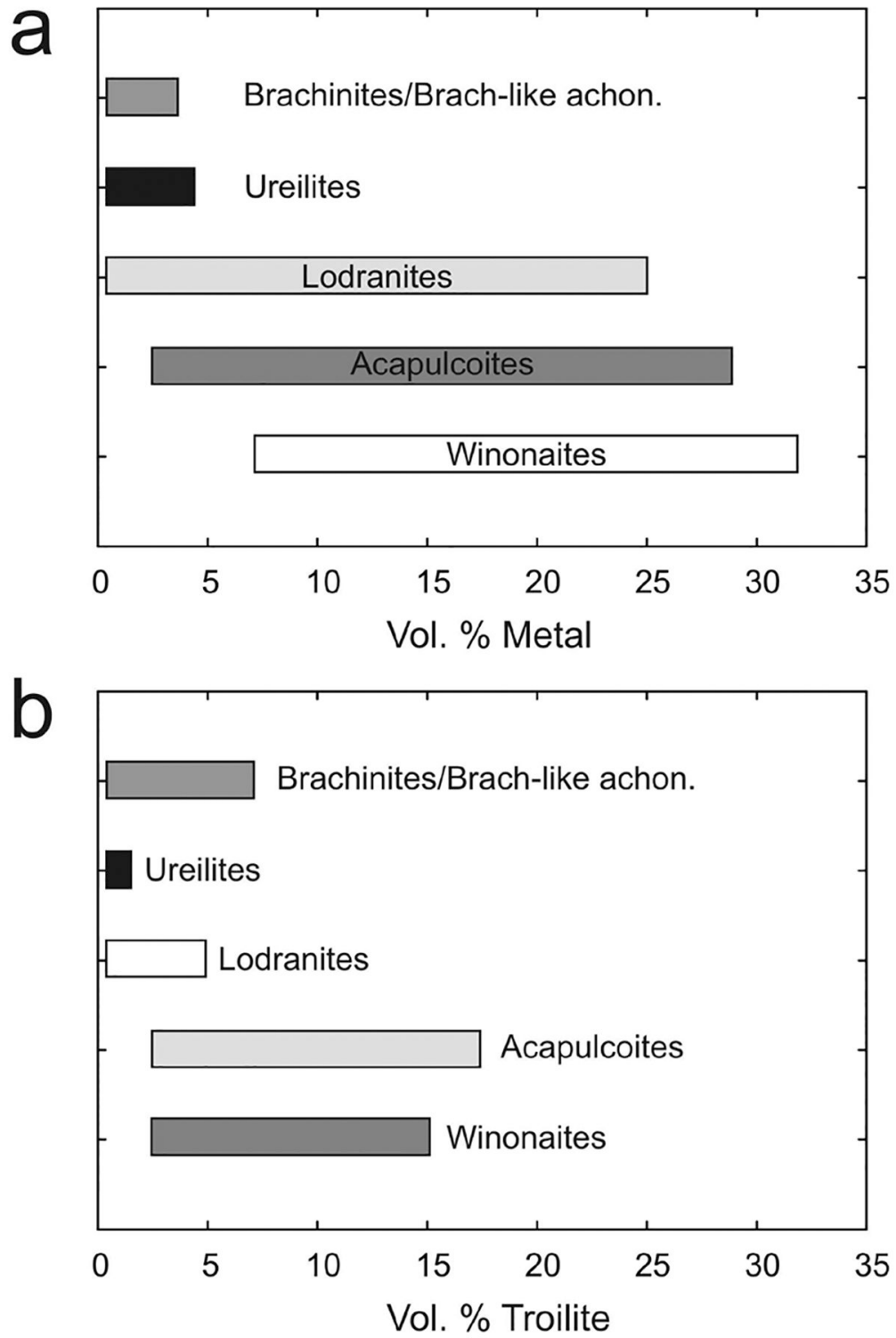

Figure 17.

Metal and sulfide loss in some dominantly silicate-bearing partially-melted achondrite meteorites as a function of increasing degrees of partial melting. The effect of increased partial melting led to the generation of efficient metal melt networks and the segregation of metal and sulfide from silicate. Winonaites can be interpreted as metamorphosed meteorites with chondritic bulk compositions (no partial melting) and brachinites represent residues after approximately 13 to $30 \%$ partial melting. (a) is modified from Day (2015). Sources of data: Nehru et al. (1983); Warren and Kallemeyn 1989; Takeda et al. (19940; Papike et al. (1995); McCoy et al. (1996); Mittlefehldt et al. (1998, 2003); Goodrich et al. (2011) and references therein. 

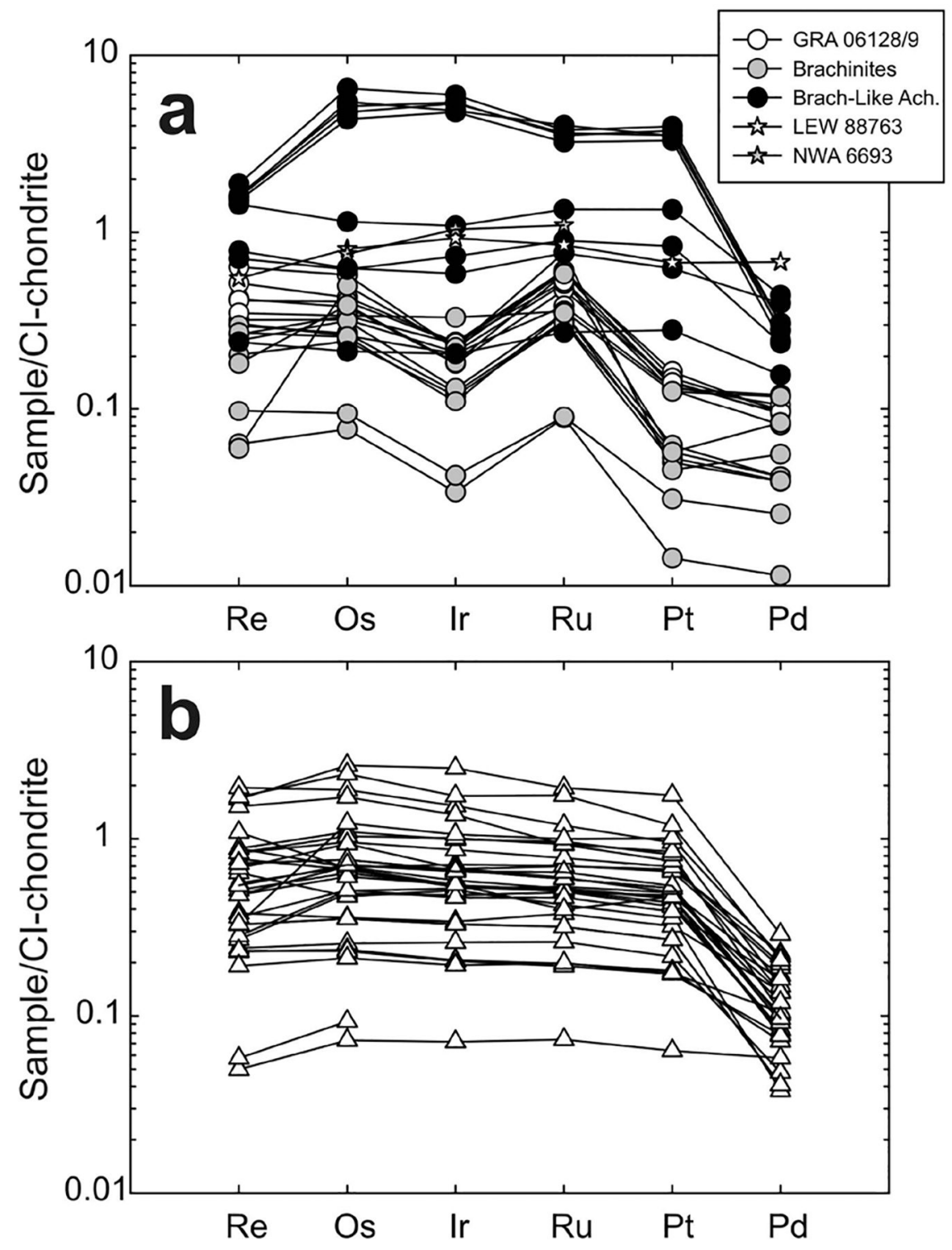

Figure 18.

CI-chondrite normalized HSE abundances for (a) GRA 06128/9, brachinites, brachinite-like achondrites, LEW 88676 and NWA 6693 and (b) for ureilites. Data from Rankenburg et al. (2008), Day et al. (2009, 2012a, 2015) and Warren et al. (2013). 


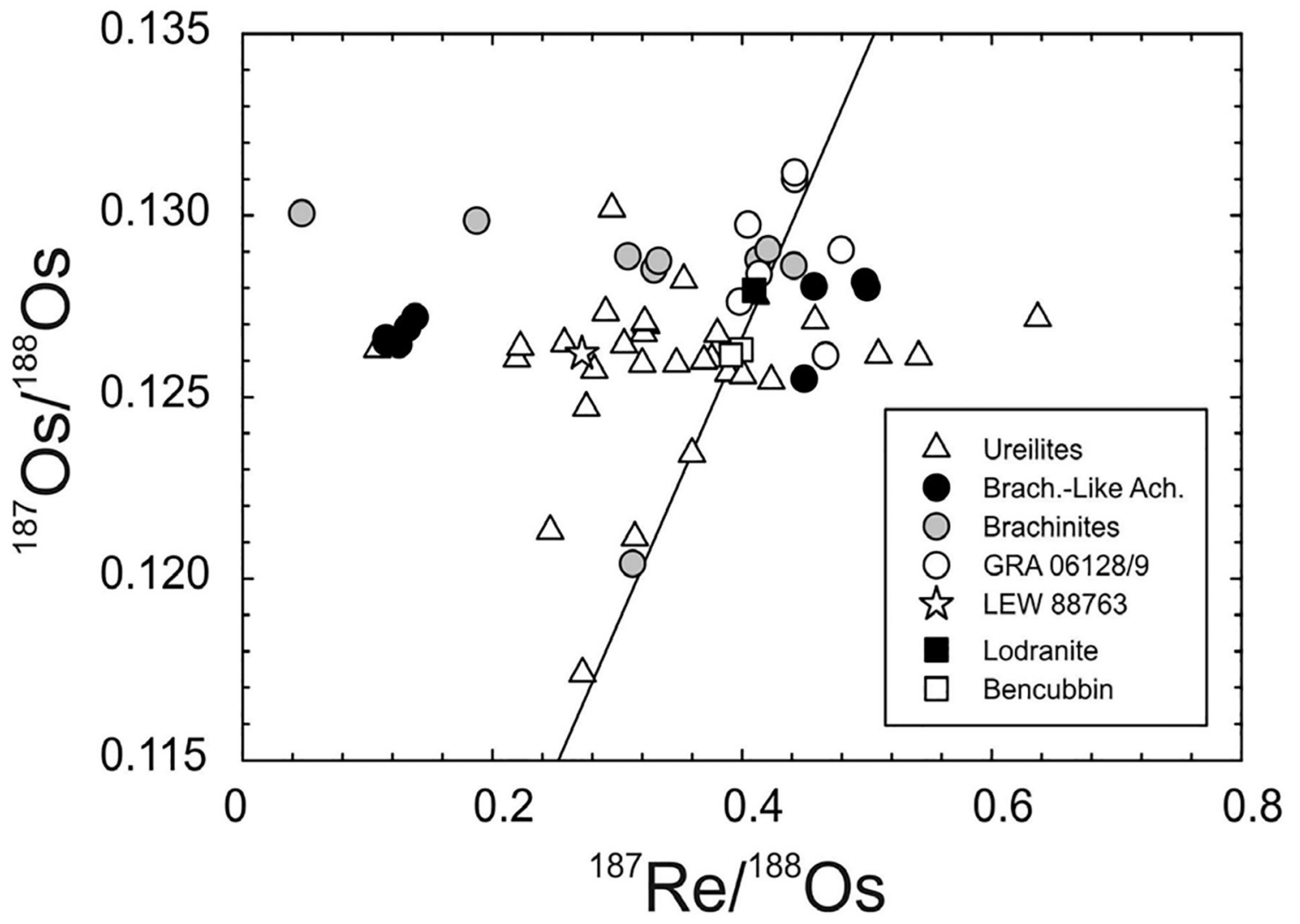

Figure 19.

${ }^{187} \mathrm{Re} /{ }^{188}$ Os versus ${ }^{187} \mathrm{Os} /{ }^{188}$ Os diagram for primitive achondrites. Data from Shen et al. (1998), Walker et al. (2002), Rankenburg et al. (2008) and Day et al. (2009, 2012a, 2015b). Shown is the $4.568 \mathrm{Ga}$ IIIAB iron isochron from Smoliar et al. (1996). 

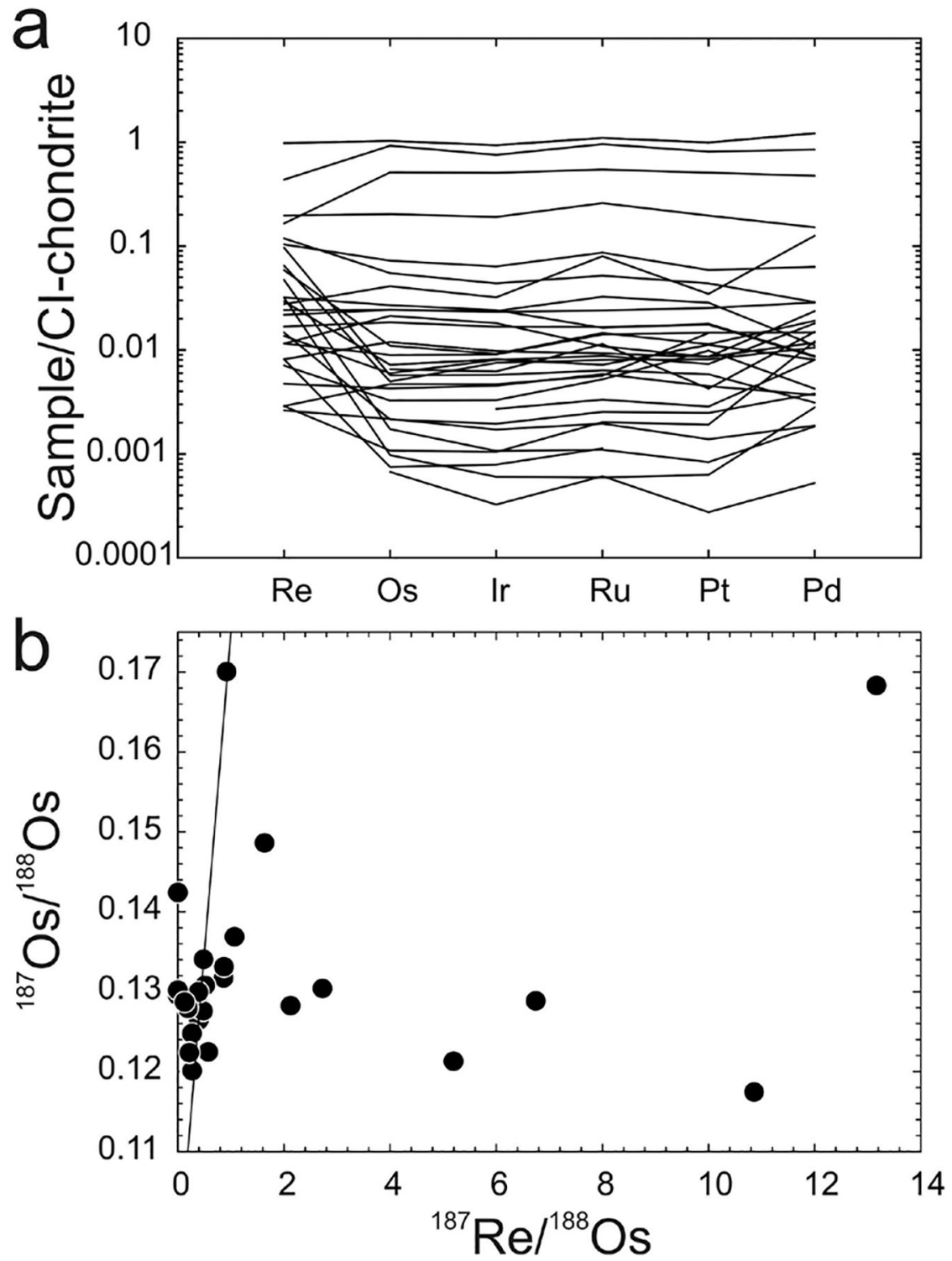

Figure 20.

(a) CI-chondrite normalized HSE abundances and (b) ${ }^{187} \mathrm{Re} /{ }^{188}$ Os versus ${ }^{187} \mathrm{Os} /{ }^{188} \mathrm{Os}$ for aubrite meteorites. Data from van Acken et al. (2012). Shown in (b) is the 4.568 Ga IIIAB iron isochron from Smoliar et al. (1996). 

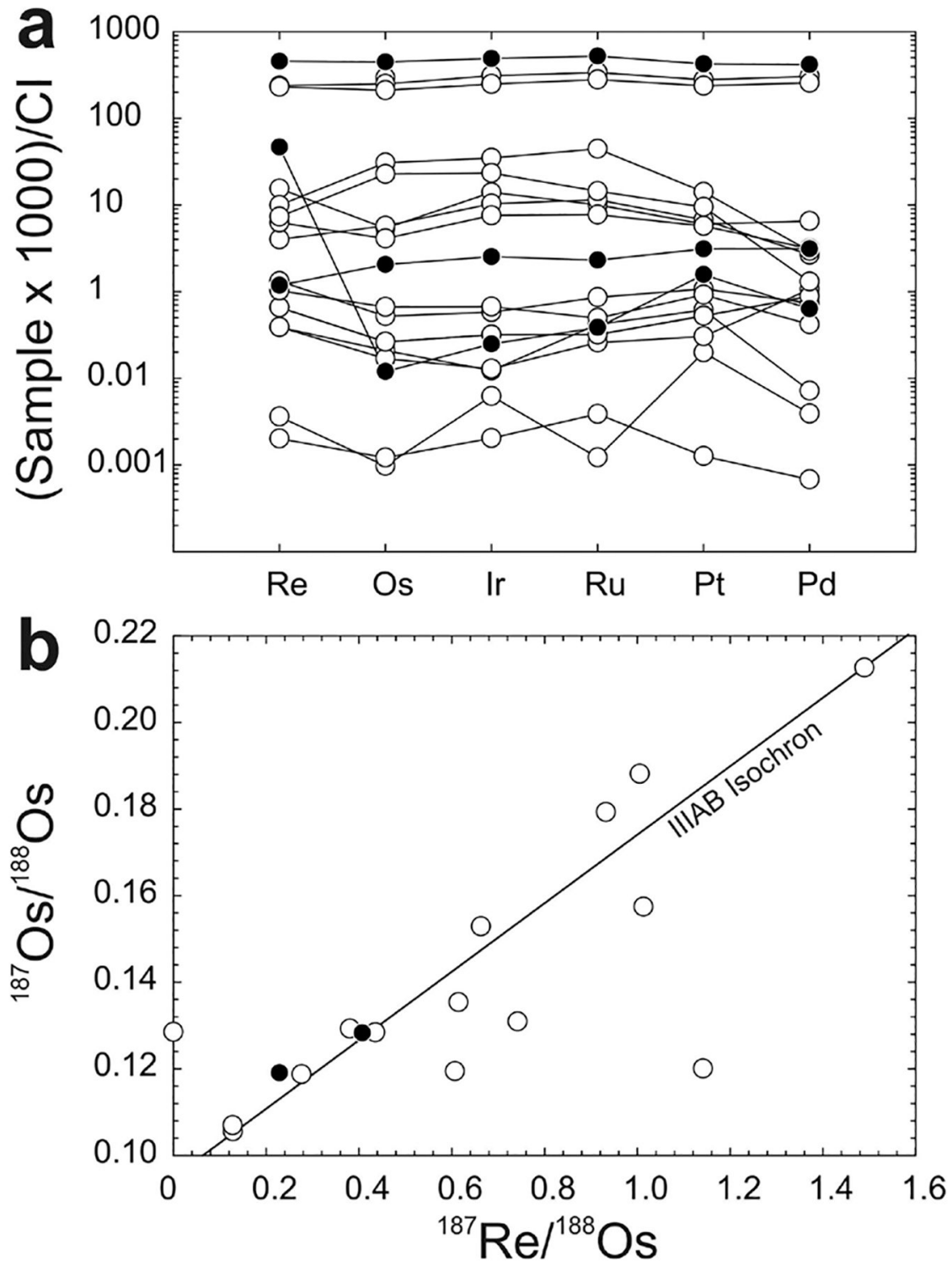

Figure 21.

(a) CI-chondrite normalized HSE abundances and (b) ${ }^{187} \mathrm{Re} /{ }^{188}$ Os versus ${ }^{187} \mathrm{Os} /{ }^{188} \mathrm{Os}$ for angrite meteorites. Data from Riches et al. (2012; unfilled circles) and Dale et al. (2012; filled circles). Shown in (b) is the 4.568 Ga IIIAB iron isochron from Smoliar et al. (1996). 

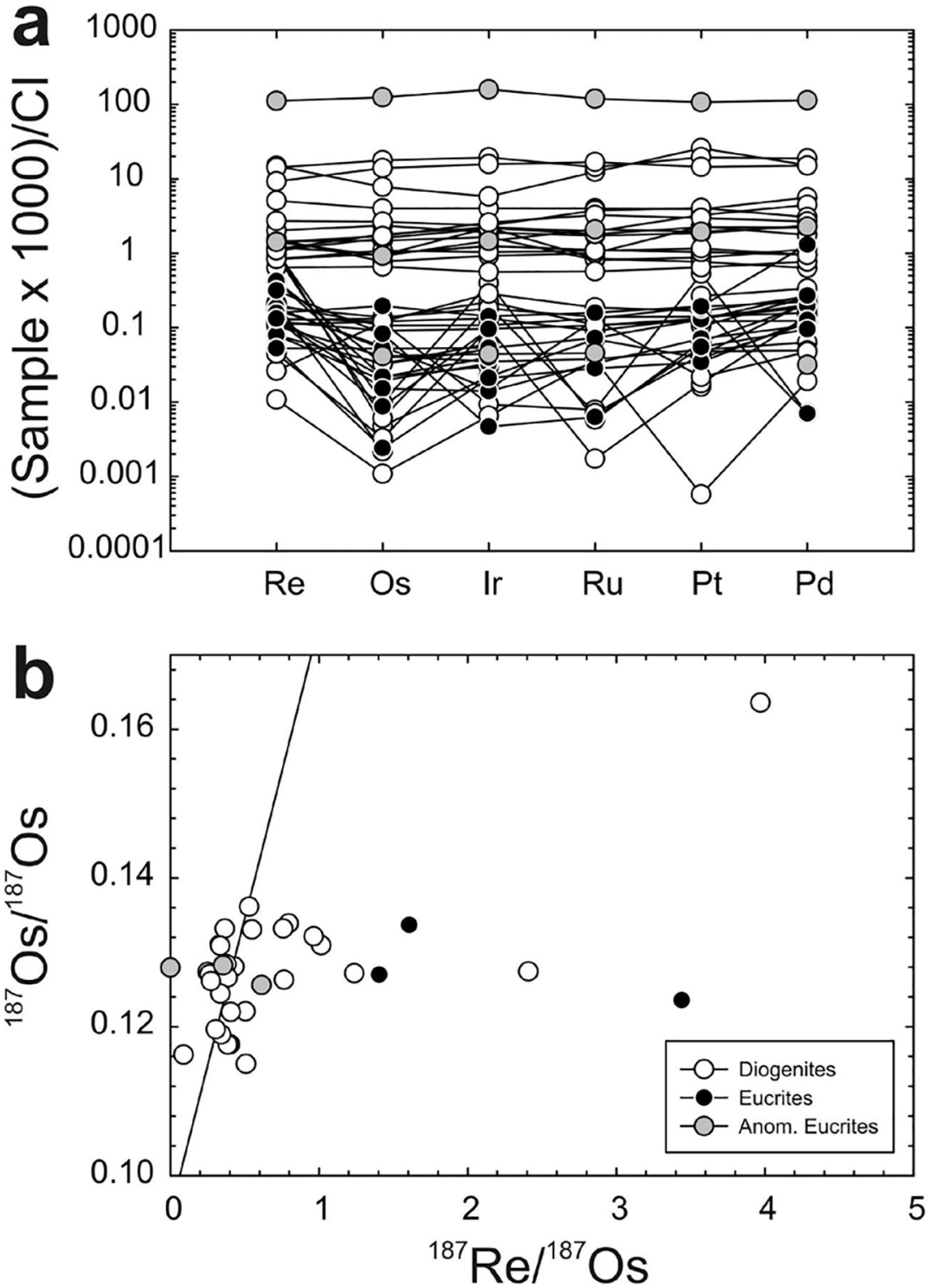

Figure 22.

(a) CI-chondrite normalized HSE abundances and (b) ${ }^{187} \mathrm{Re} /{ }^{188}$ Os versus ${ }^{187} \mathrm{Os} /{ }^{188}$ Os for eucrite and diogenite meteorites. Data from Day et al. (2012a) and Dale et al. (2012). Shown in (b) is the $4.568 \mathrm{Ga}$ IIIAB iron isochron from Smoliar et al. (1996). The highest HSE contents have been measured in anomalous eucrite, Dho 007. 

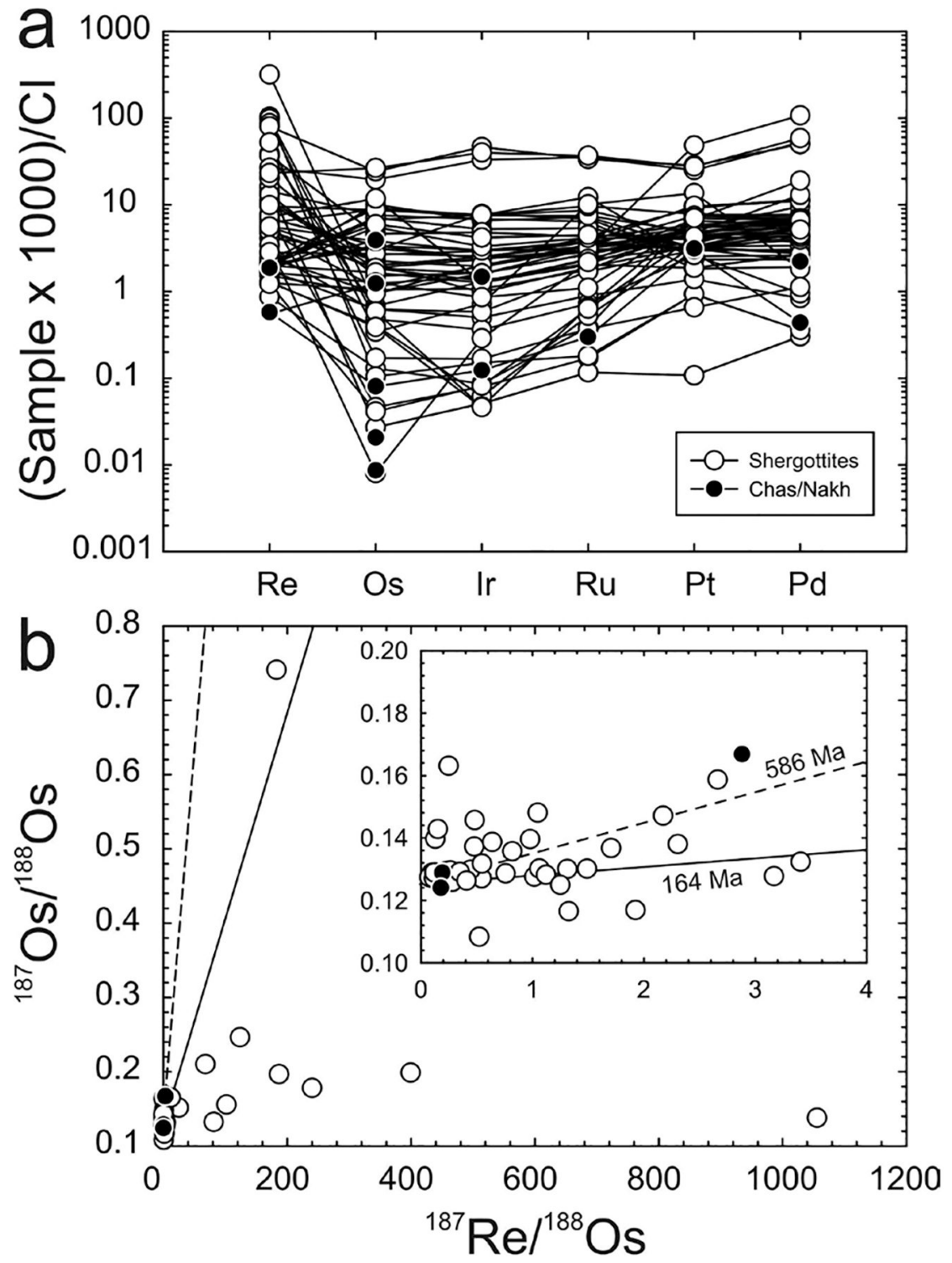

Figure 23.

(a) CI-chondrite normalized HSE abundances and (b) ${ }^{187} \mathrm{Re} /{ }^{188}$ Os versus ${ }^{187} \mathrm{Os} /{ }^{188}$ Os for martian meteorites. Isochrons in (b) are at $586 \mathrm{Ma}$ and $164 \mathrm{Ma}$, with the $164 \mathrm{Ma}$ age originating from an errorchron age of $164 \pm 12 \mathrm{Ma}\left({ }^{187} \mathrm{Os} /{ }^{188} \mathrm{Os}_{\mathrm{i}}=0.12516 \pm 18\right.$; MSWD $=$ 2.7) from EETA 79002 (Brandon et al. 2012). Data from Riches et al. (2011), Brandon et al. (2012), Dale et al. (2012) and Filiberto et al. (2012). 


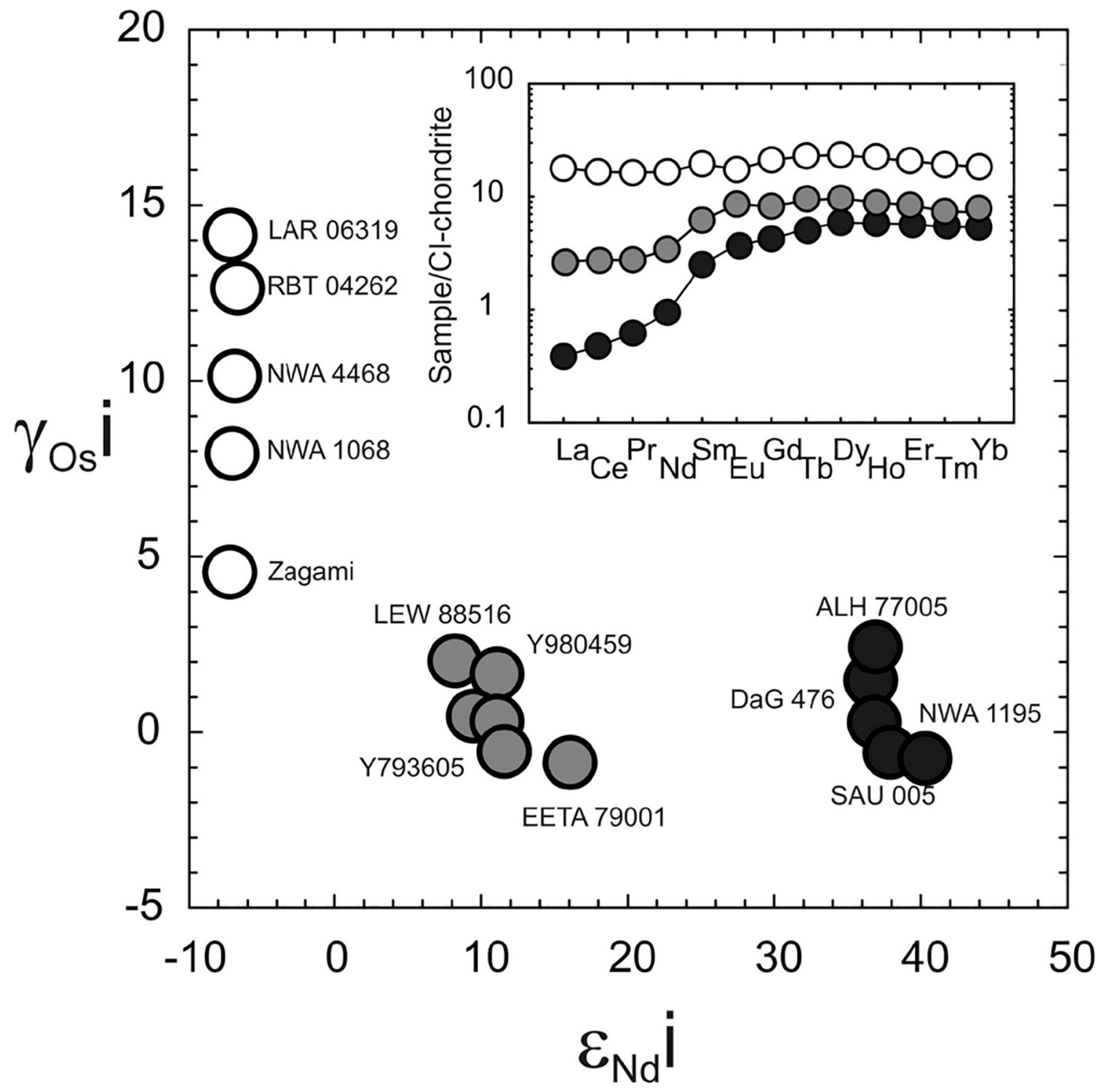

Figure 24.

The $\varepsilon_{\mathrm{Nd}} \mathrm{i}$ versus $\gamma_{\mathrm{Os}} \mathrm{i}$ for enriched (unfilled circles), intermediate (gray circles) and depleted (black circles) shergottites that have been screened for alteration. Inset figure shows examples of enriched, intermediate and depleted shergottite rare earth element abundances normalized to CI-chondrite. Sources for Os and $\mathrm{Nd}$ isotope data are given in Brandon et al. (2012). 


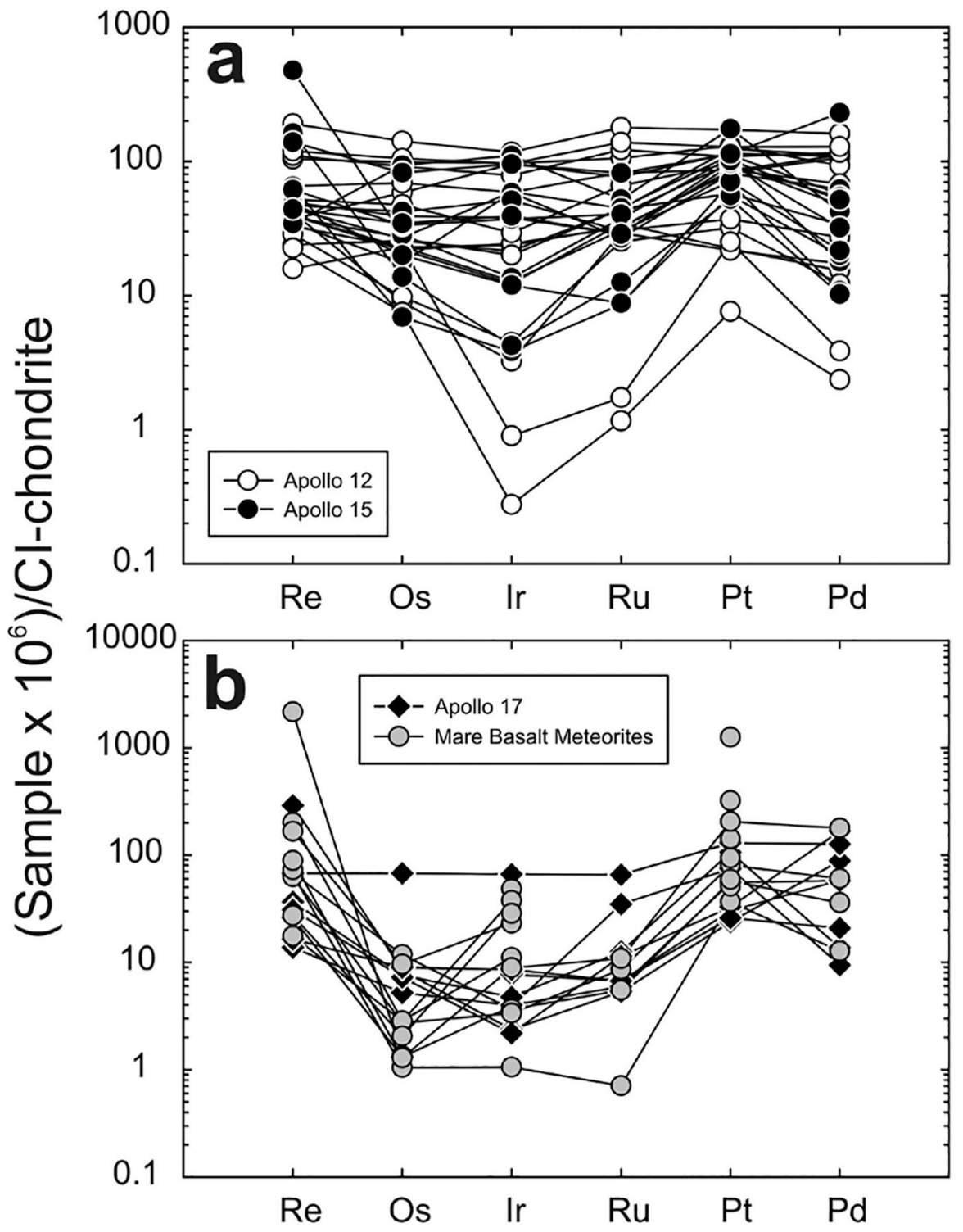

Figure 25.

CI-chondrite normalized HSE abundances for (a) low titanium Apollo 12 and Apollo 15 mare basalts and (b) high titanium Apollo 17 mare basalts and mare basalt meteorites (LaPaz basalts, MIL 05035). Data from Day et al. (2007) and Day and Walker (2015). 

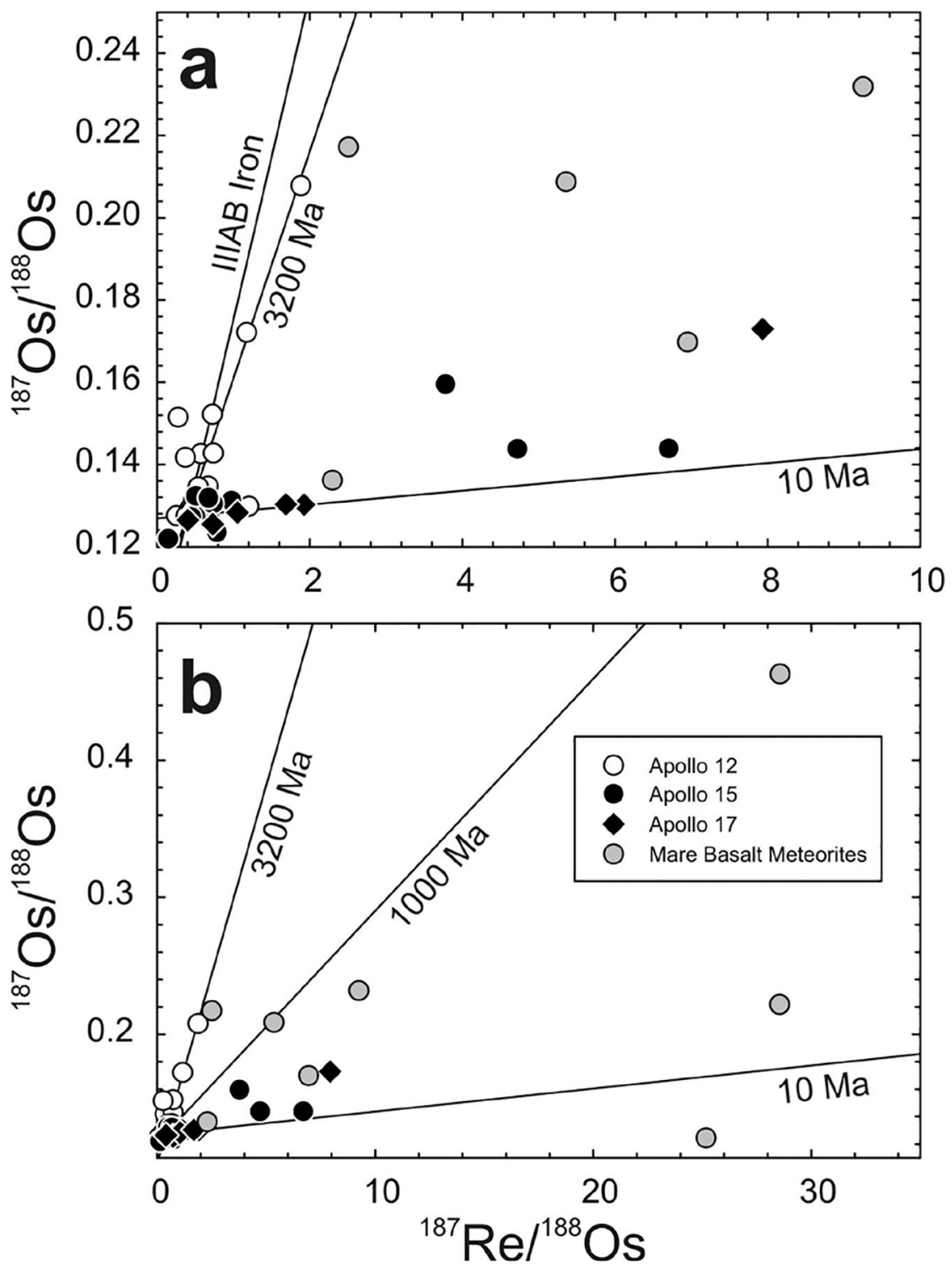

Figure 26.

${ }^{187} \mathrm{Re} /{ }^{188}$ Os versus ${ }^{187} \mathrm{Os} /{ }^{188}$ Os diagrams for mare basalts showing ${ }^{187} \mathrm{Re} /{ }^{188}$ Os from (a) 0 10 and (b) 0-35. Also shown are reference isochrons at $4.568 \mathrm{Ga}$ (IIIAB Iron isochron from Smoliar et al. (1996)), $3200 \mathrm{Ma}$ (the mean crystallization age of Apollo 12 mare basalts), $1000 \mathrm{Ma}$ and 10 Ma. Data from Day et al. (2007) and Day and Walker (2015). 


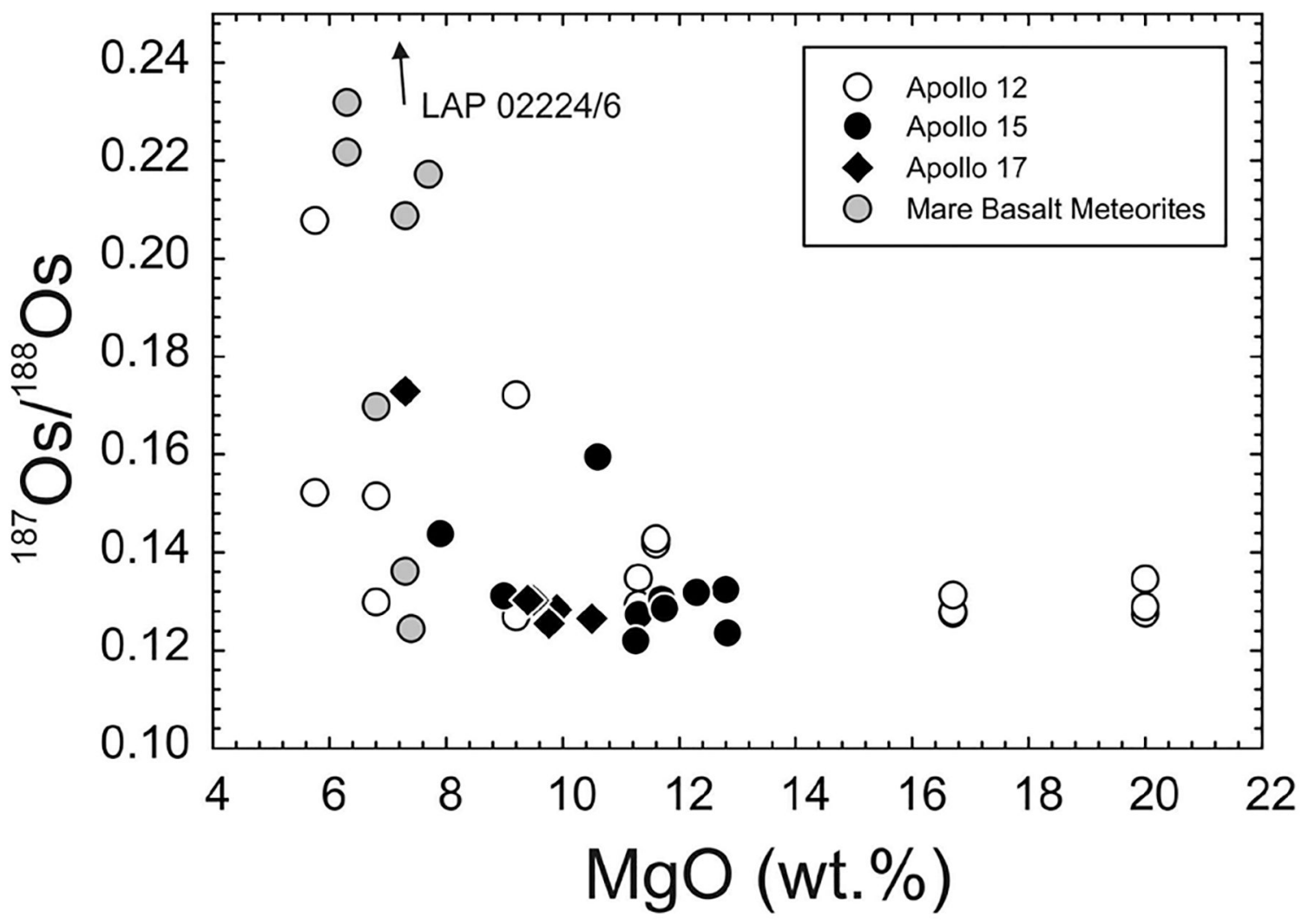

Figure 27.

Whole-rock $\mathrm{MgO}$ content versus measured osmium isotopic compositions for mare basalts. Data from Day et al. (2007) and Day and Walker (2015). 


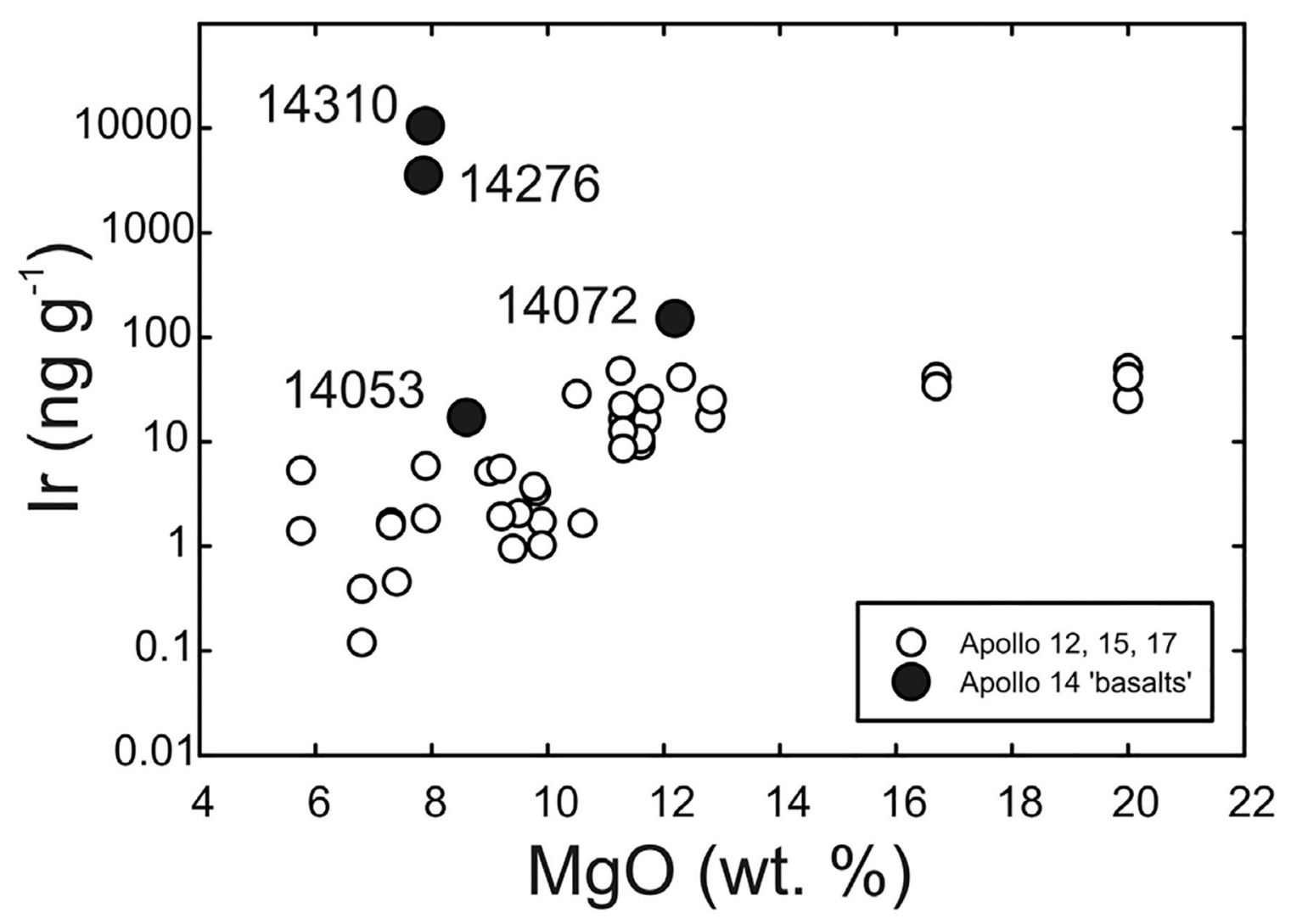

Figure 28.

$\mathrm{MgO}$ versus Ir contents for Apollo 14 samples (from Morgan et al. 1972; Hughes et al. 1973; Ebihara et al. 1992) compared with Apollo 12, 15, and 17 mare basalts (from Day et al. 2007; Day and Walker 2015). 


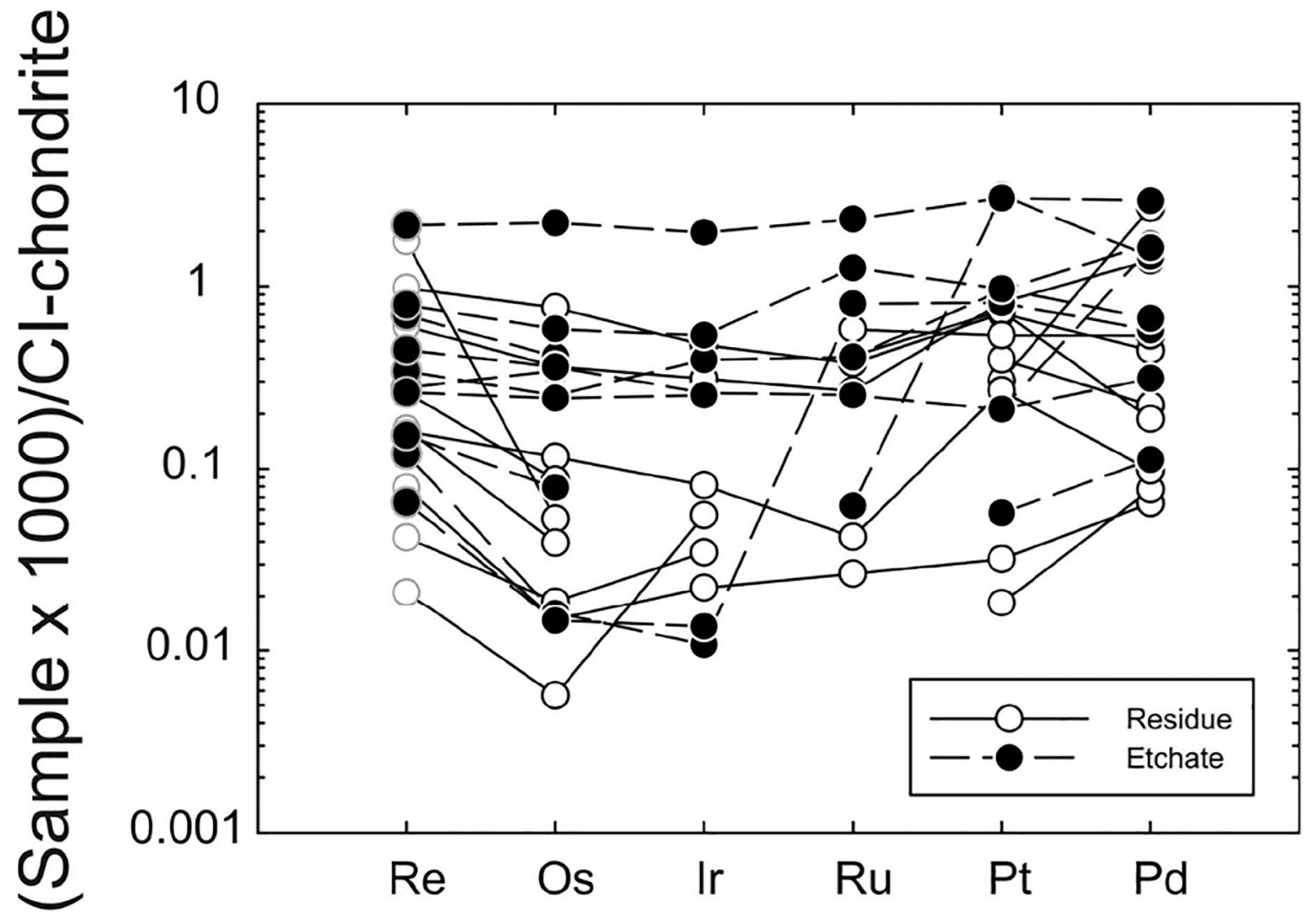

Figure 29.

CI chondrite normalized HSE abundances for etchates and residues of Apollo 15421, 15426, 72440 and 74001 pyroclastic glasses. Etchates were obtained by partial digestion and isotope dilution in Carius tubes and residue was taken from the partial digestions, washed and purified and ground prior to re-spiking. Rhenium concentrations with gray outlines are calculated from measured ${ }^{187} \mathrm{Os} /{ }^{188}$ Os and Os concentrations, assuming chondritic ${ }^{187} \mathrm{Os} /$ ${ }^{188}$ Os at age of formation. Data from Walker et al. (2004). 


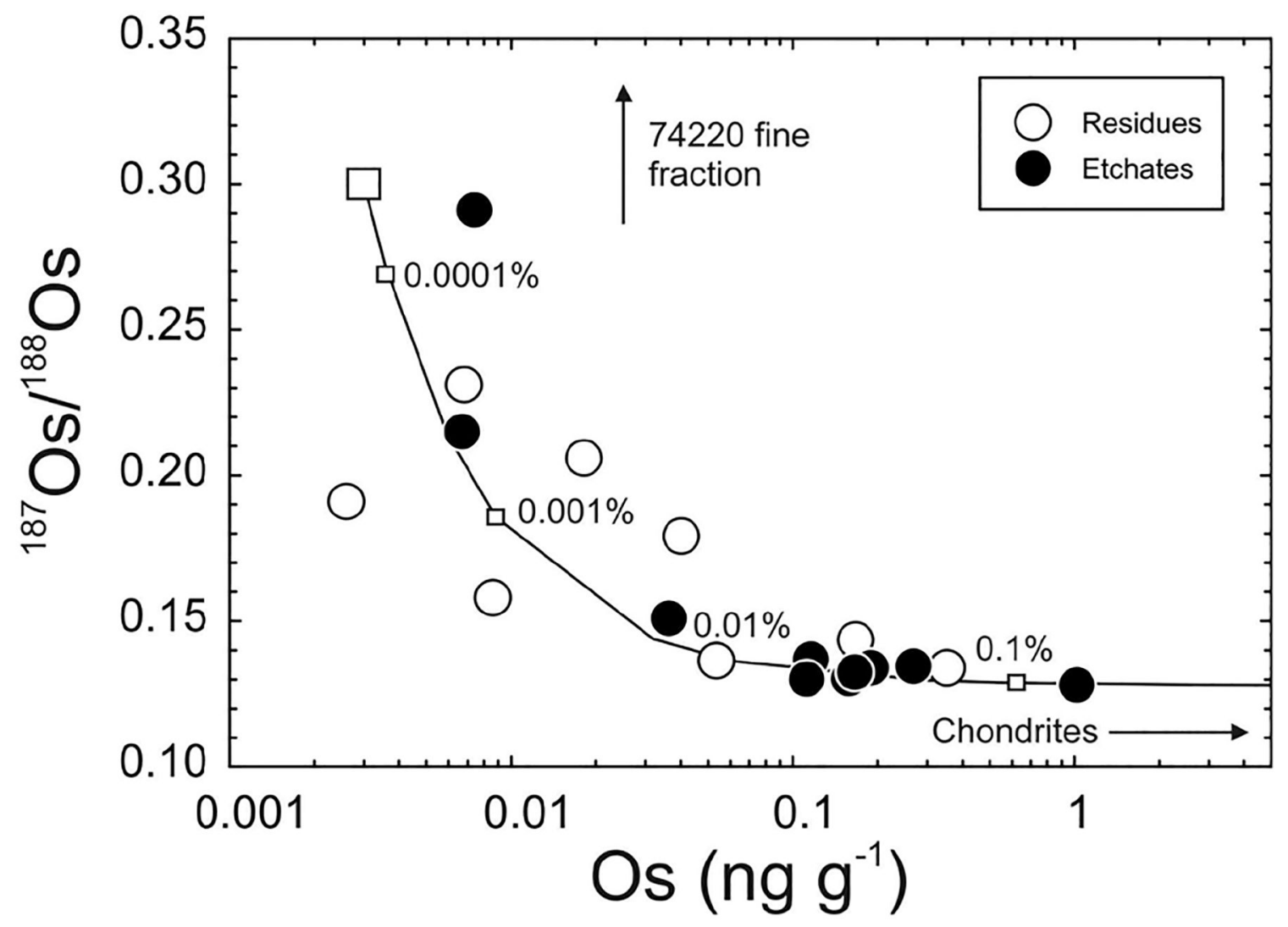

Figure 30 .

${ }^{187} \mathrm{Os} /{ }^{188}$ Os versus Os concentration for lunar pyroclastic glass bead etchate and residue experiments. Curve shows mixing between a hypothetical indigenous green glass composition $\left(0.003 \mathrm{ng} . \mathrm{g}^{-1} \mathrm{Os} ;{ }^{187} \mathrm{Os} /{ }^{188} \mathrm{Os}=0.3\right)$ and an average ordinary chondrite composition (580 ng.g ${ }^{-1} ;{ }^{187} \mathrm{Os} /{ }^{188} \mathrm{Os}=0.128$ ). Percentages (by mass) of the chondritic component are labelled. Figure adapted from Walker et al. (2004). 

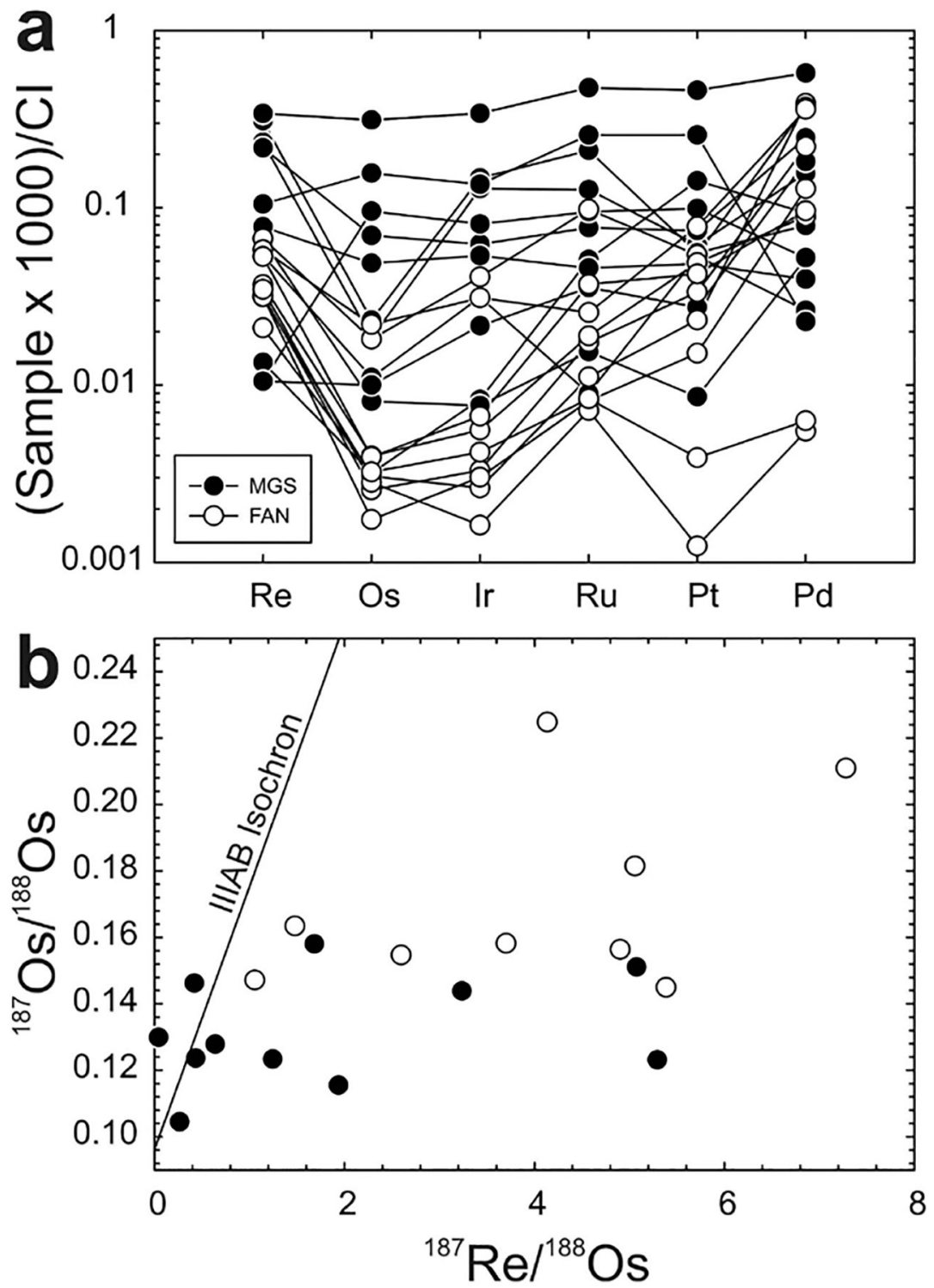

Figure 31.

(a) CI-chondrite normalized HSE abundances and (b) ${ }^{187} \mathrm{Re} /{ }^{188} \mathrm{Os}$ versus ${ }^{187} \mathrm{Os} /{ }^{188} \mathrm{Os}$ for lunar crustal rocks, including ferroan anorthosites (FAN) and magnesian suite (MGS) rocks. The MGS includes troctolites $(76535)$, norites $(15455,77215,78235)$ and dunites $(72415)$. Data from Day et al. (2010). Shown in (b) is the 4.568 Ga IIIAB iron isochron from Smoliar et al. (1996). 

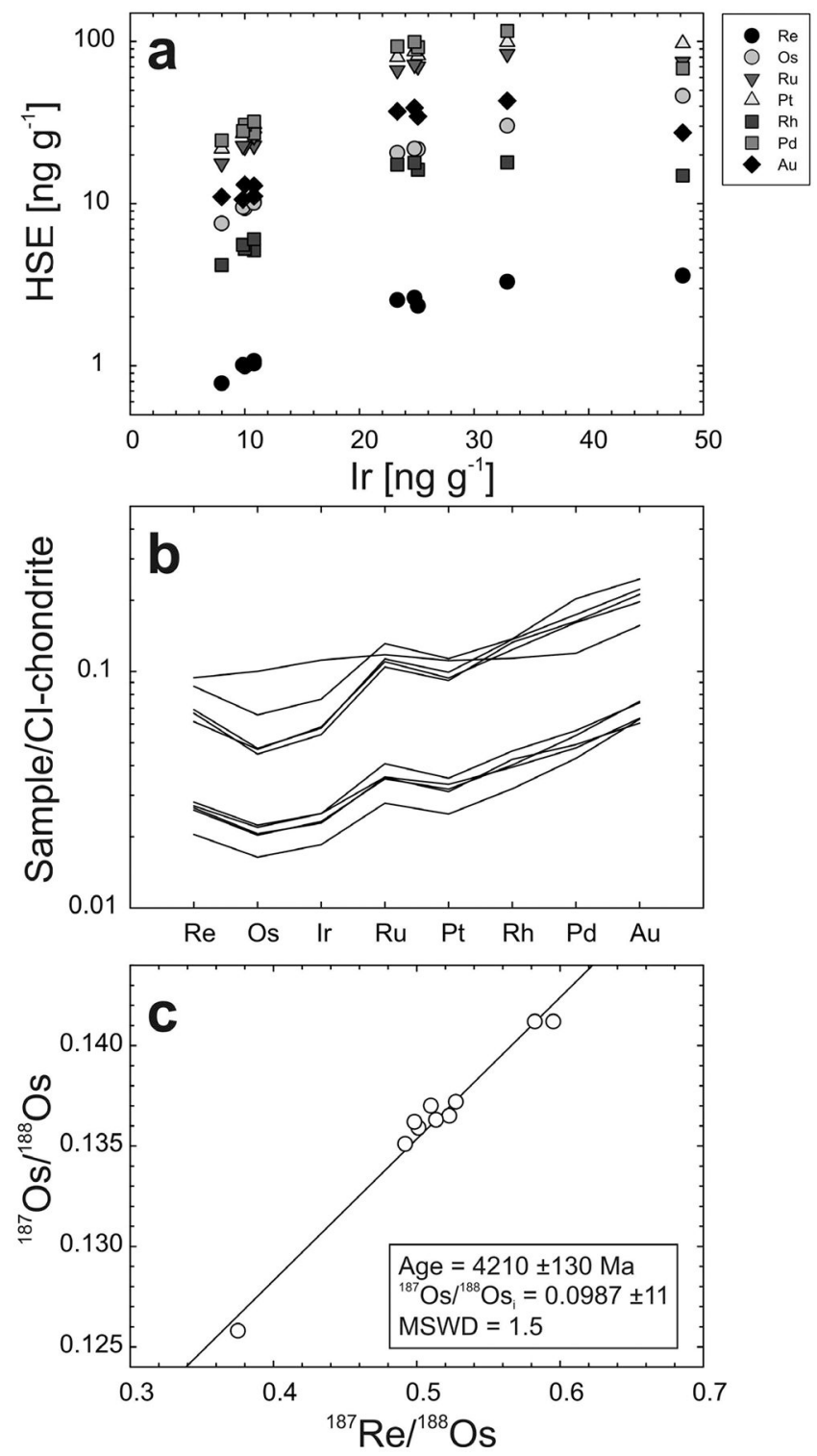

Figure 32.

An example of lunar impact melt breccia (a) variations of $\mathrm{Re}, \mathrm{Os}, \mathrm{Ru}, \mathrm{Pt}, \mathrm{Rh}, \mathrm{Pd}$ and $\mathrm{Au}$ with Ir, (b) CI-chondrite normalized HSE abundances and (c) ${ }^{187} \mathrm{Re} /{ }^{188}$ Os versus ${ }^{187} \mathrm{Os} /$ ${ }^{188}$ Os for the fine-grained sub-ophitic impact melt 67935 . This particular sample has yielded the only Re-Os isochron for a lunar impact melt rock, of $4.21 \pm 0.13 \mathrm{Ga}$, yet has one measured fraction that deviates from a potential linear correlation in (a) and has a flatter pattern (b). Data from Fischer-Gödde and Becker (2012). 

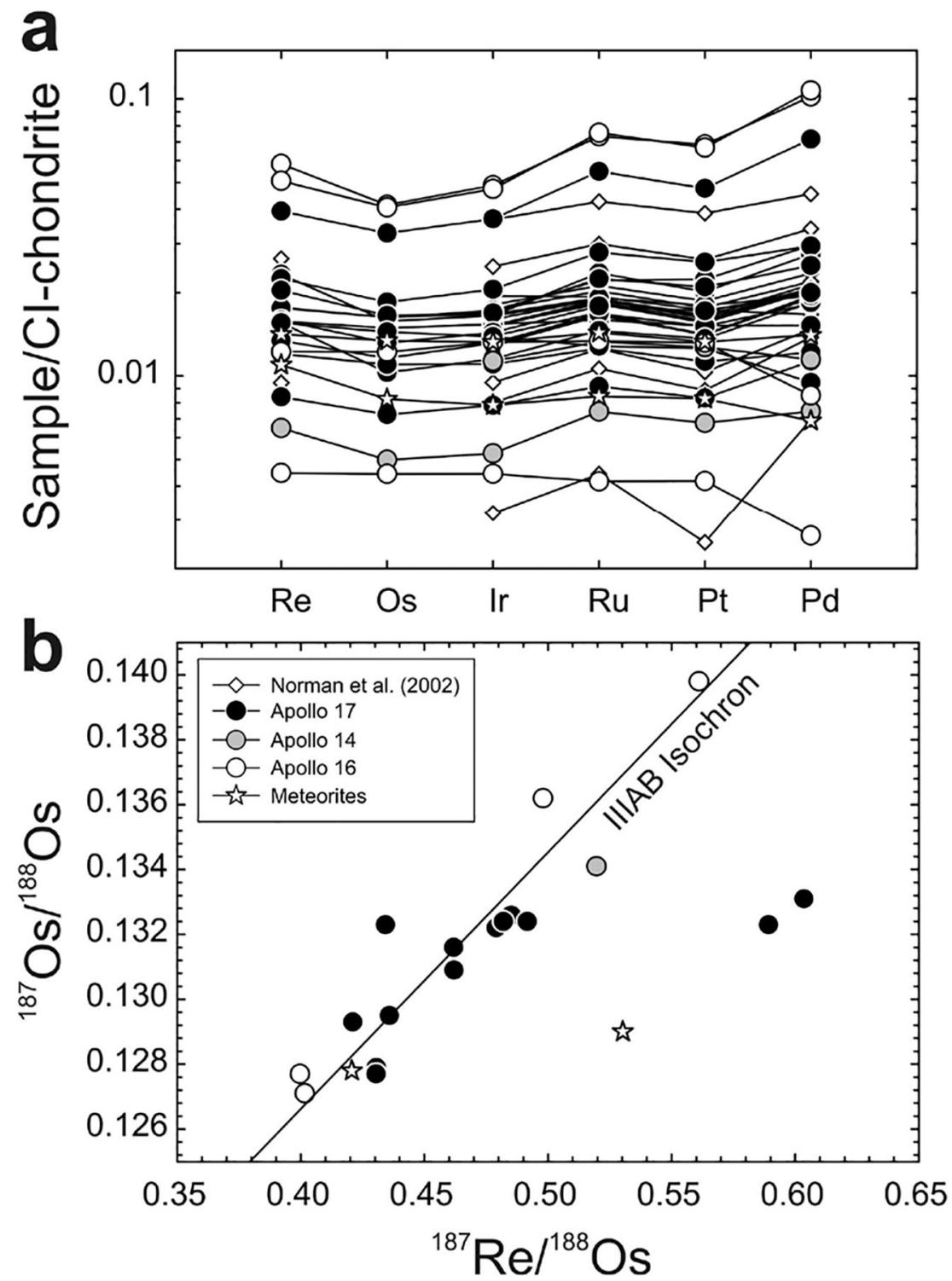

Figure 33.

(a) Average CI-chondrite normalized HSE abundances and (b) ${ }^{187} \mathrm{Re} /{ }^{188}$ Os versus ${ }^{187} \mathrm{Os} /$ ${ }^{188}$ Os for lunar impact melt breccias. Data are from Puchtel et al. (2008), Fischer-Gödde and Becker (2012), and Sharp et al. (2014). Shown in (b) is the 4.568 Ga IIIAB iron isochron from Smoliar et al. (1996). 'Meteorites' refers to lunar regolith breccia meteorites. 


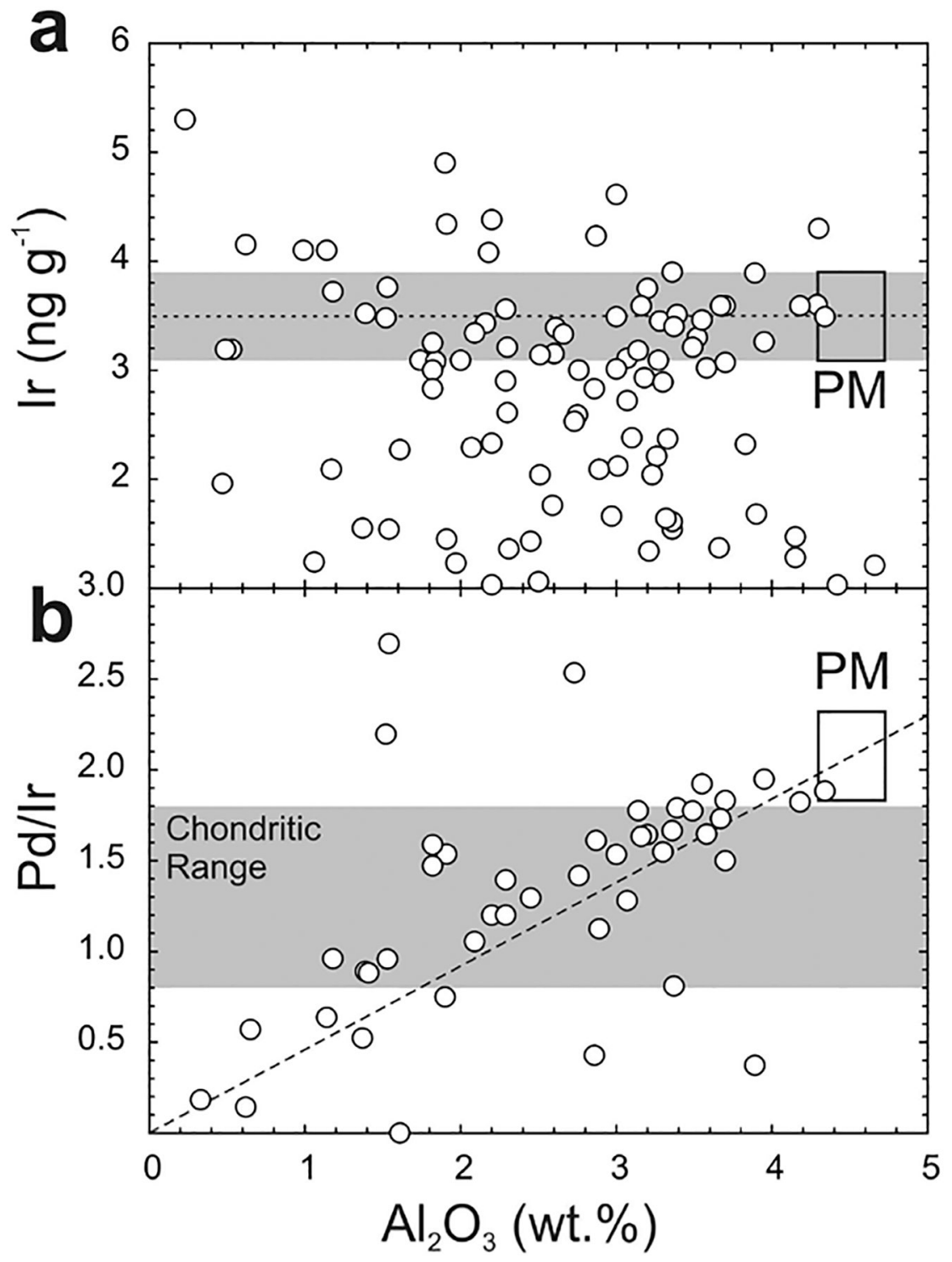

Figure 34.

Estimating mantle composition using terrestrial peridotites. (a) Ir versus $\mathrm{Al}_{2} \mathrm{O}_{3}$ for a global suite of variably melt-depleted peridotites. The solid horizontal line represents a regression for all samples with $>2 \mathrm{wt} . \% \mathrm{Al}_{2} \mathrm{O}_{3}$. The intersection of the trend with the estimated range for $\mathrm{Al}_{2} \mathrm{O}_{3}$ in the primitive mantle, and the associated uncertainties (shaded region) gives an Ir concentration for PM of $3.5 \pm 0.4 \mathrm{ng}$. $\mathrm{g}^{-1}$. (b) $\mathrm{Pd} / \mathrm{Ir}$ versus $\mathrm{Al}_{2} \mathrm{O}_{3}$ for a global suite of variably melt-depleted peridotites allow the elemental ratio determination of PM and, consequently estimated abundances of the HSE relative to Ir. The gray band in (b) is $\mathrm{Pd} / \mathrm{Ir}$ for chondritic meteorites. Methods and data are from Becker et al. (2006) and references therein. 


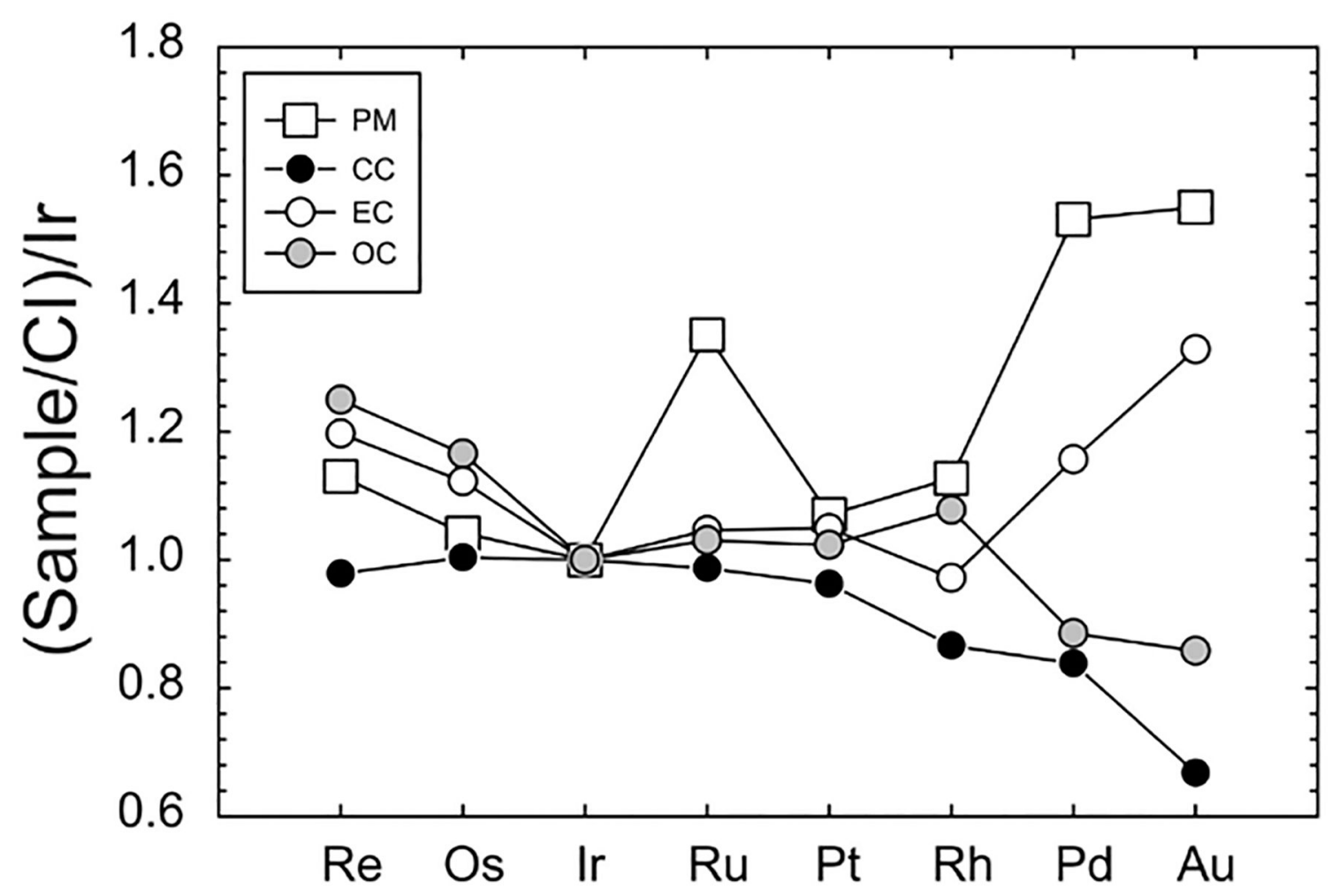

Figure 35.

Plot of the estimated concentrations of the HSE in the primitive mantle (PM) double normalized to CI chondrite concentrations (Orgueil) and the ratio of Ir/CI. Error bars are not shown to aid in clarity. Palladium and Au values for PM only overlap with enstatite chondrite compositions. Data sources are listed in the tables and $\mathrm{CC}=$ carbonaceous chondrites, $\mathrm{EC}=$ enstatite chondrites and $\mathrm{OC}=$ ordinary chondrites. 


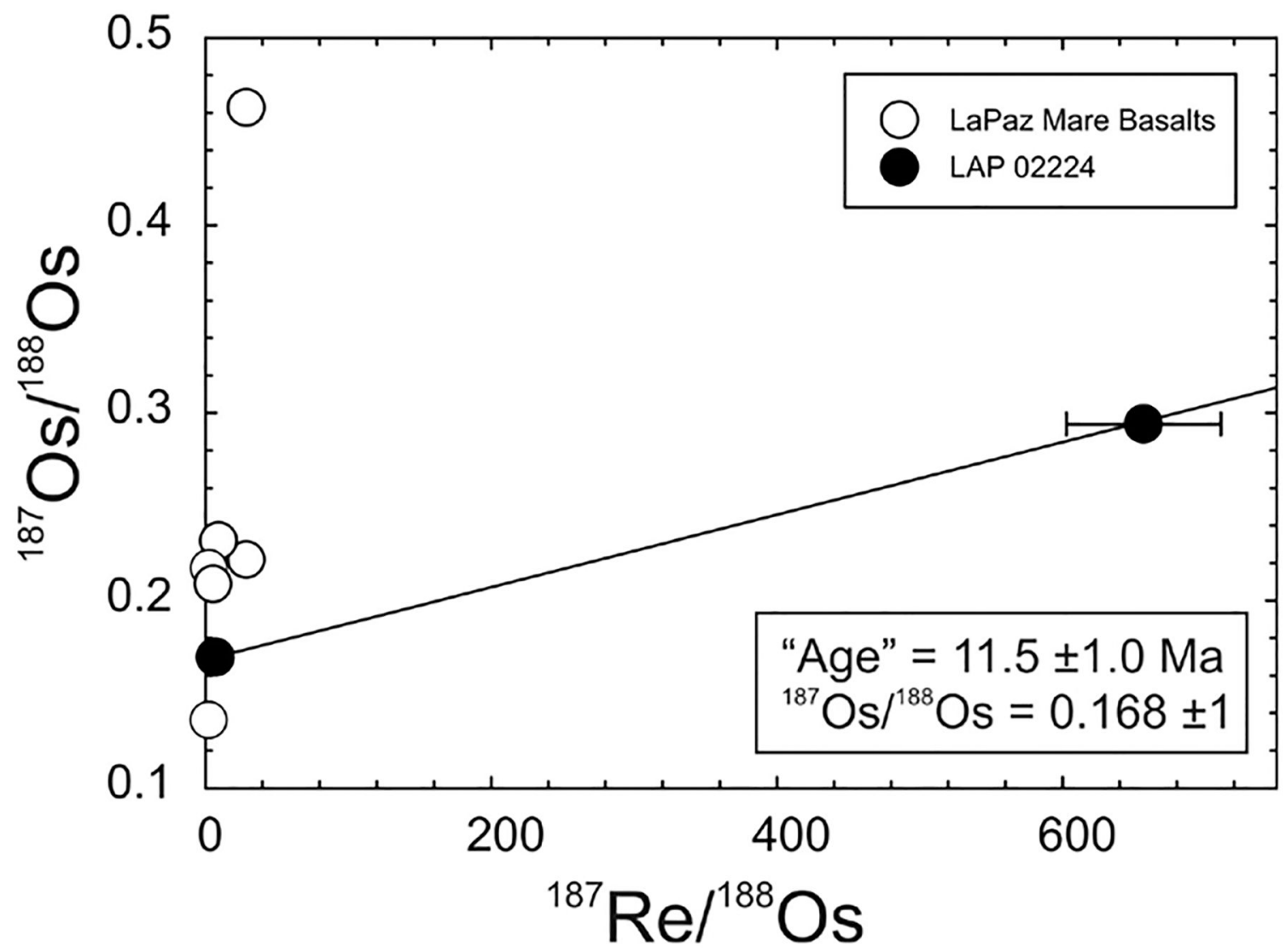

Figure 36.

${ }^{187} \mathrm{Re} /{ }^{188}$ Os versus ${ }^{187} \mathrm{Os} /{ }^{188}$ Os diagram for the LaPaz mare basalt meteorites. Fractions of LAP 02224, one with (high Re/Os) and one without (low Re/Os) fusion crust yield an apparent age of $\sim 11.5 \mathrm{Ma}$. This relationship is interpreted to reflect recent disturbance of the Re-Os isotope system from atmospheric entry, friction heating and mobilization of Re in the meteorite. Data from Day et al. (2007). 


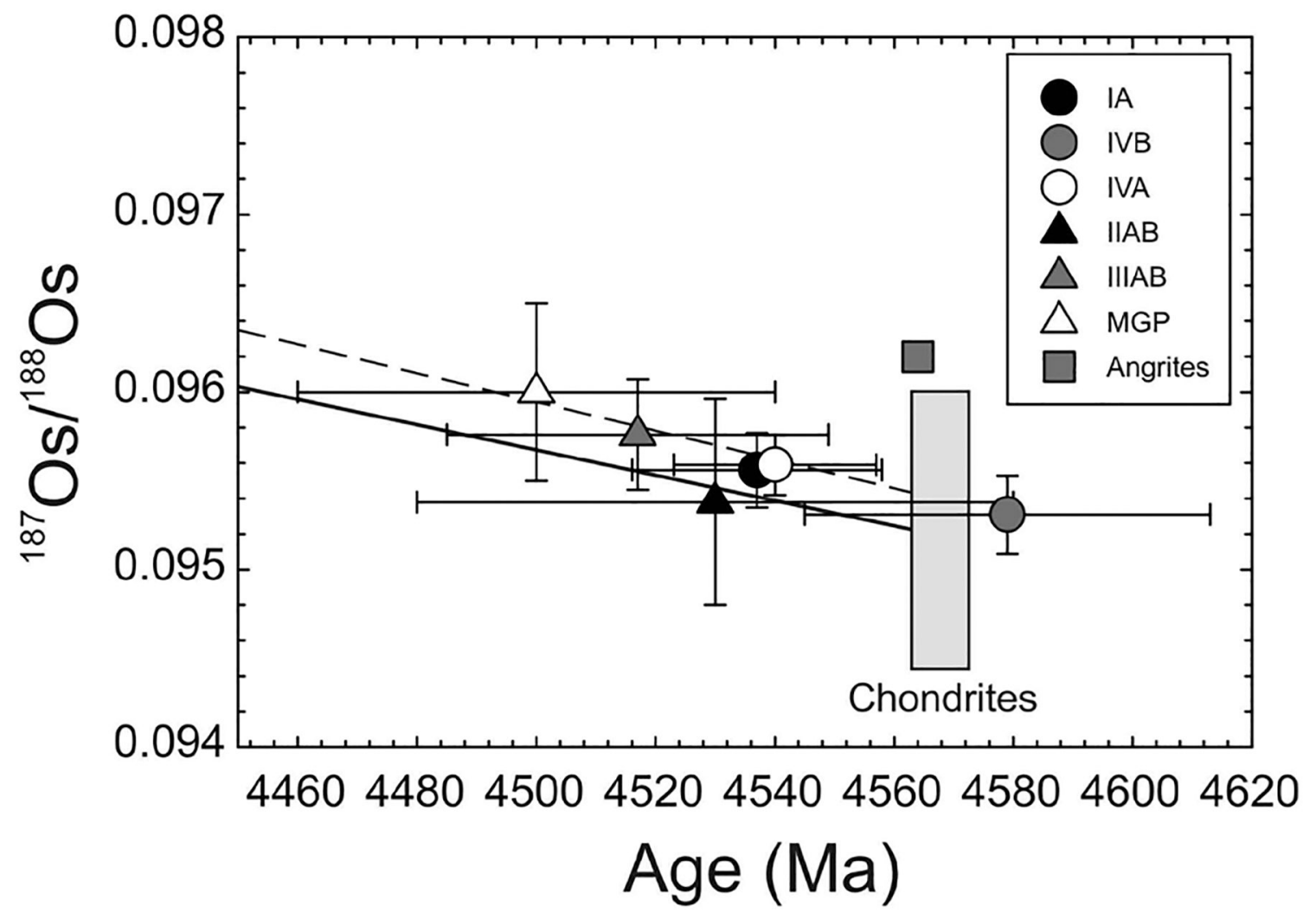

Figure 37.

Initial ${ }^{187} \mathrm{Os} /{ }^{188} \mathrm{Os}$ versus age, derived from ${ }^{187} \mathrm{Re}-{ }^{187} \mathrm{Os}$ isochrons for magmatic iron meteorites (IA, IVB, IVA, IIAB, IIIAB), main group pallasites (MGP) and angrites (estimated from least disturbed samples). Also shown is the field for least-disturbed chondrite compositions. Solid line shows the chondritic evolution line from the average initial ${ }^{187} \mathrm{Os} /{ }^{188}$ Os of chondrites and the dashed line shows the regression through the iron meteorite initial compositions. Data sources are provided in the text and provide a Solar System ${ }^{187} \mathrm{Os} /{ }^{188}$ Os initial value of $0.0952 \pm 0.0002$. 

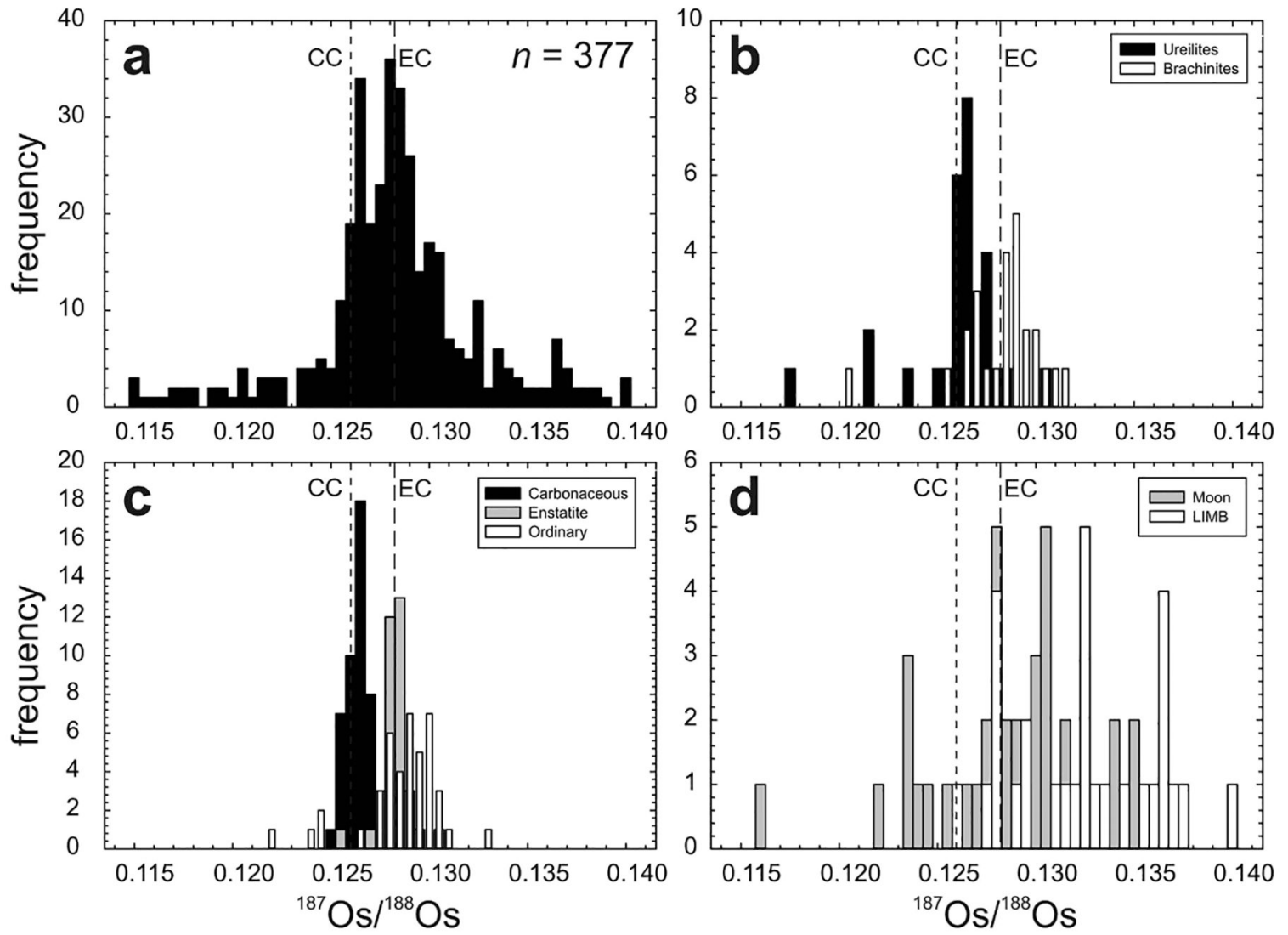

Figure 38 .

Histograms of ${ }^{187} \mathrm{Os} /{ }^{188} \mathrm{Os}$ for (a) a compiled data set of $>350$ planetary materials considered in this study, (b) ureilites and brachinites, (c) chondrites and (d) lunar mare basalts and crustal rocks (Moon) and lunar impact melt breccias (LIMB). Plots are confined to $0.113-0.143$, excluding samples with ratios higher or lower than these values. Note the preponderance of values that overlap with the composition of enstatite $\left(\mathrm{EC} ;{ }^{187} \mathrm{Os} /{ }^{188} \mathrm{Os}=\right.$ $0.1280 \pm 0.0008)$, or ordinary chondrites $\left({ }^{187} \mathrm{Os} /{ }^{188} \mathrm{Os}=0.1284 \pm 0.0020\right)$ in the dataset. Ureilites have a strong distribution of ${ }^{187} \mathrm{Os} /{ }^{188} \mathrm{Os}$ around the carbonaceous chondrite average $\left(\mathrm{CC} ;{ }^{187} \mathrm{Os} /{ }^{188} \mathrm{Os}=0.1262 \pm 0.0005\right)$. 


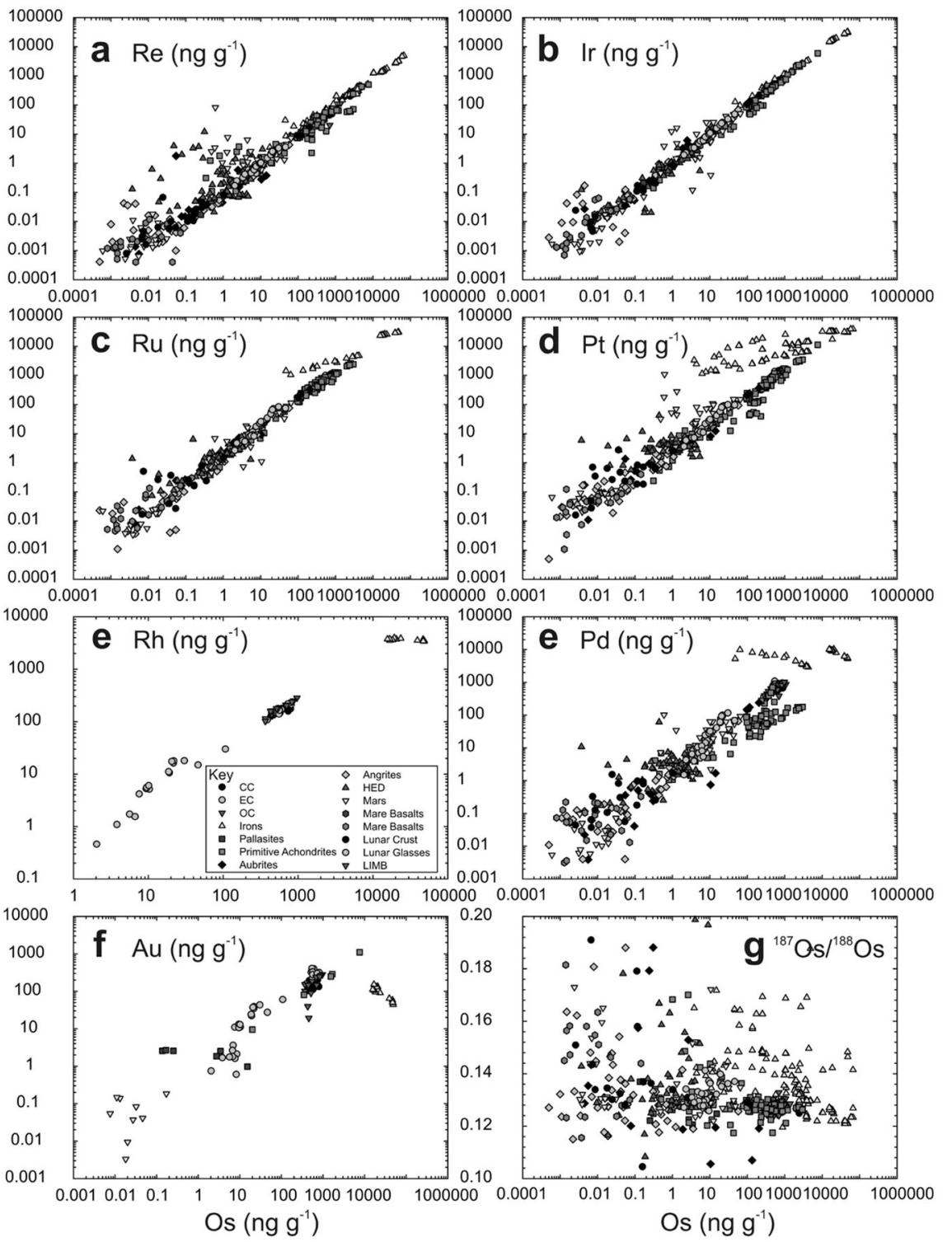

Figure 39.

Correlations of Os versus HSE and ${ }^{187} \mathrm{Os} /{ }^{188} \mathrm{Os}$ in a combined dataset of $>750$ planetary materials discussed in this study. The HSE span up to ten orders of magnitude abundance variations, between iron meteorites and mare basalts, lunar crustal samples and some eucrites that have extremely low abundances of the HSE. Note strong deviations from correlations for some iron meteorites, probably reflecting liquid metal-solid metal partitioning. $\mathrm{CC}=$ carbonaceous chondrite $; \mathrm{EC}=$ enstatite chondrite; $\mathrm{OC}=$ ordinary chondrite; HED = howardite-eucrite-diogenite meteorite. 


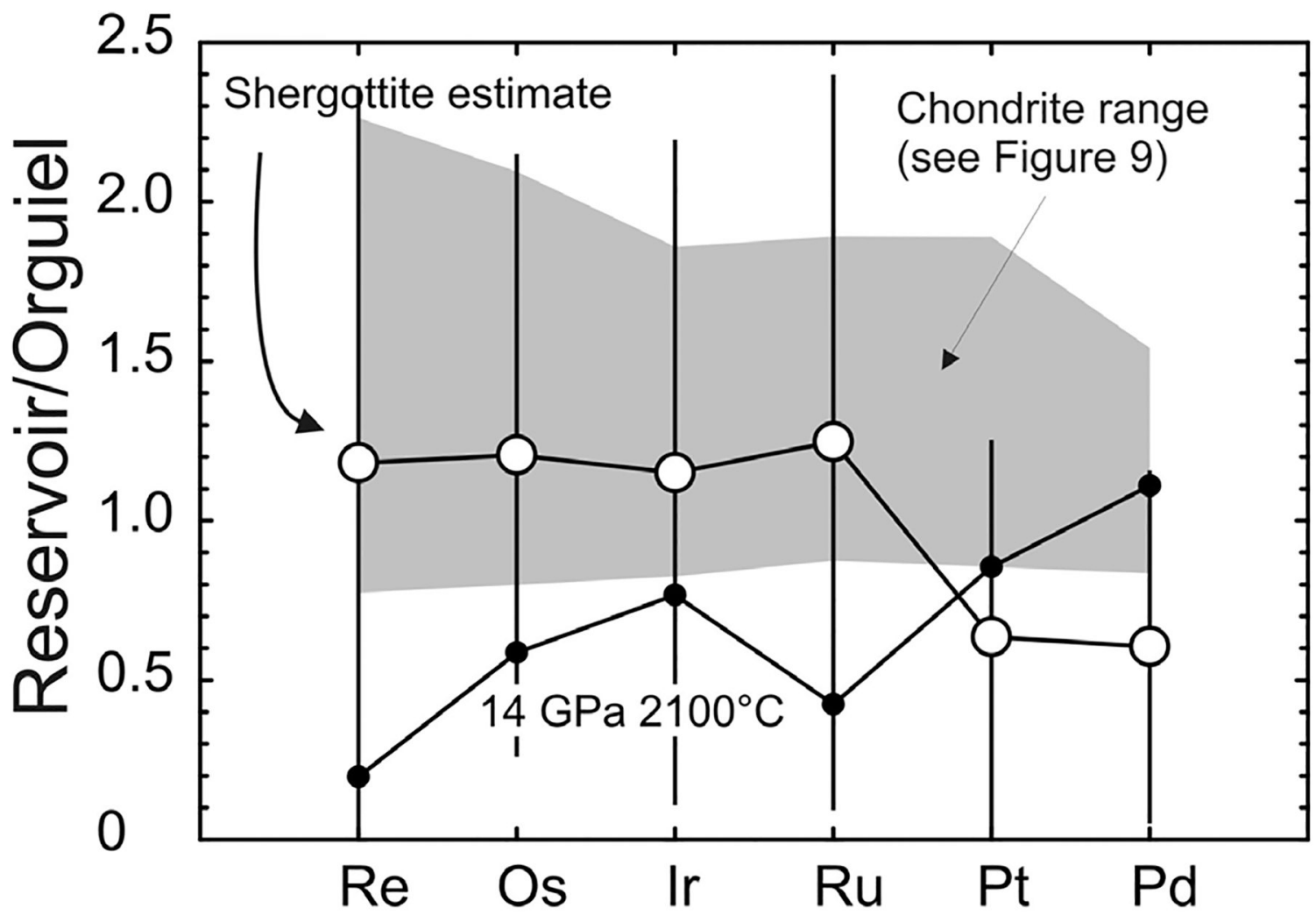

Figure 40.

Plot of the range of chondrite compositions (from Figure 9) versus martian mantle estimates from shergottite meteorites (Table $2-\mathrm{MgO}-\mathrm{HSE}$ regression method) and high- $P$ and high- $T$ experimental constraints on martian mantle composition (Righter et al. 2015) $(\times 150)$.

Estimates of martian mantle composition from shergottite meteorites are associated with large uncertainties (error bars). The high- $P$, high- $T$ estimate of martian mantle HSE content at $14 \mathrm{GPa}$ and $2100{ }^{\circ} \mathrm{C}$ does not reproduce chondritic Re/Os. Note linear scale. Orgueil normalization from Table 3 . 

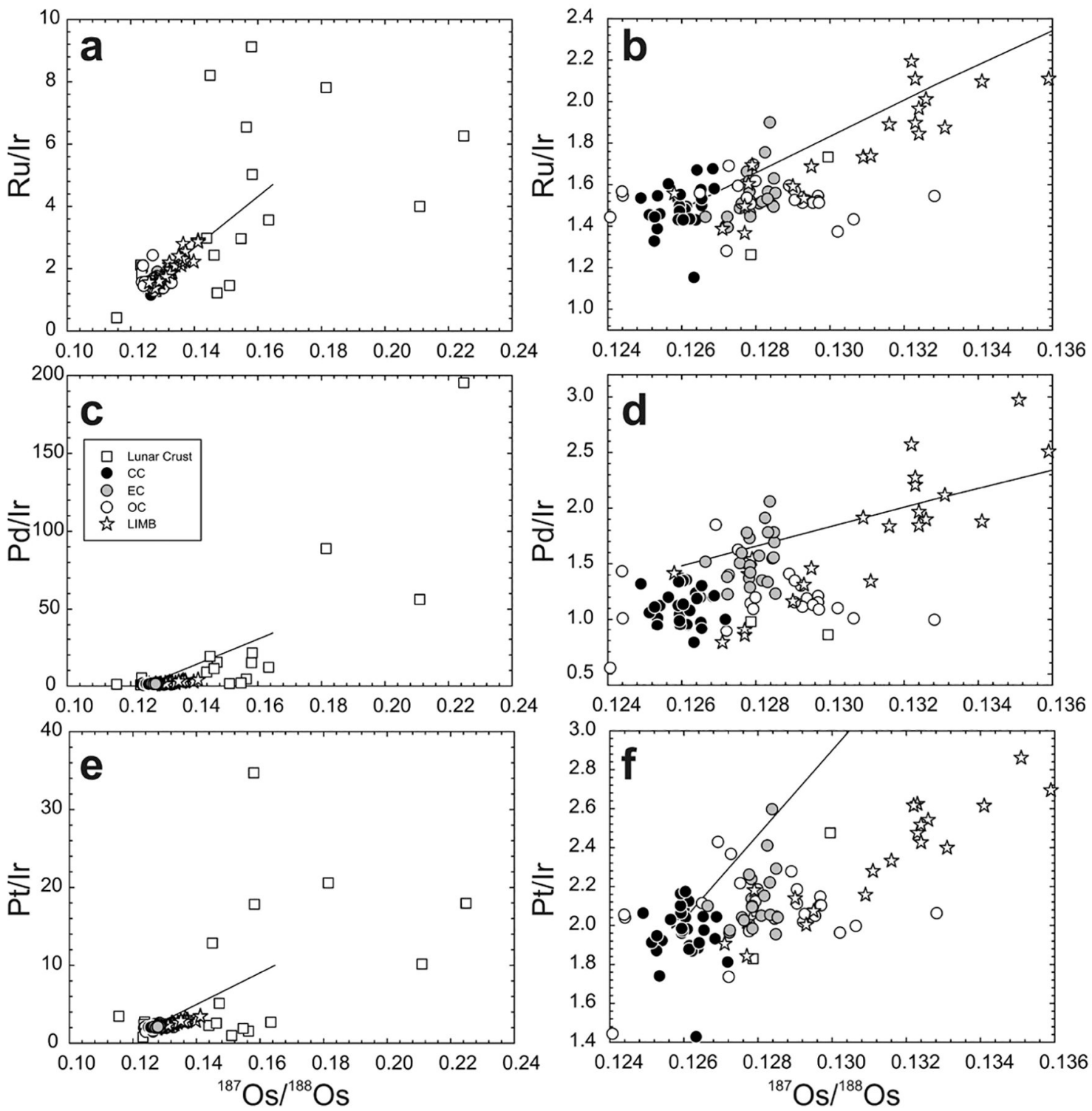

Figure 41.

Plots of ${ }^{187} \mathrm{Os} /{ }^{188}$ Os versus (a, b) $\mathrm{Ru} / \mathrm{Ir}$, (c, d) $\mathrm{Pd} / \mathrm{Ir}$ and (e, f) Pt/Ir for lunar crustal rocks, carbonaceous chondrites (CC), enstatite chondrites (EC), ordinary chondrite (OC) and lunar impact melt breccias (LIMB). Solid lines are mixing models between and average lunar crustal composition and a chondritic composition. The model curves show mixing trajectories of exogenous chondritic impactor material that mixes with endogenous melt generated during impact on the Moon. This form of mixing can potentially explain high $\mathrm{Ru} / \mathrm{Ir}$ and $\mathrm{Pd} / \mathrm{Ir}$ seen in some LIMB. Data sources are provided in the text. 


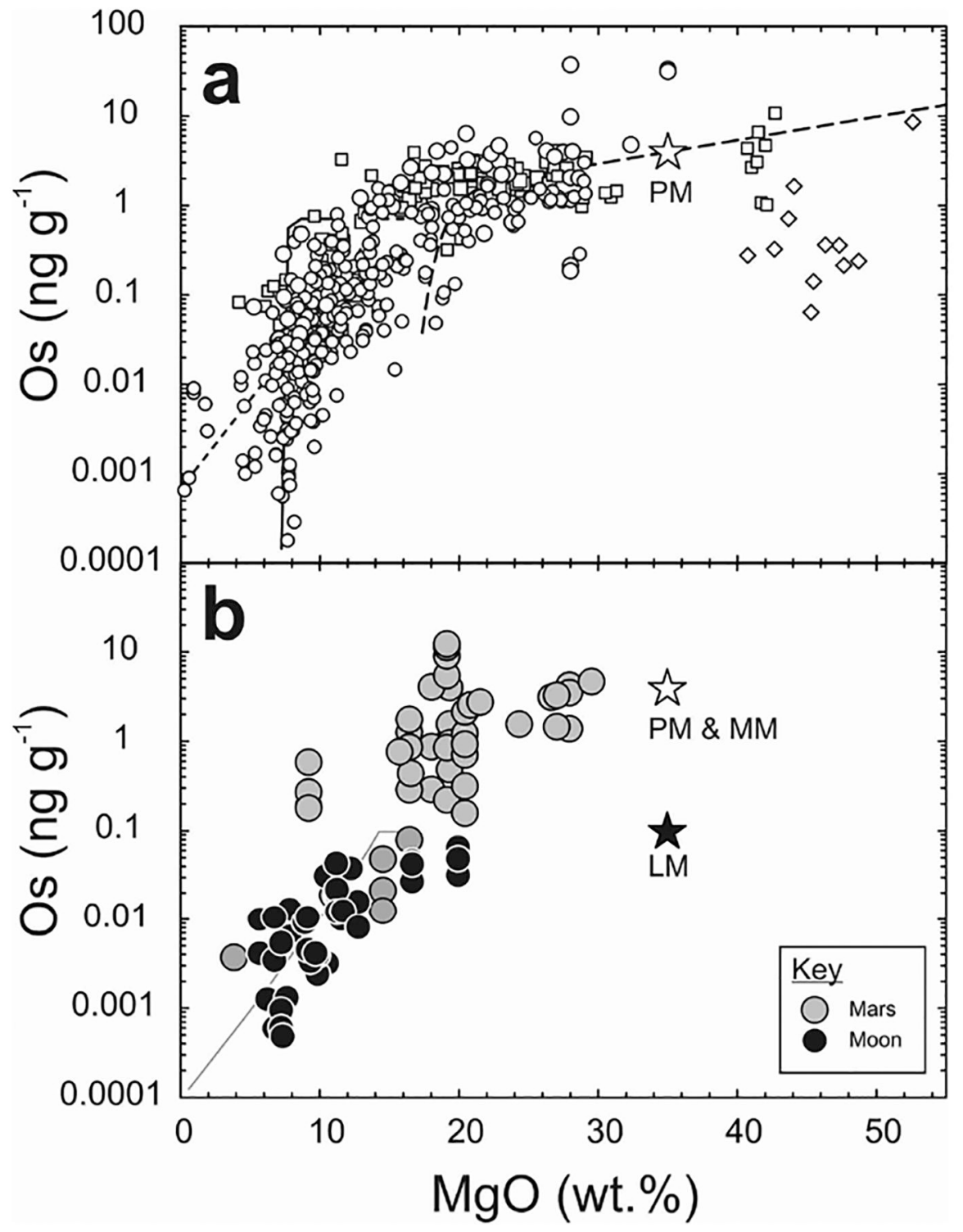

Figure 42.

Plots of $\mathrm{MgO}$ content (wt.\%) versus Os (ng. $\mathrm{g}^{-1}$ ) for (a) terrestrial volcanic rocks. Lines show modeled differentiation trends using methods of Rehkämper et al. (1999) and assuming: (1) short-dashed line - initial tholeiitic melt with $200 \mu \mathrm{g} \cdot \mathrm{g}^{-1} \mathrm{~S}$; (2) long-dashed line running through PM - calculated cumulate assemblage evolution during differentiation; (3) solid line-MORB evolution adapted from Bézos et al. (2005). (b) MgO versus Os abundance correlations for martian meteorites and lunar mare basalts. Lunar basalts have significantly lower HSE abundances than martian or terrestrial basalts, consistent with partial melting from a lunar mantle with 40 times lower HSE abundances than the terrestrial mantle. Gray model line shows melting model for an initial mare basalt melt with $0.07 \mathrm{ng} . \mathrm{g}$ ${ }^{-1}$ Os $200 \mu \mathrm{g} . \mathrm{g}^{-1} \mathrm{~S}$. Stars for LM (lunar mantle), MM (martian mantle), PM (terrestrial primitive mantle) are from Table 2. Figure adapted from Day (2013). 


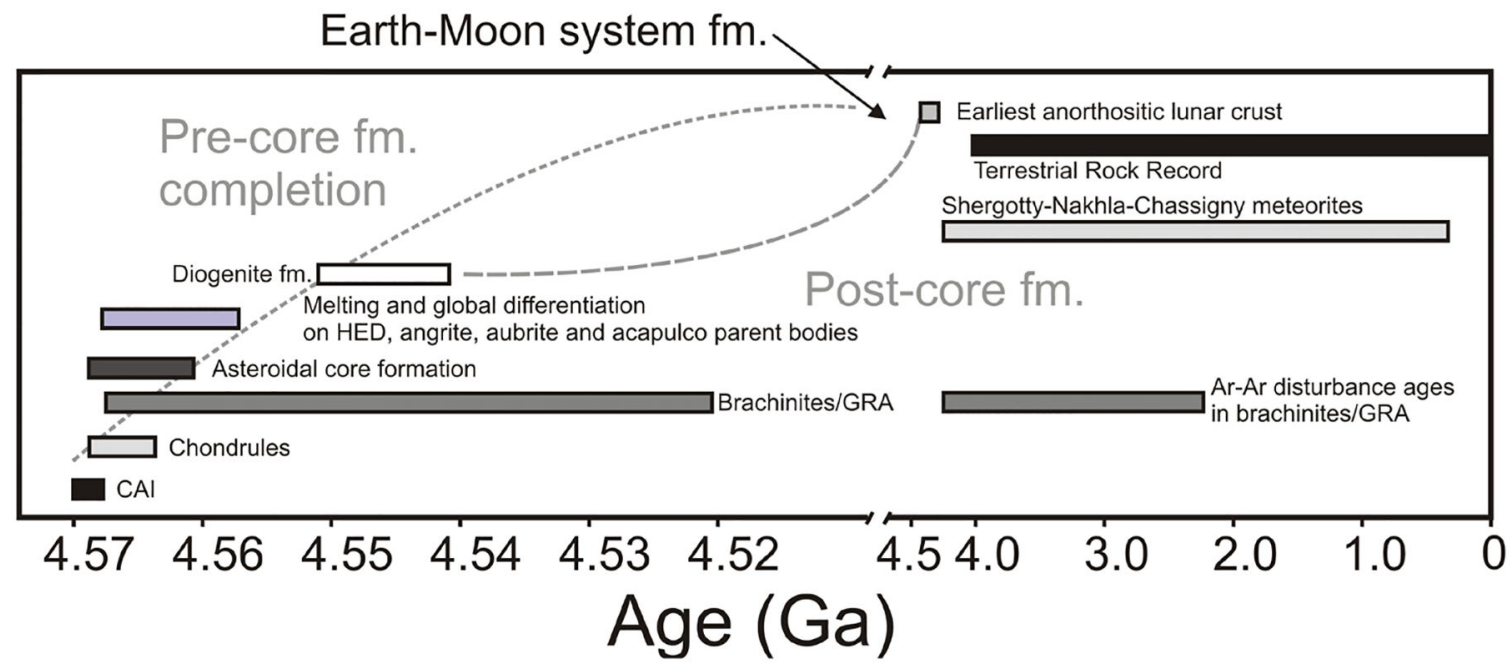

Figure 43.

Time-scales of Solar System formation and post-core formation accretion. Shown are the ages of crystallization of calcium-aluminium-rich inclusions (CAI's), chondrules and various meteorites, lunar Apollo mission samples and terrestrial rocks. Also shown is the approximate timing of Earth-Moon system formation (at least $30 \mathrm{Ma}$ after Solar System formation), and lines showing approximately when the completion of core growth (Pre-core fm. completion) and major stage(s) of late accretion (Post-core fm.) can currently be estimated from meteorites and terrestrial rocks. 


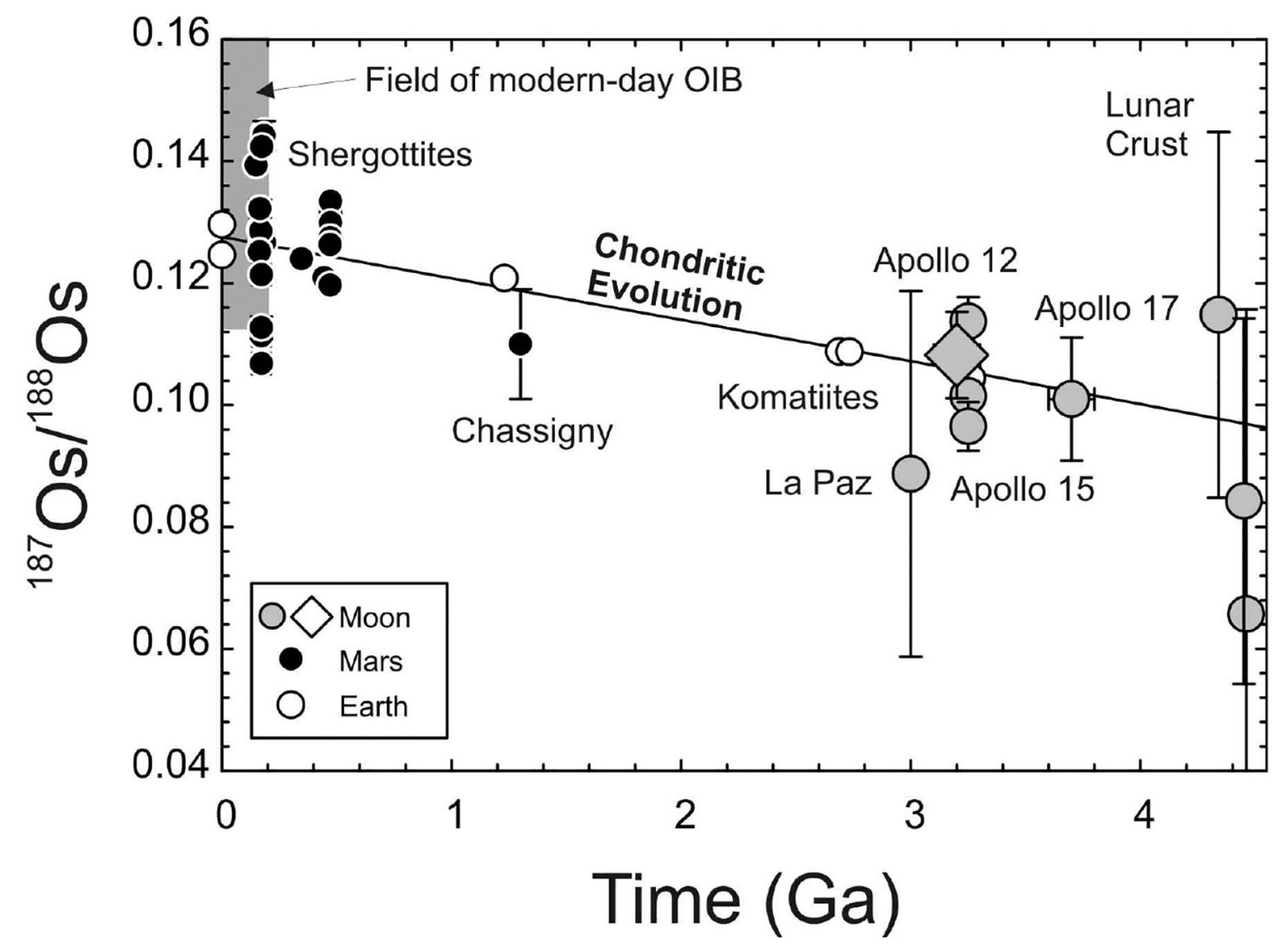

Figure 44.

Calculated initial ${ }^{187} \mathrm{Os} /{ }^{188}$ Os values for martian meteorites, lunar mare basalts and pristine crustal rocks and terrestrial komatiites and peridotites plotted relative to the averaged 'chondritic evolution' curve of carbonaceous chondrites (from Walker et al. 2002). The figure is adapted from Day and Walker (2015). 


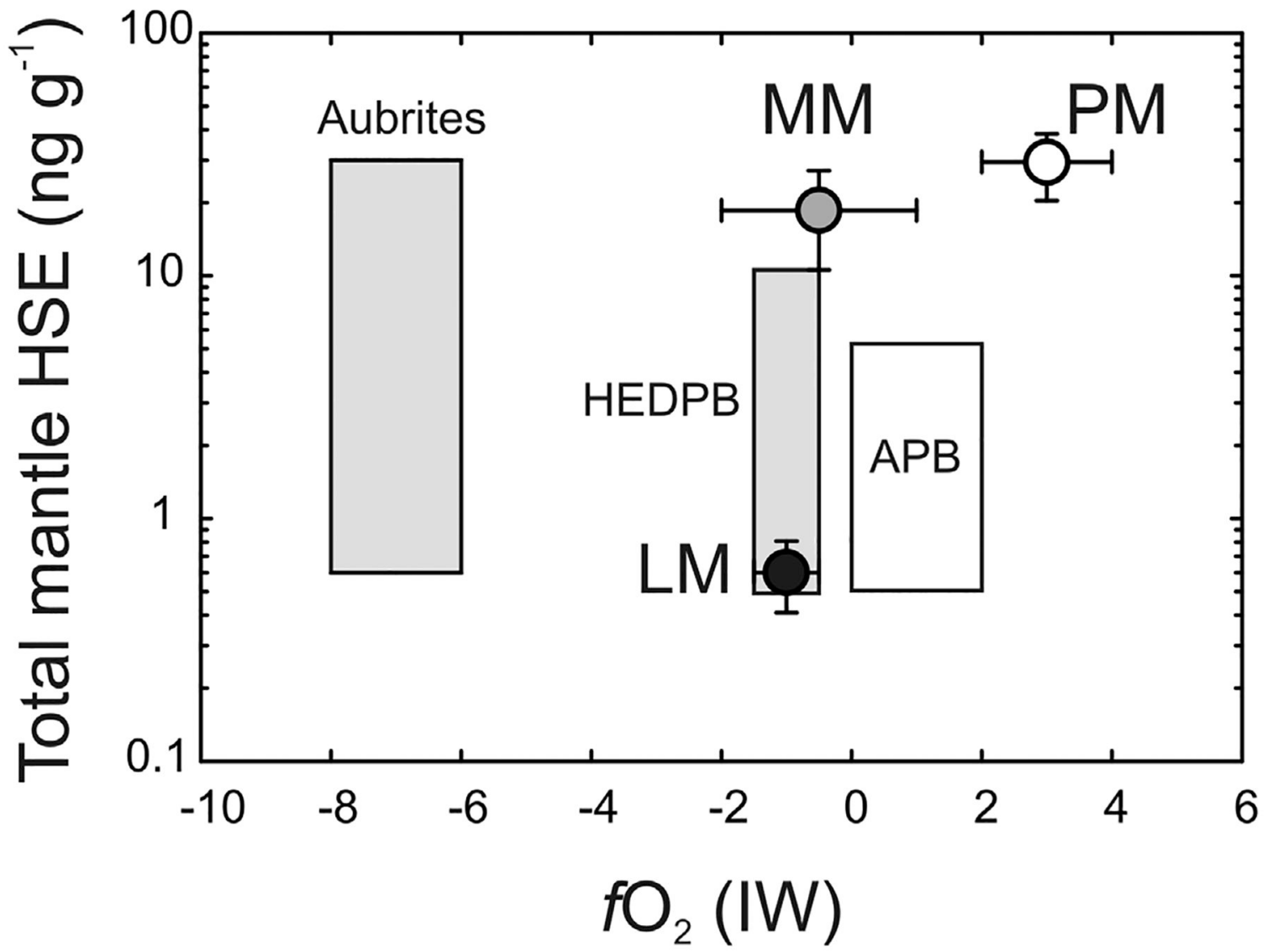

Figure 45.

Total HSE concentration estimated for parent bodies versus oxidation state (log units relative to iron-wüstite buffer). Fields for aubrites, Howardite-Eucrite-Diogenite parent body (HEDPB) and angrite parent body (APB) reflect the conservative range of HSE compositions measured in the meteorites. $f_{\mathrm{O}_{2}}$ states are taken from Dale et al. (2012) and van Acken et al. (2012) LM, MM, and PM stand for lunar, martian and primitive terrestrial mantles, respectively. 
Table 1.

Analyses of Os isotopes and HSE (in ng. $\mathrm{g}^{-1}$ ) in the Allende CV 3 carbonaceous chondrite and comparison with standards used for planetary materials research.

\begin{tabular}{|c|c|c|c|c|c|c|c|}
\hline Sample & Lithology & Compared with & Method & $n$ & Os ( \pm 2SE) & $\operatorname{Ir}( \pm 2 \mathrm{SE})$ & $\mathrm{Ru}( \pm 2 \mathrm{SE})$ \\
\hline \multirow[t]{14}{*}{ Allende } & \multirow[t]{13}{*}{ CV3 Chondrite } & Chondrites & $\mathrm{CT}$ & & 749 & 704 & \\
\hline & & Chondrites & $\mathrm{CT}$ & & 767 & 716 & \\
\hline & & Chondrites & $\mathrm{CT}$ & & & 717 & 1016 \\
\hline & & Tagish Lake & $\mathrm{CT}$ & & 785 & 720 & 1118 \\
\hline & & Chondrites & $\mathrm{CT}$ & & 689 & 644 & 1007 \\
\hline & & Chondrites & HPA & & 795 & 705 & 1073 \\
\hline & & Chondrites & HPA & & 732 & 660 & 997 \\
\hline & & Chondrites & HPA & & 709 & 762 & 997 \\
\hline & & Chondrites & HPA & & 703 & 654 & 991 \\
\hline & & Chondrites & HPA & & 749 & 680 & 975 \\
\hline & & LEW 88763 & $\mathrm{CT}$ & & 738 & 718 & 1031 \\
\hline & & LEW 88763 & $\mathrm{CT}$ & & 666 & 657 & 995 \\
\hline & & Peridotites & $\mathrm{CT}$ & & 763 & 700 & 1140 \\
\hline & Average Allende & & & 13 & $737 \pm 78$ & $695 \pm 68$ & $1031 \pm 110$ \\
\hline Allende & Low Level Dilution (0.19\%) & Lunar glasses & $\mathrm{CT}$ & 3 & $759 \pm 27$ & $691 \pm 66$ & $1012 \pm 10$ \\
\hline \multirow[t]{5}{*}{ UB-N } & \multirow{5}{*}{ Spinel-Bearing Serpentinite } & & HPA & 13 & $3.71 \pm 0.53$ & $3.37 \pm 0.43$ & $6.30 \pm 0.58$ \\
\hline & & LIMB & $\mathrm{CT}$ & 4 & $3.85 \pm 0.32$ & $3.58 \pm 0.40$ & $6.93 \pm 0.47$ \\
\hline & & Peridotites & $\mathrm{CT}$ & 4 & $3.51 \pm 0.25$ & $3.26 \pm 0.25$ & $6.51 \pm 0.65$ \\
\hline & & Peridotites & $\mathrm{CT} / \mathrm{HPA}$ & 19 & $3.53 \pm 0.5$ & $3.16 \pm 0.44$ & $6.43 \pm 0.76$ \\
\hline & & Peridotites & $\mathrm{CT}$ & 6 & $3.66 \pm 0.3$ & $3.24 \pm 0.62$ & $6.48 \pm 0.58$ \\
\hline \multirow[t]{4}{*}{ GP13 } & \multirow[t]{4}{*}{ Spinel Lherzolite } & Intrusive Rocks & $\mathrm{CT}$ & 5 & $3.61 \pm 0.12$ & $3.70 \pm 0.35$ & $7.66 \pm 0.87$ \\
\hline & & Peridotites & $\mathrm{CT}$ & 8 & $3.87 \pm 0.17$ & $3.56 \pm 0.33$ & $6.97 \pm 0.23$ \\
\hline & & & HPA & 4 & $4.06 \pm 0.03$ & $3.33 \pm 0.09$ & $6.25 \pm 0.39$ \\
\hline & & Diogenites & $\mathrm{CT}+\mathrm{HPA}$ & 9 & $3.36 \pm 0.20$ & $3.32 \pm 0.40$ & $6.92 \pm 0.41$ \\
\hline HARZ 01 & Harzburgite & Diogenites & $\mathrm{CT}$ & 8 & $4.21 \pm 1.30$ & $3.38 \pm 1.36$ & $5.73 \pm 2.19$ \\
\hline \multirow[t]{2}{*}{ TDB-1 } & \multirow[t]{2}{*}{ Basalt } & & HPA & 7 & $0.12 \pm 0.02$ & $0.07 \pm 0.02$ & $0.20 \pm 0.02$ \\
\hline & & Achondrites & HPA & 7 & $0.11 \pm 0.02$ & $0.06 \pm 0.01$ & 0.23 \\
\hline Sample & Lithology & Compared with & Method & $n$ & $P t( \pm 2 S E)$ & Pd ( \pm 2SE) & $\operatorname{Re}( \pm 2 \mathrm{SE})$ \\
\hline \multirow[t]{10}{*}{ Allende } & CV3 Chondrite & Chondrites & $\mathrm{CT}$ & & 1336 & 662 & 60.1 \\
\hline & & Chondrites & $\mathrm{CT}$ & & 1345 & 682 & 61.8 \\
\hline & & Chondrites & $\mathrm{CT}$ & & 1364 & 678 & \\
\hline & & Tagish Lake & $\mathrm{CT}$ & & 1421 & 682 & 63.5 \\
\hline & & Chondrites & $\mathrm{CT}$ & & 1321 & 652 & 62.0 \\
\hline & & Chondrites & HPA & & 1380 & 681 & 64.0 \\
\hline & & Chondrites & HPA & & 1334 & 684 & 58.7 \\
\hline & & Chondrites & HPA & & 1409 & 676 & 58.4 \\
\hline & & Chondrites & HPA & & 1321 & 692 & 58.6 \\
\hline & & Chondrites & HPA & & 1379 & 657 & 61.4 \\
\hline
\end{tabular}




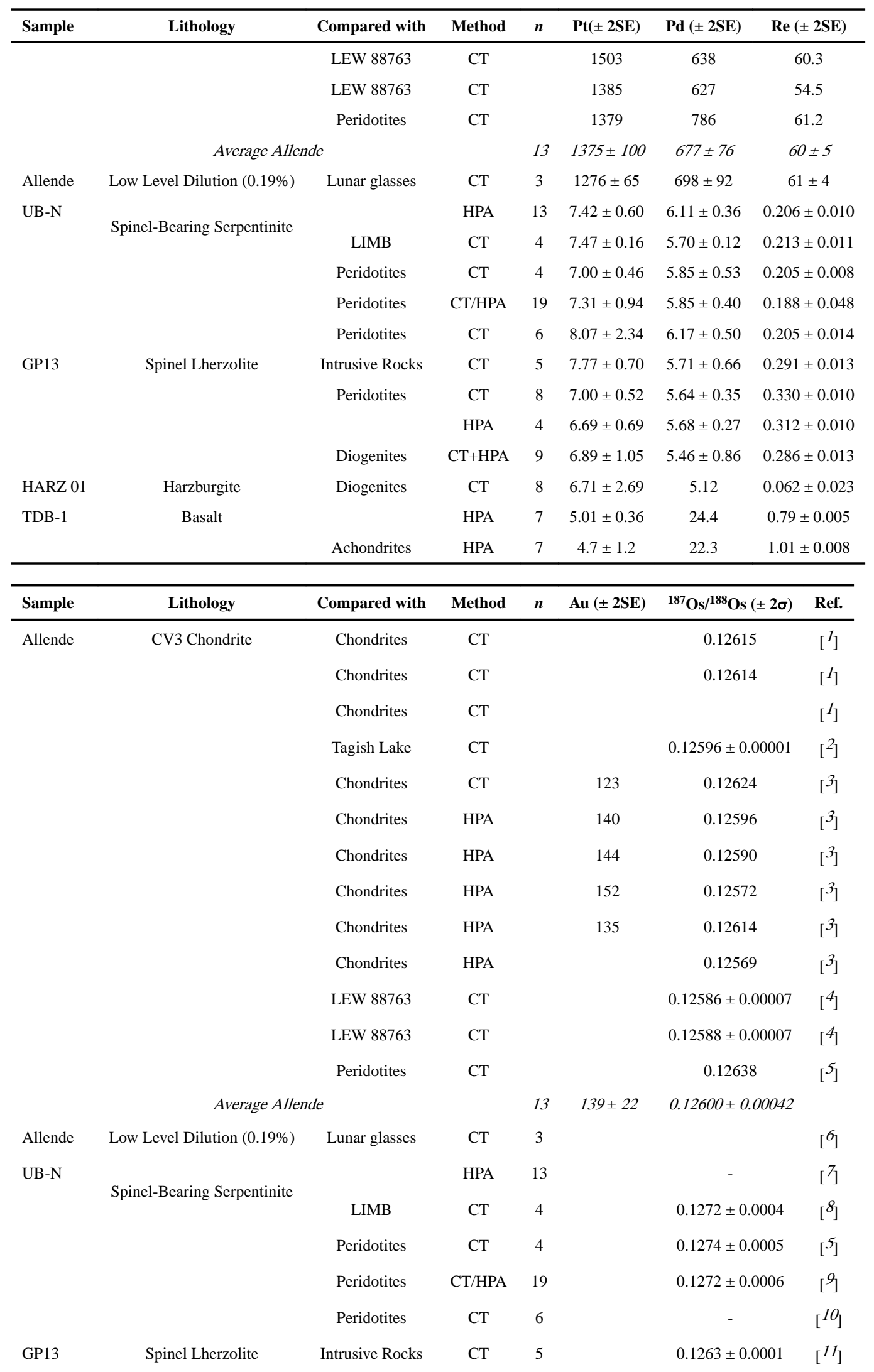




\begin{tabular}{lccccccc}
\hline Sample & Lithology & Compared with & Method & $\boldsymbol{n}$ & $\mathbf{A u}( \pm \mathbf{2 S E})$ & ${ }^{187} \mathbf{O s} /{ }^{188} \mathbf{O s}( \pm \mathbf{2 \sigma})$ & Ref. \\
\hline & & Peridotites & CT & 8 & 0.1262 & {$\left[{ }^{12}\right]$} \\
& & HPA & 4 & - & {$\left[{ }^{7}\right]$} \\
& & Diogenites & CT+HPA & 9 & $0.1263 \pm 0.0008$ & {$\left[{ }^{13}\right]$} \\
HARZ 01 & Harzburgite & Diogenites & CT & 8 & $0.1254 \pm 0.0014$ & {$\left[{ }^{13}\right]$} \\
TDB-1 & Basalt & & HPA & 7 & & {$\left[{ }^{7}\right]$} \\
& & Achondrites & HPA & 7 & $0.98 \pm 0.13$ & {$\left[{ }^{13}\right]$} \\
\hline
\end{tabular}

References:

${ }^{[1]}$ Walker et al. (2002); Horan et al. (2003)

${ }^{[2]}$ Brandon et al. (2005a)

${ }^{[3]}$ Fischer-Gödde et al. (2010)

${ }^{[4]}$ Day et al. (2015b)

[5] Becker et al. (2006)

${ }^{[6]}$ Walker et al. (2004)

[7] Meisel and Moser (2004a)

${ }^{[8]}$ Puchtel et al. (2008)

${ }^{[9]}$ Fischer-Gödde et al. 2011

${ }^{[10]}$ Luguet et al. (2007)

${ }^{[11]}$ Day et al. (2008)

${ }^{[12]}$ Pearson et al. (2004)

${ }^{[13]}$ Dale et al. (2012)

Definition of terms: HPA = high-pressure asher $\mathrm{CT}=$ Carius tube LIMB = lunar impact melt breccia . 


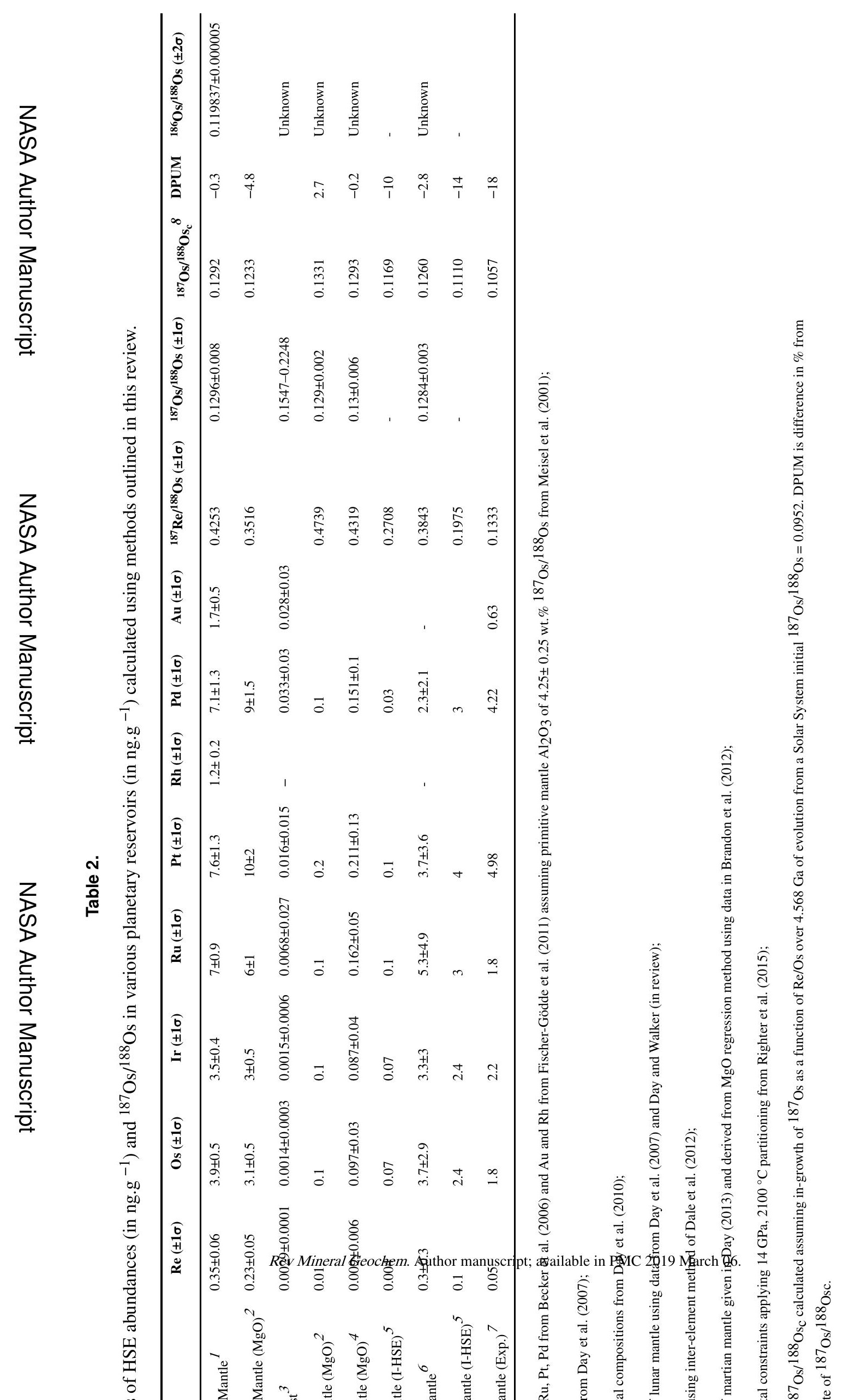




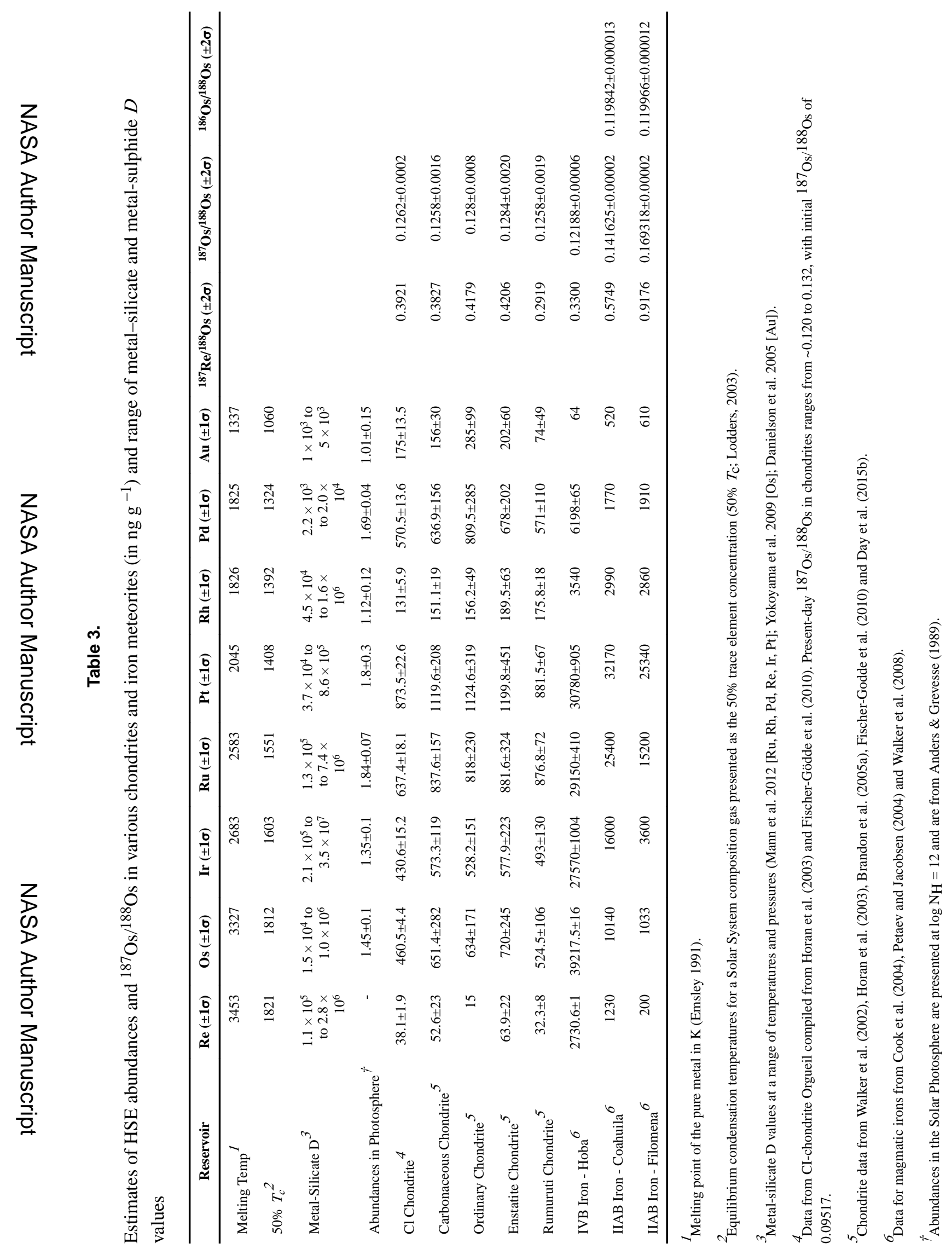
Rev Mineral Geochem. Author manuscript; available in PMC 2019 March 06. 
Table 4.

A simplified list of planetary materials and examples of HSE studies applied to them.

\begin{tabular}{|c|c|c|c|c|}
\hline $\begin{array}{l}\text { Meteorite Type } \\
\text { (asteroidal, unless stated) }\end{array}$ & Sub-divisions & Typical mode of origin & $\begin{array}{l}\text { Earliest Time of } \\
\text { formation }\end{array}$ & $\begin{array}{c}\text { Examples } \\
\text { of HSE } \\
\text { and Os } \\
\text { isotope } \\
\text { studies }\end{array}$ \\
\hline \multicolumn{5}{|c|}{ Primitive meteorites ( witnessed limited/no igneous differentiation) } \\
\hline \multirow[t]{4}{*}{ Chondrite ${ }^{*}$} & $\begin{array}{l}\text { Ordinary (H, L, LL) }[\sim 85 \% \text { of } \\
\text { all meteorite finds] }\end{array}$ & "Cosmic sedimentation" & Early Solar System & $\begin{array}{c}\text { Walker et } \\
\text { al. (2002); } \\
\text { Horan et al. } \\
\text { (2003, } \\
2009) ; \\
\text { Brandon et } \\
\text { al. } \\
(2005 \mathrm{a}, \mathrm{b}) ; \\
\text { Fischer- } \\
\text { Godde et } \\
\text { al. (2010); } \\
\text { Archer et } \\
\text { al. (2014) }\end{array}$ \\
\hline & $\begin{array}{l}\text { Carbonaceous (CI, CM, CR, } \\
\mathrm{CB}, \mathrm{CH}, \mathrm{CV}, \mathrm{CO}, \mathrm{CV})[\sim 5 \%]\end{array}$ & "Cosmic sedimentation" & Early Solar System & \\
\hline & Enstatite EH, EL) $[\sim 2 \%]$ & "Cosmic sedimentation" & Early Solar System & \\
\hline & $\begin{array}{l}\text { Ungrouped, Rumuruti or } \\
\text { Kakangari-Type }\end{array}$ & "Cosmic sedimentation" & Early Solar System & \\
\hline Chondrite-impact melt rocks & - & Impacts of chondrite asteroids & Early to late & $\begin{array}{l}\text { Norman } \\
\text { and } \\
\text { Mittlefehldt } \\
(2002)\end{array}$ \\
\hline Winonaites & - & Metamorphism of chondrites & Early Solar System & \\
\hline \multicolumn{5}{|c|}{ Iron and stony-iron meteorites } \\
\hline \multirow[t]{2}{*}{ Iron meteorites } & $\begin{array}{l}\text { Primitive Irons (e.g., IAB, IIE, } \\
\text { IIICD) }\end{array}$ & Partial melt differentiated core? & Early Solar System & \\
\hline & $\begin{array}{l}\text { Magmatic Irons (e.g., IAB, IC, } \\
\text { IIAB, IIC, IID, IIE, IIIAB, } \\
\text { IIICD, IIIE, IIIF, IVA, IVB) }\end{array}$ & Early asteroidal Fe-Ni core & Early Solar System & $\begin{array}{l}\text { Walker et } \\
\text { al. }(2008) \text {; } \\
\text { McCoy et } \\
\text { al. (2011) }\end{array}$ \\
\hline \multirow[t]{2}{*}{ Stony-iron meteorites } & Pallasites & Differentiation: core-mantle material? & Early Solar System & $\begin{array}{l}\text { Shen et al. } \\
\text { (1998); Lee } \\
\text { et al. } \\
(2006)\end{array}$ \\
\hline & Mesosiderites & Differentiated metal-rich materials & Early Solar System & $\begin{array}{l}\text { Shen et al. } \\
\text { (1998) }\end{array}$ \\
\hline \multicolumn{5}{|c|}{ Partially melted achondrites } \\
\hline Acapulcoite-Lodranites & - & Partially melted rocks $(\sim<5$ to $>20 \%)$ & $4563 \pm 2 \mathrm{Ma}$ & \\
\hline Ureilites & - & Melt residues & Early Solar System & $\begin{array}{l}\text { Rankenburg } \\
\text { et al. (2007; } \\
\text { 2008) }\end{array}$ \\
\hline Brachinites & - & $\begin{array}{c}\text { Melt residue after }<30 \% \text { partial } \\
\text { melting }\end{array}$ & $4565 \pm 1 \mathrm{Ma}$ & $\begin{array}{l}\text { Day et al. } \\
(2012 b)\end{array}$ \\
\hline Ungrouped achondrites & $\begin{array}{l}\text { e.g., **Finds LEW } 88763 \text {, } \\
\text { NWA 6693) }\end{array}$ & Variable & Variable & $\begin{array}{l}\text { Day et al. } \\
(2015 b)\end{array}$ \\
\hline Brachinite-like achondrites & - & Melt residues & Early Solar System & $\begin{array}{l}\text { Day et al. } \\
(2012 b)\end{array}$ \\
\hline GRA 06128/9 & - & Melt from brachinite parent body & $4567 \pm 1 \mathrm{Ma}$ & $\begin{array}{l}\text { Day et al. } \\
\text { (2009) }\end{array}$ \\
\hline
\end{tabular}




\begin{tabular}{|c|c|c|c|c|}
\hline $\begin{array}{l}\text { Meteorite Type } \\
\text { (asteroidal, unless stated) }\end{array}$ & Sub-divisions & Typical mode of origin & $\begin{array}{l}\text { Earliest Time of } \\
\text { formation }\end{array}$ & $\begin{array}{l}\text { Examples } \\
\text { of HSE } \\
\text { and Os } \\
\text { isotope } \\
\text { studies }\end{array}$ \\
\hline \multicolumn{5}{|c|}{ Achondrites from differentiated planetary bodies } \\
\hline Aubrites & Enstatite achondrite meteorites & Melted and crystallized igneous rocks & Early Solar System & $\begin{array}{c}\text { van Acken } \\
\text { et al. } \\
\text { (2012) }\end{array}$ \\
\hline \multirow[t]{2}{*}{ Angrites } & Slowly-cooled & Crystallized melts and cumulates & Early Solar System & $\begin{array}{c}\text { Riches et } \\
\text { al. (2012); } \\
\text { Dale et al. } \\
\text { (2012) }\end{array}$ \\
\hline & Fast-cooled & Crystallized melts & & $\begin{array}{c}\text { Riches et } \\
\text { al. (2012); } \\
\text { Dale et al. } \\
\text { (2012) }\end{array}$ \\
\hline \multirow[t]{3}{*}{ HED meteorites (4 Vesta?) } & Howardites & Breccias from eucrites/diogenites & Early Solar System & $\begin{array}{l}\text { Dale et al. } \\
\text { (2012) }\end{array}$ \\
\hline & Eucrites & $\begin{array}{c}\text { Extrusive and intrusive basalts/ } \\
\text { dolerites }\end{array}$ & & $\begin{array}{l}\text { Dale et al. } \\
\text { (2012) }\end{array}$ \\
\hline & Diogenites & Intrusive rocks and possible mantle & & $\begin{array}{c}\text { Day et al. } \\
\text { (2012a); } \\
\text { Dale et al. } \\
(2012)\end{array}$ \\
\hline \multirow[t]{5}{*}{ Martian Meteorites (Mars) } & Shergottites & Extrusive and intrusive igneous rocks & $200-500$ million years & $\begin{array}{l}\text { Brandon et } \\
\text { al. (2000, } \\
\text { 2012); } \\
\text { Warren et } \\
\text { al. (1999); } \\
\text { Jones et al. } \\
\text { (2003) }\end{array}$ \\
\hline & Nakhlites & Intrusive or extrusive wehrlites & $1.3 \mathrm{Ga}$ & \\
\hline & Chassignites & Intrusive or extrusive dunite & $1.3 \mathrm{Ga}$ & \\
\hline & ALH 84001 & Intrusive orthopyroxenite & $4.1 \mathrm{Ga}$ & \\
\hline & NWA 7074 & Impact/regolith breccia & $4.4 \mathrm{Ga}$ & $\begin{array}{l}\text { Goderis et } \\
\text { al. (2014) }\end{array}$ \\
\hline \multirow[t]{4}{*}{ Lunar meteorites (Moon) } & Unbrecciated basaltic & Extrusive basalts & $3-4.4$ billion years & $\begin{array}{l}\text { Day et al. } \\
\text { (2007); } \\
\text { Day and } \\
\text { Walker } \\
(2015)\end{array}$ \\
\hline & Feldspathic-dominated breccias & $\begin{array}{c}\text { Dominantly anorthositic crustal } \\
\text { breccias }\end{array}$ & & $\begin{array}{l}\text { Warren et } \\
\text { al. (1989); } \\
\text { Puchtel et } \\
\text { al. (2008) }\end{array}$ \\
\hline & Basalt-dominated breccias & Breccias from mare basalt regions & & $\begin{array}{l}\text { Warren et } \\
\text { al. (1989) }\end{array}$ \\
\hline & \multicolumn{2}{|c|}{ Apollo and Luna mission samples } & & \\
\hline Apollo 11 & High-Ti mare basalts & Extrusive basalts & & \\
\hline Apollo 12 & Low- to high-Ti mare basalts & Extrusive basalts & & $\begin{array}{l}\text { Day and } \\
\text { Walker } \\
(2015)\end{array}$ \\
\hline Apollo 14 & $\begin{array}{l}\text { Mare basalts, impact melt } \\
\text { rocks }\end{array}$ & & & $\begin{array}{l}\text { Puchtel et } \\
\text { al. (2008) }\end{array}$ \\
\hline Apollo 15 & $\begin{array}{l}\text { Low-Ti mare basalts, crustal } \\
\text { rocks }\end{array}$ & & & $\begin{array}{c}\text { Day et al. } \\
\text { (2007); } \\
\text { Day and } \\
\text { Walker } \\
(2015)\end{array}$ \\
\hline
\end{tabular}




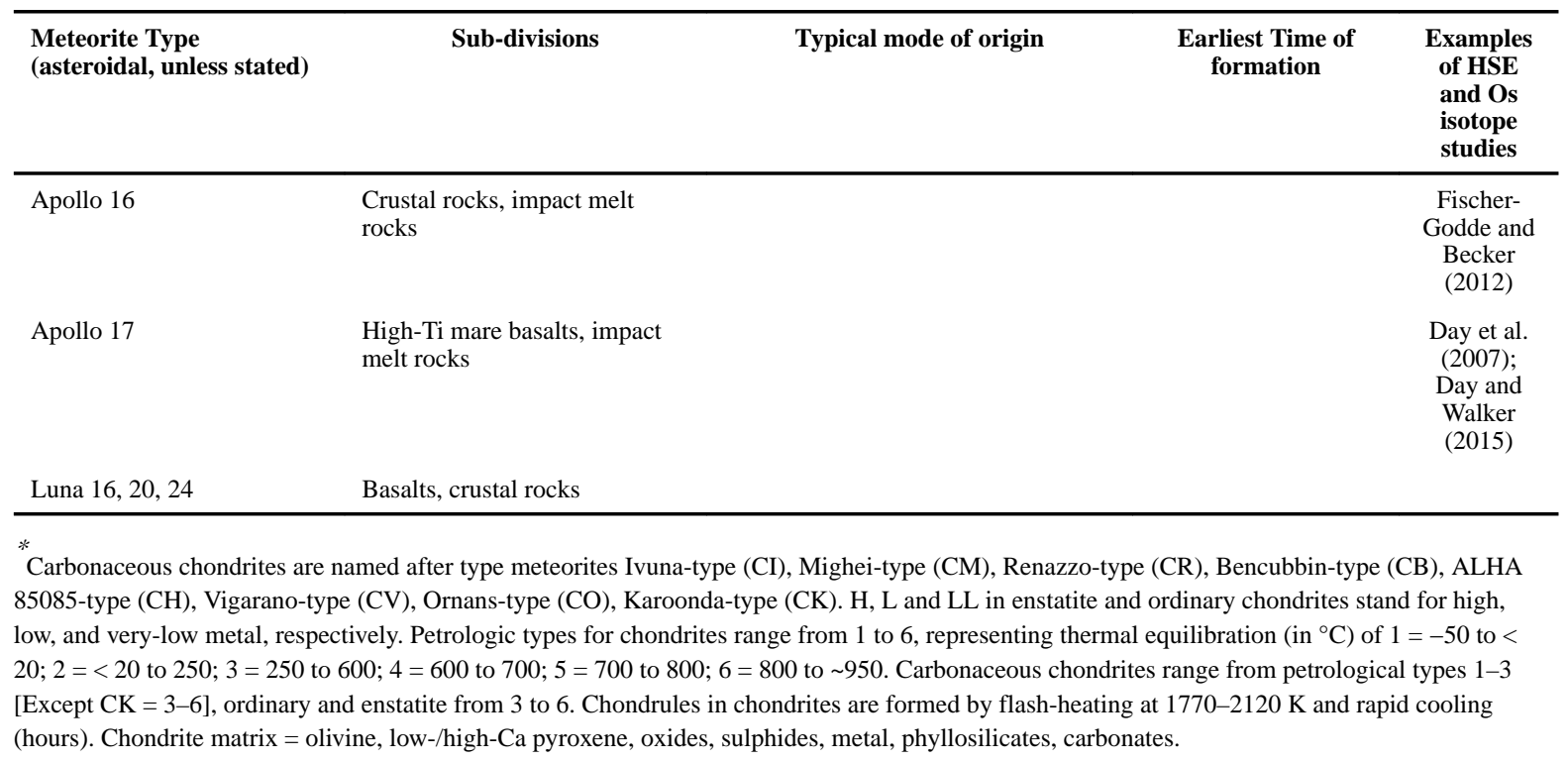

